\title{
The Security-Development Nexus
}

\section{Expressions of Sovereignty and Securitization in Southern Africa}

\author{
Edited by \\ Lars Buur, Steffen Jensen and Finn Stepputat
}

NORDISKA AFRIKAINSTITUTET, UPPSALA HSRC PRESS, CAPE TOWN 
Indexing terms:

Violence

Crime

Economic and social development

Politics

Government policy

State

International relations

Peaceful coexistence

Citizenship

Human security

Regional security

South Africa

Mozambique

Namibia

Zimbabwe

Language editing: Peter Colenbrander

Index: Jane Coulter

ISBN 978-91-7106-583-4

(C) The authors and Nordiska Afrikainstitutet 2007

Printed in Sweden by Elanders Gotab AB, Stockholm 2007

Published in Africa by HSRC Press

Private Bag X9182, Cape Town, 8000, South Africa

www.hsrcpress.ac.za

ISBN 978-0-7969-2184-0 


\section{Contents}

\section{INTRODUCTION}

Lars Buur, Steffen Jensen and Finn Stepputat

The Security-Development Nexus

INTERNAL AND EXTERNAL BOUNDARIES

Thomas Mandrup Jorgensen

You Do Need a Stick to Be Able to Use It Gently

The South African Armed Forces in the Democratic

Republic of Congo

Steffen Jensen and Lars Buur

The Nationalist Imperative

South Africanisation, Regional Integration

and Mobile Livelihoods

Lalli Metsola and Henning Melber

Namibia's Pariah Heroes

Swapo Ex-Combatants Between the Liberation Gospel

and Security Interests

\section{STATES, DEVELOPMENT AND VERNACULAR SECURITY}

Lars Buur

The Intertwined History of Security and Development

The Case of Developmental Struggles in

South Africa's Townships

Helene Maria Kyed

The Politics of Policing

Recapturing "Zones of Confusion" in Rural

Post-War Mozambique

Guy Lamb

Militarising Politics and Development

The Case of Post-Independence Namibia

Jacob Rasmussen

Struggling for the City

Evictions in Inner-City Johannesburg 
IDENTITY, VIOLENCE AND RIGHTS

Steffen Jensen

Through the Lens of Crime

Land Claims and Contestations of Citizenship

on the Frontier of the South African State

Amanda Hammar

Criminality, Security and Development

Post-Colonial Reversals in Zimbabwe's Margins

Tina Sideris

Post-Apartheid South Africa - Gender, Rights and

the Politics of Recognition

New Avenues for Old Forms of Violence?

233

LIST OF AUTHORS …………………….............................................. 252

LIST OF REFERENCES ………………...................................... 257

INDEX 


\section{Preface}

Amid the hype surrounding the 9/11 tragedy, much attention was given to the linkage between security and development. Little noticed was the fact that this linkage is by no means a recent invention. Rather, this nexus was an important element in the state policies of colonial as well as post-colonial regimes during the Cold War, and it seems to have re-emerged in new configurations during the present wave of democratic transitions. The purpose of this book is to situate and explore the nexus between security and development in a variety of contexts from South Africa, Mozambique, and Namibia, to Zimbabwe and the Democratic Republic of Congo.

The book explores the nexus and our understanding of security and development through the prism of peace-keeping interventions, community policing, human rights, gender, land contests, squatters, nation and state-building, social movements, disarmament, demobilisation, repatriation (DDR) programmes and the different trajectories democratisation has taken in different parts of southern Africa. At a generic level, this volume draws our attention to the ways in which linkages are changing between "hard", militarised forms of power related to the production of sovereignty, and apparently benign, "soft" forms of power related to the enlightenment agenda of human progress and betterment. Consequently, we hope that the book will also be of interest to scholars working outside the region of southern Africa and that the approach in the book will spur debate and research on the nexus between security and development more generally.

We would like to thank the Danish Social Science Research Council for its support of a research network and a series of workshops that have played an important role in the development of our thoughts on and approaches to the security-development nexus. The research network, From Inequality to Insecurity? The Place of Crime and Violence within Development Thinking and Practice (2003-05), brought together researchers 
and practitioners who have directly or indirectly influenced the ideas presented in this book. We are thankful to Mark Duffield, Anna Leander, Martijn van Beek, Nils Ole Bubandt, Cristian Lund, Henrik Rønsbo, Fiona Wilson, Siri Hettige, Birgitte Refslund Soerensen, Gerald Sider, Darius Rejali, Danny Raymond, Jairo Munive Rincon, Stine Finne Jacobsen, Jeffrey Gamarra, Carlos Orantes Troccoli, Jose Miguel Cruz, Tracey Viennings, Graeme Simpson, João Paolo Coelho, Henrik Vigh, Andrew Jefferson, Thomas Blom Hansen, Dennis Rodgers, Anton Baaré, Nicholas Stockton and, of course, the contributors to this volume for the many stimulating presentations and discussions. We also want to thank the Nordic Africa Institute (NAI) as well as the Centre for Research and Rehabilitation of Torture Victims (RCT) for funding a number of the overseas participants, from whom we benefited enormously.

Finally, we would like to thank Ane Toubo both for her tireless work in organising the three workshops of the research network and for her subsequent work on the manuscript. 
INTRODUCTION 



\title{
The Security-Development Nexus
}

\author{
Lars Buur, Steffen Jensen \\ and Finn Stepputat
}

It has become commonplace to talk about the all-encompassing role of security in the post-9/11 world. Security concerns and measures are creeping into new corners of everyday life in rich as well as in poor regions of the world. State-regulated security sectors, both private and public, are being reinforced in terms of budgets, media coverage, powers and influence over all domains of governance, including the management of welfare systems, refugees, migration, money transfers, internet use and so forth.

Development is one important domain that has been increasingly merged with and subjected to security concerns (Duffield 2001a). What we may call the "securitisation of development" became more visible during the 1990s in relation to the salience of internal armed conflict in poorer countries and the growing preoccupation with crime and violence in developing and rapidly urbanising economies. Policy-makers and researchers came to see economic inequality, underdevelopment and poor governance at the root of armed conflict and crime, a causal link that has been reinvented in the new millennium to provide explanations for terrorism. As the British prime minister, Tony Blair, declared in 2004: "We know that poverty and instability lead to weak states which can become havens for terrorists and other criminals ... Even before 9/11, al-Qaeda had bases in Africa ... They still do, hiding in places where they can go undisturbed by weak governments, planning their next attacks which could be anywhere in the world, including Africa" (Tony Blair, quoted in Mail \& Guardian 7 October 2004).

While underdevelopment could explain armed conflict, the calamities of conflict were themselves seen as having huge costs in terms of missed development opportunities, disintegrating and failing states and low indexes of human development. This circular argument - or, in Ken Menkhaus's (2004) words, the "vicious circle metaphor" evident in, for example, the World Bank's notion of "the conflict trap" (World Bank 2003) - obliges development institutions to coherently integrate crime prevention, conflict resolution and post-conflict reconstruction, demobilisation, security 
reforms and good governance into development intervention (UNRISD 1995, OECD/DAC 1997, World Bank 1998, Danida 2004). In addition to its traditional tasks of generating economic development, infrastructure, education, health and sanitation as a legitimate domain of governance, development is being charged with the responsibility of enhancing security and non-violent forms of behaviour at all levels of society (Stiglitz 1998). As Williams (1988:102-3) explains, the modern use of the concept of development is related to certain notions of the nature of economic change based on the idea of a society passing through definite evolutionary stages. Seen from this vantage point, development has been "radicalised" in its civilising mission (Duffield 2001a).

At the same time as development has been securitised and radicalised, the concept of security has also undergone changes, resulting in particular in a broadening of the concept to include referents other than states. Using the notion of "human security", for example, security has been "developmentalised" in the sense that a number of basic human needs have been suggested as being indispensable for the survival of the individual (UNDP 1994). Unlike the traditional concept of (national) security, the human security agenda focuses on the safety of people rather than states, and on a concept of sovereignty that is conditioned by the state's respect for the rights of its citizens (Duffield 2004a), rather than by sovereignty representing the absolute and unfettered power of the state over its citizens.

Such conceptual and institutional changes call for a rethinking of the concepts of development and security and for a thorough investigation of the effects of these changes. The aim of this volume is to contribute to this task by considering some avenues for future research on the securitydevelopment nexus by presenting a collection of essays that analyse different configurations of security and development in the region of southern Africa. In various ways, this volume is a departure from previous work on the security-development nexus as represented, for example, in the journal Conflict, Security and Development. The latter's approach grows out of engagements with international humanitarian and military interventions, notably in high-profile contexts such as Somalia, Bosnia-Herzegovina, Kosovo, East Timor, Afghanistan and now Iraq. International engagement in southern Africa has provided numerous instances of post-conflict security and development operations, in particular Disarmament, Demobilisation and Reintegration (DDR) schemes, and military, police and justice reforms, which have been thoroughly and competently investigated elsewhere (see, for example, Gleichmann et al. 2004). 
In contrast, this volume extends the field of study in two ways: institutionally and historically. Firstly, instead of analysing international programmes, the contributions to this volume explore the security-development nexus in national government practices, such as those employed in South African policies regarding housing and the privatisation of service provision, national policies for gender equality, the involvement of the South African National Defence Force in the Democratic Republic of Congo and the Zimbabwean government's land policies. We also examine specific security and development institutions, such as those used by the Namibian government in dealing with ex-combatants from the liberation war and Mozambican-style community courts, community policing forums and the role of authorised chiefs as local agents of law-and-order enforcement. Secondly, in relation to history, the contributions explore configurations of security and development during the Cold War period, such as the South African counter-insurgency programmes of the 1980s and the Portuguese and Frelimo (Frente de Libertação de Moçambique) villagisation programmes of the 1970s and 1980s. The intention is to demonstrate that the recent merger of security and development is but one concrete instance of the production and reproduction of political communities, this being a much more common phenomenon than has been recognised in the current examination of the nexus thus far. ${ }^{1}$ Finally, the historical perspective also permits us to identify continuities and differences in the imagination of threats and the design of cures between the Cold War period and the present configurations of development and security.

Thus, rather than regarding the security-development nexus as a recent invention of the hegemonic international community, this volume will explore, at a more generic level, whether and how linkages are changing between "hard" militarised forms of power linked to the production of sovereignty, and apparently benign "soft" forms of power linked to the enlightenment agenda of human progress and betterment. Importantly, we analyse development and security at the material as well as discursive levels, and as different types of institutional set-ups and practices, but also as circulating and increasingly media-produced ideas and perceptions of life, risk and power. In this regard, we understand development as a set of governance practices for enhancing the well being of populations, in particular in poor countries (Foucault 1978, Escobar 1995). The notion of development,

I. As explored at the January 2004 workshop, "Regional Histories of Security and Development" at the Danish Institute for International Studies, where several of the contributions to this volume were first presented. See also Jensen 2005a. 
which has been institutionalised since the Second World War, has a benign ring to it, but it is obviously normative in its implicit and explicit definitions of desired directions and good/bad development. Ultimately, we may understand development agencies as (state-sanctioned) civilising missions, which produce distinctions between more and less desirable forms of life for the betterment of people and institutions.

Like development, security is used in many different ways and contexts, but generally it is associated with perceived threats to the survival of individuals and states and with the use of exceptional means of countering these threats. Security is about real questions of safety and violence, but it is also a way of representing particular problems in a manner that makes them exceptional and a question of survival. By making an issue a security problem - by "securitising" an issue, that is - it takes on new dimensions (Wæver 1997, Kappeler and Potter 2000). As Wæver argues, security is not a pre-given or unproblematic unit of analysis. Who is identified as a threat depends on power relations in the given context. In other words, this question is concerned with which groups of people are in a position to define other groups as a security threat. As Wrver (1997:14) has phrased it: "By saying 'security' a state-representative moves the particular case into a specific area; claiming a special right to use the means necessary ... 'Security' is the move that takes politics beyond the established [democratic] rules of the game, and frames the issue within a special kind of politics."

Wrver's work has been influential in defining the special properties of what a process of securitisation means, but it is not all securitised issues that are taken beyond the established rules of the game. In his chapter in this volume, Thomas Mandrup Jørgensen explores how the deployment of the South African National Defence Force (SANDF) in the UN-controlled peacekeeping mission in the Democratic Republic of Congo (DRC) was clearly legitimised and triggered by public speeches delivered and sanctioned by the top leadership of the African National Congress. The involvement in DRC was presented as being necessary to protect South Africa's national interests. However, as Mandrup shows, the means to carry out the peacekeeping mission were not released, with disastrous consequences not only for SANDF in DRC, which basically ceased to be operational: it also had adverse consequences for the international reputation of South Africa, which was trying hard to present itself as a key player on the continent. It is therefore not enough to securitise an issue by means of acts of public speech: force and resources also need to be deployed to support such actions. 
Wæver's perspective on securitisation is also challenged and/or extended in other ways in this book. Where Wrver sees the identification of threats as something that state representatives have the power to declare, several contributions argue otherwise. Besides exploring the capacity and power of state representatives to move political struggles beyond the established democratic rules, the chapters here explore the particular configuration of state power in southern Africa. All four countries that we deal with - Mozambique, South Africa, Zimbabwe and Namibia - have emerged from protracted liberation wars followed by internal struggles between different political and ethnic factions, and even, in the case of Mozambique, a devastating sixteen-year civil war.

The effects of these histories are profound. On the one hand, states do not necessarily exercise a monopoly of violence, while on the other hand the particular histories of liberation struggles have created forms of resistance, ideas concerning threats to the national unity of which liberation movements claim to be the sole guardians and a political ethos of monism that makes the separation between state, party and government hard to identify. Instead, ambiguous figures of popular sovereignty exercise power derived from an alleged history of political resistance. This form of power often sits uncomfortably with the operation of the new constitutional democracies: whereas constitutional democracy sees political order as being derived from the constitution, it involves consuming and legally taming the political energies that made its creation possible in the first place (Mouffe 1999). Dissidence becomes a question of security when it threatens the new order by exposing failures of identity and the consequences of these for the multitude of interests and forces that the new order should be uniting. As Helene Kyed, Lars Buur, Lalli Metsola and Henning Melber each describe in different ways in their contributions to this volume, the securitisation of dissidence through acts of speech is inscribed in the pre-existing sociopolitical orders from which they draw their power. This makes clear "that democratisation in Africa is not a unilinear process, a technical procedure with predetermined means and goals" (Englund 2004:3): this observation applies to the particular ways in which sovereignty and the monopoly of violence are configured as well.

Taken at face value, security and development are two different but somewhat complementary domains of hard and soft power - in other words, of pure force and negotiated change. However, if we analyse these domains through the conceptual lenses of biopolitics and sovereignty, they appear to be overlapping and interdependent rather than just different or 
complementary. This analysis points towards different dimensions of the security-development nexus to be taken up in the following chapters. These dimensions concern 1) the changing discourses of recognition and identity at the interface between security and development; 2) the changes in security-development linkages that have accompanied the transitions from autocratic and military regimes to democratic ones; and 3) some of the continuities that emerge when we look, for example, at how space is organised in different concrete expressions of security and development.

\section{Sovereignty and biopolitics}

Biopolitics concern the management of life at the level of populations through programmes of health, education, population control, agricultural extension services, environmental protection and so forth (Dean 1999). Biopolitics are linked to the development of popular sovereignty and the modern state, which, in addition to providing protection, has the welfare of the population as its legitimising raison d'être. Foucault (1979) saw biopolitics and normalising, diffuse systems of power/knowledge in the modern state as superseding sovereignty through the rule of the sword, which he considered an archaic form of power. Although his perspective and interpretation differ from mainstream political theory, Foucault's work forms part of the modern myth, according to which governance and politics render rule by physical violence obsolete as a form of power.

But obviously, the state's willingness and ability to use force is still very much with us, despite the verity that there is no longer an "outside" to networks of modern governance that can be pacified (Hardt and Negri 2000). Today's enemies, that is, the major threats to security such as terror networks, "failed states" (e.g., Andersen 2005) and criminals (e.g., Buur 2003a), are enemies "within", shaped by former generations of development and security regimes, even though they are now being defined as external to the "moral community", the "national body", the "international community" and the "civilised world". In Duffield's words, global governance as a design of power is shaping its own external threats, its own security environment (2004b). Still, as represented in the media, the problem consists of the enemies not being modern enough, in their being archaic survivors belonging to the past, still having to catch up with the 21 st century. Therefore, they have to be disciplined through force and reformed through development before they can take their place in the global ecumene. The hard 
kernel of violence upon which the modern territorial state was founded has to be reproduced again and again.

Contrary to the perception of sovereignty being rendered obsolete by biopolitics and discipline, recent attempts to theorise sovereignty regard biopolitics as the original form of sovereignty: "the production of a biopolitical body is the original activity of sovereign power. In this sense biopolitics is at least as old as the sovereign exception" (Agamben 1998:6). Drawing on the work of Carl Schmidt, Agamben's analysis of sovereignty centres on who embodies the exception. Instead of focusing on the ruler, "the state" or whoever makes the decision, Agamben's understanding of sovereignty focuses on the effects of the decision, the exclusion of somebody from the political community and the protection provided by its laws and rights. We understand this "bare" or "naked life", in Agamben's words, as persons or groups of persons that others, with impunity, can treat without regard for their psychological and physical well-being (see Buur 2005a:204, Jensen 2005b, Hansen and Stepputat 2005:17).

The exclusion of somebody thus becomes a foundational moment for political power and the political community. According to Agamben (2000a:5), "the state of exception, which is what the sovereign each and every time decides, takes place precisely when naked life ... is explicitly put into question and revoked as the ultimate foundation of political power". In order to be effective, sovereignty must be performed and inscribed on bodies that are being excluded. This logic of sovereign power, which founds the political community by excluding various forms of "life" that threaten it, has not disappeared with the emergence of modern biopolitical forms of governance - on the contrary, as Hansen and Stepputat argue:

The essential operation of totalitarian power was to reduce the population to pliable bodies that could be improved, shaped and regimented, but also exterminated if deemed unnecessary or dangerous ... This operation ... had its counterpart in the rise of disciplinary institutions and welfare governmentality in Western democracies. (Hansen and Stepputat, 2005:17)

Approached in this way, sovereignty can be explored as a set of practices aimed at improving "the people", including the ideologies and techniques of "uplifting" the poor, the plebeian, the ignorant or backward, and turning them into good citizens worthy and capable of entering the community, the nation or the state. Defining who can be improved and uplifted to become members of the political community and who should be excluded as dangerous or abandoned as useless is a sovereign act that makes sover- 
eign power visible, as well as the boundaries of political community. Some would object to this, using the argument that it is exactly these forms of power and such authoritarian governments that liberal democracy has been so successful in demolishing during the recent wave of democratisation in southern Africa. It is certainly true that liberal rule works from the premise that the less governments interfere in the lives of the people the better. But as Hindess (2001:100) argues, in any given territory there are people who "are not endowed with a capacity for autonomous action", and who must be dealt with through what he calls "liberal unfreedom". Hindess identifies three responses by governments to this incapacity for autonomy: extermination, authoritarian intervention and welfare intervention. Extermination is for those who are judged by sovereign power to be incapable of managing freedom, no matter what is done: consequently the only possible response is to remove them from society. The authoritarian response, which is based on the idea that capacity for freedom can only be fostered through compulsion and extended periods of disciplining, is especially applied to colonised populations, the unemployed and the deviant (Hindess 2001:101-6). Finally, the welfare response has been applied to those who have suffered setbacks and only need help to acquire the capacity to manage freedom. Therefore, far from being an oddity, sovereign acts are inscribed in the body politic of liberal democracies.

From this perspective, both practices of development and security are implicated in the production of sovereignty, political community and different forms of bare life. Several chapters in the volume take these points further, as they are concerned with the modern production of citizens, which works through the exclusion of people who are considered improper, out of place and dangerous. In Jakob Rasmussen's chapter, the local government in Johannesburg has initiated urban renewal projects that work partly through the eviction of people who have few or no formal claims to Johannesburg's new urban space. Rasmussen demonstrates how the conflicts between residents of dwellings occupied by "illegal" migrants, the local government authorities of Johannesburg and the Inner City Forum (a social movement helping to organise "illegal" residents) became a struggle over whose notions of democracy and development were legitimate to become manifest and dominant. This struggle was fought by asking who belongs to the "people" of the African National Congress (ANC), and, by extension, the national polity. Drawing on Agamben (2000a), Rasmussen evokes the question, "Who are the people?" The answer defines both rightful claims to housing as well as the right to citizenship and to the entitle- 
ments that the new welfare state brings with it. As Rasmussen makes clear, conflicts to define both urban space itself and who belongs to it are not new: they were at the heart of the struggle against the apartheid regime.

Amanda Hammar explores similar processes on Zimbabwe's rural frontier, where rural dwellers with long-term residence in the northeast were being relabelled "squatters" by local government, following which they were evicted violently with loss of livelihood. As Hammar points out, the processes she describes were tragically replayed in 2005 when Operation Murabatswina targeted hundreds of thousands of urban dwellers in Zimbabwe. But as she makes clear, state cleansing and containment campaigns are a familiar aspect of historically continuous processes of state formation in Zimbabwe, just as they are in many other African post-colonies. Such campaigns, in which direct state or state-sanctioned violence has been used to varying degrees, including, very often, forced displacement, have been conducted in diverse settings and on different scales. Sovereign state violence as an overt expression of physical force and of structural violence through dispossession is therefore not an aberration, but rather an ever-present possibility and fairly common practice in contemporary African states.

Paradoxically, recasting of forms of bare life through the modern production of citizens - working through the exclusion of people who are considered "out of place" and dangerous - has taken another twist in South Africa, with consequences for the whole region. As Steffen Jensen and Lars Buur show in their joint chapter, the moment the new South Africa assumed its place as a senior partner within the southern African region, migrants took on a new role and South Africa began to protect its national borders against them in ways different from those of the apartheid regime. The authors argue that the surge in xenophobia that became endemic after 1994 was related to the way in which the democratic transition reconfigured citizenship. With the emergence of a democratic South Africa, the country became home to all nationalised South Africans, without regard to their political, ethnic or racial affiliations. This implied a radical recasting of citizenship as it was pursued under apartheid, where it mattered little whether a migrant came from inside South Africa (for example, from the black homelands) or from across the international border. Outsiders were all black migrants coming from outside White South Africa. In their view, what has taken place since 1994 is a problematic process of "South Africanisation", where citizenship has been reconfigured and the external borders of the republic have taken on a new meaning. While the dissolution of the internal borders of the new nation state in order to unify the 
nation has been inclusive, it has recast the external borders as the threshold of national belonging, with dire consequences for members of the southern Africa region, which have been excluded from pursuing crucial economic and social livelihood strategies. The nationalist project founded on the functional nexus between a defined territory and a state, with the inscription of nativity within this nexus, left no permanent space open for migrants from southern Africa. Instead, when caught inside the new nation state, they are confined to "protective camps", such as the infamous Lindela Repatriation Camp, where, as "bare beings", in Agamben's understanding, they are outside the law yet at the same time constitutive of South Africa's new national order.

Exclusionary processes can also trigger strong and powerful counter claims, as Lalli Metsola and Henning Melber show in their chapter: excombatants from the Namibian liberation war organise, make petitions and camp in front of government buildings, sometimes for weeks on end, in order to force their political leaders to respond to their grievances and demands. In their struggles, ex-combatants both counter and exploit the ways in which they have been portrayed and problematised. They use their representation as national heroes who sacrificed their lives for the liberation, but also, when necessary, their embodiment as persistent social problems in need of economic, social and psychological rehabilitation and reintegration. This places them in a strategic position in the dominant nationalised history, but it also allows them to play on fears of what would or could happen if their grievances are not addressed. To be a "security risk", therefore, does not have a settled outcome, nor is it a pre-given or unproblematic entity of analysis: it can also be exploited in political struggles over resources.

\section{Development/security beyond the state}

It has frequently been pointed out that the "security-development complex" currently involved in humanitarian and military intervention comprises governmental, non-governmental and private organisations. In the extended understanding of security and development being put forward here, we identify a series of ambiguous institutions in the blurred zone between the state and society that take the kind of sovereign decisions described above with regard to the desirability of different forms of life, as well as to the possibility of improving some but not other forms of life. Such "twilight institutions" (Lund 2001) are characterised by, on the one hand, organising in opposition to the state, and on the other by employing different lan- 
guages of stateness, technologies and imaginaries associated with the state (Hansen and Stepputat 2001).

Herbst (2000) has drawn attention to the legacy of colonial boundary making, which has made post-colonial sub-Saharan African countries plural societies. Governments thus face the daunting task not only of moulding nations out of competing modes of belonging and forms of identification, but also of enforcing the governmental and developmental state apparatus over vast and often thinly populated territories. Here the problem is not only those vast territories within African societies that are not captured by the state, but also the fact that states are in intense competition with other forms of authority. Thus, vigilante groups, political parties, hometown associations, traditional leaders, religious congregations, sports clubs, militias and networks of organised crime may constitute a kind of public authority either because the state has "outsourced" certain functions to them (see Buur 2005a), by "default" (Manor 1999) - that is, because of the absence or lack of interest of state institutions - or because they are directly challenging the state in no-go liberated areas (see Buur and Kyed 2005, Jensen 2005b). Within justice enforcement, for example, a variety of different groupings provide for social regulation and enforce local notions of justice, from community policing forums in Kenya (Ruteeree and Pommerolle 2003) through conservative forms of ordering in Uganda and Tanzania (Heald 1986, Bukura 1996, Fleischer 2000), traditional authorities in South Africa (Tshehla 2005) and Mozambique (Helene Kyed in this volume) to mob formations in Nigeria and South Africa (Gore and Pratten 2003, Jensen and Buur 2004). Some of these organisations do this in sharp opposition to the state, such as the mobs of young men burning witches, while others have the official sanction of the police, like the community policing forums and traditional authorities in Mozambique.

Elsewhere, Buur and Jensen (2004) have outlined the different characteristics of these twilight institutions, giving special attention to groups that organise themselves around local, non-state forms of judicial enforcement. Typically, they have a highly ambivalent relationship to the state: they present themselves as the representatives and defenders of a moral community, while at the same time seeking to stabilise and incorporate particular groups seen as threatening the moral community of good and worthy citizens. Indeed, as shown in Steffen Jensen's contribution, many of these institutions engage in the education, disciplining and moral guidance of members of the supposed moral community. The claim to represent particular identities can be found in autochthonous movements in, 
for instance, Cameroon (Geschiere and Nyamnjoh 2000), or among war veterans in Zimbabwe (Worby 2003).

Guy Lamb in his chapter explores how nation-building initiatives and development programmes in Namibia have had to become militarised in order to protect the Namibian government from the dissidents challenging it. Lamb shows how the hallmarks of nation-building strategies as pursued by youth brigades - at least in the forms developed in Namibia and neighbouring countries (Malawi and Zimbabwe) - become authoritarian in nature whenever they are put into practice. Creating national unity by socialising former freedom fighters and unemployed youth in the national cause is, on a policy level, motivated by the desire to achieve a greater efficiency and effectiveness for government services and the exercise of state power. In practice, these groups were used by the Namibian government to quell resistance and dissidence to its policies. Lamb sees the authoritarian ethos of nation-building initiatives as being intimately related to the counter-insurgency pursued by the apartheid regime during the liberation war. This provided lessons in how to deal with resistance and produced a military response mechanism in the governing Swapo leadership, which has subsequently proved difficult to remove through policy reforms.

Identity proponents often draw a picture of a stable community identity coming under threat from either the state or from criminals (Jensen 2004, Buur 2005a). However, the evidence shows that the idea of community never goes uncontested and that any claim to represent it is an attempt to produce what is allegedly there already and always has been (Bourdieu 1991). Community must therefore be performed over and over again in order to make it real. It is, in Laclau's words, "not just an impossibility but a very productive impossibility [as] it also triggers action that is the act of identification and the struggle to re-suture the political field" (Laclau 1994:34-5). Hence, the harder it is to make the impossibility invisible, the greater the power struggles will be. Several contributions in the present volume explore these issues.

Helene Kyed shows how the decentralisation process in Mozambique has given rise to new forms of extra-state practices, often with the participation of state officials. Kyed's ethnographic explorations highlight the attempt by the Mozambican police force to produce specific communitycitizens and re-establish state control in former war-torn areas. Through state and extra-state practices, the police engage both discursively and practically in producing "political communities". The result was the production of groups of people who, on the one hand, form part of the Unidade, or the 
unity between the population, the police and Frelimo, and on the other hand its constitutive outsiders, that is, those who continue to pay allegiance to Frelimo's old foe, Renamo. Therefore, at the core of the efforts to create unity are struggles over who has the authority to define what constitutes proper forms of citizenship, even when practice clearly falls outside the law. The demonstration of what is "right" and "wrong" is most pronounced in public meetings involving communities that do not fit the model of unity and the police, and where "law-breakers" are put on public display. By drawing attention to the importance of public spectacle in the production of communal unity, Kyed follows in the footsteps of Mbembe (2001) in his important work on the centrality of public spectacles when the state apparatus is weak and less capable of securing control of territory and of delivering services and rights to its citizens. State spectacles allow the state, and relationships between the state and its subjects or citizens, to be reworked within established registers of power, be they legal or illegal.

Steffen Jensen's piece also explores how non-state organisations produce particular forms of moral community. His analysis focuses on how gendered and generational moral communities are produced through violence, often with the aim of obtaining economic advantage. Jensen's analysis takes as its point of departure the question of how, with the democratic transition in South Africa, access to land and economic opportunities have reconfigured social and economic opportunity structures. Access to land has increasingly been capitalised, triggering a process of class differentiation in which discourses on crime provide one of the languages through which members of moral communities are differentiated. Because all members of the communities that Jensen deals with, from Nkomazi in the former KaNgwane on the border between Mozambique and South Africa, are in principle entitled to land, accusations of crime function as a legitimate way to distinguish between those who have the right to belong to the community and those who do not. Here, the production of the moral community is effected through vigilante practices by both more or less ad hoc groups of young men and more or less well-established non-state forms of social ordering under the control of traditional leaders. The differently constituted ordering mechanisms are the "midwives of community" production, which permit, in Jensen's vivid descriptions, the reordering of various registers of the self as moral persons based on not only class, but also on age and gender. 


\section{Democratic transformations and discourses of (mis) recognition}

Whether implicitly or explicitly, the chapters in this volume deal with the transformation of southern African societies from autocratic and military regimes into liberal democracies. But how can this transformation be related to changes in the security-development nexus at the national and regional levels, and how have more global trends during the past thirty years been played out in the region? These questions cannot be answered without reference to the ways in which discourses of identity, recognition and misrecognition have changed along with the overall transformation of southern Africa. From colonial times to the present, changes in domination and the structures of governance have worked by shifting discourses of recognition, with huge effects on the politics of identity.

As Englund has asserted in regard to the present period, "the spectre of discrete identities is a global predicament, promoted by the specific turn that liberal ideas have taken to facilitate neoliberal reform in national communities" (Englund 2004:11). To be recognised as poor, as needy, as a soldier for demobilisation compensation, as a counterpart or stakeholder in concrete development projects, or just as a "good" citizen, always involves and necessitates "a specific aesthetic, a particular form that claims - and the social relations that they delineate - must assume in order to be recognised" (Englund 2004:10). If such forms are not readily available, then they must be produced, as Buur and Kyed (2005) make amply clear with regard to the recognition of traditional authorities in post-conflict Mozambique. Despite being banned and seen as colonial creations, enemies of the post-independence state and the cause of civil war, they continue to haunt the new party-state. At the beginning of the new millennium, they have been recognised and recast as "community authorities" and given extensive duties with regard to development implementation, tax-collection, policing and judicial enforcement, and also form part of the decentralisation reforms and of post-conflict preventive measures.

In a similar way, Lars Buur in his chapter deals with the attempts of the new government of the African National Congress (ANC) in South Africa to gain control over social movements and civil society organisations that contest its macroeconomic policies and strategies. Buur situates these attempts in a matrix of "making up" a particular form of liberal democratic participation with the aim of "taming" or "domesticating" forms of developmental contestation, which, during the earlier struggle against 
apartheid, had been inherently uncontrollable and violent. While the attempt to incorporate township residents in a participatory forum was based on an inclusive ideology, in effect it became exclusive, simply because it was at odds with the organisational basis of movements and campaigns.

Tina Sideris's chapter also explores how democracy has had contradictory results for the new regime in respect of gender equality in South Africa. On the one hand, women have found new confidence, as state and civil society organisations assist them both legally and financially. On the other hand, this process has generated an urgent sense of disempowerment among some men, which is potentially leading to increased gender violence. Sideris's fine-grained analysis of the effects of institutionalising and investing in new legal regimes to uphold gender rights through the massive expenditure of resources comes as a timely warning against legal attempts to prevent violence. By framing the analysis within notions of human security and development, Sideris importantly calls attention to an often-overlooked link between discourses on rights, state intervention and violence. It is important to consider that gendered violence in the new South Africa cannot simply be understood as a residue of the apartheid order, one that will disappear when the democratic transition has been finalised and rights - social, political and individual - have become entrenched. According to Sideris, violence is one of the languages through which rights are negotiated in everyday practices. Also, past violence in intimate relations is reconstituted and reproduced under new conditions and emerges in often surprising forms when it is least expected.

Common to these contributions is the fact that processes of change either create subjects who identify themselves with their new identities or individuals and groups who deny, contest or challenge such forms of identity. When the particular aesthetic form in which discrete identities are rendered becomes the object of contestation, such forms of identification are transformed into figures that are (or easily could be) identified as threatening the security of state or community. In this way, they become the bodies on which sovereignty is inscribed. Other chapters, especially Kyed's and Jensen's, deal with the transformation from political to criminal violence as the predominant form, which constitutes a separate set of changes associated with political transformation in southern Africa. Contrary to the expectation that development, in the form of democratisation, would reduce levels of violence and enhance security, violence and crime seem to be multiplying, with the result that crime and violence have become political issues that states and governments have to take seriously (Jensen 2004, Buur 
2003, 2005a). In South Africa, media representations and public opinion claim that crime has spun out of control and that the country is being caught up in a spiral of violence. For some commentators (Shaw 1996, Kinnes 2000, Baker 2002a), this is hardly surprising. They see increased levels of crime and violence as being a natural result of transitions from highly militarised regimes towards democracies in which social controls are relaxed and where the state apparatus, which has often been de-legitimised by its past transgressions, is at its weakest.

This argument, whether it has merit or not, indicates that there is a different relationship between development and security, since increasing security problems are seen as invariably following democratisation. The argument is based on the claim that crime and violence are in fact rising. This is not necessarily the case, as the experience of South Africa indicates (Schonteich 2000; see also Fajnzylber et al. 1998). However, the argument might still have merit if we distinguish between "real crime levels", that is, crime levels that are measurable, and perceptions thereof. Then, transitions do not necessarily make societies more violent: rather, transitions are periods during which most identities are destabilised, institutions are placed under reconstruction and ontological insecurity dominates (Schärf 2001). In South Africa, as elsewhere, many ordinary people and state representatives argue that democracy compounds the problem of crime and violence because it protects the criminals through its elaborate system of rights. Human rights activists in turn will argue that rights are not problematic if and when the police and the criminal justice system manage to sort out their problems. According to this line of thought, security problems are temporary problems of incipient and imperfect democratisation: when the first phases have been completed, society will continue on the development course.

However, other commentators insist that there is a more foundational relationship between security, criminalisation and development as improvements of forms of life in its present neo-liberal configuration. In his chapter, Buur, for instance, challenges the thesis of imperfect democratisation. He demonstrates how law enforcement can produce criminal actors. Social movements and campaigns contesting the ANC government's social and economic policies have had to adapt to the new democratic dispensation, in which a new set of acts and regulations aimed at reforming repressive apartheid legislation on public gatherings soon demonstrated that even the most comprehensive, human-rights sensitive constitution provides the state with potentially powerful tools for curbing public dissent. Interpretation 
of the legal frameworks by state officials meant that demonstrators were arrested on their way to legally sanctioned meetings and strict bail conditions were set. Moreover, the acts were interpreted in such a way as to make public gatherings illegal and criminal. Whereas some acts used to be political, they have now been criminalised. Buur highlights the link between developmental contestations and criminalisation. When the state "has the monopoly of the political, the preservation of order within the state is essentially a problem not of politics, but of the police" (Preuss 1999:161). Decisions regarding who is criminal and, therefore, the object for securitisation are consequently intimately linked to "symbolic violence" (Bourdieu and Wacquant 1992), that is, forms of procedural and bureaucratic authority that legitimise certain practices and render others illegitimate and undemocratic.

Duffield (2001a) also takes issue with the treatment of security problems as simply passing problems of incipient and imperfect democratisation. $\mathrm{He}$ relates the securitisation of development to the disappearance of the bipolar world and to reconfigurations in global capitalism. Whereas violence and conflict were previously seen as an occasionally justified indicator of social transformation in many Third World countries, today's policy makers and observers view violence as indicators of danger, social dysfunction and anomie (see also Wieviorka 2003). Inequality is no longer a sufficient reason for conflict. Rather, inequality and the ensuing violence are dangers from which the wealthy part of the world must protect itself through increased surveillance and security interventions (Duffield 2001a:7).

Duffield's argument that security has travelled from the rich part of the world to the underdeveloped part of the world is expanded by Wacquant (1999), who argues that a neo-liberal orthodoxy on security has been disseminated from American think-tanks to the rest of the world. This neoliberal orthodoxy is "aiming to criminalize poverty - and thereby to normalize precarious wage labour. [It has been] incubated in America, [and] is being internationalized ... in the realm of 'Justice"' (Wacquant 1999:321). This has led to the proliferation of concepts such as the "war on drugs", "war on crime" and "zero tolerance" across the globe, from New York to Cape Town (Wacquant 1999:329). According to both Duffield (2001a) and Wacquant (1999), this discursive shift has profound implications for processes of democratic inclusion and exclusion, and the ability to sustain livelihoods for those areas and groups that are being criminalised.

At a general level, analysts have characterised the post-Cold War epoch as having transformed political discourse. As post-colonial abandonment, 
de-industrialisation, the collapse of welfare states, the breaking down of bipolarity and "accumulation by dispossession" (Duffield 2004b) have proceeded, the "other" of hegemonic political discourse has ceased to be identified as the colonial subject, the proletarian, the disenfranchised but struggling racial minority or the communist. As Feldman (2004) notes, the "other" has reappeared as the drug dealer, the person living with AIDS, the terrorist, but also, we would add, the illegal migrant and political adversaries. In the securocratic ideology of "public safety wars" (Feldman 204:331-2), they are demonised as border crossers in a world where national borders are perceived as leaking. Hence border controls are being replaced by different designs of spatial control, as the co-authored contribution from Jensen and Buur aptly illustrates.

\section{Old and "new" sites of development and security}

Knowing that power always works through the social organisation of space in different "territorialising regimes" (Wilson 2004), it comes as no surprise that the production of spaces and boundaries represents certain continuities in development-security linkages from colonial times to the present. When ideas of people being differently valued and endowed in terms of capacities for development, self-determination and decency combine with strategic designs for the containment and control of danger and threat, we tend to get a "police concept of history" (Rancière, quoted in Feldman 2004), that is, the production of a visual dichotomy of ideal, safe spaces and dystopic, risk-laden spaces that impinge on and threaten safe spaces. As de Certeau (1984) has argued, this division of space between civilised, "proper places" and an unruly (barbarian) environment that can be made subject to surveillance from the proper places, is a constant figure of strategic thinking in military, political and business circles. Against the grain of Duffield's (2004a) insistence that the merging of development and security is a recent phenomenon, we find this spatialised configuration of sovereign power and biopower, of violent oppression and the development of moral citizens, at different points in the history of southern Africa, from colonial times through the Cold War counter-insurgency wars to the era of democratic dispensations with wars on crime, illegal migration and political enemies.

In colonial times, the nexus of development and security was present in the form of the divide between the directly ruled, more or less democratic, predominantly white urban areas, and the indirectly ruled rural ar- 
eas, where traditional, non-democratic forms of governance predominated (Mamdani 1996). Elaborate schemes were put in place to control the influx of the rural population into the cities by means of the law. The enforcement of these laws took the form of policing the "internal frontier" (Chandavarkar 1998:206). Chandavarkar, whose work explores colonial policing in Bombay, notes that it worked on the premise that the subaltern, colonised people were highly inflammable, and consequently, that the colonial authorities "should, for the sake of its own subjects as much as itself, maintain and strengthen public order and stamp out disturbances at the first sign of their appearance" (Chandavarkar 1998:216). If disorder were allowed to persist for long, it would become virtually impossible to stamp out: therefore it had to be dealt with through any conceivable means, including excessive violence. It was common knowledge among colonial authorities in both India and South Africa that white rule was utterly precarious (James 1987, Brogden and Shearing 1993, Chawthra 1993). Consequently, enormous efforts were spent on policing the internal frontier, that is, the fine line separating white rule - read civilisation - and the miasma of chaos that would be sure to ensue should the subaltern population gain the upper hand. Policing the internal frontier of the colonies has nonetheless left many traces that have re-emerged either directly or in revised versions in different constellations.

Although the Portuguese colonial system of indirect rule never became as well developed as that of the British colonies, by the turn of the 19th century it had come to rely on governance through chiefs. Over time, a bifurcated society emerged, divided along racial and cultural lines, separating the population into indigenas governed by African custom on which colonial laws were superimposed, and não-indigenas entitled to full Portuguese citizenship (Kyed 2005:5). During the 1960s, when decolonisation set new normative standards for the evaluation of colonial regimes, the coercive character of Portuguese colonial rule came under criticism from the international community. This was reflected in a range of policy changes for the Mozambican colony, where the Indigenato was abolished and greater efforts were made towards improving rural development and stabilising rural populations through territorial arrangements. Borrowed from the UN strategy for development in the 1950s and adopted by the British and French in their colonies, "community development" was introduced. With it came "villagisation" or aldeamento, which aimed to concentrate the population in development clusters (see Scott 1998:223-61, Kyed 2005:7-8). 
Using communities as sites of governance was an attempt to make rural dwellers responsible for their own development and reduce colonial administration costs. In practice, community development was also viewed as an effective tool to counter the nationalist liberation struggles raging on the African continent, which finally came to Mozambique too (Coelho 1993:151-3). Accompanying the use of communities as sites of development was the deployment of "psycho-social service" workers who, in the name of "community development," gathered intelligence "anticipating what would be, in the following years, a truly hearts and minds campaign against Frelimo" (Coelho 1993:158). Making communities legible to the colonial state by establishing the influence of chiefs over defined territorial units over which they had jurisdiction has had a profound bearing on how the rural populations have been governed since this policy was introduced. The most recent example of this has been the recognition, in 2000, of traditional leaders as "community authorities" whose core aspects and concepts bear an alarming similarity to colonial modes of governance.

The nexus between development and security thus has a long history, but it became even more obvious in relation to the counter-insurgency campaigns of the 1970s and 1980s analysed in the chapter by Buur. Here, spatialised security-development linkages in the form of "Winning Hearts and Minds" (WHAM) strategies, which had been advocated by, for example, Trinquier (1961) and McCuen (1966), were further developed. In their analysis, and taking account of revolutionary guerrilla tactics, counter-insurgency strategies must concentrate on areas loyal to the regime with a high population density, which must be cleansed of insurgents by using excessive violence. This is the so-called "oil-spot" strategy. Extending from this "proper place", in de Certeau's terminology, still more areas are pacified and rendered open to a different form of state presence, while displaced or captured populations pass through centres or rituals of re-education before they can be (re-)integrated as citizens and organised in self-defence patrols (Stepputat 1999). When an area has been cleared of the enemy's presence, the civil administration must be made to function again to help and support the population. As one of the main protagonists of the philosophy of counter-insurgency noted: "The government has the task of not only counter-organising the population, but creating a favourable environment for the population to counter-organise. Vital to this environment is the establishment of an effective administration with the welfare of the people at heart" (McCuen 1966:326). 
The purpose of counter-organisation is to establish sustainable secure bases throughout the country so that the army will not need to liberate the same areas repeatedly. Hence, counter-insurgency is not just a military or security issue, but a "psycho-politico-military process" (McCuen 1966:327) in which populations are divided into two groups: those who can be improved and re-educated, and those who have to be exterminated. In other words, programmes and discourses of development are deliberately used for purposes of security. This also means that security personnel become "armed bureaucrats" (Seegers 1987:158), while military personnel need to be "dynamic". This is not something that is confined to one role, but, as Seegers has shown for the South African Defence Force's (SADF) involvement in Namibia, increasing numbers of military personnel came to serve as "teachers, veterinarians, agricultural advisors and technicals, dentists, doctors, psychiatrists, nature conservationists, and social workers" (Seegers 1997:158). This process was not confined to Namibia, but also became a known strategy in South Africa, with "the army of development" and "Bantustan bureaucrats" operating in both urban and rural areas, providing "more than just services" by playing a key role in securing "healthy human and race relations" (Seegers 1997). Here the image of the soldier was, of course, that of a man of action, but equally a person working in areas populated by people deemed worthy of "heart-and-minds" treatment: "a friend of the Black man who is prepared to defend him" (Seegers 1997). The merger of development and security makes it obvious that any linear transition from "war" to "peace" is difficult to maintain, but it also shows how development has been entrusted with the task of controlling and pacifying target populations, as well as being a bridgehead for security.

Democracy, it is asserted, not least in southern Africa, should herald a new age in which state violence is replaced by a new social contract between the state and its citizens, in which contemporary processes of democratisation include a transition to multi-party competition, decentralisation and an increased emphasis on community participation in local governance and development. Underpinning this shift has been an increased focus on universalising human rights, as well as securing social, cultural and political rights in the form of policies that permit the inclusion of formerly excluded individuals and groups of people. As such, democracy functions implicitly and therefore silently as a normative backdrop for a priori judgments on past policies and practices. As Arendt (1982:80) has pointed out with Kant in mind, the faculty of imagination provides both schemata for cognition and examples for judgment. Understood in this manner, democ- 
racy has become an important imaginary in southern Africa, allowing for the evaluation of apartheid security strategies, direct and indirect colonial rule, former development strategies and so on. As a political imaginary, it promises to change ideals and practices, but this may sometimes occur without substantial change in the discursive representations and concrete practices of state and non-state actors.

Contrary to ideas of radical change, we re-encounter a number of the strategic moves associated with counter-insurgency in relation to the war on crime and political opposition. In a replay of counter-insurgency strategies from the 1980s, the criminal or the political adversary has replaced the insurgent (the revolutionary, the communist, the terrorist, etc.), but the methods are not dissimilar. ${ }^{2}$ One example is the Broken Window or Zero Tolerance strategy, which American experts are promoting across the globe (Wacquant 1999) and which is based on the analysis that misdemeanours and minor crimes lead to greater crimes. Hence, the forces of order should pay particular attention to disorder, jay-walking, begging, illicit street trading and other visible signs of social decay, as this constitutes the enabling environment in which serious crimes, like drug peddling, gang activities, robberies and murders, can thrive. If the police target misdemeanours, this will prevent crime and violence from rising. Former chief of the New York police department William Bratton (1998), widely seen as the father of Zero Tolerance, ${ }^{3}$ identifies a number of differences between the police who were losing the war on crime in 1990 and his police. Before he took over, the police operated in respect to "the three R's": rapid response, random patrolling and reactive investigation (Bratton 1998:30). Consequently, they were always running after crime while at the same time not being visible. He changed these priorities through what he called "the three P's": partnership, problem-solving and prevention. More police should be employed, and they should be visible.

Clearly, it would be unfair to "community policing", which is what Bratton calls it, or "concerned policing", as Dennis (1998) calls it, to compare it indiscriminately to counter-insurgency strategies. However, there

2. Parnell argues that, "The past cold war East-West opposition of communism versus capitalism could be transformed today into the myopic relationship of cops and robbers" (2003:14).

3. The term "broken window" was first used by Wilson and Kelling (1982). When William Bratton took over the New York transit police in 1990 and became chief of police in New York, he introduced the strategy, to which he, and many others, attribute the sharply falling crime levels in New York. 
are a number of similarities. First, both strategies are psycho-politico-military projects that combine security and development through the identification of particular spaces - problem zones - that are pacified through security measures. Secondly, both past and present strategies work from the premise that the government must strike hard and decisively. A lone bandit or beggars in the metro are not minor problems that should be dealt with lightly: they are the first signs of a much larger problem that needs to be fought like a war. Thirdly, both counter-insurgency and US-style policing strategies work by organising those in support of the regime or the police to defend themselves against the onslaught, whether from insurgents or from criminals. In other words, they work through the local population to regain and secure lost territory by building partnerships between law-abiding citizens in the affected areas, the police and local government structures to help develop those areas (Bratton 1998:31-3).

The critics of the introduction of US-style policing methods on the African continent have suggested that it forms part of "a new colonialism" (Brogden and Shearing 1993:95, Dixon 2000:8) mainly governed by the requirements of "overseas aid" (Brogden 1996:225). But the spread of this type of policing is not restricted to Africa. The emergence of community policing during, for instance, the Mozambican and South African political transitions forms part of wider systems of globalised changes in governance in which the community and its representatives become the spaces that order the interface between citizen-subjects and global institutions (Rose 1999; Garland 2001). More substantially, the critics have suggested that what is taking place is the imposition of a potentially proactive model of policing especially on underdeveloped countries, which, some would claim, lack the democratic history that underpins the community policing role in long-established democracies (see in particular, Bayley 1995:91). The introduction of community policing has, quite legitimately, been seen as part of the enforcement of a particular form of liberal democracy that may have little or no relevance to the African experience, but is guided primarily by the need for social stability in pursuit of economic growth strategies, rather than community priorities (Brogden 2004). As Buur (2005b) has shown, the South African community-policing model includes the use of a spatial matrix based on the local governance unit of the ward for ascendancy, which is more often than not at odds with the organising basis of non-state judicial enforcement organisations. The model can therefore be seen as a formal redrawing of the space for governance between the authority of state on the one hand, and the liberty of rights-bearing, autonomous, individual 
subject-citizens of the nation on the other. One can debate, however (see Buur 2005b:257), to what extent it is solely autonomous individuals that are produced, rather than individuals conditioned by political allegiance to a dominant government too.

As Helene Kyed illustrates in her chapter on the former war zones of Mozambique, community policing works through a double-edged process of recognition/inclusion and reordering/exclusion structured by clear political imperatives. Here, party political affiliation informs the categories of citizen/non-citizen and non-criminals/criminals. Superimposed on these categories are emic denominations drawn from the 16-year civil war. Where the enemy was then referred to as the "people who make confusion", that is, Renamo insurgents, "confusion" today refers to criminals, that is, anybody who supports or potentially could support the opposition political party. Here, for instance, a person declining to pay the obligatory head tax becomes an index of political affiliation. At the core of this is a particular political ethos that cannot be understood without taking into account the history of the liberation struggles and civil wars that characterise southern African countries. As Buur demonstrates, less than a decade after South Africa's apparently miraculous transition from apartheid to constitutional democracy, the political culture of monism developed during the 1980s is still structuring the implementation of new government policies, as well as the forms of resistance that such policies trigger, though in a displaced perspective. The key to decoding political contestations in the new South Africa is thus based on the circulation of past struggle narratives concerning hidden and evil forces and the enemies of the ANC (Jensen 2001). Consequently, any opponent of the government's economic policies becomes recast as a (past) enemy, and cannot therefore be included in democratic forums. Classification as an "enemy" of the ANC, Buur shows, a priori undermines any claims to legitimacy and allows exceptional means to be deployed, even killing.

The point is, as Metsola and Melber, Rasmussen and Hammar also point out, that within selected spaces citizens have been simultaneously criminalised and securitised through particular benevolent state campaigns, often conducted in the name of development. Subjects of development are turned into objects of security. A common characteristic of these practices of criminalisation and simultaneous securitisation is the identification of a dangerous "other" who can be eliminated (by fire, demolition, displacement, torture, even death), contained (by imprisonment, intimidation) and/or ignored (by being denied access to crucial services). These 
practices have been justified publicly by invoking the law, backed up by particular administrative, developmental and/or moral-political projects. This combination of discourse and practice exploits an image of the responsible and caring state that is nonetheless able to assert its sovereignty fully and exclude from development those it considers a threat or defines as enemies of the state. Where violent state practices have in some cases both increased and become visible, in other cases criminalisation and securitisation have become invisible by being embedded in ordinary development projects. In order to capture this double-edged movement, there is, as Hammer points out, a methodological need to explore in greater depth how subjects encountering discourses and practices working with and through the security-development nexus themselves experience and respond to acts of state violence and exclusion. That is, closer attention should be paid to the ways in which those who have been violated and excluded by diverse and often benevolent state projects and practices redefine the terms of their entitlement to livelihoods, security and belonging, while also trying to relegitimise their claim to citizenship. 

INTERNAL AND EXTERNAL BOUNDARIES 



\title{
You Do Need a Stick to Be Able to Use It Gently The South African Armed Forces in The Democratic Republic of Congo ${ }^{1}$
}

\author{
Thomas Mandrup Jørgensen
}

\section{Introduction}

The primary function of the SANDF is defence against external aggression. The other functions are secondary (Department of Defence 1998:29)

From the outset, the relationship between defence and development is seen as both an oxymoron and a contingent relationship (Williams 2001:57f). Investment in defence has traditionally been considered as the use of state resources in an unproductive sector, something that is highly contested, especially in developing economies with limited resources. However, the role of the armed forces is changing from the traditional narrow territorial defence to a broader societal approach, in which the armed forces are just one element in dealing with the security threats that modern societies face. In South Africa, the South African National Defence Force (SANDF) has increasingly been asked to handle secondary tasks, such as domestic policing, border control and, since 1999, international Peace Support Operations (PSO).

South Africa's recent involvement in the Democratic Republic of Congo (DRC) is an example of the government's new foreign policy strategy, in which SANDF should ideally help to secure the foundations of peace and stability in the volatile transitional phase between conflict and post conflict, and thereby help to promote development. However, South Africa's participation in the United Nations PSO in the DRC, known as MONUC, illustrates the country's commitment to international multilateral solutions and the UN in particular. At the operational level, the deployment of the SANDF as part of MONUC is an example of how the forces cope with the

I. The research for this article is part of a larger study on the role of the SANDF in South African foreign policy. Background interviews were conducted in 2003-04 both in South Africa and in the DRC. For further reading on the methodological criteria and limitations, see Mandrup Jørgensen, "Salvation or Despair of Africa? - A Study of the Post-apartheid South African Government's Use of the Military Tool in its Foreign Policy Conduct", forthcoming. 
new broadened concept of defence used by the politicians, and shows how the two levels interact. ${ }^{2}$ This chapter will analyse how the African National Congress (ANC) government's economic and political development ambitions are incorporated into national security thinking. It will also investigate how the Pretoria government has used the SANDF strategically as part of its general foreign policy approach towards the DRC and establish whether the peace-making role in the DRC has been securitised.

\section{SANDF's new role in Peace Support Operations}

We have to put as much muscle as words into the "African renaissance" ... There can be no African renaissance without the military. ${ }^{3}$

In the SANDF, there has been a tendency to understand the concept of security within a classical security studies framework, based on past experiences from the counter-insurgency warfare during the border war era in the 1970s and 1980s. The South African Defence Force $\left(\mathrm{SADF}^{4}\right)$ was under the auspices of the State Security Council (SSC) and was tasked with conducting both retaliatory attacks and pre-emptive operations against rebel forces operating from and supported by neighbouring states. It is accepted that Western societies 5 are in a transitional phase, being faced with a number of new and broader security challenges. The focus has moved away from a "peace-crisis-war logic", based on the mobilisation of a defence force, to dealing with declared and undeclared challenges or conflicts, which means that modern society is in a state of constant preparedness against a multitude of mostly unconventional security threats. ${ }^{6}$ The consequence of this

2. The SANDF has serious structural and capacity problems and has problems in executing the tasks given to it by the government. For further reading on the structural problems in the SANDF, see Mandrup Jørgensen, "Salvation or Despair of Africa? - A Study of the Post-apartheid South African Government's Use of the Military Tool in its Foreign Policy Conduct", forthcoming.

3. South African chief of staff, Gen. Nyanda, quoted in the Mail \& Guardian, 20 August 2003.

4. The name of the South African armed forces changed in 1994 from SADF to SANDF to mark the political transition.

5. Here I consider South Africa as being part of the 'Western Society' framework, even though the country is in many respects a developing country.

6. Lecture given by Niels Madsen, Danish Emergency Service, at DIIS, Copenhagen, April 2004. 
is that traditional distinctions between civilian readiness, both state and $\mathrm{NGO}$, and military readiness are undergoing significant change and are being incorporated into what is called "integrated thinking" in defence circles. ${ }^{7}$ Professor Bengt Sundelius has described this as a move away from "total defence" to "societal defence", the difference being that, within traditional total defence thinking, every societal sector supports the defence forces' efforts against an external aggressor. In the societal defence concept, the defence force is reduced to being part of the combined efforts of the different government institutions in securing the safety and security of the society. ${ }^{8}$ It can to a certain extent be argued that the strategic thinking introduced in the 1977 South African Defence white paper, the so-called total national strategy and the national security management system, was to an extreme degree organised to be able to handle both declared and undeclared security challenges in an attempt to protect the interests of white South Africa. The idea of "integrated thinking" was therefore the driving element in this strategic thinking. However, the post-1994 military tasks given to the SANDF were significantly different from the previous counterinsurgency experience. The new government wished to reduce the offensive capability of the force as a confidence-building measure in relation to neighbouring countries. The SANDF was, together with other government departments, to take part in creating security for the individual South African citizen.

Another element in determining the role of the South African armed forces in the society is to look at the perception of what constitutes a security challenge, i.e., what is singled out by the securitising actors as constituting a security threat. As argued by Wæver, this is not the act of individuals, but the result of a political bargaining process (Wæver 2004:12). Security is basically concerned with survival. The security thinking of the late apartheid regime is very instructive in this respect, because its main objective was the survival of the white-led regime in South Africa. Neighbouring states were consequently considered to constitute a threat to the survival of the regime, and were securitised accordingly. The military strategy, the total national strategy, was developed to create security from this urgent threat to existence. By the late 1980s, however, it ended up creating insecurity, because the regime found it increasingly difficult to defend itself against massive

7. Lecture given by Commander R.D.N. Torben $\varnothing$. Jørgensen at the seminar DanishSouth African Dialogue on Security, May 2004.

8. Lecture given by Professor Bengt Sundelius, at DIIS, Copenhagen, 29 April 2004. 
civilian resistance. Even though the total national strategy was defensive in nature, it included offensive strategic measures in an attempt to defuse the threat against apartheid South Africa. ${ }^{9}$ Apartheid policies were also securitised in the neighbouring countries, where South Africa was perceived as a direct threat to the sovereignty of these states. Despite this, the Pretoria regime managed to keep the Frontline States dependent on South Africa, particularly by forcing them to use South Africa as the main transit route for the import and export of goods. The main security challenge for the Pretoria regime was, apart from the threat posed by the large majority of its own population, to destabilise the neighbouring states to an extent that they did not constitute a direct conventional threat to South Africa. This strategy was very successful except in Angola, where the involvement of Cuba and the USSR during the 1980s made it increasingly difficult for the apartheid forces to match the combined Angolan/Cuban/Russian/SWAPO forces. ${ }^{10}$

After the transition in 1994, seven different armies were merged into the SANDF ${ }^{11}$, which now had to define and find a new role for itself. The new constitution secured civilian control over the national security structures, by establishing among other things a civilian defence secretariat in the Department of Defence (DOD). The idea was to pull back the SANDF from the political sphere, and confine it to being a defence force serving the state and the South African nation ${ }^{12}$ in its totality. There were even sections of South African society that questioned whether the new South Africa needed a defence force at all. The 1996 defence white paper on defence and the subsequent 1998 review stipulated that the future defence force's

9. Even defensive military strategies, for instance, Non-Offensive Defence (NOD), have offensive elements built in, both in terms of actual force design and strategic set-up. The SADF constituted a relatively small permanent force with a large mobilisation capacity, which could be deployed in the event of a crisis. It was designed as a reaction force, attempting to deter potential attackers. Despite the nature of the regime, the apartheid state did not have any territorial ambitions towards the neighbouring states, and the major issue was defence against internal and external threat.

Io. For further reading on the counter-insurgency wars during the apartheid era, see Mandrup Jørgensen 2001.

II. The seven armies were the SADF, the Azanian People's Liberation Army (APLA), Mkhonto we Sizwe (MK) and the four homeland armies.

I2. It is, of course, debatable whether in an ethnically heterogeneous society it makes any sense to talk about a nation. The point of using the term in this context is to stress that the new SANDF was to serve and represent all groups in society, and not just a small segment. 
primary task would be to protect the territorial integrity of the state, and only limited resources were to be set aside for international PSOs. One of the problems that the SANDF faced from 1994 until 1999 was a lack of consistency in South Africa's foreign policy. The SANDF found it difficult to choose a development path in its efforts to create the necessary capabilities for future PSOs, because the government had no policy in this field. Within the force, there was moreover in the mid-1990s widespread opposition, especially among the former SADF officer corps, to participation in international PSOs (Heinecken 1999, 56f). There was a fear among officers of being dragged into open-ended missions on a weak UN mandate, together with weak African partners. However, this attitude seems to have changed, partly as a consequence of successful participation in several UN and AU PSOs. ${ }^{13}$ Some of the sense of insecurity detected by Heinecken's survey (Heinecken 1999) was caused by the widespread downsizing of the armed forces, a perception of a lower quality of training, the lack of funds to buy new military equipment and the resignation of experienced officers from the forces. ${ }^{14}$ These issues created a sense of doubt and uncertainty among staff members about the military capacity of the SANDF to deal with future PSOs (Heinecken 1999:56f).

However, in 1999 the government did, despite the vagueness of the recommendations, present its policies on South African participation in PSOs in the white paper on peace missions. Foreign Minister Zuma stated in an address to the South Africa Institute of International Affairs (SAIIA) on 1 November 1999 that:

The fact that South Africa now has a policy on peace keeping and has made a practical commitment to start participating in multinational peace missions makes it incumbent on the Government to recognise the role that the Defence Force will play. This puts a new dimension to the Defence Force in terms of South Africa's international obligations. (Zuma 1999)

13. No recent major surveys have been conducted on the attitude among SANDF staff towards deployment in international PSOs. However, the series of interviews of SANDF personnel by the author did not detect widespread opposition to this kind of mission. On the contrary, several members noted they had applied to be part of this deployment, primarily because of the extra pay

I4. An important issue and limiting factor is the widespread HIV epidemic among SANDF personnel. It has been estimated that up to 30 per cent of the soldiers are HIV positive and cannot, according to UN Department of Peacekeeping Operations (DPKO) regulations, be deployed for UN PSO. The official SANDF figure is 21 per cent. 
One of the pressing issues that led to the publication of the white paper was the national and international debates on what could be expected of South Africa in relation to participation in PSOs. The paper aimed at outlining what could realistically be expected of South Africa in this regard, and to draw up a national policy so that the SANDF could prepare. The paper stated:

Although South Africa acknowledges its global responsibilities, the prioritisation afforded Africa in South African foreign policy makes Africa the prime focus of future engagements. South Africa has an obvious interest in preserving regional peace and stability in order to promote trade and development and to avoid the spill over effects of conflict in the neighbourhood. (DFA 1999:21)

It is outlined in the white paper that, in principle, South Africa is willing to participate in all kinds of international PSOs, including peace enforcement and humanitarian assistance, primarily in Africa. However, Pretoria's recent commitments to African PSOs show that the government has moved beyond the single battalion ${ }^{15}$ anticipated in the white paper on peace missions, which has now been declared to be outdated. ${ }^{16}$ In March 2005, South Africa had deployed more than 3,000 SANDF personnel as part of African and UN PSOs. (DOD 2005a) The Pretoria government has increasingly focused its attention on external structural challenges and in 2004 the primary function of the SANDF was, apart from protecting the state against foreign aggression, to support the government's diplomatic drive in Africa. It was furthermore decided to phase out SANDF's permanent support for the police. ${ }^{17}$ South Africa is politically and militarily involved in both actual African PSOs and in establishing the new African continental and regional collective security regimes, in an attempt to limit tension and the perception of threat between African states. However, even though several apparently important securitising moves have been made in the form of diplomatic efforts in Africa and subsequent military involvement, this has

15. An extended South African battalion is in theory approximately 1,000 soldiers. In reality, it often consists of only 600-800 soldiers.

I6. Interview with SANDF chief director strategy and planning, Rear Admiral Hauter, and chief of policy and planning, deputy director-general DOD defence secretariat, Mr. Motumi in the DOD, 26 November 2003.

17. Since 1994, the SANDF has at all times had between 1700-3000 soldiers deployed on domestic operations. For further reading, see Mandrup Jørgensen, "Salvation or Despair of Africa? - A Study of the Post-apartheid South African Government's Use of the Military Tool in its Foreign Policy Conduct”, forthcoming. 
not led to extraordinary political commitments, such as increased resource allocations for the SANDF. In order to understand this schism it is necessary to investigate the role that securitisation has played in the formation of South Africa’s national security policy.

\section{South Africa and national security}

In effect, the most difficult military problem to resolve is that of establishing a security system, as inexpensive as possible in time of peace, capable of transforming itself very rapidly into a powerful force in case of the danger of aggression (DOD 2004)

Security deals with the future, i.e., what happens if we do not act upon a perceived threat, or what happens if we act as recommended by the securitising actors (Wæver 2004:20). Issues that are securitised constitute a threat to the survival of the state, and justify the use of extraordinary measures in the attempt to handle them (Buzan et al. 1998:21). Extraordinary means have to be understood here as setting aside normal political considerations. The intervention in Lesotho, affirmative action and black empowerment policies in South Africa are examples that lie outside the scope of normal politics, i.e., issues that are deemed essential for the survival of the state. The actions of the apartheid regime in the 1980s, which declared a state of emergency on several occasions overruling "normal political procedures", are an example of this. Then, "normal" political processes were partly suspended and partly replaced by presidential or State Security Council (SSC) decision-making bodies. But the nature of what is perceived as constituting threats to existence in South Africa has, since 1994, been undergoing profound change, and the traditional focus on military sector affairs as constituting threatening issues is no longer necessarily clear cut. Other types of task have been delegated to the military sector, tasks which might not normally be characterised as constituting threats to national security, for instance participation in international PSOs (Buzan et al. 1998:22). In this chapter a security issue is defined as being

... posited (by a securitising actor) as a threat to the survival of some referent object (nation, state, the liberal international economic order, the rain forest etc.), which is claimed to have a right to survival. Since a question of survival necessarily involves a point of no return at which it will be too late to act, it is not defensible to leave this issue to normal politics. The securitising actor 
therefore claims a right to use extraordinary means or break normal rules, for reasons of security. (Buzan and Wæver 2003:71)

In analysing what constitutes "national security", it is important to have distinguished clearly what instances constitute a security issue, the risk of course being that more or less everything ends up being a question of security (Buzan and Wæver 2003:71). "Security" basically deals with survival, i.e., in the case of what constitutes South African national security, it deals with referent objects that are seen by the securitising actors as constituting an urgent threat to the survival of the state. This is the case both if the focus is on soft human security issues, e.g., social empowerment of marginalised groups, or on long-term planning of hard security measures, e.g., defence acquisition strategies. For instance, an area that was quickly securitised in South Africa was race relations. The political level decided to implement unyielding affirmative action (AA) programmes, because the issue of proportionate racial quotas was deemed to constitute a direct and urgent threat to the state, and the ANC itself, if not addressed. ${ }^{18}$ Official South Africa had to reflect the demographic composition of the population, and harsh public employment and right-sizing reforms were initiated. The main political opposition, the Democratic Alliance (DA) has criticised government for its strategy and argues in favour of a softer version of AA. ${ }^{19}$ According to Buzan et al., the securitising situation must be understood as one extreme end of a continuum, where the other pole is non-politicised issues, i.e., matters that the state, the media, etc., have no interest in. In between the two are the issues that are politicised, i.e., the topics that are part of the public debate. The process of securitising an issue will often be the result of a bureaucratic bargaining process involving the securitising actor and the audience about whether an issue should be securitised or not (Buzan et al. 1998:26). However, the actors are not equally important and influential in the securitising process, and cultural and social capital, in a Bourdieuan sense, have an importance in how the legitimacy of a particular statement is viewed. As Buzan et al. argue, the important question in analysing security is "who can 'do' security in the name of what" (Buzan et al. 1998:45). The South African president since 1999, Thabo Mbeki, will for instance, generally have a better chance of succeeding in a securitising

18. It has to be remembered that the issue of race has long been securitised in South Africa, and that it has merely continued to be so, with, however, a different content.

19. See for instance DA policy paper 'Opportunity for all' http://www.da.org.za/da/ Site/Eng/Policies/Downloads/Empowerment.asp 
move in respect of national security than the average man on the street. However, in South Africa individual researchers and NGOs had, and to a certain extent still have, significant influence in the drafting of the various white papers and thereby shaping the foundations of the national security strategy. This might be one of the reasons why, today, there exists a dichotomy between the structure and capabilities of the SANDF and the political ambitions and realities at the political level.

\section{Contemporary security challenges to South Africa}

The South African society is today confronted by a number of security challenges that the society needs to prepare for. These threats are basically fourfold:

1. Armed attack by another state, i.e., military intervention;

2. Armed attack by another actor, e.g., terrorists;

3. Attack by another state, e.g., through trade, financial or other types of non-military intervention; and

4. Attack by another actor, e.g., information operations, critical infrastructure, virus attacks

On top of these issues are structural threats that are not intentional attacks, e.g., nuclear plants, epidemics, state failure and collapse, violent civil unrest and migration (often the direct consequences of conflict, lack of development and instability). ${ }^{20}$ Challenges can generally be divided into those which create insecurity, i.e., threats that the society cannot defend itself against, and those that create security, i.e., threats that the society is able to defend itself against (Wæver 2004:13). Former President Nelson Mandela has repeatedly argued that the single largest threat to peace and stability in South Africa itself is poverty and social inequality, which falls into this last category. Generally, the political parties in parliament seem to agree on the securitisation of these issues, though disagreements exist on the implementation strategies. ${ }^{21}$ According to former Minister of Defence Joe Modise, the new understanding of national security has been broadened so that:

20. Lecture given by Professor Bengt Sundelius, 29 April 2004, at DIIS, Copenhagen, 29 April 2004.

2I. See, for instance, President Nelson Mandela's speech at the Freedom Day celebrations in Umtata, 27 April 1999. 
In the new South Africa national security is no longer viewed as a predominantly military and police problem. It has been broadened to incorporate political, economic, social and environmental matters. At the heart of this new approach is a paramount concern with the security of people. Security is an all-encompassing condition in which the individual citizens live in freedom, peace and safety; participate fully in the process of governance; enjoy the protection of fundamental rights; have access to resources and the basic necessities of life; and inhabit an environment which is not detrimental to their health and well-being (Lekota quoted in Cawthra 1999:7f)

The result is that from 1994 domestic social development and the government's Redistribution and Development Programme (RDP) ${ }^{22}$ have become central elements in South African security thinking. ${ }^{23}$ Especially issues such as land redistribution and black economic empowerment are topics that the present government has presented as issues that are so urgent and fundamental that they need to be moved beyond the scope of "normal" political processes. One of the reasons for this is that the strength of a state has more to do with its internal socio-political cohesion than its actual power. The stronger its socio-political cohesion, the more likely it will perceive its security challenges as being predominantly external. ${ }^{24}$ In the case of South Africa, it can be argued that the government focused on domestic issues as constituting the biggest threat to security during its first ten years in power after the transformation from apartheid.

When politicians like Modise and Mandela designate particular soft issues as existing threats, their action legitimises the use of extraordinary means to deal with the situation. ${ }^{25}$ The SANDF planners therefore have to look to these primary tasks in their planning and determine where the priorities are to be found. Domestically, South Africa is faced with the HIV/

22. Replaced by the more liberal economic Growth, Employment and Redistribution (GEAR) programme in 1996.

23. Wæver argues that much literature on what security is, in reality is about what is also security. Modise's statement falls well within this category, and must be seen as a classic example of the thinking in government circles in Pretoria. For further reading, see Wæver 2004:8.

24. For further reading, see for instance Buzan and Wæver 2003 and Jackson 1993.

25. In South Africa, an example of this is the secrecy surrounding the statistics concerning the incidence of HIV/AIDS in the armed forces: DOD is extremely reluctant to give out accurate figures, because this has been deemed a strategic issue. This is a departure from normal procedures in the DOD since 1994. The department has been extremely open, giving the public access to many reports and documents that in most states would be classified. 
AIDS epidemic, poverty and crime as the most pressing issues, which have become national strategic issues. In Southern Africa, the structural threats and political and economic intervention by other states are the most pressing issues, because no direct conventional military threat exists. However, South Africa is geographically located in what Holsti defines as a zone of war $^{26}$ and experiences constant pressure on its borders from refugees and illegal immigrants from its Southern African neighbours, who see South Africa as the land of opportunity. SANDF therefore needs to be able to plan according to these perceived security threats. A central security threat is the failed and fragile states that are closely interlinked with the issue of migration. Individuals flee from poverty and conflict. The concept of national security has traditionally been investigated at the national state level. However, security is of a relational nature and should be investigated at a regional level (Buzan and Wæver 2003:43). In the case of South Africa, the state's national security concerns cannot be analysed separately from those of the Regional Security Complex (RSC) it belongs to. ${ }^{27}$ Questions as to what can be considered security are therefore often closely interlinked with foreign policy issues. Security issues such as food security, access to water, drought and political instability cut across territorial borders, and can have serious implications for peace and stability in a region. This type of issue therefore has direct bearing on areas that traditional security theory defined as national security. ${ }^{28} \mathrm{~A}$ nation's foreign policy reflects the perception of security that dominates the decision-making actors' actions. Ideas and norms are an important element in this process, because they function as a kind of road map and guide the choice of the main political objectives. By choosing one path, other avenues are no longer open and political decisions therefore also function as limiting elements. To choose in favour of something also means to remove other options. Ideas and norms therefore also function as a determining factor in forming and joining alliances, because the very basic ideas and norms will often form the basis for a larger sense of community among the actors in an alliance or regime. Political ideas will,

26. For further, reading see Holsti 1996.

27. South Africa is tied closely to its immediate sub-region, traditionally the SADC, and excluding Tanzania and the DRC, which constitutes the RSC in Southern Africa. After the transition in 1994, the South African sphere of influence has been widened and the Regional Security Complex (RSC) arguably increased.

28. The political crisis in Zimbabwe can be seen as an example of this, where for instance food security is used by political actors and becomes a question of national security and the survival of the state/regime. 
if accepted by the actors, become settled rules or norms over time. In its foreign policy conduct, South Africa has been pivotal in introducing new political ideas and reforms, which have led to the establishment of new African institutions and collective security frameworks. ${ }^{29}$ This has led to new norms, and rules have been introduced and are becoming rooted on the continent.

\section{South Africa in its new role as the "African peace broker"}

The DRC conflict has been called the first African "World War", because by 1999 it involved six or seven foreign states and a large number of rebel factions in the DRC itself. There was by then a risk that the conflict would escalate into a conventional interstate African war. Luckily, the conflict did not spill over into the region and was contained within the borders of the DRC..$^{30}$ The war began in late 1996 when the combined anti-Mobutoist rebel forces of the Alliance of Democratic Forces for the Liberation of Congo-Zaire (ADFL) led by Laurent Désiré Kabila, with support from Rwanda and Uganda, started its advance on Kinshasa: by 16 May 1997 the reign of Mobuto had ended. Kabila promised a sceptical international community that he would initiate a democratisation process and call general elections within three years. In return, he received both international recognition as the new legitimate leader of the DRC and membership of Southern African Development Community (SADC). However, in early 1998 joint eastern Congolese rebels and Rwandan and Ugandan government forces started an offensive against Kabila's regime as a result of the increased political disagreement between Kabila and his former allies. Forces from Zimbabwe, Angola and Namibia came to Kabila's rescue, the result being a military stalemate. ${ }^{31}$ Both Uganda and Rwanda had their own strategic considerations for being involved: Uganda wanted to target antigovernment rebel forces operating from Ituri province in particular, while

29. For instance, institutional reform in SADC, SACU, the establishment of AU/ NEPAD, the Peace and Security Council under the AU.

30. This is not to say that domestic conflicts in Angola, Central African Republic, Rwanda, Burundi and Uganda were not linked with the conflict in the DRC, but merely to stress the point that the fighting inside the DRC between the parties did not lead to interstate military confrontations outside the DRC.

3I. For further reading on the so-called SADC allied force, see Mandrup Jørgensen, "Salvation or Despair of Africa? - A Study of the Post-apartheid South African Government's Use of the Military Tool in its Foreign Policy Conduct”, forthcoming. 
Rwanda still had the former Hutu génocidaires operating from the Kivus to deal with (Breytenbach et al. 1999:8). At a later stage in the conflict, other elements such as economic incentives, became important factors in fuelling the conflict, as was evident when heavy fighting broke out in 1999 between the forces of the two alliances to control the city of Kisangani.

In 1999 the foreign parties to the conflict signed the Lusaka peace agreement, securing a cessation of hostilities among themselves and creating a framework for the withdrawal of foreign forces from the DRC. However, as argued by the South African Foreign Minister Zuma in 2000, the:

... problems with the Congo agreement were two-fold. Firstly the neighbours, Burundi and Uganda, had armed groups based in Congo thus creating a military conflict. The major problem foreseen was dealing with the armed groups that were not signatories to the agreement and not committed to peace. Secondly there was no movement in terms of democratization in the Congo and the people were feeling despondent. (Zuma 2000)

The 1999 Lusaka agreement had settled the basis for the withdrawal of foreign forces from the DRC, but did not settle the issues related to the domestic conflict. The Inter-Congolese Dialogue (ICD) was a result of the Lusaka agreement, and was initiated in Addis Ababa in October 2001 with active South African involvement (DFA 2003). However, the necessary resources and framework for the negotiations were not in place, and the ICD was adjourned and relocated to Sun City, and partly financed by South Africa. The negotiations were to be all inclusive and under the supervision of Sir Ketumile Masire, the SADC-appointed mediator, but from 9 April they were partly taken over by President Mbeki. The first phase of the ICD finished on 18 April 2002, with a partial agreement signed by one of two major rebel movements, the Mouvement de libération du Congo (MLC), and the Kabila government. Despite the late intervention by President Mbeki, the Rwanda-backed Rassemblement congolais pour la démocratieGoma (RCD-Goma) and a coalition of civil society groups refused to sign this agreement, partly as a result of heavy pressure from Rwanda, which wanted security assurances from the Kabila government, but also because of disagreements over the arrangements for power sharing during the transitional phase. Foreign Minister Zuma stated in parliament about the Sun City agreement that:

The recently concluded Inter-Congolese Dialogue in Sun City provides the necessary impetus for the inclusive process towards peace and stability. Only an all-inclusive agreement that will lead to the re-unification of the Congo and 
a transition to democracy will create sustainable peace and spare the war weary people of Congo more hardship. (Zuma 2002)

In her speech to parliament in May 2002, Foreign Minister Zuma thus underlined that the government's all-inclusive negotiation strategy had been and still was the only way forward in finding a lasting peace. By stating this, she also underlined that the strategy put forward by the warring states would not lead to a lasting solution of the problems facing the DRC. In the month after the Sun City conference, the South African government, with President Mbeki in charge, worked hard to bring the remaining groups into an all-inclusive agreement. This objective was only reached after the signing of a bilateral agreement between the governments of Rwanda and DRC on the conditions for the withdrawal of Rwandan troops in the summer of 2002. Joint South African-UN led negotiations were resumed in South Africa in October 2002 and were finalised with the signing of the so-called Global and All Inclusive Agreement in Pretoria on 17 December 2002. This provided for the establishment of a transitional government with Joseph Kabila ${ }^{32}$ as president, with four vice-presidents each representing one of the two major factions, the government and civil society. The central areas of responsibility were also divided between the main parties. Multi-party elections were scheduled for June 2005.

A central element in the peace agreements among the parties in the conflict relates to the disarmament, demobilisation, repatriation, resettlement and reintegration (DDR(RR)) of both foreign and domestic combatants. The $\mathrm{DDR}(\mathrm{RR})$ process has in several instances been deemed to be pivotal to the possible cessation of the conflict and instability in the eastern part of the DRC. In a report by the UN Security Council drafted as early as 2001, it was stated that:

The disarmament, demobilization, reintegration and repatriation or resettlement of armed groups is the key to ending the conflict in the Democratic Republic of the Congo. Resolving the remaining problems would remove any need for foreign troops to remain in the east of the country, immeasurably improve the security and quality of economic life for the area's inhabitants, and neutralize a dangerous source of conflict and instability in the region. (UN 2001:16)

South Africa has from the outset been closely involved in this process as part of the oversight and verification committees. South African involve-

32. Became president in January 2001 after the assassination of his father. 
ment must furthermore be seen as running along three parallel tracks, one being the mediating role, another being participation in the UN PSO mission in the DRC and the third being post-conflict reconstruction, for instance, screening and training the new army. The close linkages between the two latter are to be found in the areas of the DDR(RR) of foreign fighters and the DDR process for domestic non-statutory forces, numbering an estimated 300,000 combatants (Boshoff 2005:8), and the subsequent agreement among South Africa, Belgium and the DRC on assistance in forming a new army. However, the DDR(RR) process has been proceeding much slower than initially expected. The continued instability in especially the eastern DRC has meant that the combatants have been reluctant to hand in their weapons..$^{33}$ According to the South African military attaché, the DRC lacks the necessary resources to execute the process. At the political level, the actors in the transitional government have so far dragged their feet about creating the needed institutional framework. The law regulating the new army, for instance, was not passed until in October 2004, after long negotiations, more than a year after the formation of the new transitional parliament and government. According to the South African ambassador to the DRC, there was for a period a disagreement between the UN and the South African government regarding mandate for the DDD(RR) process provided for in Resolution $1565 .{ }^{34}$ In the minutes attached to the resolution, it was stated that:

The Mission was ... tasked with ensuring the protection of civilians, including humanitarian personnel, under imminent threat of physical violence, and to seize or collect the arms and any related materiel whose presence in the territory of the country violated measures imposed by resolution ... The Mission was also tasked with ... supporting operations to disarm foreign combatants led by the Armed Forces of the Democratic Republic of the Congo ... (UN 2004)

The disagreement regarded the interpretation of the mandate on the use of force in disarming primarily the so-called foreign fighters in the DRC. South Africa argued in favour of a more robust strategy, while the MONUC leadership rejected this as inconceivable. The argument by the UN officials was that the Rwandan army, with stronger forces, was unable to do this,

33. Interview with SA military attaché in the DRC, Lt. Col. Jack Khanye, 1 November 2004, at the SA embassy in Kinshasa.

34. Interview with South African ambassador to the DRC, 3 November 2004, in Kinshasa. 
and such actions would therefore be impossible for the smaller UN force. In September 2004, the UN Security Council strengthened MONUC with an additional 5,900 soldiers and the force reached 16,700, making it the largest UN mission with an estimated budget of $\$ 900$ million. ${ }^{35}$ The South African ambassador, on the other hand, argued that there was no sense of reality in the DDR(RR) section in MONUC HQ, because the Hutu rebels would never give up their weapons voluntarily. ${ }^{36}$ It is not only South Africa that supports a forcible disarmament, but also the AU Peace and Security Council. In a communiqué after the January 2005 meeting in Gabon, it stated that it preferred forceful disarmament of the estimated 10,000 Hutu rebels operating in the eastern DRC, if need be by an AU force (Reuters 2005). However, in February 2005, as a response to an attack on UN peacekeepers (nine of whom were killed), MONUC altered its strategy and attacked a militia compound in the Northern Ituri province, killing an estimated 60 local militia members. This has proved to be a turning point in the UN's approach to disarmament in DRC, especially in Ituri province. The operation was conducted by Pakistani, Indian and South African forces, arguably some of the most capable forces in MONUC. However, MONUC is generally faced with the kind of problems that have plagued the UN since the failures in Bosnia, Rwanda and Somalia in the early 1990s, namely that the majority of the forces made available to it are Third World soldiers who are badly trained, ill disciplined and insufficiently equipped. ${ }^{37}$ Given this consideration, and the South African government's stated peaceful strategy, it may seem strange that the South African government favours forceful disarmament.

35. However, the number falls short of the more than 23,000 recommended by the UN. The force number provided by Resolution 1565 was in reality short of the proposed Kasai and Katanga brigades. Interview with Dep. Dir. Policy Grignon, 2 November 2004 in UN HQ in Kinshasa and UN Security Council Resolution 1565, 30 September 2004. The force number was increased once more in September 2005, and forces have been transferred from the UN mission in Burundi to help secure the July 2006 elections. The budget was increased once more in December 2005 to $\$ 1,153.80$ million for the financial year July 2005-June 2006.

36. Interview with South African ambassador to the DRC, 3 November 2004, in Kinshasa.

37. This ignores the language barrier, which creates tremendous problems during operations. Another issue is the missing correlation between mandate and the resources made available to that mandate. 


\section{South Africa's military contribution to MONUC}

South Africa will not commit itself to participating in any peace mission which is patently under-resourced and which does not have sufficient means to achieve the set mandate. (DFA 1999:17)

The South African contribution to MONUC is a natural extension of the involvement in creating a negotiated political solution in the DRC. The participation in MONUC and in drafting the Lusaka peace treaty can be seen as a test of the South African foreign policy strategy of political settlements supported by both military and civilian peace-keeping and reconstruction efforts. ${ }^{38}$ The involvement should be seen as being part of the nexus between economic development interests and security concerns, which are issues within the new South African national security strategy that can be separated only with difficulty. In the white paper on peace missions it was stated that South Africa had an obligation to contribute to UN PSOs, especially on the African continent (DFA 1999:13f). One of the conditions for South African participation that was emphasised in the white paper was that a clear exit strategy had to be included in the mandate for an operation, but the government was determined to make a contribution to MONUC and chose to put aside these guidelines (Mbeki 2000). It was more important to be present in the DRC than to abide by its white paper's own recommendations, e.g., that the mandate provided should be sufficient to achieve the objective, that all parties should have signed the peace agreement and that there were clear entry and exit strategies. The initial South African commitment to the MONUC operation was limited and primarily in support functions, an approach that minimised the potential risks to SANDF forces and the political risks to the government. However, since the expansion in 2003 of the South African contribution within a Chapter VII mandate, which allows for the use of all necessary means, the potential risks to the South African forces have increased. ${ }^{39}$ MONUC is too limited

38. In many respects this resembles the so-called Nordic peacemaking strategy that dominated the UN's approach to peacekeeping, especially during the Cold War. For further reading, see for instance Trevor Findlay, The Use of Force in UN Peace Operations.

39. Casualty capacity is an important element in this equation, because the South African public has turned out to be relatively sensitive to combat loses. The experiences from the joint South African/Botswana intervention in Lesotho, Operation Boleas, in 1998 are very germane in this respect. 
in scope to fulfil its mandate, and the risk of resumed fighting is very real. ${ }^{40}$ The potentially dangerous nature of the MONUC for the deployed contingents was underlined in February 2005, when nine Bangladeshi soldiers were killed in an ambush. ${ }^{41}$ These dangers have continued into 2006, with several fatalities among and abductions of MONUC personnel.

Even though South Africa is considered to be a regional great power and played a pivotal role in drafting the peace agreements in the DRC, etc., the SANDF has been unable to live up to the expectations that military leaders in MONUC HQ in Kinshasa had beforehand. The standards of training, discipline and equipment have turned out to be not much better than troops from the other African states. ${ }^{42}$ This correlates badly with the government's stated political ambitions of wanting to make a significant contribution and difference, i.e., being an example for others to follow. The conduct of SANDF forces, especially off duty, has become an embarrassment to authorities in Pretoria, who have in the domestic media attempted to downplay the seriousness of the situation. The forces in the DRC are deployed with equipment that several UN inspections have declared "nonoperational" and vital strategic components are unavailable. ${ }^{43}$ For instance, of the 18 South African Armed Personnel Carriers (APC) ${ }^{44}$ deployed in the DRC in August 2004, 13 were declared non-operational because of maintenance problems. ${ }^{45}$ This pattern was confirmed during a re-inspection

40. This was confirmed by the fact that the UN Security Council did not get the number of troops for MONUC requested in Resolution 1565.

4I. MONUC had by 1 April 2005 had 45 fatalities since 1999.

42. Interview in MONUC HQ with Lt. Col. Iffland, MA to the force commander.

43. Interview in MONUC HQ with Lt. Col. Iffland, MA to the force commander and SANDF WO I A. Meier, member of the UN inspection team, in Camp Iveco, 11 November 2004.

44. The Casspir armoured personnel carrier is the primary vehicle used by the SANDF. This APC has been used by the force since 1980 and was battle-proven in Angola during the liberation/border wars. The quality of this APC has recently been recognised by Russia, which bought 100 Casspirs because of their unique protection against mines.

45. The inspections are standard UN routine: deployed forces are inspected at least once every six months to check their force readiness (FR) level. The UN also inspects the state of the equipment in a separate inspection. During the two most recent FR inspections, South African forces were found to be in an unsatisfactory state. Apart from the non-operational APCs, the camp was insufficiently protected, and soldiers had no bullet-proof vests and no batteries for their binoculars and did not know the operational orders and procedures, etc. The soldiers' personal equipment was also not in order and several soldiers did not have local area maps, 
conducted in November $2004 .{ }^{46}$ This situation indicates that the stated political commitment is not matched by actual commitment on the ground. Warrant Officer I (WO I) André Meier from the South African special forces stated that the problems faced by the forces in DRC mirrored the day-to-day problems faced by the SANDF in South Africa. ${ }^{47}$ The realities on the ground stand in stark contrast to statements made, for instance, by Defence Minister Lekota, who in parliament argued that peacekeeping is a very serious task (Lekota 2004). Dysfunctional equipment creates a series of problems for the South African government, because the UN does not pay for it. However, this does not affect the defence budget directly, because the reimbursement does not go to DOD but to the national revenue fund. ${ }^{48}$ The argument can be made that this removes an incentive for the cash-strapped DOD, because it is not directly affected. Nevertheless, the problem for the SANDF is that it does not have the resources to ensure the regular maintenance of its equipment, which means that every time it deploys new forces it is faced with an expensive maintenance backlog, which must be addressed. ${ }^{49}$ The SANDF received an extra R500 million ${ }^{50}$ as part of the last defence budget to cover the extra expenses associated with its international deployment, but this amount does not cover the actual expenses and DOD has been forced to find the resources within its ordinary budget, thereby compromising the resources available for training and exercises. However, the problem for DOD is also that as long as the department

medical kits, mortar grid maps, etc. Interviews in MONUC HQ with Lt. Col. Iffland, MA to the force commander and WO I Meier, member of the UN inspection team 11 November 2004.

46. Interview with SANDF WO I A. Meier, member of the UN inspection team, in Camp Iveco, 11 November 2004.

47. Interview with SANDF WO I A. Meier, member of the UN inspection team, in Camp Iveco, 11 November 2004 This can also be confirmed by reading several SANDF reports and briefings on this issue.

48. Indirectly, it does affect the DOD because it has to apply to the national treasury for additional funding to cover its additional costs for international deployment.

49.Former SANDF deputy chief of staff, Admiral Trainer, confirmed this at the defence hearing in parliament in October 2004. Also in Defence Vote 21, 2005 it was pointed out that the maintenance backlog has left the SANDF with extraordinary expenses.

50. Approximately $\$ 90$ million. See also DOD, Briefing to the Portfolio Committee on Defence: Medium Term Budget Policy Statement: 5 November 2004. 
manages its resources so inefficiently, it is difficult to make a valid claim that the resources available are insufficient. ${ }^{51}$

\section{South African lessons learned from participation in MONUC}

It is also the responsibility of the Government to ensure that our peacekeepers are adequately equipped and that they receive the logistic support that is necessary to fulfil their mandate. The Government must take into account the true capacity of the SANDF before committing itself to international peacekeeping initiatives. Extending the mandate of the SANDF without proportionate funding is dangerous. To put it plainly, the SANDF is overstretched. (Sayedali-Shah 2004)

Two immediate lessons learned have emerged from the ongoing South African deployment as part of MONUC. The first is that the SANDF is overstretched and has found difficulty in keeping the contingent operational while on mission. The SANDF no longer has the high military standards that the old SADF was (in)famous for during the apartheid era. This has been a disappointment to the military leadership in MONUC, who had high expectations of the South African contingent. The irony is that only a relatively small additional commitment from the Pretoria government is needed to get the equipment in functional order. However, the second lesson is that strategically the government does not deem the SANDF contribution to the combined effort in the DRC as important enough to warrant the commitment of significant extra funding to cover the additional cost of participation in the international PSO, and other pressing political issues are prioritised by the ANC government. This means that DOD must use the resources it already has. ${ }^{52}$ An interesting example concerning the government's priorities can be found in the DOD procurement system. One of the main reasons DOD has experienced equipment problems in the DRC is that it cannot get the spare parts it needs. It can take from one to seven months to get spare parts from South Africa, because government

5I. Interview with Maj. Gen. (retd.) Len Le Roux at ISS in Pretoria, 21 October 2004.

52. The DOD's budget constituted in 20041.6 per cent of GDP, which is low compared to other SADC countries, or approximately R20 billion, i.e., \$3,6 billion. It is furthermore important to stress that this debate on resources for PSOs is not unique to South Africa 
regulations stipulate that DOD must place orders by open tender that favour black empowerment companies, often with longer delivery times. ${ }^{53}$ Thus, for government it is more important to secure the black empowerment policy than to achieve the fastest delivery time for the deployed SANDF forces.

Regarding the criticisms that SANDF has garnered during its DRC deployment, in February 2005 Defence Minister Lekota stated in parliament that he and the department had received no reports from UN concerning the SANDF's conduct and that "the SANDF was held in high esteem" (Parliament 2005). Given the unsatisfactory state of readiness of the force, the ongoing investigation of sexual abuse by, among others, SANDF personnel and MONUC force commanders' complaints about the disciplinary record of the SANDF troops, Lekota's statement seems strange, even an attempt to cover up the realities on the ground. One excuse used to explain the inadequate performance of the SANDF is that it is in the middle of a learning process, i.e., learning how to function and operate in a UN PSO. ${ }^{54}$ However, by November 2004 South African forces in the DRC were in their fifth rotation, and several soldiers were there a second time due to rotation problems. Some even had experience from the Burundi mission. The SANDF cannot indefinitely claim to be "inexperienced" and in the middle of a learning process. It must be considered an alarming sign when officers continue to lack the capacity to exercise what in the British army is called "good order and control". 55 The SANDF does not, for instance, have what in the British army is called "the two-can principle" to pre-empt disciplinary problems caused by alcohol. ${ }^{56}$ In October 2004, the SANDF battalion commander Col. Greyling was summoned to Kinshasa by the MONUC force commander, who ordered the South African contingent to introduce strict disciplinary measures. Several cases involving South African soldiers were being processed in the military legal system during the author's visit

53. Interview with SANDF WO I A. Meier, member of the UN inspection team, in Camp Iveco 11 November 2004

54. This was stated both by the South African military attaché in Kinshasa and by the commander for the SANDF contingent.

55. In MONUC HQ in Kinshasa, the SANDF is known for having the worst disciplinarily record in the entire mission. Interview in MONUC HQ with Lt. Col. Iffland, MA to the force commander. Two South African soldiers stand charged in the pending sexual abuse case being held under UN auspices, and a number of other soldiers have been repatriated.

56. The two-can principle means that if a soldier drinks more than two cans of beer and gets into trouble, the matter will be considered to be his fault. 
in October-November 2004. Involvement in prostitution, excessive use of alcohol and violence were frequent occurrences. The lesson from MONUC seems to be that the problems that the SANDF is faced with back in South Africa also occur during deployment. Financial constraints reduce the SANDF's capacity to operate, which, combined with the low health standards and the problematic force structure, reduces rotation intervals. ${ }^{57}$ Discipline is a serious issue that the defence leadership must take full responsibility for and deal with effectively. ${ }^{58}$ On the positive side, it can be said that the SANDF has proved capable of operating in a UN mission and has proved an effective force in an operational environment.

\section{Conclusion: Is South Africa's involvement in the DRC conflict a question of national security?}

South Africa, working through the UN and OAU, is very involved in finding a long-term solution that will ensure stability in the DRC. This stability will allow the economic potential of the entire region to be recognised. (DFA 1999)

South African involvement in the DRC must be understood within the context of domestic politics. Economic inequality, unemployment and slow economic growth have made it a prerogative for the ANC government to create peace and stability in Southern Africa as a means to pave the way for trade and economic growth, i.e., a strategy of short-term investments for long-term gains (Clark 2002:169). Foreign Minister Zuma has argued in parliament that South Africa's future depends on an Africa that is peaceful, democratic, free and prosperous (Zuma 2005). Another element in this is the South African ambition to contain the conflict and prevent it from spilling over, and thereby prevent migration of refugees and illegal emigrants from the region towards South Africa. The South African military attaché to the DRC argued that the government has tried to create a new policy framework for security in Southern Africa and, through that, attempt to attract new foreign direct investment. All these issues are in-

57. The tooth-to-tail ratio has left too large a percentage of the force in support and staff functions. Interview with Maj. Gen. (retd.) Len Le Roux at ISS in Pretoria, 21 October 2004

58. See, for instance, statement by Maj. Gen. van Rensburg during DOD briefing of the Portfolio Committee on Defence, 25 February 2005. 
tegrated parts of what constitutes South Africa's national security. ${ }^{59}$ The war in the DRC, and South African involvement in finding a solution to it, has consequently gained importance in the domestic political debate in South Africa. The news media have more or less daily reports from the DRC, particularly since the deployment of South African troops in 2001. Interestingly enough, there seems to be general consensus in parliament on the need for South Africa to contribute to the African PSO, and the government's strategy that political solutions cannot be reached by military means has broad support in parliament (Leon 2000). The former chief of staff of the SADF, Gen. Constand Viljoen, argued in parliament regarding the DRC that:

The military solution is not the solution to this problem. Hopefully time, stability and responsibility can be bought with that, but then, in my opinion, much more than four battalions of troops should be sent there. Without the real political solution the military effort will be a waste of money. (Viljoen 2000)

Even though Viljoen recognises the government's approach, he also warned the ANC leadership that the military contribution could be a waste of money if the political solution had not been found. South Africa seems to be caught between two major security incentives. At the political level, there seems to be increased recognition and acceptance of what can be termed the special South African responsibility as the dominant regional power. ${ }^{60}$ However, opposition parties argue that the ANC government needs to consider the number of missions to which it commits itself, because resources are still needed for domestic security (Sayedali-Shah 2004). This underscores the basic problem facing South Africa today: increased involvement in international missions requires increased resources, while, nationally, the government has to handle, for instance, an unresolved crime pandemic. The government must constantly balance domestic and foreign policy concerns. By framing involvement in, for instance, the DRC and Burundi as part of what constitutes national security, the government attempts to increase the importance of these initiatives, to securitise them and remove them from realm of "normal" politics. The audience, here primarily understood as the political parties, research community and the

59. Interview with SA military attaché in the DRC, Lt. Col. Jack Khanye, 1 November 2004 at the SA embassy in Kinshasa.

6o.Interview with SA military attaché in the DRC, Lt. Col. Jack Khanye, 1 November 2004, at the SA embassy in Kinshasa. 
broad media, accepts that South Africa has an obligation to deploy as part of African PSOs, but differences exist as to how the resources allocated are spent within the force, and to what extent the DRC deployment differs significantly from the guidelines put forward in the defence white paper and the subsequent review, namely that national security was more or less something that stopped at the national borders. ${ }^{61}$ The result of the political consensus has been seen on several occasions during which the government, personified by Mandela, then Zuma and Thabo Mbeki, played a pivotal role in brokering the Lusaka and Sun City agreements. South Africa has subsequently signed a number of bilateral agreements with the Kabilaled government, including the future training of the army. South African businesses have started to invest heavily in the DRC in areas such as mobile telephone networks, energy and mining. However, South African involvement in the DRC has been conducted on all levels within the framework of what constitutes "normal politics". The involvement has no direct bearing on the short-term "survival" of the South African state, and the issues have not been "securitised" in the South African political debate. Attempts to declare the conflict in the DRC as part of an integrated "national security" is in reality not security in terms of securitisation, but an expression of political interest. What South African involvement illustrates is a conscious foreign policy strategy in terms of which South Africa increasingly sees its future economic growth and development as closely intertwined with that of the continent. Involvement in the DRC is part of the strategy to stabilise the continent to create peace and markets for South Africa, but not to the extent of the having the government use extraordinary means. The importance and prestige that the South African government places on its involvement in the DRC was also seen in mid-2003, when it decided to contribute a helicopter unit to the EU/French-led Operation Artemis into Ituri province to stop a potential genocide. ${ }^{62}$ The South African gov-

6I. The DA, for instance, argues that the Strategic Defence Package (SDP) should be replaced by a focus on preparing the SANDF for PSOs. The UDM called for an increased focus on the HR issues within the forces instead of the present focus on new equipment. Debate in parliament, 8 June 2004

62. On 30 May 2003, the UN Security Council adopted Resolution 1484. This authorised establishment until September of an Interim Emergency Multinational Force in Bunia to contribute to the stabilisation of the security and humanitarian situation there, with authority to take all necessary measures to fulfil its mandate. The UN Security Council requested the Secretary-General to deploy in the Ituri district a tactical brigade-size force, including the reinforced MONUC presence in Bunia, by mid-August 2003 to replace the interim force. It also requested the Sec- 
ernment's decision to deploy troops to MONUC has to be understood as not just a part of a general commitment, but also as a clear foreign policy statement that South Africa wants to fulfil its responsibilities in relation to the tasks at hand in the UN and in the world in general. Choosing to take part in MONUC is also a way of serving South Africa's national security interests in the sense that the country's future development is intertwined with the general development of Africa. There is no intrinsic direct link between the contribution to the UN mission and South African involvement in the DRC in general, something that UN officials in MONUC were very keen to stress. ${ }^{63}$ Nevertheless, the South African government has repeatedly emphasised that its involvement, diplomatically, politically and militarily, in the DRC is part of the overall strategy to create peace and stability on the continent, a necessary condition for the creation of economic growth and development. This was argued for instance in the white paper on peace missions that stipulates that any form of participation in peace operations is an extension of South African foreign policy (DFA 1999:30). This is a significant change in the role previously played by the South African armed forces, which, prior to 1994, was as a means to destabilise the enemies of the apartheid state. However, the South African government's involvement in peace negotiations in the DRC also has strong elements of economic and political power, as underlined by the ANC MP, Dr. Jordan, who stated that:

South African diplomacy minimised the capacity of non-African powers to interfere in the Congo, so as to give the Congolese and their neighbours a chance to resolve their problems. After three years of talks, interrupted by outbreaks of terrible bloodletting, the Congolese factions agreed to constitute a government of national unity. South Africa has invested millions of rands to keep hope alive in the Congo. Even today South African forces are serving as peacekeepers in that country and South African investors have committed themselves to the rehabilitation of the Congolese economy. That might not be much, but it is a beginning. (Jordan 2004)

retary-General to deploy MONUC military observers in North and South Kivu and in Ituri in order to report regularly on the position of armed groups, the presence of foreign military and information on arms supply.

63. For instance, interviews with director for DDR(RR), Peter Swarbrig, 29 October 2004 and Dep. Dir. Policy Grignon, 2 November 2004, at MONUC HQ in Kinshasa. 
The involvement in the DRC is therefore also a statement to the international community that South Africa can and will play the role of regional great power, however, within the framework of normal politics. Nevertheless, South Africa's foreign policy is faced with problems because its military contribution to the UN mission in the DRC has thus far had trouble in meeting the standards set by the UN. While the government's diplomatic efforts have shown the ability and capacity of the new regional great power, its military participation has shown the limitations in its current dominant position and the apparent discrepancy between operational realities and foreign policy ambitions. The SANDF involvement in the DRC more than indicates that South Africa, in its current state and condition, does not possess the capacity to act as the lead nation for future African-headed peace missions. South African involvement in the DRC illustrates how South Africa's role and influence have expanded since the mid-1990s, but also shows how government has become dependent on the SANDF to secure and sustain this influence. However, if the SANDF is to secure the "African Renaissance", the politicians need to prioritise both the needs of the SANDF and the tasks given to it. The government and the DOD still have the chance to reverse the damage to their reputations from their military commitment. This requires the will and courage to deal with and act on the problems at hand in a way that no one to date has been willing to do. 


\section{The Nationalist Imperative \\ South Africanisation, Regional Integration and Mobile Livelihoods}

Steffen Jensen and Lars Buur

\section{Introduction}

Since the breakdown of apartheid, shifting ANC-led governments have reiterated their pledge to return South Africa to Africa. South Africa should assume its rightful place as the natural leader of an African Renaissance. The pledge has been articulated through a number of policy initiatives. These initiatives include the resurrection of the Southern African Development Initiative in the form of SADC (Southern African Development Community), the leading role played by President Mbeki in the creation of NEPAD (New Partnership for Africa's Development) and funding of the African Union. Furthermore, South African governments symbolically evoke a Pan-African identity when they insist that, for example, the 2010 World Cup in South Africa is a victory for Africa, or when they attempt to secure a permanent South African seat on the UN Security Council. These initiatives and the symbolic production of African-ness are perceived simultaneously as a pay-back for the support the ANC received during the struggle against apartheid and in South Africa's best interests: only by playing a constructive role on the African continent can South Africa hope to create a better life for all. However, this invocation of a Pan-African identity and destiny exists parallel to another, more nationalist defence of the South African border, especially in relation to Southern African migrants. It is the production and maintenance of this parallel nationalist undercurrent and the consequences it has for migrants that is the subject of this paper.

In spite of the progress that has been made in South Africa since the fall of apartheid, and in spite of the regional pledges, the treatment of undocumented migrants, especially from the Southern African region, remains a blot on the country's human rights record. The maltreatment of migrants and refugees is not the prerogative of one group, but is shared across the diverse society. State functionaries, army personnel and ordinary citizens of all colours participate in the abuses, often premised and legitimised on the assertion that migrants are to blame for crime, unemployment, AIDS 
and other social ills. However, against the grain of some analyses, we argue that part of the explanation of xenophobia and the subsequent legitimisation of abuse must be sought in the way in which the democratic transition reconfigured citizenship for different groups.

Citizenship is understood as a codified set of constitutional rights and duties that define membership of a political community. When apartheid broke down, South Africa became the home of all South Africans. This constituted a radical recasting of citizenship as it was pursued under apartheid. The South African-ness that emerged in apartheid legislation in the 1950s not only related to the now internationally recognised borders of South Africa, but was also subdivided it into tribal (African) territories separate from modern (White) South Africa (Mamdani 1996a). In the mind of the white South African regime, it mattered little whether a migrant came from Transkei inside South Africa or from Mozambique, as all were migrants coming from outside White South Africa. "South Africanisation" - or the reconfiguration of citizenship after 1994 - must therefore be understood not only as asserting the external borders of the Republic, but also as dissolving the internal borders of the new nation-state in order to unify the nation.

In the context of the present volume, the reconfiguration of citizenship within the regional powerhouse has had consequences for Southern African economies and societies. The remittance revenues that bank-rolled families and communities for decades dried up and non-South Africans were criminalised: they became people against whom the new South Africa had to defend itself and its national democratic revolution. Paradoxically, the moment when the new South Africa assumed its place as a senior partner within the Southern Africa region was also the moment when it became aware of and began to protect its national borders in new ways.

This paper is the story of the reconfiguration of citizenship and the consequences it has had for the people now categorised as a threat. We begin by focusing on how identities and consequent rights of belonging of different groups of migrants have been reconstituted by the transition. We distinguish between one group of migrants, now firmly lodged within post-1994 citizenship - namely Zulu migrants from present-day Kwa-Zulu Natal - and migrants from Southern Africa ${ }^{1}$ who were left out of nationalist politics. By bringing these two groups together in the analysis, we

I. We are grateful to Morten Lynge Madsen who, from his fieldwork station in Johannesburg among migrants from Mozambique, has provided useful information and insights regarding migrant living strategies in Johannesburg. 
also bring two distinct academic and political debates together: one on migration from Southern Africa and another debate analysing the violence between IFP and ANC supporters in the first half of the 1990s. ${ }^{2}$ In the literature, these domains seem to be largely unrelated, despite the attention that both have attracted not only from South Africans but also a world audience. However, by reading the two developments together, we can examine the different political spaces or languages that opened up to include formerly excluded groups. We begin by tracing the changes in the migrant system from the 1980s and explore how they were caused by political and economic developments. This is followed by an analysis of how the new South Africa has been recast in terms of insiders and outsiders. In the third section, we explore how the recasting of citizenship, together with the transformation of nationalism and the economy, has affected the livelihoods of the two migrant groups. Finally, we move on to analyse the production of differentiated political subjectivities in post-apartheid South Africa.

\section{Mobile livelihoods in Southern Africa}

Since the discovery of gold around Johannesburg in the late 19th century, Southern Africa incrementally developed one of the most complex migrant systems of the 20 th century. ${ }^{3}$ The system incorporated areas as far north as Tanzania and became an integral part of the destruction of older African economies and their insertion into a capitalist economy. The migrant system was unstable and characterised by flux and change, but until around the mid-1970s it was an expanding system. From the 1980s, this was to change dramatically. Employment in the mining sector never really recovered from the global crisis of the early 1970s and, with increased capital intensification of production, employment in the mining sector plummet-

2. Both these debates are highly sophisticated. For the debate on migration, see in particular the research emanating from the South African Migration Project (e.g., Crush 1997a, Crush and McDonald 2001, Klaaren and Ramji 2001, Crush and McDonald 2002, Peberdy 2002, Lubkemann 2002). For the debate on the violence on the Rand, see for instance Sitas 1996, Zulu 1993, Mamdani 1996a, Maré and Waetjen 1999, Chipkin 2004.

3. Although space does not allow us to detail the emergence of the migrant system, the literature on the subject has been particularly rich. For elaboration on the emergence and political and economic rationalities, see e.g., Mamdani 1996a, Norval 1996, Evans 1997, Terreblanche 2003:3-22. For analyses of consequences see, e.g., First 1983, Crush 1992, Ramphele 1993, Davies and Head 1995, Moodie 1995, Kynock 2000. 
ed further from the mid-1980s (Terreblanche 2003). This was caused by lower prices for minerals, liberalisation of the South African economy and efficiency gains in production (Davies and Head 1995, Solomon 1997). In 1985, for example, the industry employed a total of 806,000 workers, dropping 25 per cent over a ten-year period to 610,000 (Solomon 1997:22), a trend that is set to continue. For the gold industry, employing 477,000 workers in 1986 (266,000 were South Africans and 211,000 came from outside the country), the downscaling between 1986 and 1992 resulted in the loss of 154,000 formal jobs. In total, 95,000 South Africans and 59,000 foreigners, mainly from Lesotho and Mozambique, lost their jobs (Solomon 1997:23). The downscaling continues, and the most optimistic estimates were that the number of workers in gold production would be reduced to 137,000 by 2005 . According to the study, 70,000 of this total would come from outside South Africa and 67,000 from South Africa (Solomon 1997:24).

The consequences of the massive downscaling of the mineral sector have been far reaching, not only for the South African economy but also for the Southern African region as a whole. Beginning with the national economy, the mining sector's contribution to tax revenues decreased from 12.5 per cent in 1986 to 1.4 per cent in 1994. Furthermore, a fall has been observed in the export contribution from 66.7 per cent in 1985 to 48 per cent in 1994 (Solomon 1997:27). Apart from fiscal consequences, the effects of the downscaling, not only on dependent households but also on second order employees in support industries and services, have been devastating. Literally millions have lost their livelihoods in Southern Africa. ${ }^{4}$ The effects of such massive retrenchment in one sector have obviously spread into the wider economies of, primarily, South Africa, Mozambique and Lesotho. For instance, in Mozambique legal migration to South Africa decreased from 128,381 people in 1975 (First 1983:24) to an estimated 27,000 by

4. A commonly accepted formula for the mining industry is 2.5 jobs outside the industry for every job in the mining sector. Applying this to the numbers of retrenched workers, the total reduction of mine employees from 806,000 in 1985 to 610,000 in 1994 would mean that 196,000 first order direct jobs were lost, affecting 490,000 first order indirect and second order indirect livelihoods. The implications of this are frightening when one takes into account that this is an ongoing process. Add to this that conservative models estimate there are 4 dependants for each formal job in the mining sector in South Africa. Some analyses estimate that the ratio of dependants is even higher - between 7 to 11 dependants per worker in the mining industry (Solomon 1997:29). However the Chamber of Mines's own estimation is 1:16, which implies that 500,000 employees in the mining industry support approximately 8 million people (Davies and Head 1995:449-50). 
2000. Coupled with decreasing economic prospects in Mozambique, the retrenchments in the mines are devastating.

The remarks above suggest that the migrant world has undergone a profound transformation, leaving it in crisis. As the South African economy shifts towards more capital-intensive production, internalises its labour force and suffers the effects of neo-liberal global reform, so do migrant livelihoods become more precarious and subject to change in terms of gender. But the political transition also impacts migrant livelihood, not least because questions of nationality become important, as distinctions between South African nationals and those from neighbouring countries attain new meaning. It is to this political transition that we now turn.

\section{National recasting and societal changes}

Contrary to the present-day strong normative celebration of human rights, or what Wilson (2001) calls "rights-talk", citizenship as "the active or passive membership of individuals in a nation-state" (Janoski and Grant 2002:13) needs to be reassessed. When citizenship as rights is placed in its proper context of the old trinity of "state-nation-territory", the celebration of rights brings to the fore "the very ambiguity of the fundamental notions regulating the inscription of the native ... in the judicial order of the nation-state" (Agamben 2000a:17, 8). The question, "Who is the native?" logically begins with determining who belongs and who does not belong to a nation-state, thus establishing the national personhood - that is, those who are recognised as citizens with rights out of the totality of natives, subjects of the territory and denizens.

To understand how the inscription of the "native" took the form it did, we begin with the South African Truth and Reconciliation Commission - one of the most heralded institutions of the new South Africa. The commission aimed at promoting national unity, publicly extending citizenship to all regardless of class and race and promoting the "new" national unifying values of human rights. It became partly instrumental in producing the larger ideological constructions of national identity emerging in South Africa during the 1990s. The work of the commission is indicative of the increasingly self-centred understanding of apartheid that developed throughout the 1990s. Although the commission both democratised memory and retraced a multiplicity of pasts, its official work bears many of the formal attributes of nationalist narratives, including an intense focus on "national identity" and territory, which is rooted primarily in the narrative of his- 
torical origin, i.e., in a - selectively chosen, shared past (Boyarin 1994:16). As Wilson asserts, "official truth commission work, state-building and the creation of what is termed a 'culture of human rights' cannot be so easily separated from nation-building ... but are drawn into the services of reformulating nationalist imperatives" (Wilson 1996:7).

In one of the very first paragraphs in the foreword of the commission's final report from 1998, chairperson Desmond Tutu states, "The Report ... tries to provide a window ... a road map to those who wish to travel into our past. It is not and cannot be the whole story; but it provides a perspective on the truth" (Final Report 1998:2). What is so striking, besides the territorial metaphor of a "road map", in Tutu's introduction to the work of the commission and how apartheid is conceptualised, is the total absence of acknowledgment of apartheid's Southern African dimensions. Not one word is offered on these issues. Instead one finds references to "South Africans" and the use of "we", and "ours" - "our past", "our nation", "our country", "our diversity", "our differences", "our people", "our history" and "fellow South Africans" (all phrases taken from the introduction to the final report). In this light, although apartheid was very much a Southern African reality, the commission interpreted it as the regime's human rights violations against some of its "own" citizens exclusively (Final Report 1998:18). The commission and Tutu in particular make nativity or birth within the territory (modelled on apartheid's external boundaries) the foundation of the new South African nation-state. Here everybody who is not born within the territory of South Africa is written out of the national script.

The emphasis on individual human rights and the apartheid state, according to Mahmood Mamdani (1996b), minimises the "legacy of apartheid" by turning it into the "banality of evil". Mamdani pleaded for a change in focus on to how the "legacy of apartheid" should be understood. Focus on human rights violations highlights solely the relationship between a small group of perpetrators and those victimised by perpetrators. Invisible are the many white beneficiaries of apartheid and the African majority, thereby displacing any considered attention to both the colonial reality of bifurcated governance and the wider economic consequences of apartheid. Instead, the South African experience became a story about South African victims of human rights violations (see also Peberdy 2001:26-7). The conflict was rephrased, time and again, as a tale of "brother fighting brother", or the "South African experience" of "fellow compatriots" killing each other (Desmond Tutu in Final Report 1998 vol.1:3) - where all South Africans were betrayed by the former apartheid state, which in turn 
had used, "turned" and "seduced" them into doing things they would not otherwise have done (Buur 2000). By rephrasing the past conflict as a conflict between people who did not, at the time, think of themselves as fellow citizens, the commission inscribed itself in one of the common paradoxes related to national imagination. The overall aim of the commission was formulated as a task of reconciling brothers and sisters - be they members of a racialised population, different ethnic groups or political groupings - whom the apartheid regime had denied mutual recognition by each of the other.

The commission, then, follows the logic of formation and stabilisation of an exclusive and selective national identity through constitutively identifying and exorcising the other, i.e., apartheid (Anderson 1991, Peberdy 2001). As we have argued elsewhere, this is both logical and has been important for the nation-state building project the new South African government embarked on after 1994 (Buur 2001a, Jensen 2001). Through an ironic twist, migrants came to embody apartheid, as the ANC identified the homeland system and the migrant system as some of the worst elements of the apartheid regime. This legacy of apartheid had to be combated by all means and expelled in order to render the "new" South Africa possible. Migrants were easily ignored and squeezed out of the national recasting project, as their presence constituted a threat to the new South Africa and its citizens' entitlements to state resources (Peberdy 2001:29). ${ }^{5}$ This did not mean that all migrants ended up being treated in the same manner. If the construction of nation-state identity in South Africa made nativity the foundation of its own sovereignty, then rights could be attributed only to migrants who were citizens of the new nation-state. In the following sections, we examine how political and economic restructuring affected two groups of migrants differently: one group from Kwa-Zulu Natal and one less clearly identifiable group of migrants from neighbouring countries, notably Mozambique. As migrants' livelihood options change with the South Africanisation process, a comparison of cases from inside and outside the borders of the new South Africa illustrates how changes in regulations and in the political status quo can have different consequences.

5. As Peberdy (2001:28-9) illustrates, the idea that some rights are for all who live in South Africa while others are for citizens only is firmly established in the constitution, thereby reproducing "differential" citizenship in a different configuration than during apartheid. 


\section{Violence on the Reef}

Between 1990 and 1994 thousands of people lost their lives in faction fighting, especially on the East Rand and around Durban in Kwa-Zulu Natal (Sitas 1996:235). Most of the violence erupted between Zulu-speaking Inkatha Freedom Party (or IFP) supporters from or with links to KwaZulu Natal but living on the East Rand in male-only hostels on one side, and township residents leaning towards the ANC on the other side. This violence at one stage seemed poised to destroy the South African miracle. The IFP-aligned hostel dwellers usually drew heavily on (re-invented) Zulu traditions of clothing and weapons (Zulu 1993). As IFP supporters were credited with most of the violence and killings (Final Report 1998, vol. 3), the threat to the democratic revolution was embodied by these Zulu impis (warriors) on the rampage in the townships surrounding the hostels.

The violence on the Reef has prompted multiple explanations. Many commentators have focused on what is called "The Third Force", that is the active but secret support of the security forces for the IFP-affiliated hostel dwellers (e.g., Zulu 1993, Ellis 1998). "Third Force" did certainly play a part, but it cannot alone explain the violence in full. As Mamdani asserts, "even if the beneficiaries [the agents of the former regime] of the violence understood their interests fully and acted in line with it, what explained the fact that direct participants of this violence were so readily available for this manipulation?” (Mamdani 1996a:224). ${ }^{6}$ Another line of reasoning explains the violence as a consequence of the closed environment of the hostels - the social and cultural marginalisation of hostel dwellers both as men (Maré and Waetjen 1999) and as workers (Zulu 1993). According to this hypothesis, such marginalisation made hostel dwellers more disposed to mobilisation. Although this explanation seems valid to some extent, it also fails to account for why direct participants chose to engage so voluntarily in the violence. Furthermore, the assertion of hostel isolation is also questionable (Chipkin 2004). Although some of these explanations do carry weight, we suggest that it is necessary to take into account at least two more factors: firstly the conflictual relationship between hostel and township dwellers over everyday issues of resources, and secondly what

6. Allegations of "Third Force" activities were also made in relation to the faction fights between ANC supporters and Marashea, the Sotho organisation working in and around Sotho workers. Both miners and Marashea emphatically denied the claim. In his analysis, Kynock found no proof that these links existed. For an analysis of the strategic employment of the discourse of 'Third Force', see Jensen 2001, Buur 2001a. 
Chipkin (2004) calls the "rise of nationalist politics" that emerged on the Rand during the 1980s.

Much of the violence erupted over housing issues related to the status of the hostels in the new South Africa (Mamdani 1996a). Tensions had been on the rise between hostel and township dwellers for the better part of the 1980s. Hostel dwellers had become increasingly marginalised in the struggle, which became the domain of permanently urbanised young men living in the townships (see also Maré 2000). Hostel dwellers were also economically threatened by the downscaling in mining and industrial production. As the apartheid regime lost control over the townships during the mid1980 s, township organisations began to have an increasing say in the social and economic issues affecting them (Seekings 1996). The mining companies were only too happy to relinquish control of the hostels, which were taken over not only by the highly politicised civic organisations but also, crucially, the unions. The agendas of the various civic organisations and unions were not always in harmony with those of the migrants. As Chipkin (2004) argues, changes in union politics were especially important. Migrants had formed a significant part of union membership during the early 1980s. However, as unions became increasingly preoccupied with fighting the apartheid regime alongside the UDF and other civic organisations, they worried less about traditional union issues like wages, health hazards and job safety. These nationalist politics did not to the same extent feed the aspirations of the Zulu migrants, preoccupied as they were with preserving their mobile livelihoods. These concerns included a range of economic strategies and a cultural apparatus of generational roles, gender relations and traditions that sometimes clashed with UDF policies. One of the main issues leading to rising tensions between hostel and township dwellers was the discussion over what was to become of the hostels themselves.

As far back as 1986, the civic organisations, preoccupied with generalising the opposition to apartheid to all social and economic issues, voiced the suggestion that hostels should be turned into family units instead of remaining as single-sex units for men. These demands became more vocal at the beginning of the 1990s, and as one civic member stated, "we started with an identification of problems, overcrowding and privacy" (Mamdani 1996a:271). The solution, as opted for by the civics and later the ANC, was to either demolish the hostels or turn them into family units. These suggestions were based on the correct analysis that conditions inside the hostels were intolerable and dehumanising. The humiliations and hardships of migrants came to be the incarnation of the very crimes of racial capitalism as 
instituted under the apartheid regime. As such, the suggestion was based less on evil scheming against the migrants and more on a particular reading of the legacy of apartheid, namely the devastation it had caused, for example by separating women from their partners and removing social responsibility from the corporate sector by reproducing labour outside white South Africa. What the civics did not realise was that the migrants, in spite of the humiliations, needed the single-sex hostels, as they supported their mobile livelihood strategies. By now the entire lives of many migrants were organised around moving between the rural home and the city ${ }^{7}$. What was at stake was the urban base of their mobile livelihoods. ${ }^{8}$ The ensuing tensions were further fuelled after the ANC's unbanning in February 1990, when it suggested that the hostels be evacuated to make space for returning ANC members from exile (Mamdani 1996a:273).

The extent to which the migrant world was isolated in ethnic enclaves has been hotly disputed. Mamdani (1996a), Kynock (2000) and Moodie (1995) seem to argue that there was a certain ethnic coherence before the 1990s. They most often locate this in structural issues. Mamdani, for instance, asserts that one possible reason for the ethnic divide was that both Pondoland and Transkei, the traditional abodes of Xhosa-speaking people, were relatively more impoverished and land was scarcer there than in Kwa-Zulu Natal. Thus, the hope that was nurtured by many migrants - of using migrancy as a stepping stone for the creation of a rural homestead - was more sustainable among Zulu- than among Xhosa-speaking people (Mamdani 1996a:276). Xhosa migrants were therefore forced to establish homes in the townships much earlier. Furthermore, Moodie (1995:190ff) points to the way in which mine management promoted ethnic mobilisation to prevent cross-ethnic solidarity. Chipkin (2004) on the other hand, asserts that townships and hostels were not so easy to categorise ethnically and that integration between hostels and townships was considerable. However, both agree that from the end of the 1980s the rift between the two groups increased and townships and hostels became ethnically more

7. Maré and Waetjen suggest that, in fact, the migrant men used the dehumanising experience of migrancy to pass through a rite of passage in order to attain full manhood. Thus, men could only become men if they went through the emasculating, dehumanising experience on the mines and in the hostels, as this would provide the proof of the prowess (Maré and Waetjen 1999:203).

8. Mamdani may be exaggerating the coherence of the migrant world. As Chipkin (2004) argues, the migrant world was in deep crisis on the eve of the democratic transition. This does not, however, invalidate the argument. As the migrant system faced crisis, the need to sustain it arguably became more acute. 
homogenous. This situation was exacerbated as people from each ethnic group were chased out of townships and hostels respectively, and as the violence erupted, two distinct groups with profoundly polarised views on crucial socioeconomic issues were pitted against each other.

The IFP turned the hostel issue into an issue between the two political entities, the ANC and the IFP, each with its own political agenda. Paulus Zulu helpfully calls this a "nationalisation of the hostel issue" (Zulu 1993). What originally fuelled the tension, the threat to mobile livelihood strategies caused by the ANC's demand for either conversion or demolition of the hostels, was lost from sight. All that remained was the traditionalist and national political agendas of the IFP pitted against the modernist vision of the ANC. But why did hostel dwellers participate in the violence? Paulus Zulu's explanation is that the harassment performed by certain IFP leaders against reticent hostel dwellers caused them to participate out of fear (1993). However, and maybe more to the point, Mamdani argues that it was extremely difficult, if not impossible, for hostel dwellers to free themselves from the grip of the IFP. The Zulu movement was the only organisation taking a stance against the threat to their livelihoods. The IFP-aligned South African Hostel Dwellers Association claimed "that the campaign of the ANC and its allied forces (South African Council of Churches and Cosatu) to abolish hostels is aimed at enforcing urbanisation of Africans and dispossessing Africans of their land" (quoted from Mamdani 1996a:278).

The entry of IFP culturalist discourse into nationalist politics and real here-and-now social issues produced an environment that was conducive to the violence on the Reef. As Mamdani asserts, "without the series of ANC demands regarding the hostels ... it is difficult to believe that the IFP could have secured more than a toehold in most Reef hostels" (Mamdani 1996a:275). Likewise, it is hard to imagine that the violence would have taken the particular form it did, had it not been for the nationalisation of the hostel issue and the rise of nationalist politics. The violence ended in 1994 when the IFP decided, despite its initial vows to the contrary, to participate in the national elections. Thus, the political and everyday issues that had been at stake in the Reef violence were subsumed under the political system. Although the IFP discourse of federalism and tradition was at loggerheads with the ANC vision of a centralist, modern South Africa, these political antagonisms were absorbed into the debates on the future of South African democracy. The constitution allows for traditional authority without specifying what that entails. There are provincial and national assemblies of traditional leaders, and the provinces were allowed a measure 
of autonomy that was not initially envisioned by the ANC. These issues are far from settled, and the spectre of the Reef violence continues to loom over the debates ${ }^{9}$, but they continue to be settled within the democratic system. Political antagonists thus found a legitimate political language through which to voice concerns other than through violent means.

\section{Informalised mobile livelihoods}

The IFP nationalist defence of mobile livelihoods and its urban base was only possible for certain migrants - those that through the national democratic revolution had been granted political rights and citizenship in South Africa. National politics that in principle affected all migrant groups was primarily an option for the Zulus or migrant groups that could be inscribed in the judicial order of the new nation-state. For other migrant groups, like the Basotho and Mozambican migrants, national politics was not an option. Instead, they remained "aliens" - unwanted, delegalised - the ultimate "other" in the new South Africa: without the autochthones' territorial claim or national belonging, and hence cut off from most of the entitlements bestowed on South Africans (Peberdy 2001:28-9). In this sense, post-apartheid South Africa continued the practices of the past by which the regime labelled every non-South African an "alien" if he or she did not have formal labour relations in the mining or agricultural sector, and where no differentiation was made between refugees and informal migrants from, for instance, war-torn Mozambique.

Protection in post-apartheid South Africa came most often from outside the nationalist political framework in the different organisations working with human rights questions. These organisations primarily employ a language of "humanity" (as opposed to "national rights") and emphasise the historical significance of migrant work in South Africa in their critique of the xenophobic and abusive treatment of "aliens" (the official notion) or "un-documented" migrants (the term preferred by human rights organisations). They protest against the use of abusive language and behaviour, not least from state bureaucrats, and attempt to influence the national drafting of legislation on international migration to include a rights-based enforcement of migration policy, but often to no avail, as state bureaucrats,

9. In a debate over the role of traditional leadership, the Zulu king, King Goodwill Zwelethini, threatened in 2003 that traditional leaders would not accept significant reductions in the power to allocate land, as was suggested in the eighth version of the Communal Land Act, but would react with violence. 
politicians and the general South African populace have held the general view that "Africa is flooding the new South Africa" (Crush and McDonald 2001).

Neither migration to South Africa nor concerns over it are new. What has changed is the ways in which these movements are classified, talked about and acted upon. Crush and McDonald (2002:3-7) identify seven new trends that affect the numbers and ethnic make-up of the migrant group, namely increased formal unemployment; informalisation of migrants; gender patterns of those migrating; informal trade networks; more undocumented migrants; increased refugee flows and the permanence of those coming to South Africa. The public debate attaches the highest importance to the increased numbers of illegal migrants. Some official estimates put the figure as high as 4.1 million illegal migrants, whereas more conservative estimates put the figure as low as half a million (Crush and McDonald 2002:6). Despite the discrepancies in numbers, there is little doubt that a significant number of migrants come into South Africa illegally. As economic structures change and migrants continue to have no legitimate political language, they have to invent or follow new routes to secure livelihoods. This leads to greater degrees of informality (Davies and Head 1995:439, Crush 1997:4). We begin at the most formal end of the continuum of strategies.

In order to continue formal (mine) employment, young men made their way to the mines where they intended to work. Here they paid corrupt WENELA/TEBA or mine officials to "request" their labour. They then returned to their home country and waited for the telex requesting them to come (Davies and Head 1995:444). The "buy-a-telex" strategy was premised on the so-called "two-door policy", where the front door was the Aliens Control Act of 1991 and its 1996 Amendment (Crush 1997b, 1997:2-3). However the act also made provision for a number of exceptions constituted by bilateral labour agreements between South Africa and the governments of Mozambique, Botswana, Swaziland, Malawi and Lesotho. These agreements were the "back door" into South Africa, as they allowed for "special recruitment schemes". Not surprisingly, it was primarily employers with considerable political clout - especially in the mining industry and among white commercial farmers - who could exploit the exceptions to the tight influx control.

The strategy became more important as the number of alternative avenues for obtaining legal rights in South Africa decreased. Although a range of new "job seeking" categories for temporary residents was added to the 
Aliens Act in 1994, the Department of Home Affairs (DHA) formalised an informal policy where "no immigrants in unskilled or semi-skilled categories would ... be admitted to work in the country" (DHA quoted in Crush 1997b:4). This meant that practically no migrant worker from the SADC countries could enter South Africa on a legal work permit. The telex strategy combined with a practice DHA officials. This made it possible to change one's status from "illegal migrant" to "legal migrant" with the ensuing minimum of rights that official holders of papers could draw on.

Another strategy was to engage in sub-contracting. Although it entailed higher degrees of informality, subcontracting followed the logic of entering illegally and moving towards a form of legality. The illegal migrants only registered with official authorities (such as TEBA or DFA) once they had found work (Davies and Head 1995:444, Crush 1997a:6). The number of sub-contracted workers employed on the gold mines rose from 5 percent of the workforce in 1987 to 10 per cent in 1994 - a total of 34,733 workers (Crush 1997a:6). Sub-contracting was not a new phenomenon, but while sub-contracting was previously confined to mine development work (dangerous work like shaft-sinking and construction), in line with global trends in capitalism mining companies also out-sourced core production (Davies and Head 1995, Crush and McDonald 2001). The changing employment status of migrants mattered also in that, before, employers simply formalised employment through a letter of support. With tighter immigration control, it was difficult to change the "purpose of entry", and once the migrants were illegally inside South Africa, both they and the employers had an interest in circumventing the rules (Crush 1997a:3). Migrants were in consequence increasingly vulnerable and invisible with regard to formal rights and statistical presence.

A large number of first-time migrants ended up in (seasonal) agricultural work as a first step in the direction of larger urban centres. In spite of the very low wages and hazardous working conditions, migrants often chose this sector as it was the least controlled and regulated - or simply because the agricultural centres were situated close to the main illegal migrant routes from Zimbabwe and Mozambique. However, it was a precarious livelihood. Well-organised criminal groups targeted illegal migrants on both sides of the borders, work conditions were hazardous and pay was low. In spite of this, a temporary job might be the only option they had for surviving the first weeks or months in South Africa.

The rights of migrants working in temporary jobs are also precarious. In contrast to industrial labour regulations, the agricultural sector was rela- 
tively free to seek migrant labour, and the DHA allowed post-hoc temporary resident and work permits for "foreign" agricultural migrant labour. Special border-posts with Zimbabwe were opened to facilitate the movement of cheap seasonal labour. "Clearing houses" on the border were set up, where farmers with a special permit from DHA or the department of labour acquired cheap labour if they stated that they could not obtain local workers (Crush 1997b:5). In general, the system and the exceptions allowed for high degrees of corrupt practices and collusion between commercial farmers and the various authorities. Working conditions were horrendous and salaries often did not exceed R30-40 per month. There were reports of how illegal migrant workers (or "slaves" as the reports often call them) were reported to police if they refused to work for the salaries offered. Other workers, hired on a monthly contract without registration, were rounded up by the police after a telephone call to the local police a few days before pay day. There were also reports of collusion between the farmers and DHA officials in Mpumalanga, where officials allegedly "sold" Mozambican illegal migrants to farmers. Farmers bought documents formalising the status of the immigrants from DHA officials and kept the papers. If the now legalised workers left the farms they could be arrested and deported as "aliens", as they did not have the proper documentation.

For many migrants, entering the formal economy in the above more or less formalised ways was either not possible or not worth choosing. Instead, they entered the informal sector as street hawkers in small-scale enterprises (Peberdy 1997; Peberdy and Rogerson 2002) operated by better-off Central or West African migrants. This was particularly the case for Mozambican illegal migrants who tried to generate capital for self-employment through "piece-jobs", which were based on limited initial capital (Madsen 2004a). Most street hawking generated little income, and, what is important for our purpose, it fell outside the regulative framework of worker legislation, pension and health insurance. The competition with South African hawkers over prices and access to trading space was fierce and often violent (Human Rights Watch 1997). The "migrants-hiring-migrants" strategy can therefore be seen as a form of creating zones of security-in-numbers in an otherwise hostile and increasingly xenophobic environment. Whereas the formal labour market was regulated, even to some extent with the involvement of labour unions, no such protection existed in relation to street hawking. ${ }^{10}$ The lack of any formal protection and the physical visibility

IO. The only organisations working in this area, the trade organisations, although representing only 14 per cent of the hawkers (Peberdy 1997:11), have generally been 
meant that non-South African hawkers were exposed not only to popular wrath but also to persecution from the former Internal Tracking Unit and the "metro police" operating in all the major cities (Madsen 2004b). Importantly though, in spite of the harsh environment in which they had to operate, many of these informal traders were relatively optimistic about the future, as Peberdy and Rogerson (2002) report. They would most probably continue to come to South Africa in spite of the xenophobia of the general population and the zeal of the South African state in protecting the country from the foreign influx.

\section{The new national legislation process}

Partly due to increased public pressure and fear of migration, the South African government began drafting a new act on migration in 1997. The process was characterised by the ambiguity and contradictions that have characterised South African migration policy. Opposing perceptions of what should be the role of migrants ran deep and oscillated between fear of migration and pragmatic and/or idealistically based arguments in favour of migration. Of these views, the fear of migration seemed, by far, to hold sway.

The initial tenets of the new policy, outlined in a draft green paper in 1997, were an attempt to strike a balance between the need to "pro-actively recruit immigrants with the skills, expertise and resources to make a contribution to the development of our country" and the need to regulate the entrance of migrants who "are not authorised to be here" (Draft Green Paper 1997:2). The white paper issued in 1999 in many ways opposed the green paper. It shifted "administrative and policy emphasis ... from border control to community and workplace inspection with the participation of communities and the cooperation of other branches and spheres of government" (White Paper 1999:1). Thus the responsibility for law enforcement was partly taken away from the DHA and extended to civil society. The white paper accepted the green paper's attempt to include those migrants valuable to South African society, but it put the primary emphasis on the protection of South African citizens. Promoting South African interests should be considered as foremost on a hierarchy of interests, followed by SADC people and Africans in general and ending with the rest of the world. This last qualification is extremely ambiguous. On the one hand, the paper proposed that SADC migrants had priority second only to South

opposed to trading rights for non-South Africans (Peberdy 1997:3). 
Africans. On the other hand, they had to be skilful and yet still not deprive South Africans of opportunities. It is fair to presume that the drafters of the white paper were not talking about unskilled or semi-skilled Africans, who competed at the lowest end of the labour market. Rather, they were addressing the level of, for instance, Zimbabwean academics or engineers. Although there were incidents where skilled illegal migrants were deported, most of the endeavours seemed to be directed towards the less socially fortunate migrants, like hawkers and agricultural labourers.

The difference between the green paper and the white paper expressed in many ways the different approaches to migration within South Africa, where the more restrictive and defensive approach gained the upper hand (Crush and McDonald 2001, Peberdy 2001). This became evident when the new Immigration Act, which introduced very restrictive regulations, was finally made public in June 2002. However, the act was immediately challenged in court by a national non-profit organisation, Lawyers for $\mathrm{Hu}-$ man Rights, which won its case. The human rights organisation's victory pointed to the contradictions and ambiguities that characterised migration policy and practice. One remarkable example of the sometimes benign interventions were the three periods of amnesty extended to certain groups of migrants between 1995 and 2000 under which thousands of migrants were able to apply for residence permits (Crush and McDonald 2001:5).

This could be seen as invalidating the argument, but in some ways the contradictions and ambiguities produced effects to the detriment of migrant rights. The reason for this was that the legislative vacuum meant that regulation of migrants (legal or illegal) in South Africa depended less on law and more on discretion, courtesy and the ethical sense of the various law-enforcement agencies. These agencies proliferated in urban centres and on the borders with neighbouring countries, invariably followed by a significant diffusion of responsibility and accountability.

Central to the enforcement of migration policies has been the South African Police Services and more specifically the Internal Tracking Unit (ITU), as mentioned above. But with the disbandment of the ITU's during the latter part of the 1990s, law enforcement was in the hands of provincial special units operated by various role-players: police, border units, ad hoc special units, commandos ${ }^{11}$ and even vigilante-style organisations. The same applied to the urban areas, where "normal" police, metro police,

II. The commandos are part-time uniformed staff. Originally commandos were the basic unit in the South African war on the Afrikaner side, and as such carry enormous historical baggage for whites as well as for blacks. During apartheid, they 
special operational units and even military platoons sometimes work together, for example during Operation Crackdown (see Klaaren and Ramji 2001). However, the proliferation of law enforcement units under different commands and legislation did not seem to change the methods involved in dealing with "foreigners". These included, among others, searching hawking stands, pick-up points for day labourers and residential areas of "known" undocumented migrants. The core activity of the various units involved was hence to identify, arrest and deport "them" as expeditiously as possible.

Identification of undocumented migrants has remained a constant concern into the present. As documents can be forged, it is of little use to check whether those arrested have legal documentation. The DHA has asked the public to report on undocumented migrants, and operations such as Operation Crackdown have offered rewards for calling special telephone numbers and reporting "aliens". But in the final instance, in a strange replay of the apartheid logic of racial classification, the body is the ultimate source of certainty. This involves evaluating the use of language (accent and pronunciation of words) and appearance (hairstyle, clothing, vaccination marks and physical characteristics) (Crush 1997b, 12; see also Human Rights Watch 1997). With time, identification relating to the body has become increasingly technological. An example of this is the new "barcoded" official document with fingerprints that all non-South Africans are required to hold. According to DHA officials, the bar-coded document has a humanising effect: "Your barcode and your fingerprint will make life easier for you in South Africa. It humanises you" (Michael Thlomelang quoted in Wagner 2002:9).

Those who do not carry the mark of the right to stay, even if they carry documents or are South African, have forfeited their rights to stay in South Africa. Many people in this situation, South African or not, end up in the Lindela Repatriation Centre. Lindela is managed by a private company, Dyambu, and several state departments, namely DHA, justice, correctional services and safety and security. Law enforcement agencies also proliferate in Lindela. Rampant and unpunished use of force in the form of mistreatment, rape, beating, torture and excessive detention, besides intentional (or unintentional) bureaucratic incapacities are widespread. As the South African Human Rights Commission, which has published two reports on Lindela, asserts, "Arrested persons were deliberately prevented from provid-

became the central unit in white, semi-private rural protection and became notorious for their use of violence against rural blacks (see Manby 2001, 2002). 
ing accurate documents, valid identity documents were destroyed, bribes were taken for avoiding arrest or for release without documentation and processes were delayed by inefficient investigation methods and insufficient communication between different departments" (SAHRC 2000:36). Even though guards at Lindela have the legal duty to assist assaulted persons, prevent abuse and protect detainees (SAHRC 2000:15-16) this often does not happen. Here the normal rules of law seem suspended and in spite of protests from human rights organisations, violence and abuse take place in a measure that appears to depend on the civility and ethical sense of the police, Dyambu guards and DHA personnel.

After Lindela, those found to lack the credentials to stay in South Africa are deported. Most, however, vow to come back as soon as possible (Madsen 2004a). In this there is probably an important lesson: the options for migrants in their home countries are such that they will continue to brave the hostile South African environment in pursuit of better days.

\section{Political subjectivities in the new South Africa}

In this essay, we have examined the emergence of new political subjectivities for different migrant groups after 1994. We began by exploring the emergence and subsequent crisis of the elaborate migrant labour system into which people from the entire Southern African subcontinent were drawn to work in the huge mining and agro-industrial sectors of the apartheid state. This economic system was constantly in flux, but from the mid1980s the crises began to become more radical, and increasing numbers of workers were laid off as the mines downscaled, outsourced core activities and became more capital-intensive. From around 1990, when the winds of political change began to blow over South Africa, the radical restructuring of the economy merged with a re-negotiation of insiders and outsiders in the new South African nation-state.

The democratic revolution included large sections of the South African black population for the first time, but it also further excluded and marginalised vast numbers of migrants from the SADC countries. The effects of the national recasting and the economic restructuring have had very serious but dissimilar effects on migrant livelihoods. Whereas the democratic revolution opened avenues for some - those who are now nationalised migrants - it blocked avenues for those without claims to South African nationality. The localised manner in which the national recasting took place meant that a particular language of national political representation was made acces- 
sible to the ethnic group of Zulus in order to challenge the threat posed by the ANC's discourse and practice. The ANC strategy was not only aimed at political adversaries within the IFP, but also at what the party considered to be one of the worst incarnations of the evil apartheid regime: the system of racial capitalism supported by the migrant and hostel system. The problem of Zulu migrants was that they had based their economic and cultural livelihood on this system. From 1990 to 1994, one of the few possible avenues of protest for the hostel dwellers was to align themselves with the culturalist, chauvinistic, nationalist Zulu agenda of the IFP. The merging of these elements - economic restructuring, nationalist politics and the ethnicisation of the hostel issue - produced the violence on the Reef. This violence died out as legitimate spaces opened up for the negotiation of IFP grievances within the nationalist political realm.

However, the nationalist project revolved around nativity, and no permanent political space opened up for migrants from the SADC countries. While the presence of migrants in South Africa was relatively well regulated for formal migrants during the apartheid era, it was less so in the new South Africa. At the same time, post-apartheid South Africa seemed to be continuing at least some of the more malign characteristics of the former regime's practices towards what both referred to as "aliens". Coupled with the economic restructuring, migrants' avenues for securing a livelihood were often blocked, and they were exposed to both structural and physical violence.

A number of commentators and academics have, with a great sense of urgency and concern, pointed to the similarities between apartheid practice and the practices of the new government. Klaaren and Ramji (2001) and a number of associates in the South African Migration Project (SAMP), for example, argue that migration policy in South Africa still revolves around apartheid legislation, notably the Aliens Act of 1991, and that law enforcement continues to be "dramatically similar to apartheid policing practices" (Klaaren and Ramji 2001:35). In this sense, apartheid becomes the benchmark of evil that a truly democratic South Africa must distance herself from. Although we recognise the empirical thrust of the argument, we feel less comfortable with the "othering" of apartheid. This is not because we see apartheid as anything less than malign. It is because positing apartheid as the benchmark of evil - or as being opposed to the rule of law in the new South Africa - prevents us from gauging the broader political issues around the production of national political subjectivities and sovereignty at 
stake in the apartheid regime as well as in the democratic South Africa. To examine this, we need to make a short excursion into political theory.

In constitutional democracy, the law is the highest principle, the norm from where all political legitimacy is derived. This is the principle replayed in the new constitution's second article, which states that "The Constitution is the supreme law of the republic; law or conduct inconsistent with it is invalid". Contrary to this assumption, the Italian philosopher Giorgio Agamben asserts that political subjectivity under the rule of law is premised on and constituted by a twin figure outside the rule of law. Following Carl Schmitt (1985), the first figure is the sovereign with the power to decide when law is law, and when it must be suspended due to a perceived extreme emergency that threatens the rule of law. The second constitutive figure outside the rule of law is that embodiment of the extreme emergency - she or he whose life threatens the body politic. This person who has forfeited the constitutional rights, Agamben terms Homo Sacer or "naked life", that person who can be killed without repercussions and whose death cannot be ritualised (Agamben 1998:82). According to Agamben, the assertion that "there is nothing above the law", which is the benchmark for differentiating between apartheid and democratic rule, hides this twin figure of sovereign power and naked life that both is constitutive of the rule of law and stabilises it.

In our analysis, the new South African state, rather than only reproducing old apartheid categories, draws on them in expressing something integral to the rule of law. It decides on the exception and locates the extreme emergency with migrants. These people are then relegated to a space outside the normal workings of the law, founded on the trinity between nation, state and nativity that provided Zulu hostel dwellers, represented by the IFP, with a political language in which to express their grievances. This space outside the law is what Agamben calls the "camp". The notion of the camp should not be taken too literally as a concentration camp. $\mathrm{He}$ says, "The essence of the camp consists in the materialization of the state of exception". In this space, he continues, "human beings ... have been so completely deprived of their rights and prerogatives to the point that committing any act against them would no longer appear as a crime" (Agamben 2000a:40). In South Africa, many places serving as "spaces of the exception" qualify as camps, but nowhere more so than Lindela Repatriation Camp.

The camp figures prominently in the modern history of the nationstate. Contrary to what one could expect, the camp is not born of ordinary law, but of Schutzhaft - protective custody - as a means to "avoid threats 
to the security of the state" (Agamben 2000a:37). The camp is intimately related to the political system of the nation-state being founded, as explained above, on the functional nexus between a determinate territory and a state in which the inscription of nativity (birth within this nexus) becomes synonymous with the nation-state. Migrants, immigrants and refugees challenge this particular constitution of the nation-state. According to Agamben, we can interpret the camp as the "hidden regulator of the inscription of life" (Agamben 2000a:42) in the order of the nation-state, because laws on citizenship and denationalisation emerge exactly when this nomos can no longer inscribe increasing groups of people in the order of the nation-state. The present intense focus on "foreigners" in South Africa seems to present a similar situation of crisis - real or perceived - for the inscription of national personhood. It is in this situation of insecurity about the national political subject that Lindela - and other similar spaces outside the law that regulate legitimate political activities - becomes crucial for stabilising the New South Africa. This is not a replay of apartheid politics, nor is it something destined to disappear when transformation is complete. It is the originating moment of sovereignty upon which post-apartheid South Africa partly rests. Hence, at the very moment that post-apartheid South Africa assumed its place in the Southern African Renaissance, the nationalist imperative hardened the boundaries towards the Africa that Pan-African discourses had attempted to re-inscribe. In an ironic twist, the pledge to regional solidarity and development seems to be compromised by the more invisible pledge to national security. 


\title{
Namibia’s Pariah Heroes
}

\section{SWAPO Ex-Combatants between Liberation Gospel and Security Interests}

\author{
Lalli Metsola and Henning Melber
}

\section{Introduction}

In 1989, when the war between the occupying power, South Africa, and the liberation movement, Swapo ${ }^{1}$, came to an end, fighting forces on both sides were demobilised. The demobilised soldiers and fighters were soon identified as a problem in need of "integration" or "reintegration". ${ }^{2}$ During the following 15 years of independence, the issue of ex-combatants and former fighters has attracted repeated attention. ${ }^{3}$ This chapter explores questions related to state formation and emerging forms of citizenship and belonging since Namibia's independence, as illustrated by the case of the ex-combatants. ${ }^{4}$ Several studies have examined conditions for successful reintegration

I. Before independence, the official name of the movement was South West Africa People's Organisation (SWAPO), later SWAPO of Namibia. After independence, it was changed to "Swapo Party". In this chapter, we use "Swapo" throughout, unless quoted differently.

2. Both terms appear in official and research parlance.

3. Former guerrillas of Swapo's military wing, the People's Liberation Army of Namibia (PLAN) are at the core of the Namibian understanding of the concept of "excombatant". The term is sometimes used in a broader sense to cover all those who have been targeted by reintegration programmes, including non-guerrilla former exiles and former members of the colonial army, the South West African Territorial Force (SWATF) and the special counterinsurgency unit "Koevoet" ("crowbar"). However, those who fought on the South African side are more often referred to as "former fighters". While the distinct treatment of the groups in the process of "(re-)integration" would be of additional interest, this chapter limits its focus to the former PLAN combatants.

4. It is based on a longer paper by Lalli Metsola (2005), which has subsequently been revised by Henning Melber. Data have mainly been collected during Lalli Metsola's fieldwork in north-central Namibia and Windhoek in 2002-03. It consists of life stories and thematic interviews with about 90 ex-combatants and former fighters, notes of personal observations and informal discussions and interviews with approximately 40 government and Swapo personnel as well as "civil society" representatives, complemented by programme documents, official correspondence, parliamentary debates and media items. Lalli Metsola wishes to thank all those 
and assessed state interventions with regard to this group (Tapscott and Mulongeni 1990, Tamas 1992, Preston et al. 1993, Simon and Preston 1993, Gleichmann 1994, Colletta et al. 1996, Preston 1997, LeBeau 2005, McMullin 2005). The aim of this chapter is different. Its concern is not whether the stated objectives of reintegration have been met or how they could be better met. Rather, it will examine why the question of ex-combatants has received so much attention and what courses of action the state (and ruling party) functionaries have taken. We focus firstly on the construction of categories and ways of speaking about the ex-combatant issue. Second, we look at the practices of classifying, including and excluding associated with "reintegration". Third, we examine the interplay between the state and party actors and ex-combatants. By doing so, we try to contribute to understanding the nature and current formation of the Namibian state and its relations with its citizens or population. We conclude by discussing the competing tendencies of personalised versus bureaucratic forms of power and associated forms of subjectivity and agency in Namibian political and social arrangements.

This chapter connects with studies that see the state less as a set of administrative institutions that have been established at a certain point in time than as "a set of practices and processes and their effects" (Trouillot 2001:131; see also Mitchell 1999) that is formed in a continuous negotiation of interests and identities between various actors (Steinmetz 1999:9). A closely related current lays stress on how the state is performed and experienced in the everyday encounters of state agencies and functionaries with the citizenry or population (Gupta 1998, Fuller and Bénéi 2001, Das and Poole 2004, Hansen and Stepputat 2005 and 2001, Corbridge et al. 2005).

We argue that in Namibia, security concerns provide a crucial link between "reintegration" and state formation. Although issues of security have always been central to state agendas, it has been proposed that recent years have witnessed a shift towards securitisation of development (Duffield 2001a and 2001b). Crime and conflict prevention, conflict resolution, post-conflict reconstruction, and more generally, poverty reduction, pro-

\footnotetext{
who have shared their views and knowledge, with special thanks to Gideon Matti and Likius Ndjuluwa for indispensable research assistance and to Jeremy Gould for constructive comments on earlier versions of this work. The Academy of Finland provided the financial means for the study, while the Department of Sociology of the University of Namibia helped both in academic and practical terms during periods of fieldwork.
} 
vision of basic needs and good governance have entered the mainstream of development in the belief that security and development are mutually implicated. In a sense, Namibian ex-combatant "reintegration" efforts can easily be placed in the context of securitisation of development. Although it is questionable to what degree and in what sense "reintegration" measures have contributed to the stated objectives of security and development, discourses that lay stress on the security-development link have certainly played a role in justifying "reintegration". However, we wish to contribute to a particular perspective, proposed by the editors in their introduction to this volume, of national and local security practices - and ultimately, sovereignty in the sense proposed by Agamben (1998) - building on the biopolitical activity of including and excluding, and working differently on included and excluded bodies through civilising and "upgrading", on the one hand, and exclusion and violent "downgrading", on the other.

Based on Bourdieu's (1999:57-63) notion of different forms of capital, we can think of different kinds of security towards which dominant actors in society strive. These include physical or territorial security (sought through the military and policing), social security (sought through the pacification of "the population" by economic and social policy) and symbolic security (sought through the creation of shared perceptions, for instance by bureaucratic classification, codification and unification as well as by nation building through narratives and practices of commemoration). Broadly speaking, the ways of achieving security can draw on coercion, persuasion and various combinations of the two. The more the dominant social groups manage to combine different aspects of security by violence, social and economic policy and symbolic production, the more likely will be the continuation and consolidation of the status quo. However, this is a project complicated by the heterogeneous demands and interpretations of the "population" or "citizens". The formation of statehood and citizenship occurs in this interplay of interventions and the agendas of the people targeted or left out. However, the distinction between state interventions and the people's responses and claims is far from clear-cut, as will become evident when one pays attention to subjectivity. Many state practices - intentionally and unintentionally - contribute to the very formation of people as citizens and subjects through biopolitical techniques and government, in the sense of "the conduct of conduct" (Foucault 1982:220-1, also Foucault 1991, Dean 1999, Rose 1999, Cruikshank 1999, Walters 2000, Ferguson and Gupta 2002). While Western forms of government and biopolitical techniques have spread into societies of the South during the last few cen- 
turies, they have not swept aside the local and the particular. Rather, they have a history of interaction, conflict and cross-pollination with local forms of social relations and power. It is therefore essential to focus on the empirical trajectories of particular forms of government and associated subjectivities.

\section{Prelude: April 1989 revisited}

In November 2005, road construction works in the northern parts of $\mathrm{Na}$ mibia (previously called Ovamboland) - former war-zone under curfew since the 1970s - brought to light some of the gruesome evidence of the recent past, when shallow mass graves were discovered in the vicinity of former South African military bases. Subsequent information from local residents led to the identification of a growing number of similar places where corpses had been unceremoniously buried in bigger or smaller numbers without any trace of their identity and the concrete circumstances of their violent deaths. Seemingly, the existence of these mass graves was common knowledge among the local people, though since Namibian independence they had never been turned into a matter of wider public interest. The bodies hastily disposed of some 15 years earlier were most likely those of Swapo fighters killed by members of the South African forces in execution-style massacres during the first days of April 1989, when hundreds of the liberation movement's guerrillas were ordered to surrender their arms under the ceasefire agreement. The discovery of the mass graves was a reminder of one of the single bloodiest events in Namibia's liberation struggle that took place at a time when hopes had been nurtured for a peaceful transition, a transition which was, by this act called into question at the last moment. What exactly happened during those early days of April 1989 and who is to blame for murdering the hundreds of people who expected to lay down their arms, remains hotly disputed, and is a blame game that we are unwilling to join. But the strong emotional and ideological responses that were provoked show that the decolonisation of Namibia and the fate of the liberation movement's guerrilla fighters remains a contested theme. John Matshikiza, himself a South African ANC activist in exile until the early 1990s (and familiar with the situation in the neighbouring countries through his own experiences on the ground), commented in his South African newspaper column "With the Lid Off" that "amnesia is a wonderful thing", and posed some embarrassing questions to all the parties who were involved in Namibia's transition to independence: 
Who were all those guys whose skulls have just been dug up anyway? Would anybody miss them? To Geldenhuys [then in command of the South African army] and his faceless masters in Pretoria (some of whom were to go on to win the Nobel Peace Prize in later years), they were just so many units of vaguely menacing vermin. To the UN, far removed among the wealthy towers of New York, they were abstract black pawns in a recently abandoned East-West power game. To the liberation movement, they were troublesome mouths to feed and clothe, the voice of the people taking on a life of its own of a kind that was never intended. Believe me, there were rebellions in all the Southern African liberation movement camps, the rank and swine, as they came to call themselves, champing at the bit in the face of leaderships that veered from indecisiveness to naked corruption. (Matshikiza 2005)

For Sam Nujoma, Namibia's first head of state from 1990 until 2005 and president of Swapo since its founding in 1960, the last parts of this statement would be a crime amounting to high treason. In late November 2005, parliament, in which Swapo's enjoyed a two-thirds majority, conferred upon him the official title of "Founding Father of the Namibian Nation". While many (mostly outside Swapo) resented the fact that a single person could be declared the parent of a whole country and its people, parliament's action symbolises a significant perception deriving from the "struggle days", namely that of vesting patriarchal responsibility over minors in the one and only leader as the ultimate form of personified state power. This responsibility, executed on behalf of the movement, translates social processes into personalised initiatives. While a John Matshikiza can ask pertinent questions and offer his thoughts as quoted above, Sam Nujoma and his comrades cannot allow space for such reflections. Instead, they announce that once the mass graves are neatly taken care of, monuments will be erected to commemorate these heroes of the liberation struggle who sacrificed their lives for Namibia's independence. The circumstances of their deaths, however, will not be investigated further. In his capacity as Swapo president, Nujoma emphasised at a central committee meeting of the party in December 2005 that no old wounds would be reopened by "digging up the past" (a peculiar expression in this context). ${ }^{5}$

A cloak of secrecy therefore will most likely continue to hang over one of the last steps in the process of decolonisation. Swapo's president, despite the lack of any convincing evidence, quickly reinforced a "patriotic history" version of the April massacres, blaming them on an imperialist conspiracy

5. Quoted from a report in Allgemeine Zeitung, 12 December 2005. 
initiated by the Thatcher government. This pre-empted any meaningful alternative debate, which might have created public space for critical assessments of the role and decisions taken by the liberation movement's leadership during the final stages of formal decolonisation. The few who, due to their own involvement at the time, openly dared to challenge the propaganda version, or at least intimated a differing approach not supportive of the obvious cover-up of the unresolved matter, were sidelined and even removed from office. ${ }^{6}$

This episode illustrates that there are several dimensions of the ex-combatant issue that have not yet been dealt with in a way that would allow it to be put to rest as part of an established history of anti-colonial resistance. Namibia's liberation movement opted to put aside public debate on such matters. For instance, a truth and reconciliation commission was not established, unlike in neighbouring South Africa where, despite its limitations, it was evidence of a willingness to discuss sensitive issues in public in an attempt to forge unity in a deeply divided society. Instead, the notion of "national reconciliation" was used as an argument for why the past should not be discussed. However, issues such as the position of ex-combatants and former fighters in independent Namibia touch upon so-called nation building and the way it is approached and defined by those in power.

\section{The political economy of Namibian state formation}

Namibia was colonised by Germany from 1884 onwards and by South Africa from 1915 until 1990. Colonial rule created a "bifurcated" (Mamdani 1996a) and strongly policed state, divided into white settler areas, where whites enjoyed liberal citizen rights, and ethnically determined, indirectly ruled "homelands". The movement and activities of the colonised were under strict surveillance and had deep social and cultural repercussions. The colonial economy uprooted large numbers of people to work as migrant la-

6. As a former PLAN fighter on the ground, the acting secretary-general of the Swapo-affiliated trade union umbrella body National Union of Namibian Workers (NUNW), Peter Naholo, dissociated himself and his organisation from the unauthorised release of a trade union statement in support of Nujoma's propagated view. As a direct consequence, he was in December 2005 ousted from office by a pro-Nujoma faction in the NUNW's higher echelons. At the next NUNW congress at the end of April 2006, this group managed, amidst great controversy, to confirm the dismissal of both Peter Naholo as well as the NUNW president, Risto Kapenda, who had refused to act against Naholo. As a protest against the dubious procedures adopted, delegates of the mineworkers' union (MUN) and the teachers' union (NANTU) left the congress. 
bourers. Missionaries and colonial officials sought to root out "uncivilised" and "un-orderly" practices and promote self-improvement through education, work and care of one's self and home (see e.g., Comaroff and Comaroff 1991 and 1997, Gordon 1998, Melber 2000a, Wallace 2002). Namibian nationalist movements emerged in the 1950s. Among them, Swapo soon rose to prominence and became the ruling party when Namibia gained its independence in 1990. Swapo originated as an organisation that campaigned for Ovambo migrant workers' rights, although the nascent urbanised intellectual elite (with an Ovambo background) played a significant role in its leadership and mobilisation (Tapscott 2001:309). Despite soon broadening its objectives into national liberation and denouncing ethnic factionalism, the movement has remained predominantly Ovambo-supported. Swapo increasingly operated in exile from the early 1960s onwards, whence it launched its armed struggle in 1966. Tens of thousands of $\mathrm{Na}$ mibians, mainly from Ovamboland or Oshiwambo-speakers from other parts of the country, went into exile after the mid-1970s and joined Swapo. At the end of the war, the fighting forces were demobilised and exiled $\mathrm{Na}$ mibians repatriated. This translated into approximately 45-50,000 returnees (Preston 1997:454, Saul and Leys 1995:63-4), of whom an uncertain number were People's Liberation Army of Namibia (PLAN) ex-combatants. $^{7}$

At independence, a system of multi-party democracy and parliamentary representation was established and a moderate liberal constitution adopted with fundamental rights guaranteed to all individual citizens. ${ }^{8}$ However,

7. Whereas the number of demobilised SWATF and Koevoet fighters is available $(25,000)$, since the South African administration had them on record, it is more difficult to arrive at the number of ex-PLAN combatants and other former exiles. Swapo either did not have exact lists of its combatants or has not, for one reason or another, disclosed them. PLAN forces were demobilised before repatriation and returned as civilians. Some PLAN members remained in Angola until late 1989 as a reserve. It is hard to say how many of the returnees had been PLAN combatants either immediately before or at some point before repatriation. Sources give widely divergent numbers ranging from around 9,000 to around 30,000, at least partly depending on how "ex-PLAN-combatant" is defined (see e.g., Gleichmann 1994:136, Colletta et al. 1996:131-2, Preston 1997:455).

8. This has been explained in various ways, including changes in global and regional political dynamics, the attainment of Namibia's independence through international negotiations, the drafting of the constitution on the basis of principles accepted by the UN Security Council in 1982, and the fact that Swapo did not gain the two-thirds majority required to draft the constitution on its own (see e.g., Dobell 1995b:175-6, Dobell 1998:69-76, 82-105, Cliffe et al. 1994, Erasmus 2000:79-83, Melber 2004). 
in practice, different kinds of political organisation still exist and influence national politics, including local forms of authority that derive from both precolonial and colonial times. Other "non-liberal" tendencies have entered the Namibian state through the practices of the former liberation movement. In exile, Swapo was clearly authoritarian, which is hardly surprising, given the war in which it was engaged. However, this fact has had important repercussions for Namibian political culture after independence. It has been argued that Swapo's practices have not been greatly transformed, and through its dominance of the political field (made possible by an absolute majority in parliament) the authoritarian tendencies have to some extent spilled over into the way the state is steered (see, e.g., Leys and Saul 1994, Leys and Saul 1995, Dobell 1998, Tapscott 1995 and 2001:319-21, Melber 2003b and 2003c).

Namibia's economy is dominated by a capital-intensive primary sector that contributes considerable revenue to state coffers but offers few job opportunities. The public sector remains the main formal employer and welfare provider. After independence, the new black elite increased its share by allocating influential government positions with considerable side benefits as well as mining concessions, fishing quotas, and land or cheap farming loans to the "previously disadvantaged", often along informal lines of camaraderie and kinship (Melber 2003e and 2005a). In the name of maintaining political stability, preventing the flight of capital and attracting investments, government policies have largely preserved old, highly unequal social and economic relations. These policies walk a fine line between the interests of the new black elite and middle class and white farmers, entrepreneurs and civil servants, on the one hand, and the largely un- or underemployed majority that survives on subsistence agriculture and informal economic activity, on the other, confronted by increasing rates of unemployment, chronic poverty and destitution (Melber 2005c). It therefore comes as no surprise that essential policies have been justified in terms of the maintenance of "peace and stability", "national unity" and "reconciliation", that is, security concerns. This is based on Namibia's long-standing history of organised violence, on the volatility of the ruling pact as well as on the importance of controlling the state apparatus for securing resources. Ex-combatant "reintegration" has emerged as an important sub-question in this context. The ex-combatants have confronted the elite vision of governing Namibia with one of its most direct challenges to date. 


\section{Ex-combatants as a contested issue}

The Swapo leadership returning from exile filled most of the top positions in the newly established Namibian government. Those who had obtained an education abroad became part of the higher public service or joined the private sector and contributed their number to the emerging black middle class. However, the majority who had never made it further than the camps and field of combat often found themselves without employment or useful skills. There was no reintegration policy in the period immediately following the demobilisation and repatriation of ex-combatants and other returnees (Colletta et al. 1996, Preston 1997). The government assumed that they would return to their homes and resume their lives back in their local communities. But social realities had dramatically changed since the activists had left for exile and a return to a status quo ante was simply not possible. The passivity of the Swapo leadership was therefore tantamount to abandoning its rank and file members, who returned from exile to a home country that no longer offered them the necessary means to survive in dignity. Even some "living legends" never managed to secure a position within the higher ranks of the party in exile, despite their personal sacrifices for the common cause, and were not spared such sobering and painful, if not degrading subsequent experiences. Eliaser Tuhadeleni, also known as Kaxumba kaNdola, is a particularly prominent case in point. He was the no. 1 accused in the 1967-68 Pretoria trial, State v. Eliaser Tuhadeleni and 36 others, for which the notorious retroactive Terrorism Act was enacted. He was sentenced to life imprisonment and spent the next 18 years mainly on Robben Island. Released in 1985, he left Namibia and returned in 1989 during the transition to independence. He lived in Windhoek without secure income, no support and was moved around for shelter. His family was unable to be properly reunited in the absence of an established home. According to one of his daughters, he felt "sad, rejected, and unwanted. He got heart broken ... He waited for his call to service day after day. He was always ready for duties. This never happened, but inside him were the expectations of "freedom and work'" (Namhila 2005:143). Tuhadeleni finally moved back to his original homestead in the north and rebuilt his home with his own hands. After he died in November 1997, he received a hero's funeral. His contributions to Namibia's liberation, however, were never honoured during his lifetime.

The first wave of "reintegration" was a side effect of the formation of a new national army and police (Preston 1997:463). However, this absorbed only about 8,000 to 10,000 ex-combatants and former fighters (Preston 
1997:459, 463), which meant that a large number of them remained unemployed and expected help from what they saw as "their government". By August 1990, groups of ex-combatants were demonstrating. Consequently, the first ex-combatant registration took place, followed by the first "reintegration" measures. These included a gratuity payment for registered ex-combatants and former fighters, a skills development project (the Development Brigade), a resettlement programme and rehabilitation of the wardisabled (Colletta et al. 1996, Preston 1997:455, 463). The Development Brigade - later Development Brigade Corporation (DBC) - aimed at skills training and was the first large-scale, long-term "reintegration" project. It managed to incorporate only 4,000 ex-combatants, and most of them were retrenched during the last years of the corporation. Although the DBC was initially meant for fighters from both sides, eventually its membership was almost exclusively drawn from the ranks of ex-PLAN (Colletta et al. 1996, Preston 1997:463-5). By the late 1990s, the subsidiary companies of the DBC had largely gone bankrupt and the DBC was dissolved in 2001. What the DBC did manage to do, however, was to defuse ex-combatant resentment to some extent and provide those whom it incorporated with a lifestyle notably similar to that in exile. ${ }^{9}$ There were also a number of other initiatives. Ex-combatants became one of the major groups catered for in the country's resettlement programme (Preston 1997:466-7, Republic of Namibia 1997). ${ }^{10}$

From the mid-1990s onwards, there has been a shift from various uncoordinated schemes to centrally coordinated direct government employment. ${ }^{11}$ A committee of deputy ministers was appointed and a socio-

9. Life in exile was largely military or semi-military and strongly communal. Apart from a minority who were sent for studies, the exiles lived in camps, called Namibian Health and Education Centres, or were deployed in PLAN units. Swapo sought to reform the exiles into loyal cadres through military training and political and other education. These arrangements had both practical, disciplinary purposes and more pervasive, "civilising" aims. For more detailed accounts of life in exile, see Metsola (2001:129-73), Mbamba (1979), Hishongwa (1983:58-66), Katjavivi (1986:307-11), Peltola (1995:143-6, 150-3, 162) and some of the evidence in Leys and Brown (2005) and Becker (2005). The dissident view of those declared "traitors" and "spies" by Swapo is documented i.a. by Nathanael (2002), but also Groth (1995).

Io. However, the scheme has not been viable in the long run because of inappropriate targeting and other problems. Another initiative required companies applying for government tenders to employ a certain number of ex-combatants.

II. This shift followed from the proposals of the Technical Committee on Ex-combatants (Republic of Namibia 1998:15) but is also in line with earlier recommenda- 
economic integration fund formed to find ways of solving the issue of excombatants. After another registration of ex-combatants in 1995, cabinet decided in 1996 to transfer responsibility for addressing the ex-combatant question to the National Planning Commission (NPC). A company, the Socio-economic Integration Programme for Ex-Combatants (SIPE), was established through the NPC. Its tasks included seeking and creating job and training opportunities for ex-combatants as well as assisting children whose parents had died in exile while participating in the liberation struggle.

During 1997 and 1998, there were recurring demonstrations throughout the country. They culminated in July and August 1998 when thousands of ex-combatants assembled in Windhoek to camp there for weeks in defiance of orders to disperse. A similarly spectacular mass action took place at the Ondangwa airport in northern Namibia. By means of both these public incidents, ex-combatants articulated their grievances about being neglected and their demands to be employed by government. The cabinet set up a technical committee to address the problem. Significantly, it was placed under the cabinet committee on defence and security and consisted of permanent secretaries and other high-ranking officials from various ministries, government institutions and Swapo. All of them had extensive leadership experience within the liberation movement's exile structures, especially its military wing (Republic of Namibia 1998:4-5). In cooperation with SIPE, the committee carried out a countrywide registration of ex-combatants and made a number of proposals (Republic of Namibia 1998:3-5, Republic of Namibia 2000). These included direct government employment for most of those registered and the discontinuation of DBC. The proposals were put into practice from late 1998 onwards and came to be known as the Peace Project. ${ }^{12}$ Under this project, by 200218,361 ex-combatants and former fighters had been registered. Of these, 14,875 had been employed and 2,297 classified as war veterans. Of those employed, 9,188 were placed under the ministry of home affairs, mainly the

tions of the World Bank (Colletta et al. 1996) and a study by ILO consultants that was funded by the EU (Republic of Namibia 1996).

I2. "We propose to the Namibian Nation to honour the integration of ex-combatants into the working life as a 'Peace Project'". Minister of Finance Nangolo Mbumba (since 2005 minister of education) on 7 April 1999 in Parliament; Debates of the National Assembly, vol. 32/1999. 
Namibian police (Nampol), ${ }^{13}$ and ministry of defence, mainly the defence force. The ministry of prisons and correctional services and the ministry of environment and tourism employed 2,058 ex-combatants, many of them as prison and game wardens. Five other ministries accounted for a total of 3,446 ex-combatants. Only 183 were employed elsewhere. ${ }^{14}$

\section{Ex-combatants as heroes and a social problem}

In post-independence Namibia, the image of the former guerrillas has been dual. On the one hand, they are portrayed as national heroes who made sacrifices for liberation. On the other, they are perceived as a persistent social problem, in need of economic, social and psychological rehabilitation, and a potential threat to social, political and economic stability. The idea of the ex-combatant or war veteran as an archetypal hero of the nation flows directly from the nationalist narrative of Namibian history. ${ }^{15}$ It has

I3. Thousands of ex-combatants have been recruited into the Special Field Force (SFF), a paramilitary Nampol unit assigned with tasks beyond ordinary policing duties. The SFF is mainly responsible for patrolling the borders, but also supplements the activities of other branches of Nampol by patrolling in other parts of the country. The SFF outnumbers other Nampol personnel by nearly 3 to 1; "[W]e have plus minus 7000 members of the Special Field Force and 2000 regular police ... This has been as a result of the ex-combatants we have taken in over the years since 1996." Minister of Home Affairs Jerry Ekandjo (since 2005 minister of lands and resettlement), 9 November 2001, Debates of the National Assembly 53/2001.

A fascinating admission of the special character of the SFF was given by Ekandjo on 29 April 1999: "The main function of the Special Field Force is to patrol the borders of Namibia. The borders are long ... These people sleep in the field, no mosquito nets, no tents, nothing whatsoever. So the money budgeted for this must cater for medicine, malaria tablets, for snake bites, for field kitchens, tents, etc ... We have put up substations and at every substation we allocate one properly trained police officer and maybe ten members of the Special Field Force. The officer who is properly trained is the one in command ... [and] must man the police station ... These people [the SFF] patrol by foot in the villages where there are many cuca shops. The Special Field Force patrols the squatter areas in Katutura. We want the properly trained police to investigate crime". Debates of the National Assembly, vol. 34/1999. Note the distinction between the SFF and "properly trained" police officers. SFF units were deployed alongside the National Defence Force (NDF) to respond with force to the failed secessionist attempt in the Caprivi region in August 1999.

I4. Figures obtained by Lalli Metsola from SIPE during an interview with Nghidinihamba Ndilula, the general manager of the company and member of the technical committee (29 October 2002).

I5. For closer analysis, see Metsola (2001:34-48) and Melber (2003d and 2005b). Before Namibia's independence, the nationalist interpretation of history was de- 
been used to characterise ex-combatants in official documents, political debates and the media alike. For example, then Minister of Health and Social Services Libertine Amathila (since 2005, deputy prime minister) justified the proposed War Veterans Subvention Bill in the following way on 27 October 1998 and 4 March 1999:

Ex-PLAN combatants ... did not have time for education ... Some of them bear evidence of the war to this date ... A brief reflection on their contribution makes this bill a moral and ethical imperative. These are the people who braved the hazards of nature ... [and] who engaged the enemy militarily so that Namibia is independent today ... [T] hey are the ones who sacrificed their education, sacrificed their everything and we have to look after them. (Debates of the National Assembly, vol. 30/1998 and vol. 32/1999)

Nahas Angula, then minister of higher education, vocational training, science and technology (since 2005, prime minister), supported the bill on 3 November 1998:

[T] his Bill is not just about alleviating the economic and social plight of the veterans, it is a Bill to affirm and reaffirm their contribution made and their sacrifices ... When we sing the National Anthem we are singing about the heroes - these veterans. When we affirm here our commitment to the Constitution, we are affirming to their contribution, because that Constitution is there as a symbol of their sacrifice ... [It is] our moral obligation to make sure that some of these people ... who have lost their limbs or lost their parents, husband, wives, can live comfortably in the country which is of their creation. (Debates of the National Assembly, vol. 31/1998)

Not least, the ex-combatants themselves have consistently referred to the register of heroism in their recurrent demonstrations over the years, as a reminder of the sacrifice they made for liberation. This was not merely a tactical choice intended to soften the hearts of policy-makers and the public, but a narrative that also has considerable existential significance for ex-combatants. ${ }^{16}$

veloped in publications by Swapo, the United Nations Institute for Namibia and various, mostly Western solidarity organisations. It has been continued in struggle literature published after independence, the most important example being Sam Nujoma's "autobiography" (Nujoma 2001; for a critical analysis see Saunders 2003).

I6. This aspect came across strongly in the interviews and discussions conducted with ex-combatants for this study. It can also be discerned in documentation of mili- 
When used by politicians and government officials, this language of (military) heroism has mainly been directed towards a home audience. As it connects with the dominant narrative of national history, it could be used to draw support from the public, as well as the legislators, by turning the question of ex-combatants into a moral issue at the centre of the nation's historical identity. More specifically, this language is also directed at the ex-combatants themselves, as a soothing recognition and a form of containment. Here we touch on an important aspect of why ex-combatants have featured so centrally in the Namibian political scene. As they occupy a strategic position in the dominant narrative of the nation's history, they are crucial for the ruling party's version of nation building not just in practical terms, but also symbolic terms. Indeed, one of the motives for ex-combatant "reintegration" may have been to prevent them from starting to "misremember", from the ruling party's point of view, the history of the "liberation struggle", thus feeding memory politics and struggles over collective remembering. ${ }^{17}$

The other prevalent view of the ex-combatants and former fighters is of them as potentially subversive, as needy, helpless and dangerous. They are antisocial, roaming from the rural areas to the city and back, as well as idling on the streets, prone to drunkenness, crime and promiscuity (and hence a particular risk group for HIV), in short, incapable of engaging productively in the economy. This view can be found across Namibian discursive terrain, from parliamentary debates and government documents down to bar talk. An early example of both main discourses on ex-combatants being combined is provided by the editor of the independent local daily, The Namibian, in one of her weekly columns:

$[T]$ he former combatants ... should not be forgotten because of the sacrifices they ha[ve] made. But we also fe[el] they should not be neglected in the new Namibia because of the inherent dangers posed by thousands of former combatants and soldiers who are unemployed and frustrated, many with easy access to arms. (Lister 1992)

tary narratives from the "struggle days" in the post-colonial public sphere (see e.g., Namakalu 2004 and numerous examples in Melber 2003d and 2005b).

I7. This is a theme which has surfaced as a contested issue in the current debate over the April 1989 events referred to at the beginning of this chapter. On various aspects of memory politics in the Namibian context, see Kössler (2003), Saunders (2003), Metsola (2001) and Melber (2003d and 2005b). 
Then Finance Minister Nangolo Mbumba grounded a similar argument in broader economic terms when he talked of the need for the Peace Project in his annual budget speech:

It is this Government's firm decision to address the ex-combatant dilemma once and for all by directly offering public employment for close to 9000 ablebodied ex-combatants ... Cabinet considers the full integration of ex-combatants into the social, political and economic tapestry of our country as an investment in stability, democracy and above all, peace ... I would also like to ... urge all public enterprises, chambers, associations and the private sector in general to support the programme ... through the creation of similar employment commitments. After all, they as property and business owners are the biggest beneficiaries of the Peace Project. (7 April 1999, Debates of the National Assembly, vol. 32/1999)

This view makes a link between assisting the ex-combatants and the interest of making society economically effective, healthy or secure (from the point of view of those with the power to "develop" it). Employing the ex-combatants would pacify them, which in turn would contribute to general stability, democracy and peace. Specifically, "property and business owners" would benefit, apparently directly through a decrease in property crime and indirectly through the positive influence of increased stability on the business climate. Prime Minister Hage Geingob's reasoning in April 1999 follows similar lines:

I have been hearing from business people and I was pleased when they told me: "Mr. Prime Minister, it is not only your problem, it is our problem." That is why I call it a Peace Project, because if we do not solve this problem, the peace that we are enjoying today can easily be undermined if we have so many people who are trained, some of them with arms, and just roaming around the streets. (27 April 1999, Debates of the National Assembly, vol. 33/1999)

This view of ex-combatants is also elaborated in the technical committee report. The ex-combatants are mainly defined from a paternalistic administrative perspective. They appear not as active agents but as subject to difficulties and, thereafter, to corrective actions by Swapo and the government:

Some of the freedom fighters left the country at a tender age and do not know any other life except the one provided under the care of SWAPO. They did not know how to lead an independent life ... The returning Namibian exiles were ill prepared psychologically to start a new independence [sic] life. They expected to be taken care of like in exile ... Some still felt bound by the military 
rules of PLAN waiting to be "commanded". This in part explains the widely held view among the former fighters that "SWAPO shall come one day". (Republic of Namibia 1998:3, 14)

The only form of independent agency on the part of ex-combatants that appears in these documents (as well as in many interviews) is that of potential social disruption if they are left to their own devices. Indeed, the fact that the Peace Project was adopted amidst calls for cutting the size of the public sector was mainly justified as a sacrifice of short-term objectives (fiscal prudence and a balanced budget) in favour of the broader, long-term goals of maintaining social stability. Finance Minister Mbumba argued:

Should the [ex-combatant] programme not have been introduced, the overall deficit would have come down to 3 per cent of GDP in 1999/2000 and would have brought us to our stated NDP1 target. The fact that the Government has allowed an upward deviation from this target, clearly demonstrates the priority given to accomplish the Government's Peace Project. (7 April 1999, Debates of the National Assembly, vol. 32/1999)

Maintaining peace and stability is the most widely cited reason for $\mathrm{Na}$ mibian ex-combatant policies, in government reports, interviews and research literature alike. The ex-combatants are said to have organisational capacity, strategic knowledge and skills that might in certain conditions translate into social unrest. This perception was obviously reinforced by incidents during which ex-combatants overstepped the conventional limits of demonstrating. For instance, in 1995, ex-combatants briefly took the deputy minister of lands, resettlement and rehabilitation hostage and in 1998 the minister of trade and industry narrowly escaped a similar fate. Four regional councillors were held hostage in Oshakati for a few hours in 1997. According to the former secretary to the cabinet and the president's secretary, "it was going to be a question of the first bullet being fired at a minister, post-independence". ${ }^{18}$

The view of ex-combatants as a "social problem" is relatively widespread in the upper echelons of government, politician and civil servant alike. This perception has not been restricted to the Namibian public and decision-makers but has also included the international community, especially donors. To a degree, Namibian "reintegration" efforts follow the global discourse on "demobilisation, rehabilitation and reintegration" or, more broadly, "post-conflict reconstruction" and donors resort to it to justify

I8. Isaac Kaulinge in an interview with Lalli Metsola, 14 July 2003. 
policy choices. The imagery of ex-combatants as a social problem gains further currency from the security concerns of the elite. Many of the evils that ex-combatants are associated with - migration, crime, alcoholism, loosening of family ties, indiscipline, HIV/AIDS - have a prominent place in upper and middle class discourse. They pose a direct threat to their lifestyle, revealing the rift between the haves and the have-nots and, more generally, threatening the orderly course of development as modernisation.

However, there are deeper historical roots that connect Namibian "reintegration" efforts, the security concerns of the country's elite and international post-conflict management. The Namibian concern with ex-combatants as a social problem is hardly new and many of its aspects are by no means specific to Namibia. On the contrary, poverty, the crumbling of "the community" and moral decay are classical concerns about an uncontrolled and negative form of modernisation that runs counter to the intended form of "development". Such concern dates back to the early stages of governing poverty at the beginning of the 19th century when a floating, poor population started to be seen as a threat to the proper functioning of the economy. It was a social danger, described in terms of fluidity and indefiniteness, through the imagery of the mob, rebellion, vagabondage, promiscuity, ignorance, idleness, immorality and un-cleanliness. It had to be managed through interventions that combined restraint and guidance, including social assistance, public and private hygiene, reinforcement of the family and education (Procacci 1991:153-62, 164-5).

It is not just the definitions but also the practices of Namibian ex-combatant "reintegration" that grow from these roots. The rise of statistics and quantification of society coincide with the rise of the concern about managing the urban poor, the unemployed or any other "needy" population segment (Hacking 1991, Porter 2001). In line with such biopolitics, Namibian ex-combatant "reintegration" has followed a quantifiable and replicable formula that consisted of mass call-ups, queuing, screening on the basis of official documents and formal interviews, classifying applicants, documenting personal particulars, creating a database, training, civic education and work discipline. Such techniques had the practical aim of systematically targeting ex-combatants with employment and other benefits. However, as an important side effect, they formalised ex-combatant identity according to certain fixed criteria. When the ex-combatants are labelled as a group, their problems are identified as shared, similar and distinct from others: in this way, they are made suitable for intervention. 
On the basis of the above, it might seem that the practices of ex-combatant "reintegration" follow a model of biopolitical intervention that could take place in a more or less similar way anywhere. However, such a view would miss a key aspect of Namibian ex-combatant "reintegration", namely the long-standing, close - often personal - relations between state and ruling party functionaries and former exiles. Here the role of frontline functionaries of the state and the ruling party, such as members of the technical committee, governors and councillors and Swapo party representatives has been crucial. They are the officials who have practically experienced the demands of the ex-combatants and carried out the measures aimed at their "reintegration". Through their activities, the ostensibly bureaucratic practices of "reintegration" often became highly personalised in practice. What the PLAN ex-combatants and other former exiles saw in their encounters with state power was not a faceless, neutral bureaucratic machinery, but their comrades and former commanders, Swapo "calling" them as their "father" and finally taking care of them again. Thus, in addition to the languages of ex-combatants as heroes and as a social problem, there is also a third, unofficial view of them that sees them as "our brothers, sisters and children", laying stress on the fulfilment of promises in return for continuing loyalty and order.

Government policy and ex-combatant demands have both focused predominantly on formal employment in the public sector. The army and the police have been the two biggest employers of ex-combatants under the Peace Project. Rather than being a response to the personnel needs of these or other branches of the public sector, job provision for ex-combatants and former fighters has clearly been a matter of social and security policy. The jobs for ex-combatants have mainly been additional posts created specifically for them and therefore the numbers of army, police as well as other public service personnel have grown considerably. Such employment creation has attempted to harness the uncontrolled and potentially rebellious agency of the ex-combatants into obedience and loyalty. This has worked at least to the degree that after the implementation of the Peace Project there have been no major demonstrations by people claiming to be excombatants. Four major mechanisms contribute here. First, there is the purely material aspect of receiving a salary on which usually a considerable number of extended family members depend. Second, the ex-combatants are subject to varying degrees of discipline at work. Many of the jobs replicate the military hierarchy and practices familiar to ex-combatants from exile. The repetitious practices and codes of conduct contribute to 
identification with the party and the government, the winners of the war and the rulers of the land. Third, government employment facilitates the continuation of a life-historical narrative built around participating in the heroic movement of national liberation. Fourth, formal employment is an important mechanism of relating to the state, and therefore, an indicator of citizenship. Through this prism, formal employment appears as a means for including ex-combatants into full citizenship or excluding them from it. People can use their ex-combatant status to argue for employment as their right, in return for their loyalty. Here, citizenship appears less as a constitutionally determined set of individual rights than as empirical practices through which one can properly become a full member of the nation and the state (cf., Cruikshank 1999, Walters 2000, Chipkin 2003, Chatterjee 2004 and 2001).

\section{"Reintegration" as bureaucratic containment}

Namibian ex-combatant "reintegration" reflects the convergence of state capacity, patronage politics and a formally democratic political framework, as well as the security concerns that have provided a major motive for state action. The Namibian state is relatively efficient in extracting revenue and channelling resources, yet it is "soft" in the sense of being open to various particular interests and demand politics. Jobs and benefits provided by the state often appear as the most lucrative way of making a living. In this situation, state programmes become objects of competition from the point of view of potential recipients, and an important means for securing political influence and legitimating the status quo from the point of view of office holders. This was the context for ex-combatant demonstrations and demands. Ex-combatant agency relied on their strategic position as former military personnel, as liberation heroes and as caretakers of the memory of a contestable past, and "reintegration" was largely an attempt to contain it. This would seem to be a case of state formation in a very concrete and immediate sense. The Swapo government has consolidated its grip over its core support base as well as the state security apparatus by employing excombatants in the public service, especially in the uniformed services.

A few distinct languages appear in "reintegration". The first is the nationalist language of heroism that nurtures the ex-combatants' existential and emotional attachment to Swapo. Through this language, "reintegration" attempts to harness potentially contradictory ex-combatant remembrance and maintain that the liberation struggle was heroic and its military aspect 
decisive in the attainment of independence. The dominance of the ruling party is not to be explained simply by a "culture of fear" or by the expected material benefits of loyalty, but involves relatively enduring constructions of collective and personal identity. The second language is that of ex-combatants and former fighters as a social problem to be dealt with through the practical techniques of registration and "reintegration". These techniques have largely been hierarchical, orderly, en masse and semi-military - not far removed from the situation in exile. In this language, the state, and more specifically the Swapo-dominated government, appears as the container of unrest and a guarantor of peace. The third language appears in the tiny practices of implementing "reintegration" and the accounts given by excombatants and former fighters. It stresses the long-standing and close relations between state and ruling party functionaries and the ex-combatants. Through these languages, "reintegration" has augmented the reproduction of ex-combatants' linkages and allegiance to the state and the party. It has also affirmed the close intertwining of party and state, not least because frontline state officials often hold party offices as well.

Apart from reading "reintegration" as a form of selective politics of patronage, there are also deeper levels of state formation involved. First, "reintegration" demonstrates the importance of the practical encounters between state representatives and "the people" in the construction of citizenship. The negotiation of who are citizens and what their entitlements and obligations are happens in such encounters and may be in line with, but also run counter to constitutional definitions of citizenship. Ex-combatants were demanding rights and benefits on a group basis, with arguments grounded in the particular histories and current conditions of their group, and the state responded accordingly. "Reintegration" formalised excombatant identity and labelled ex-combatants as having shared problems, and therefore suitable subjects for state intervention.

Second, ex-combatant "reintegration" combines biopolitical techniques and governmentality that harnesses the "desires, aspirations, interests and beliefs" (Dean 1999:209) of the people. In the West, such techniques have largely developed hand in hand with the establishment of representative political systems, separation of powers and civil rights and liberties. In societies of "the South", these techniques have often pre-existed such political transformations, or occurred without them. They are also not as pervasive as in the West. They are part of the game played over distribution of benefits, recognition, security and political allegiance. Furthermore, when plans devised in central offices are implemented on the outskirts of the 
state, they often come to be perceived and acted on in an altered form. Yet, even if the biopolitical and governmental techniques of "reintegration" are partly trapped within Namibia's particular political conditions, they still demonstrate the capacity of the state to mobilise resources and project power through classification and registration of populations, time-economy, discipline and narratives of identity. This extends the reach and imaginary hold of state power. This duality is not restricted to the issue of ex-combatant "reintegration", but is a constant tension in the way the state operates in contemporary Namibia. The paradox could be precisely that while the reach of "the state" is extended and deepened, this does not happen equally. The state is there more for some than for others and its languages have more resonance for some than for others. Furthermore, this process is conditional on the localisation and vernacular forms of state intervention. This leads to two questions. First, could the very way in which state power is extended and deepened perhaps contain the seeds of its destabilisation? And second, will the state-citizen relations thus formed outlive the particular persons who have forged those relations? 

STATES, DEVELOPMENT

AND VERNACULAR SECURITY 



\title{
The Intertwined History of Security and Development \\ The Case of Developmental Struggles in South Africa’s Townships ${ }^{1}$
}

\author{
Lars Buur
}

\section{Introduction}

Many were shocked to witness state security forces crack down heavily on the numerous organisations and demonstrators contesting the agenda of the 2002 World Summit on Sustainable Development (WSSD) in Johannesburg. The spectrum of harassment was multiple: some marches were banned while legal permission for others was either refused or granted and subsequently withdrawn at short notice; leaders of social movements/campaigns were arrested and imprisoned prior to and during the summit, with charges withdrawn after prolonged legal battles; telephone and other forms of communication were monitored; and police and security forces employed aggressive crowd-control strategies (see Mail \& Guardian 2002, CADI News 2002, Martorell 2002, McKinley 2002, McKinley 2003, Duncan 2003, Eveleth 2003). For human rights activists, it seemed more than ironic that less than a decade after South Africa's apparently miraculous transition from apartheid to constitutional democracy, the right to protest government policies was being restrained in a manner that resembled the modus operandi of the former apartheid state (Kimani 2003; personal conversations, CALS 2004). ${ }^{2}$ For them, new laws such as the 2002 Inception and Monitoring Act, which granted security agents unprecedented and wide-ranging powers to intercept all forms of communication, were considered to be a potential threat to the rights of individuals and organisations to contest state and government policies (see Jane Duncan quoted in News24

I. The article has benefited from comments and suggestions from Steffen Jensen and Finn Stepputat, as well as from numerous discussions with research assistant Caroline Kyhlback of the Nordic Africa Institute, who oversaw the 2004 survey on the implementation of prepaid water meters in the ward of Phiri, Soweto. The research was funded by the Nordic Africa Institute, Uppsala and took place in different phases from 2003 to 2004.

2. CALS is the Centre for Applied Legal Studies, University of the Witwatersrand, Johannesburg. 
2004 and Sooka 2003). It was immediately suggested that these new laws provided the state with potentially even more insidious and iniquitous legal means than even the infamous apartheid system ever had at its disposal. ${ }^{3}$

The violence feared by human rights activists was itself also used by social campaigns/movements to show the inherent brutality of the African National Congress's (ANC) reactions to protests against its increasingly unpopular macroeconomic policies and strategies (Vally 2003). Usually playing on what is called a violence of the imagination, social campaigns/ movements engaged in forms of violence that ironically resembled those used to provoke the state security structures during the struggle against apartheid. For example, a violent rampage occurred in 2002 after 50 members of the Soweto Electricity Crisis Committee (SECC) were ferried to the city to toyi-toy outside the mayor of Johannesburg's residence in Kensington and he did not come out and address the gathered crowd. ${ }^{4}$ The protesters littered the mayor's garden with garbage and disconnected his water and electricity so he could experience "the medicine the poor receive on a daily basis" (interview McKinley 2003). In the end, a security guard opened fire out of fear, wounding several activists, mainly elderly woman. Similarly, in a drive to reduce losses on electricity provisions in the greater Johannesburg area, the parastatal electricity provider, ESCOM, began a disconnection campaign targeting households in excessive arrears. At one stage, in Soweto alone, a vast township outside Johannesburg, roughly 30,000 households were disconnected per month while the national rates for monthly disconnections of electricity services to households increased from an average of 22,320 in 1996 to 98,775 by 2001 (Green 2002). Such incidents led the SECC to embark on a reconnection campaign and encourage payment boycotts, which further exacerbated electricity arrears. The government reacted with yet another round of debt cancelling (Banda 2003), making a mockery of ESCOM's attempt to become a profitable enterprise before listing on the stock exchange with a view to becoming privatised. Clearly mimicking and playing on tense memories from the 1980s, these battles again saw state vehicles becoming the target of stone-throwing crowds, while frontline state personnel were thoroughly intimidated, making the townships temporary "no go areas" for ESCOM. In other words, in line with recollections of past forms of struggle, these violent public reac-

3. Where social campaigns/movements advocated radical civic and political organisation as a remedy, human rights activists advocated for the use of the constitution to counter potential state repression.

4. The mayor was away on a business trip. 
tions explicitly targeted government councillors. A similar trend was seen when landless rural populations and destitute township dwellers requesting proper civil housing, essential services and access to jobs, erected informal settlements on private and state land and were universally countered with state-sanctioned forced removals.

The question is, why have development challenges, which should be the foundation for building a new society, triggered such violence? In this essay I suggest that the all-embracing shadow of apartheid is still the "constitutive other" of the new democracy. This not only refers to the apartheid regime itself, with its racist ideologies and security practices, but also to the various ways in which this regime was both defended and contested by drawing on entrenched practices and ideas about threats and designs for resistance that evolved during the struggle against apartheid. Specifically, I argue that the political culture of monism developed during the 1980s is in a displaced perspective still structuring the implementation of new government policies as well as the forms of resistance such policies trigger. I pursue the argument that the violence points towards a theoretical horizon whose contours are intimately related to the ambiguous figure of popular sovereignty in South Africa at the nexus between security and development. During the struggle, popular sovereignty gained the reputation of being uncontrollable, ruled by crowd sentiments and intrinsically prone to violence, creating a "parallel sovereign" in its attempt to counter the violence of the apartheid state (Nina 1995, Seekings 2001). On the one hand, today's political leadership of the ANC distinguishes itself from popular manifestations grounded in past forms of mobilisation considered to be anachronistic or at odds with the new formal constitutional democracy. Ironically, on the other hand, the ruling party constantly draws on the rhetoric of the past struggle, insisting that the development of the new democracy remains a direct continuation of that history. This I will suggest underscores the ambiguous foundational legitimacy of "the people's government" of the ANC.

By considering past and current political mobilisation in the name of "the people" - by both government and social movements/campaigns democratic consolidation and its challenges can be analysed by examining the relationship between "the people" and the guardians of the people. In this regard, it is first worth considering Agamben's answer to the question "What is a People?" (Agamben 2000a:28). According to him, the Western political concept of "people" is inherently ambiguous because "what we call people was actually not a unitary subject but rather a dialectical oscillation 
between two opposite poles: on the one hand, the People as a whole and as an integral body politic and, on the other hand, the people as a subset and a fragmentary multiplicity of the needy and excluded bodies" (Agamben 2000a:30). The double nature inherent in the concept of "people" dialectically opposes that which always already is and that which has yet to be realised - the citizen and the poor, underprivileged and excluded subject aspiring to become a citizen. This definition of the People fits well with the 1980s ideal of "achieving people's power" and with the ANC's current democratic project, which aims to see the merger of people and People. Agamben traces the attempts in Western political history to mend this constitutive fracture as the "pure source of identity [which] yet has to be redefined and purify itself continuously according to exclusion, language, blood, and territory" (Agamben 2000a:31).

The figure of the people/People is as such a profoundly political one, driven by the quest for sameness and identity of the multitude of particularistic social forces. This quest for unity is often uncomfortable at the core of the operation of all constitutional democracies (Mouffe 1999, Preuss 1999), uncomfortable because the basic precept of constitutional democracy sees political order as created by the constitution - consuming and legally taming political energies that made possible its creation and rejects such a figure. In this situation, developmental contestations become a question of security when they threaten order by exposing the failure of identity for the multitude of interests and forces postulated as being united. As demonstrated by Jensen's recent accounts of the "coloured" Cape region (Jensen 2005a), this phenomenon is not new in South Africa's political history. Security remained the principle preoccupation of the apartheid state from 1948 onwards, and became in the 1980s, the explicit practice and goal of the state, intertwined implicitly and explicitly with developmental rationalisations. Whether the threat to security was that of the white-supremacist apartheid state or that of the black township organisations challenging it, the constant in the South African case seems to have been that enemies identified by either "side" were denied access to certain rights, spaces and opportunities, and/or banned from the right to quasi-township citizenship. This becomes apparent if one considers the constitution of the articulation between development and security with regard to the production and reproduction of political communities in South Africa.

This essay begins with a case study examining the impact of the installation of pre-payment water meters in the Soweto suburb of Phiri and focuses on the state's attempt to regulate popular participation in develop- 
ment and the resulting forms of resistance. The aim here is to provide an example of the different kinds of resistance and violence resulting from the politically charged atmosphere surrounding service delivery in the modern South African context. The second section concentrates on some of the constitutive moments in the unfolding of developmental contestations, not only during apartheid, but also since the formal end of the regime. It traces the forms of resistance and the political ethos of monism that developed during apartheid through the contestation of and protests against imposed decentralisation reforms in black townships and relates these events to the regime's development and security responses during the 1980s. Finally, this essay concludes with a more profound theoretical discussion of the relationship between development, security and popular sovereignty.

\section{Impossible depoliticisation}

The developmental impact of privatisation and Private Public Partnerships (PPPs) was intensively debated within the tripartite alliance of the ANC during the 1990s, but the political space for public discussion of these issues has been considerably narrowed over time (McDonald 2002). Central to these conflicts are the inherent differences in the conception of democracy, with 1980s mass-assembly activism and ideas concerning democratic sovereignty opposing the ANC's liberal procedural model of democracy. In this section, I will establish a link between the form of democracy practised through the implementation of state-led development initiatives and the form of democracy emerging through resistance to these projects, as practised through different modes of popular contestation and the reproduction of violence. These concepts will be explored through an examination of community participation in the installation of pre-paid water meters as part of Operation Gcin'amanzi ${ }^{5}$ (conserve water) recently implemented in Soweto.

In an attempt to regulate the wider public's perception of the state-sanctioned installation of pre-paid water meters in Soweto, the official "community liaison and social facilitation" process "was conducted through formal structures representing the community, i.e. through ward councillors and ward committee structures" (Internal communication, Johannesburg

5. Operation Gcin'amanzi is today known as "the water struggle" due to the intensity of the battles triggered by the installation of prepaid water meters. In the following narrative, I will by and large concentrate on the state's participation in the installation of prepaid meters. 
Water 2004). In October 2002 at the project pilot site of Ward 43 in Phiri, the internal process of the "Councillor Mobilisation Programme" was initiated with "ward committee workshops" and "follow up meetings of the ward committee sectors with their respective constituents" for members and specially invited core constituencies from the ANC Youth League, ANC Women's League, SACP, COSATU and so on. Here, the implementing agency, Johannesburg Water (JW), briefed the official constituencies, while the councillors made Operation Gcin'amanzi "a standing agenda item" at "monthly public meetings" from November 2002 onwards. This granted JW a platform to discuss the project and official "public meetings" were held to formally present the project to the community. Twelve "targeted sectoral information sessions" were held with stakeholders, including the women's forum; youth groups; schools, teachers and parents; and pensioners and veterans groups prior to the official start of the project, as announced at a public meeting on 26 July 2003. The subsequent public campaign distributed flyers to affected residents, and offered "consumer education including door-to-door campaigns and community workshops", with "study tours" to other townships for selected "community groupings" arranged by "community liaison officers" who had been "mandated to facilitate public meetings through their ward administrators". All members of the ward could formally participate in these open meetings.

At this point, the ward committees could only be accessed by an ANCrelated organisation and, by virtue of this official approval, could claim to be the only legitimate structure in the township. This was not the case for other formations such as Anti Privatisation Forum (APF) or SECC, which tried to organise ward residents, as well as adjoining wards, in opposition to Operation Gcin'amanzi. The formation of ward councils can therefore be interpreted as the state's attempt to contain the energies of "the people's power" within the dominant party's practices. As such, the committees became spaces that defined the interface between citizens-subjects and global institutions by allowing a measured amount of public participation in decisions that influenced public well-being. The ward council model includes the use of a spatial matrix based on the local governance unit for ascendancy, requiring that participants be registered as members of the Ward 43 of Phiri.

At first sight, this spatial matrix used by JW based on the local governance unit appears to be an attempt to be inclusive, yet it was in effect exclu-

6. Johannesburg Water uses ward "committee" and ward "council" interchangeably. 
sive, simply because it was at odds with the organising basis of movements/ campaigns that formed when pre-paid water meter systems were installed. The APF and the SECC as the main protagonists contesting the implementation of Gcin'amanzi were not organised around specific wards, but rather structured within the township of Soweto more generally (or even beyond Soweto). Members arrived for rallies and meetings from a variety of wards throughout Soweto, constituting the first frontier for legitimate participation in the Gcin'amanzi process. But while this set the formal boundary for exclusion, exclusion did also have substantial features. JW advised community liaison officers (CLOs) early in the process "not to engage with political structures as it may create the impression that this is a political project". Instead, JW advised them to "engage with structures representing community as this is a community-based project". In the beginning, CLOs tried to use South Africa's National Civic Organisation (SANCO) structures for their outreach programme and "contact sessions" were held with sub-branches from Soweto. However, it became apparent early in the process that the "fragmentation of this structure proved difficult for meaningful engagement" and there was no unified approach from SANCO for the installation of prepaid water meters - some were for, others against. JW then advised its teams not to engage with "civic associations exclusively as these are represented in the ward committee structures". Rather, key "stakeholders" representing sports clubs, schools and churches were targeted as appropriate community-based organisations (CBOs) because they were apolitical: "nobody can say that they are political, God doesn't look at the political affiliation. Church members are dedicated members of the community. They don't make troubles" (Interview, CLO, May 2004).

The CLOs searched for community members fitting the normative and ethical prescriptions defining a good citizen, such as fidelity to societal norms and respect for authority. However, this formally neutral and depoliticised approach not only captured residents in the participatory processes, but also produced the participatory process's "other" by limiting the development of contestation. The CLO made it clear that despite resistance to the installation of pre-paid water meters, they carefully selected from sports clubs and churches "members we know and trust from the past. With APF spying on us, we look for stout card-bearing members of our organisation" (Interview, CLO, May 2004). School pupils were specifically targeted to disseminate information because, if properly sensitised, they could explain the pre-paid system to their parents and grandparents, many of whom had contested their installation in APF rallies. For the same reason, the ANC 
Youth League was considered a key ally in ensuring that school pupils not become involved with the APF.

Despite the depoliticised approach, the apparently inclusive outreach programme carefully screened participants according to ANC-alliance affiliation and their allegiance to decisions made at higher levels of the ANC. Participation was therefore foreclosed as the process ensured that dissident voices not gain access to official platforms. This in turn had several repercussions. First, excluded from all official venues for public deliberation, opponents of Gcin'amanzi relied on the only language of struggle they knew, the various strategies of the 1980s (toyi-toyi, illegal rallies, boycotts, etc.). As applications for public demonstrations were rejected, hundreds of activists protested without permission, blocking main roads and toyi-toying in front of official buildings and councillors' houses, forcing fearful councillors into safe-houses outside the wards where they were elected.

Second, as conflicts escalated, protesters attempted to sabotage the implementation process by refilling the pipeline trenches, burning machinery, publicly destroying meters, installing illegal connections and attacking locally hired workers to prevent them from doing these sought-after jobs. A third effect was the criminalisation of these contestations. The approval of a plethora of laws in such diverse fields as communications, labour and safety and security by the democratic establishment with limited public deliberation, criminalised activities that in anti-apartheid struggle terms fell into the category of political and developmental activism and contestation. The laws were not solely enforced by state police, but drew on a range of state and civil society agencies, such as community policing forums, metro police units, national intelligence and private security firms.

It should be made clear that the democratic form encouraged and harnessed represents a particular form of South African political subjectivity whose "other" is partly related to the organisational form used by township residents during the 1980s. The closing of public spaces by ANC/state structures to democratic deliberation not only led to acts of violence and counter-violence but also the response was not uniform. For the leadership of the APF and SECC, the question was ideological. They were against the privatisation of state assets and consumer payment of essential goods such as water, which they considered to be a breach of the ANC Freedom Charter by the present ANC leadership. In other words, the APF and SECC leadership were reacting to the neo-liberal practices of governance and the principles behind the privatisation of common goods such as water distribution. The leaders of the campaigns/movements wanted residents to 
be radical and were not content to see local residents' groups emerge in Soweto. They wanted residents to follow their ideological hard-line while they built upon entrenched forms of violence and monism from the struggles of the 1980s to express the contestation. One strategy clearly seemed to be to gleefully provoke the ANC-led state to act in order to expose its authoritarian foundation. ${ }^{7}$

Survey data collected in Phiri and Extension Four of Orange Farm between May and November 2004 (Earle, Goldin and Kgomotso 2006 forthcoming), clearly indicate that ordinary citizens contesting Gcin'amanzi overwhelmingly attributed their grievances to the poor consultation process rather than to the ideological principle behind the installation of prepaid water meters. The lack of public debate and participatory democratic deliberation was considered to be an indication of the ANC's autocratic tendencies in attempting to manipulate the will of the people by excluding from any discussions those who legitimately questioned ANC policies. It pained the leaders of the social campaigns/movements to look on helplessly as residents contested the implementation of prepaid water, yet continued to vote for the ANC. For the local ANC cadres, no differentiation was made: they were all enemies, as we will explore below.

\section{Return to the past and the violence of bureaucracy}

The perceived need by local ANC cadres to foreclose public debate and participatory democratic deliberation relates to their interpretation of the resistance to Gcin'amanzi. According to the JW and ANC councillors, there was nothing objectionable in using only official ward governance structures and ANC-aligned organisations for the outreach programmes. Victory in successive local and national elections with well over 80 per cent of the vote automatically implied that the ANC was the formal representative of the people's will. Nonetheless, as a CLO explained:

7. This was suggested by a former member of the APF and well known radical activist from the 1980s township struggles in an interview in 2004. He had left the APF for similar reasons. According to him, at least some of the leaders of the APF were "using" ordinary township residents by bringing them into violent confrontation with the state security forces, without providing them with any protection when they were arrested. According to him, not all means were justified by the overall ideological goal of radicalising township residents. 
What confuses me is this, there were people who were [demonstrating against the installation of Gcin'amanzi] who were wearing ANC t-shirts ... There was an ex- $\mathrm{MK}^{8}$ who told us he was so disappointed with the ANC, because he believed he had been used [offered his life for a different set of policies]. They danced and toyi-toyied, singing freedom songs which I knew and some of them had changed the wording so they now made a mockery of the ANC. I don't understand this. (Interview, April 2004).

JW, ANC councillors, members of the ward committee and the CLOs responsible for the daily community participation programme wondered how card-carrying members could possibly demonstrate against their own leaders and the policies of their own organisation. One typical explanation was that it was the work of hidden forces "that tried to destabilise the process and government". This marks the return to recollections of the struggle's "friend and enemy" schemes that fuelled political conflicts in the 1980s. It also explains the obsession with screening possible members operating outside the party-political domain dominated by the ANC. The explanation for ANC members who turned against their own organisation was simple:

How can it be that at each and every APF meeting there will be food served? We are still under the structures of poverty and people need food. If you can call a meeting and inform people that there will be food served, believe me, the room or the house will be filled to capacity. That is what is actually happening and those who have been at those meetings tell people that yes, when Trevor Ngwane (the leader of SECC) calls a meeting there is a lot of food, there is breakfast, there is lunch, there is supper ... So some people are using Trevor Ngwane ... he is not working, where does he get money from to cater for more than 50 people? That's the first question; secondly he doesn't run any business that I know of ... So it came to our attention that there are people who are funding that man, and those people must be of rich nature. Hence we're saying he's been funded by the capitalists, by people who are trying to disturb the development of this country. Development made by this government. The capitalists are the ones who are against the political and economical stability. People who will want to destabilise the whole process, who want conflict to take place. It can be a black man, it can be a white man, it can be a coloured man, but it's not specific that it should be this one. But those who don't want to see stability taking place in this country are the ones who are funding this man.

8. Umkhonto we Sizwe (isiXhosa for 'The Spear of the Nation'), the ANC's military wing during the war of liberation. 
This interview extract provides, in condensed form, the key for decoding political contestations in South Africa since the 1980s: the circulation of past struggle narratives concerning evil forces and enemies of the ANC who "turn", "buy" and "use" individuals and groups of people in struggles against the People's government. The idea of such a hidden force, known since the 1980s as a "third force", can be used in particular contexts to explain why things go wrong. Here for example, it explains why ANC members organise and demonstrate against their own organisation. It also explains why Trevor Ngwane, a struggle organiser for the United Democratic Front during the 1980s, was imprisoned several times, and why later on, a prominent elected ANC councillor in Soweto turned against his organisation before being expelled from the party for publicly criticising neo-liberal changes in economic policies. The reiteration of "third force" and dissident narratives has a remarkable capacity to reconcile local and global concerns as it forms part of a lived semantic universe, and provides a constant subtext for understanding apparently innocuous and mundane incidents. The presence of hidden forces trying to create a divide in the People by turning people against People results in the slippage by people "used" and "bought" by some malevolent elements. For example, the fact that Trevor Ngwane was an ANC member and now is the leader of SECC and prominent member of APF, two organisations which receive funding from outside South Africa (from progressive organisations in Canada and the US) - are all factors supporting the claim that there was indeed a "third force" in operation.

However, "third force" narratives recycled in the context of the opposition movements to Gcin'amanzi can be said to take a different twist. It is no longer possible to identify with the same certainty the evil or hidden forces (see Jensen 2001). With a more firmly consolidated democracy, the answer to the question "who exactly should be blamed for political conflict in townships?" has become homeless. Recycling "third force" narratives in the present-day context of developmental contestations plays on popular perceptions and readily available images of inadequate socioeconomic transformation. More specifically, these narratives have led people to believe that somebody is actively trying to destabilise the ANC project through the use of certain (black) elements in the townships and is the cause of high levels of unemployment, abject poverty and increased inequalities between and

9. See Jensen and Buur 2004 for a more comprehensive description of homeless in relation to witchcraft. 
within different racial classifications. It is with great ease that these past narratives are used today to give meaning to everyday incidents and explain contingent events, events nobody can really do anything about but which nonetheless need to be rectified. To paraphrase Jensen (2001:116-17), this process provides an indication of how events are localised in one locus of evil that exonerates the ANC, the councillor and others working for the new South Africa of any guilt for the prevailing socioeconomic misery. Locating these networks today is increasingly difficult and the reference to "capitalists" in this regard is pitiful. The installation of pre-paid water meters in Phiri and other Sowetan wards was part of a private-public partnership between JW and a French multinational company. This becomes important in that it was this extraterritorial alliance, interpreted through the lens of the "third force" that became the enemy figure.

However, it is important to specify that the fear expressed by the SECC and APF is not only related to a "third force" and the semantic universe upon which it draws as seen from the viewpoint of the dominant party, it is also seen as an expression of anti-state or anti-ANC sentiment. In other words, the re-evocation of the "third force" narrative results in the delegitimisation, a priori, of any claim made by opposing communities or organisations. Consequently, any opponent of the government's economic policies becomes recast as an enemy, and cannot therefore be included in democratic forums (Buur 2005). Dissidence is interpreted through the lens of an evil past. In this way, words like "turncoat" and "sell-out" take on new meanings, as any hint of "third force" activities and the wider domain of related violence and past political struggles associated with such classifications a priori undermines any claims to legitimacy. Secondly, such classifications allow for exceptional means to be deployed, as explained bluntly by the CLO: "This is sabotage by defectors from the ANC [with the aim of setting up their own party], this is not something we can accept" (Interview, CLO, April 2004). Even if only expressed as a threat, killing and violence always loom large as a possible outcome for those perceived to be "turncoats" or "sell-outs", as the same CLO illustrates: "If you work as a double agent, if you work for APF, and yet are a member of ANC, if they find out that you are an informer or a sell out, believe me they are definitely going to make sure you get into the ground. I must be honest with you, assassinations still happen, they are going to make sure that they get rid of you" (Interview, April 2004). While in the past people were killed when such classifications were flagged or rumours circulated, today the means are different but still noteworthy, at least seen from the perspective of freedom of speech and equity. Rather than being killed or becoming the victim of 
violence, opponents of ANC policies in the townships face exclusion from scarce and highly-valued employment opportunities or, if they are have a job, face losing it. Other strategies include either physical expulsion from communities or even families, or outright banning from participation in public events.

If these remain the strategies used by members of civil and political society to curb dissidence, then the violence unleashed at the WSSD points towards the domain of the state, whose tactics are in many ways reproduced on a daily basis at township level. Here, the state's interpretation of the Regulation of Gathering Act (205 of 1993) is crucial. According to the act, the police hold the final legislative authority for granting permission for marches, demonstrations and public gatherings. The act describes two types of activities: "demonstrations" that consist of no more than 15 persons who do not march or walk in procession, and "gatherings", defined as "any assembly, concourse or procession of more than 15 persons in or on any public road ... or any public place or premises wholly or partly open to the air" (Ngcobo 2003:75). The constitution demands only that demonstrations remain peaceful and bars the incitement of "imminent violence" (see Kimani 2003:17, Seleoane 2003). What remains particularly contentious is whether one must merely "notify" the authorities or, as state law enforcement agencies insist, one must obtain "permission" in advance. Here, the need to obtain "consent" from local state authorities before holding a protest march contravenes the spirit of the constitutional guarantees of free assembly and expression. Furthermore, it also requires relatively well-established, and seldom available organisation and lines of communication to arrange, negotiate and enforce restrictions imposed by the state authorities. Equally contentious is the act's insistence that any person who has participated in the planning of the gathering is liable in the event of damage, even if she or he were not present at the demonstration itself. As Seleoane (2003) argues, this seems to negate the basic principles of criminal procedure that, as Kimani (2003:17) points out, "first require culpability to be determined before an individual is held liable". The state's interpretations of the act restrict the right to assembly and criminalise many types and forms of developmental contestation that have historically fallen under the rubric of political activism.

In the only survey investigating the consequences of the Gathering Act, it was found that some of the social campaigns/movements had "increasingly been met with prohibitions of their planned gatherings, often entailing violations of the RGA (Regulation of Gathering Act No. 205) 
[and the police had] over the course of a two year period come to issue blanket prohibitions of gatherings planned by the APF and the Landless Peoples Movement (LPM), in direct contravention of the RGA in many ways" (FXI/RED 2005:18-19). In many cases, people were even arrested on their way to legally sanctioned gatherings and strict bail conditions were set, sometimes far exceeding the bail set in criminal rape or murder cases (FXI/RED 2005). Along with prolonged and endless court trials, which have seldom resulted in prosecution to date, this has had the effect of draining the limited funds available for legal assistance. These strategies, as I will illustrate in the following sections, strikingly resemble those employed by the apartheid establishment against UDF organisers during the 1980s. As Schmitt has pointed out in his critique of liberal and constitutional democracy and its rejection of the political as constitutive of political agency, if the state "has the monopoly of the political, the preservation of order within the state is essentially a problem not of politics, but of the police" (Schmitt quoted in Preuss 1999:161). In order to understand how the historical figure of political monism at the heart of this came to be and created the political subjectivities that are still at the core of developmental struggles in South Africa today, we need to explore how developmental township struggles evolved in the 1980s and how they became intense objects of apartheid state-security strategies.

\section{Township struggle and monist politics}

Colin Bundy describes the apartheid state's reactions to the 1980s township struggle as an "awkward ambidexterity: constitutional blueprint in the left hand, sjambok in its right" (Bundy 2000:28). If the carrot took the form of self-governance and promises of developmental services, then the stick was precisely that: brute force. Struggles over services were not "created in an institutional vacuum" (Bundy 2000:26), but built on a long tradition of township organisation and non-violent direct action by representative bodies that had used boycotts and other forms of grievance-based protest since at least the 1880s (Bundy 2000:27). The campaigns that gave rise to what has been termed "the civic movement" in the 1980s cannot be described as homogeneous or spoken about "unproblematically as a singular event" (Adler and Steinberg 2000:4). Nevertheless, three commonalities can be identified: 1) these movements were initially self-limiting in their political aspirations; 2) they took on a quasi-representational role as the sole and 
legitimate representative of the people; and 3) they led towards the emergence of a political ethos of unity in opposition to apartheid.

Civic township struggles were, at least initially, ideologically "self-limiting". Both direct written and spoken public involvement in local and national political struggles was avoided, and contestation was limited to non-participation in state structures on one hand, and to the deployment of non-violent engagement and non-cooperation on the other (Seekings 2000a:54). However, the situation changed considerably during 1985-86, when civic and welfare organisations were reconceptualised as partners of the ANC alliance and, emerging from the insurrection period, embodied the vanguard of the South African masses. Here, the notion of "people's power" retrospectively gives sense to the direct insurrectionary activities in primarily black townships. These changes are rooted in the general strike of 1973 and the 1976-77 black consciousness-inspired Soweto uprisings that triggered a collective organisational awareness in certain strata of primarily urban populations (Swilling 1997:218, Bundy 2000:28). These events led to the establishment in 1977 of a new governance system of "community councils" to replace the former Urban Bantu Councils (UBCs). The devolution of central powers to self-governing councils for urban black populations was a poorly veiled attempt "to stave off underclass protest through the provision of resources ('upgrading')" (Bundy 2000:28) - a move to replace the direct administration of township dwellers by white apartheid bureaucrats with indirect rule by "black surrogates" (Mayekiso 1996). In 1982, reforms expanded the councils' powers (under the Black Local Authorities Act, or BLA) to include the allocation of housing, business licences, business sites, student bursaries and the collection of rents and service fees.

The attempt to make the BLAs fiscally independent meant that the new local authorities would not only have to govern but also to extract rent and service charges from their subject populations in order to subsidise and maintain the African populations' own suppression and ghettoisation (Adler and Steinberg 2000). The United Democratic Front (UDF) ${ }^{10}$ - formed in part as a response to the 1983 BLA election campaign and, over time, the banner under which many civic and resident organisations struggled - tried vigorously to undermine the collaboration efforts of black authorities with the apartheid regime by organising election "stay-aways" and employing various forms of intimidation including, later on, petrol-bomb

IO. UDF was a loose federation bringing together a large number of social, civic and political organisations of differing class backgrounds, racial constituencies and political orientations. 
attacks on councillors' homes. Triggered by the apartheid programme for constitutional reform and given ongoing direction by the state's violent reaction, the insurrection period begot a particular political ethos. In many ways, the form and ethos of 1985-86 township struggles have become iconic, and have had a lasting effect on subsequent developmental contestations in South Africa.

In 1984, organisations initiated "rent and service charge boycotts" in order to undercut the financial basis of the BLAs. The first recorded rent boycott was undertaken by residents of the Vaal Triangle and Evaton in September 1984 (TRC Volume 2, 1998:382). Similar events spread throughout the country, while militarised youth took it upon themselves to monitor and enforce boycotts. By the mid-1980s, residents called for "consumer boycotts" to support both national and local political demands. While initially targeting white-owned business, these boycotts later targeted businesses owned by perceived "collaborators" - for instance, black businesspeople and township residents who participated in the government-established local authorities. Government buildings were burned and looted, and those defying the boycott calls were forced to swallow such inedible products as detergents or cooking oil. Some were even killed. Death tolls escalated as attacks by community residents on "informers" increased. Methods of attack included burning and "necklacing", as well as beating, stabbing, shooting and sexual assault. After 1985 in most townships, UDFaligned organisations established their own "people's courts" as an alternative to the apartheid legislated "community guards". Many of these courts were under the guidance and protection of BLA councillors.

This marked the ironic reform and transformation of the apartheid state's direct governance into indirect governance through the BLAs and converted "physically distant agents of the state into identifiable individuals who lived and operated among those whom they ruled" (Bundy 2000:29). Beginning in 1984, and particularly from 1985, councillors were hated and became prime targets of routine attacks by ANC-and UDF-aligned youth. More importantly, as symbols of state power, they brought the frontier of apartheid into township neighbourhoods. Resistance soon targeted all figures of authority, while, at the same time, struggle leadership was being repressed and targeted by the authorities. The result was a perpetual destructive fear woven into the fabric of everyday township life. Black township youth, poetically characterised as "[t]he tyre, the petrol-bomb, the knife, the stone, the hacking: death" were feared, even among themselves, while media portrayed "young men, hungry, with hardened features and red eyes" 
(Ari Sitas, quoted in Mayekiso 1996:256). "Reckless militancy, widespread criminal activities, and harassment and coercion of adult residents transformed 'the youth' into a considerable threat" (Jochelson 1990).

The dual face of "ungovernability and organisation"11, as phrased in Nina's sympathetic accounts of "people's courts", created a parallel authority that "was seen as part of a process of organizing the future society" (Nina 1995:7). The establishment of an "alternative locus of representation" was soon construed as being a "quasi-representative" and "quasi-governmental" institution (Adler and Steinberg 2000:6) that assumed rudimentary administrative and service functions and was partly era-bound. However, contrary to many commentators' expectations at the end of the 20th century, this marshalling of a form of representation that demarcated for itself a highly privileged space "above and beyond other associations, [claiming] to be the sole and legitimate representative of the people, a sacred and untouchable place of democratic sovereignty" (Adler and Steinberg 2000:7) has endured. The pervasive mechanism of resistance infused every moment of action with a particular aim and the people spoke in public with one voice, under one leadership united in opposition to apartheid (Adler and Steinberg 2000:8). During the 1980s and into the 1990s, public discourse was, as a result, sharply divided between "friends" and "enemies" - between those who endorsed this ethos and those who did not. Even the slightest action could be considered a sign of adherence or defiance, leading to correction in the "people's courts" or violence or death. In other words, the "people's courts" granted or barred people the right to belong to (or the quasi-citizenship in) the moral and political community, "a public morality that insists virtue consists only in monist politics, a morality that construes difference as venomous opposition" (Adler and Steinberg 2000:12). As such, it "embodied a destructive logic" (Carter 1992), because it gave a priori justification to actions - violent or not - as long as political objectives were reached. The crux of the matter is, as Adler and Stenberg point out, that this struggle ethos accepts neither the liberal principle of secrecy of political allegiance nor the notion of political allegiance as relational and contingent on a pluralistic contest.

II. The term "ungovernability" was coined by the ANC national executive on 25 April 1985 through their call, "Make apartheid unworkable! Make the country ungovernable!", presented in a paper entitled: "ANC Call to the Nation: The Future is Within our Grasp" (TRC Volume 2, 1998:346). In this regard, the call by ANC for "ungovernability" can also be seen as a reaction to the UDF's launch in August 1983. 
The entrenchment of the struggle ethos cannot be understood without considering the other side of the apartheid state's "awkward ambidexterity" (Bundy 2000:28), or rather the intertwined nature of development and security. It is clear from the introduction of the WHAM (winning the hearts and minds) campaign in the mid-1980s, part of P.W. Botha's "total strategy", that development and security were intertwined both implicitly and explicitly. WHAM figured within "low-intensity conflict" management, also known as counter-insurgency warfare, rooted in military theories emerging from the experiences of the French General Andre Beaufre in North Africa and the American Colonel J.J. McCuen in Vietnam (Haysom 1989:2-7). The apartheid regime institutionalised the logic of these theories, first in the "total strategy" and later in the "Joint Management System" (JMS) approach, which dissolved "normal" boundaries between military and civil society. In addition to the obvious developmental preoccupations of service provision and "upgrading", the strategy was designed to defuse and calm hotbeds of township resistance by unravelling the 1985-86 organisation of "people's organs for power" and "people's courts". As part of WHAM, a territorial "oil spot" strategy was applied to pacify and defuse resistance, often by cordoning off areas identified as the most volatile and explosive. On the one hand, civic and union organisers and leaders were physically "eliminated" (killed, arrested, chased away or forced underground), while on the other, target populations were "pacified" by the provision of housing, water, electricity, school bursaries and so on. With the mass mobilisation of youth peaking in 1985 and 1986, thousands of stone-throwing youths were arrested. WHAM's real aim can therefore be said to be the containment and elimination of not only the "ringleaders", but of a disorderly public in general (Haysom 1989; without using the language of security, Seekings 2000a argues along similar lines).

According to Madeleine Fullard (a former TRC researcher), who scrutinised most, if not all, the State Security Council minutes from 1985 to 1990, the apartheid leadership was "obsessed with legality and legalism" particularly when dealing with the UDF, which had deliberately constituted itself as a "front" with no clear or uniform structure and no organisational plan.. In other words, it was focused on dealing with organised UDF resistance "within the law" in order to maintain some kind of legitimacy (personal communication 2000 and 2004). Minutes of State Security Council meetings clearly indicate that it was legally difficult to "clamp down" on the "front" and numerous strategies were attempted with varying degrees of success. At first, leaders and "ringleaders" were prosecuted under 
criminal law, but charges were often dismissed after endless legal battles. Secondly - and equally draining on resources - top leaders, when caught, were charged with "treason", a strategy dating back to the 1960s. Treason trials were often successful due to the ties apartheid leaders had with the legal establishment, but the attention they generated created international problems. Bail was often denied regardless of the form of trial awaited. This successfully prevented leaders from playing any sort of organisational role for the duration the often lengthy trials, or it forced leaders to take cover, thus hampering the organisation of resistance (see Seekings 2000b). It was not until 1988 that the apartheid regime managed to "restrain" UDF as a "front" by banning its activities. Later in the process, as part of declared regional and general states of emergency, the state could impose "a blanket ban on outdoor public meetings and a partial ban on indoor meetings, in terms of the Internal Security Act" (Seekings 2000b:198). In the interim, individuals within the "front" became the target.

The monist ethos of singular politics characterising the township civics and residents' groups should be understood in relation to the need to protect and "immunise" township structures against state repression. It must be noted, however, that it was equally directed against the "clandestine creation of surrogate armed forces, which organisations appear to emerge 'spontaneously' from the 'people' themselves" (Haysom 1989:3), leading to the emergence of "concerned residents" groups or "conservative vigilantes", as the South African TRC and most commentators call them, such as Inkatha (Witwatersrand, now Gauteng, and KwaZulu-Natal), AmaAfrika (Port Elizabeth), and Witdoeks (Cape Town). Their emergence was seen as the product of the "third force", who also provided these "conservative vigilantes" with weapons, legal protection or even financial support. Indeed, the TRC produced ample evidence confirming a range of endorsement, support, and management mechanisms of vigilante groupings by different "clandestine" security agencies (see for example TRC Volume 3, 1998:369). But as the commission cautiously stated, "not all vigilante activity was a product of state engineering. Intolerant actions and coercive campaigns of the UDF and its adherents mobilised genuine disaffection and anger amongst black residents, forming the basis for retaliatory actions by socalled 'vigilantes'” (TRC Volume 2, 1998:302).

In conclusion, the attempt to use development - in its various forms of service provision and indirect government - combined with heavy-handed security operations brewed a cocktail far more explosive than apartheid's direct administration. Here, in violent contestation of such state reforms, 
the vanguard of the township rebellion was formed: residents' organisations across the country mushroomed in the early and mid-1980s, becoming instrumental in the defeat of apartheid. However, one is left to wonder whether the organisational form and the ethos of political monism were left behind. Adler and Steinberg suggest that "it was clear that the function, form and indeed the very existence of civics, was strictly era-bound" (Adler and Steinberg 2000:2). With the exception of a few rumblings in the 1990s, civics no longer play the prominent role they did in the 1980s. Nonetheless, I suggest that neither the form of political contestation nor the monist ethos of politics has been left behind, just as pre-democracy security strategies seem to have endured. Rather, they have (re)emerged, and were reconfigured during the 1990 s, increasing in strength right into the new millennium. These struggles and their development over time became constitutive of political contestation in post-apartheid South Africa, and provide an iconic register and measure of such contestation.

\section{Security, development and the production of sovereignty}

If the elementary gesture of securitisation as the identification of a social element is not properly positioned or defined within society, then the intense focus on specific "speech acts" tends to overlook the mundane context in which securitisation takes place and where speech acts are decoded. As Agamben's work on sovereignty suggests (Agamben 1998, 2000a), excluding or banning somebody from the polis demarcates a threshold, delineating a special relationship of both order and exception in which the sovereign decides whether the situation it confronts is an exception or merely normal: "What is at issue in the sovereign exception is not so much the control or neutralization of an excess as the creation and definition of the very space in which the juridico-political order can have validity" (Agamben 1998:19). The link between security and sovereignty is obvious, as security is intimately related to the deployment of exceptional means used to counter perceived threats to the ultimate survival of the individual, the collective, the nation or state (see the introduction to this volume). Security, as a speech act, legitimises extreme measures by referring to an existential threat "so important that it should not be exposed to the normal haggling of politics" (Buzan, Wæver, and de Wilde 1998), and thus basically moving politics "beyond the established rules of the game, and [framing] the issue 
within a special kind of politics" (Wæver 1997:14). ${ }^{12}$ Security takes on sovereign properties through the identification of special threats and through the discourse of a special kind of politics not regulated by the law

I believe, however, that heavy reliance on discursive pronunciation by somebody performing the speech act remains a weakness of this formulation. I am not contesting that there often, if not always, is a somebody declaring a situation or threat which justifies the use of exceptional means. A cautious look at the South African case will quickly provide ample examples of how criminals, right-wing, left-wing, reactionary forces etc., over the last decade have all been declared by the political leadership a threat to either the state or the party. My critique is that the context of order providing the sounding board for such utterances is often overlooked in the theoretical literature on securitisation, as is the manner in which speech acts are inscribed in the pre-existing socio-political orders from which they draw their force.

I have tried to highlight parts of this domain by pointing towards the interpretive lens of "evil forces of the past" and "used" dissidents, which only provide proper meaning when related to the tense struggles of the 1980s. This interpretive lens has a powerful and deep historical focus that sees present contestations, which may have very different foundations, extending into the domain of the untenable. Initially being merely "against" the installation of pre-paid water meters, contesting groups and organisations are soon categorised as "betrayers" who therefore must be opposed by whatever means possible. Though this interpretive lens is shaped by the past, it uncovers present fears of the impending emergence of a political opposition to the ANC. I suggest that struggles over the installation of pre-paid water meters and the fear of opposition reflect the concern that the sovereign will of the people as instanced by the ANC would be challenged by people over which it apparently has no control. This, of course, is highly indicative of the perceptions local ANC cadres have of political and democratic contestations. More importantly, however, it points to the deeply political nature of issues related to development initiatives in South Africa.

The reaction to new social movements and campaigns contesting the policies of the ANC can, in a broader historical perspective, be characterised as "business as usual" (Robertson 1990:139). As Robertson clearly argues, once liberation movements gain power, they usually abhor the idea,

I2. Securitarisation is therefore a particular and often extreme way of politicising a contentious topic. 
and indeed the possibility, of being subjected to similar treatment and forms of dissidence they used against their predecessors. This, I suggest, is symptomatic of how popular sovereignty manifests itself more generally. I have suggested that the constitutive fracture in the concept of "the people" can be a useful way of gaining an understanding of the developmental contestations in South Africa, not only because the struggle against apartheid was fought in the name of "the people", but also because acting in the name of and for "the people" points both to the source of identity and to what has yet to be achieved. The implication is that developmental contestation should be approached from the perspective of sovereignty where "the people" is defined as the constitutive category of the sovereign political structure.

While social movements/campaigns in present-day South Africa to a large extent draw - and often in unwitting and contradictory fashion - upon an array of past symbols and concrete activities of "people's power", they nonetheless point towards another aspect of order, that of a governmental frontier which somehow awkwardly supports the intrinsic political ethos of monism. Members of social movements/campaigns such as SECC and APF invoke past associations and are both modelled on past forms of sovereign organisation. Both organisations exercise their partisanship within the new nation-state in a way that is at odds with or defies correct organisational practice and behaviour according to the new legal-political project. The use of different participatory strategies based on local governance ward structures represents a positive and productive attempt to mobilise, enrol and harness active participation in development implementation in a structured and coordinated fashion. As such, the ward model for participation can be seen as formally redrawing the space for governance lying between state authorities on the one hand, and the liberty of rights-bearing, autonomous, individual subject-citizens of the nation on the other. ${ }^{13}$ Considering the extremely violent history of democratic nation-state formation in South Africa, this is no small matter.

However, it became clear that this ideologically neutral and apolitical model for participation was far from indifferent to the residents' socio-political reality. Nor was it detached from the salient properties of the past as it re-emerged in different shapes and forms as fears of "hidden forces" and as practices modelled on past modes of radical participation. By exploring the internal frontier for participation in the installation of pre-paid water

I3. See Rose (1999:167) for a discussion on this point in relation to Western democratic participation more generally. 
meters in the ward of Phiri, I have suggested that the internal frontier was marked by the exclusion of those residents who did not belong to the political party: more specifically, by those who were not affiliated with the organised formations belonging to the tripartite alliance of the ANC. This point relates to Bourdieu's notion of "legitimate symbolic violence, i.e. the power to constitute and to impose as universal and universally applicable within a given 'nation' ... a common set of coercive norms" (Bourdieu and Wacquant 1992:112). Forms of procedural or bureaucratic authority - legislation, authorisation and restrictions - legitimise certain practices and render others illegitimate and undemocratic. The nexus upon which the legitimacy of the local governance ward forums rests can thus be said to be less on direct or popular participation by the general population and more on an adherence to a particular kind of proceduralism founded on representative constitutional democratic behaviour, along with threats posed by dissidents. Formations that do not conform to the particular model provided by the implementation process become illegitimate.

I have argued that the evolution of these practices, ideas about threats and an ethos of politics cannot be separated from the particular manner in which security and development have been intertwined in South Africa. It is important to grasp the fusion of the differently constituted domains of a powerful historical ethos of monism and its local fusion with presentday forms of procedural authority. The apparent continuities of various practices and imaginings are hardly surprising when one considers, on the one hand, the intertwined deployment by the democratic government of "hard" and "soft" forms of violence and power linked to the production of sovereignty, and the simultaneous use by social movements contesting state policies of forms of violence that aim at both producing and rearticulating sovereign practices, on the other. What seems to be at stake is moral legitimacy, with contesting ideas as to what constitutes legitimate and illegitimate forms of violence. It is therefore worth exploring further how this vernacular semantic universe contributes to the radicalisation of state measures against its opposition, as well as the opposition itself. 


\title{
The Politics of Policing
}

\section{Re-capturing 'Zones of Confusion' in Rural Post-War Mozambique}

\author{
Helene Maria Kyed
}

\section{Introduction}

As with other post-war societies, Mozambique has undergone a liberal-style democratic transition since the beginning of the 1990s. In this process, decentralisation of the enforcement of law and order to non-state institutions and official attempts to democratise the police force have been key elements. In Mozambique, post-war security sector reforms promising democratisation of the Polícia da República de Moçambique (PRM) have been slow. According to Chachiua (2000), this is largely owing to political power struggles between the warring parties, Frelimo and Renamo. Lalá (2003) adds that this situation was influenced by the Frelimo-run government's preoccupation with regaining state control over the former war zones and Renamo-controlled areas. In Frelimo discourse, these areas have been regarded as security threats and termed "zones of confusion".

In 1997, five years after the General Peace Agreement (GPA), a new Defence and Security Act (17/1997) was passed, which adhered to mainstream liberal democratic transition idiom. Besides general state security issues, it included ensuring the normal functioning of democratic institutions, the fundamental rights and liberties of citizens, the guarantee of economic and social development and the rule of law (Chachiua 2000, Lalá 2003:14-15). ${ }^{1}$ Hence, security was directly related to development, democratisation and civil rights. This approach is a marked departure from the militarisation of the PRM during the civil war (1977-92), during which its officers were preoccupied with counter-insurgency actions and the policing of "safe areas" controlled by the Frelimo state (Lalá 2003). Since the passage of the 1997 Security Act, donor-sponsored police transformation has focused on training PRM in human rights, good governance and on decentralising policing. In the urban areas, pilot project community police councils have been extended to more than 1,000 registered localities (MINT 2005).

I. New justice sector reform is still under way, guided by the mantras of human rights, legal pluralism and collaboration between the formal and informal sectors (de Sousa Santos and Trindade 2003). 
In the rural areas, the first decentralisation initiative was Decree $15 / 2000$, which granted official recognition to traditional leaders as "community authorities". Traditional authorities were to execute administrative tasks and provide local-level policing and justice enforcement. The formal decentralisation of policing to chiefs has in addition been supplemented by general encouragement of vigilança do povo ('people's vigilance') and by a range of informal methods of outsourcing policing to pessoas de confança, that is, persons the police trust. According to the Ministry of Internal Affairs (MINT), these initiatives aimed at creating "a new culture of community security" (MINT 2005:4) where "citizens are directly involved in the system of security and policing" and in "the solving of community problems" (MINT 2005:5). Community-police links are envisioned to "create a harmonious society free of violence and crime" (MINT 2005:9), and, as recently stated by a key official within the MINT, to secure development: "... our security is for our development [and] the fight against poverty means the fight against crime".

This chapter addresses how the PRM went about the task of decentralising and creating Unidade (unity) between police and Povo (people). Based on ethnographic explorations of everyday policing and public police spectacles at Dombe administrative post, a rural, former war zone in the central part of Mozambique, the chapter critically scrutinises the inclusionary and democratic promises of the decentralisation of policing. Several commentators have suggested (e.g., Wisler and Bonvin 2004 and Baker 2002b) that military imperatives continue to animate community policing projects and that the police are only marginally interested in communities and more concerned with re-establishing state control. The Dombe case confirms these arguments, but also illustrates how decentralisation is employed to produce specific community-citizens. In line with the insights of Agamben (2000a) and the general introduction to this volume, the (re)instating of state sovereignty goes beyond ensuring state monopoly over the legitimate use of force and over the prosecution of criminal cases in juridical-institutional terms. It equally centres on gaining the monopoly over the definition of righteous forms of citizenship through acts of inclusion and exclusion. Although current police strategies are cast in the name of unity of "Police and People" - hence evoking inclusion - they are also exclusionary. They rely on the production of certain individuals and groups as security threats to the state and the wellbeing of the community.

In Dombe, this takes a particular politicised form in which the criminalisation of certain forms of conduct and identification is defined not ex- 
clusively by reference to the law as legal transgressions, but also to old war divisions and contemporary party political splits. The strategies therefore echo the wartime police ethos: criminal acts and criminals are presented as embodiments of political opposition and hostility to the Frelimo state, to development and to national unity. In this way, categories of crime are also "modes of expression used to manage social nexuses of power" (Parnell 2003:1). I refer to this as the politics of policing. The concept is intended to capture how the state police, besides combating crime from a legal perspective, engage both discursively and practically in producing the "political community" of people with affiliations to the Frelimo state and their constitutive outsiders, Renamo supporters. The "politics of policing" draw on discursive categories of crime and politics in which crime and criminality are symptoms of political opposition. However, these politics are also performed in the excessive punishments of Renamo supporters.

The arena in which the "politics of policing" is particularly pronounced is at public police events or so-called "crime-combating meetings" where the main themes are the display of prisoners and the fostering of policecommunity links or Unidade. These meetings provide the core case of the chapter. In condensed form, they bring together the core characteristics of the politics of policing, not least the exceptional, often extra-legal methods of policing. These exceptional police methods rely on the discursive production of Dombe as a Renamo wartime-created Zona da Confução (zone of confusion) - as a particularly risk-laden and anarchic place where exceptional measures are necessary to combat crime, to reinstate the law and ensure development. The legacies of the war in Dombe both inform and legitimise the politics of policing with present and future consequences. Before exploring the crime-combating meetings, I trace the production of Dombe as a "zone of confusion".

\section{Dombe as a Renamo territory}

Dombe administrative post lies in the southern part of Sussundenga district. It was a fiercely contested zone during the 16 years of civil war (1977-92). Due to its proximity to Zimbabwe (then Rhodesia), it was one of the areas where the first Rhodesian-trained Renamo guerrillas entered the country only three years after Mozambique's independence (1975) (Alexander 1997). The Ndau-speaking population inhabiting Dombe was also the first to be recruited by and fill the lower and higher ranks of Renamo (Schafer 2001:219). For this reason, Dombe became a non-Frelimo 
state territory, controlled by Renamo, at a very early stage in the civil war. At the beginning of the 1980s, government military force was left in control only of the administrative headquarters - described as an "island" surrounded by enemies - on the fringes of which it fought against Renamo. In 1991, just a year before the peace accord, Renamo managed to capture the administrative headquarters of Dombe, which led to the full dissolution of the Frelimo-state's presence (Alexander 1997).

As in other central parts of the country, the war in Sussundenga district was characterised by struggles over the control of people and territories and had a rural-urban dimension (Schafer 2001). According to West (2005), this was a struggle not over "wealth in things", but "wealth in people". This was characterised by the ability to attract and sustain subordinates. It reproduced a dominant aspect of power in both the colonial era and in the post-independence strategies of Frelimo (West 2005:10-11). The Frelimo state lost control of rural areas in Sussundenga at an early stage. As a consequence, its local representatives had to withdraw to urban centres and a few "communal villages" in the central and northern part of the district. The activities of the state became focused on defence and the forced replacement of people rather than development and administration. This continued to be the case with the post-independence communal villages, which had officially been intended as developmental clusters for rural people, based on notions of popular power and participation within a oneparty state framework. As the war escalated, the villages became little more than counter-insurgency devices of the Frelimo-state. They were used as militarily enforced sites for the control of urban/semi-urban residents and for the forced removal of people believed to support Renamo (Alexander 1997:5-9).

Renamo conversely won ground in large parts of the rural areas. Parallel to attacking party-state officials and the communal villages, Renamo recruited and attempted to gain the allegiance of the residents in areas where government forces were weak or absent (ibid). Dombe became one of the few zones where Renamo managed to set up a relatively extensive system of civilian control, including extraction of labour for food production and to a lesser extent services such as education and health (Schafer 2001:221-23). The system built on chieftaincy (regulados), which, along with spiritual beliefs and Christian churches, had been rejected by the Marxist-Leninist Frelimo government at independence. In what could be regarded as an oppositional political ideology to Frelimo, Renamo not only reinstalled chiefly rule as a governance device, but also celebrated spiritual beliefs and 
traditional ceremonies. In addition, it recruited persons from the Dombe missionary station as teachers and nurses, an approach that garnered some support among religious believers and leaders in Dombe (Alexander 1997). Renamo's system of governance was nonetheless dominated by military concerns. The reinstallation of chiefly rule was accompanied by the local recruitment of Renamo police and intelligence agents, the Mujhibas, who policed the areas in coordination with Renamo soldiers (Alexander 1997:710). According interviews in 2004 , the Mujhibas worked directly under Renamo and their relationship to chiefs was to give orders to mobilise the rural population when soldiers were in need of food and/or shelter. In spite of the military imperatives, local chiefs maintained rights to resolve local conflicts.

The use of chiefs continued after the General Peace Agreement in 1992 when Dombe became one of the areas where Renamo was officially granted administrative control until the first general elections in 1994. The demobilisation of Renamo soldiers, along with the lack of resources from the state coffers to make development improvements and sustain the administration by chiefs, made it difficult for Renamo to maintain an extensive governance system after the war (Alexander 1997). Renamo nonetheless remained in power de facto until 1996, as instanced by open resistance to the re-establishment of state police posts and Frelimo representation after Frelimo won the 1994 elections. As reported in the media (Noticias 1995) and confirmed in interviews (2002-05), PRM officers were on three occasions from mid- and late 1995 driven out of Dombe, firstly by a group of disgruntled members of the population who threw stones at the police and secondly by a group of chiefs who would not allow the PRM to operate unless the chiefs were financially compensated. ${ }^{2}$ In the latter episode, the PRM was forced to leave because of an armed militia group, the so-called Chimwenje (literally meaning "those living in the bush") who had their "bases" in the mountainous areas of Dombe. Despite local uncertainties as to the identity of the Chimwenje, the Frelimo government blamed Renamo. ${ }^{3}$ The government dispatched to the area the Força da Intervenção Rapida (a militarily trained rapid reaction police force), which managed to

2. According to Chief Chibue (interview 2005), the chiefs had in November 1995, with the help of the population, torn down the tents of the PRM officers and, after a meeting with the PRM, forced the officers to leave on the back of a tractor. While the chiefs were not armed, the PRM officers feared armed assault if they stayed.

3. According to Chachiua (2000), the Chimwenje were a group of armed dissidents allegedly associated with opposition parties in Zimbabwe. 
curb the resistance and pave the way for a stable PRM presence. The chiefs agreed to a state presence in return for bicycles and radios, granted to them by the provincial governor.

The open opposition towards state re-encroachment in the mid-1990s owes much to the early commencement of the war and to the kinds of experiences that Dombians had had with Frelimo-state governance from the time of independence and throughout the war years. Due to the early arrival of Renamo, neither Frelimo's post-independence service provisions and development initiatives nor the new local governance structures and communal villages had reached the rural parts of Dombe. Frelimo's institutionalisation of locally elected dynamising groups and party secretaries, leading to the banning of chiefly rule, was only attempted within and close to the administrative centre of Dombe (Buur and Kyed 2005). In these areas, such reforms met with resistance from the local elite, notably chiefs and their assistants. But due to the fact that the new local institutions very soon came under the command of the military as part of the war strategy, they also became unpopular among large sections of the rural population. Secretaries were seen as oppressive, used to strengthen Frelimo alliances and displace people to communal villages. Until the late 1970s, people resisted villagisation. However, afterwards Frelimo soldiers began to forcibly remove the populations to the administrative centre. This move intensified the "war over people" against Renamo, and while many chose (and managed) to flee back to their homes, and therefore to Renamo zones, others remained under the control of Frelimo. Until 1991, Dombe administrative post doubled as a military base and a centro de recuperação, which "re-educated" people captured in Renamo zones. Fleeing the centres was punishable by death.

As Schafer (2001) asserts, post-war contempt for Frelimo-state reencroachment cannot simply be understood as an effect of the coercive character of the state. Renamo's relative success in gaining and sustaining allegiances in rural areas is also important and was intimately related to the rural-urban distinction bolstered during the war. The concentration of Frelimo in urban centres and the party's inability to deliver development inputs to peripheral areas, meant that rural residents felt excluded from the state project and saw it as "urban disdain for those "living in the bush" (Schafer 2001:222). Renamo, which represented itself as the champion of rural interests, capitalised on and further reinforced these views. In Dombe, this was particularly the case in the remote mountainous areas where Renamo had arrived before the Frelimo state had established a pres- 
ence. Here it was not Renamo, but the Frelimo state that was seen as the aggressor (Alexander 1997:10).

In these areas, state representation, including the PRM, was not complete until 2001 because fears of what might happen if the state (and Frelimo) approached these rural Renamo strongholds too hastily and openly (interview Chefe da Localidade, Bunga, 2002 and Chief of Police, Dombe, 2004). Fears of creating antagonism were also reflected in state police practices in the early years after the war. The PRM, according to the chief of police of Dombe, "was not allowed to be aggressive towards people. We just remained seated and if someone did a crime we would call them in politely to the station and tell them that it was illegal, but we would not arrest them." In the immediate post-war years, the state faced what Alexander (1997) has referred to as a "profound crisis of authority" (Alexander 1997:20). The state (including the PRM) was, despite transition to multiparty democracy and the constitutional abolition of the one-party state, still viewed as the agent of the old enemy, Frelimo. Renamo's electoral victories in both 1994 and 1999 in Dombe underscored this situation. Along with the crisis of legitimacy, the state was also challenged in its policing operations, as non-state actors, including chiefs, Renamo officials, the Mujhibas and curandeiros (witchdoctors and/or traditional healers) enforced the law and maintained order. These actors did not comprise a well-organised system of governance with clearly demarcated territorial constituencies, but they did share a common history of opposition towards the Frelimo state.

\section{Outsourcing and (re)claiming state sovereignty}

By the end of 2002, state representatives working alongside the Frelimo party had, in comparison with the mid-1990s, become more proactive in attempting to recapture the zones of confusion. "Re-capturing" combined strengthening political allegiance to Frelimo with administrative and security concerns structured around claiming state sovereignty. Development inputs and formal as well as informal decentralisation initiatives have been at the centre of this double-edged process of marrying state and Frelimo party concerns. Development inputs such as schools, roads and water provision, financed by donors, but launched in the "name of the Hurumende", the emic term for the conflation of state and Frelimo structures, have served as crucial reference points for legitimising state intervention in the spheres of state administration and security. 
The facilitation of a more profound political and administrative re-extension of the state and of Frelimo into the rural zones has most importantly been effected through decentralisation initiatives, beginning with Decree 15/2000. ${ }^{4}$ From 2001-02, this decree provided for state recognition of traditional leaders or chiefs as "community authorities" and for outsourcing a range of administrative, development and security functions to these authorities. Following the wider post-war political commitment to democratisation, the decree was officially launched in the name of inclusion, recognition and community participation in development and administration. Although the local state employed inclusive/participatory aspects to reorder social hierarchies, the strategies also aimed at canvassing support for Frelimo. While the outsourcing of state functions has led to the inclusion of chiefs in governance, it has also been employed as a strategy to regulate forms of non-state authority that challenged state sovereignty. Formalising chiefs provided the state and the Frelimo party with access to those areas where the Frelimo state was physically absent and had few alliances. The recognition ceremonies opened a window of opportunity for post-colonial state officials, Frelimo secretaries and PRM officers to visit remote areas (often for the first time in years) and to disseminate information about government policies. This was followed by the actual outsourcing of the functions to chiefs and the use of the latter for mobilising the population for public meetings, development projects, taxation, election campaigns (2004) and for community-like policing. The chiefs, who were seen as representatives of territorially based communities, provided a pivotal first link between the Frelimo state and populations living in remote areas in a process of reordering rural society.

Following the recognition of chiefs in 2002, the PRM gradually expanded its scope of operation outside the confines of the administrative posts. The PRM worked on two interrelated fronts to expand its form of law and order and to produce a political community: the formal juridicalinstitutional (re)ordering and informal measures of outsourcing policing, as well as a set of disciplinary and educative measures. In relation to formal juridical-institutional reordering, chiefs and their subordinates and assistants have been pivotal. The outsourcing of policing and justice enforcement functions to them has been ambiguously structured by attempts to reclaim state (police) monopoly over the use of force and over defining and

4. For a detailed analysis of the initial steps in implementing the decree in Dombe and the rest of Sussundenga district, see Buur and Kyed 2005a and Kyed and Buur 2005b (forthcoming in Journal of Southern African Studies). 
prosecuting "criminal" acts (more serious thefts, homicide, drugs, fights where blood is spilt, rape of minors [not adults], stabbings, arson, murder threats and insults against state functionaries). Simultaneously, PRM had to ensure that conflicts and misbehaviour not defined as "criminal" (e.g., witchcraft, adultery, insults/threats of a minor nature, beatings that do not involve the spilling of blood, lesser thefts, violations of customary law and land disputes) are solved only by those authorities recognised by the state and not by ordinary individuals or groups of individuals themselves.

Within the sphere of everyday policing, the PRM in Dombe has further developed a set of unwritten obligations and prohibitions for chiefs. They have nonetheless been promulgated as if they are state law and enforced as such. Decree 15 merely states that community authorities have to assist "administrative and police authorities in dealing with all infractions committed and in the localization of troublemakers" (Regulamento do Decreto 15/2000, art. 5d.). In Dombe, community authorities, as well as sub-chiefs, have been obliged to localise "troublemakers", to arrest and question suspected law-breakers and bring them to the police station. However, in a deeply contradictory move, chiefs are both prosecuted when they usurp the state's monopoly of force and when they do not turn in criminals to the police. Recent cases in Dombe illustrate that lack of collaboration with the police and compliance with the locally formulated obligations and prohibitions can lead to severe (physical) punishments. ${ }^{5}$ Conversely, other cases from 2004 illustrate that chiefs and their policing assistants can in practice use physical force against criminals, when and if this is ordered by the PRM. These cases, which take place outside the formal legal domain, highlight core elements of the current process of reclaiming the state's sovereign power by way of outsourcing restricted elements of such power. They illustrate the ambiguities of the process. On the one hand, the prohibition on chiefs from prosecuting criminal cases and using corporal punishment has created new forms of criminalisation. On the other hand, outsourcing of policing as an element of marking out the boundary of the state's sovereign power is often characterised by the employment of measures that lie outside the law. It may seem contradictory that the state police break the law in the very name of enforcing it. However, as Hansen (2005), following Carl Schmitt, argues, sovereignty originates in the capacity to suspend the law

5. One of the chiefs was prosecuted for solving a crime case and the other two for not informing the police about criminals. The cases were not taken to court, but were dealt with at the police station, in two cases with corporal punishment and 24-hour imprisonment. 
(Hansen 2005:171). In this way, the oscillation between playing the legal card and trespassing upon the law is at the core of producing and sustaining state power.

In Dombe, the PRM's use of exceptional measures outside the law nonetheless goes beyond momentarily marking out the boundary between state authority and chiefs: the measures rely on and create more enduring categories of crime/criminals that are not written in law, but are employed in the production of the "political community" and its "Other". This point emerges from the array of police strategies that centre on educating and disciplining the rural population, but also on creating forms of allegiance to the (Frelimo) state. Informal ways of outsourcing policing and creating partnerships with ordinary citizens provide one such strategy. This includes the introduction of vigilança do povo, where ordinary citizens from within the rural population collaborate with the police in identifying criminals and sometimes even act as the extended arm of the PRM. According to the Dombe chief of police, the aim of "people's vigilance" is to unite good law-abiding "community" members with the state police against family members, neighbours and friends who commit crimes or who are suspected of intending to do so in the future. Although "people's vigilance" has an inclusionary element, its employment in Dombe has relied on non-legal categories in terms of which those who do not turn in criminals or are unwilling to speak openly about a criminal case are treated as potential criminals. The "crime" of non-collaboration is essentially presented by the PRM as a symptom of moral decay or confuçao - of incivility, lack of education and erosion of basic values. According to the district commander of police, many years of exposure to war and affiliation with Renamo cause this:

Crime and the lack of knowledge of the law have to do with the war. The majority of the population that lives in Dombe lived in the military bases of Renamo. And for this reason they still have this "Renamista" mentality, this anarchistic doctrine ... it makes people capable of committing all that is outside of normal human conduct. (Police Commander, Sussundenga, 30 August 2004).

Crime-fighting aims to change this mentality in order to reverse the perceived "state of anarchy" said to reign in Dombe. However, policing is also instrumental in settling the question of political affiliation. There are two aspects to the "politics of policing": on the one hand it equates crime/criminals with political affiliation with Renamo, and on the other it is employed to produce allegiance to the Frelimo state. The discursive production of 
Dombe as a Renamo-inflicted "zone of confusion", inhabited by persons generically prone to commit crime, has practical consequences for how allegiance is secured. For security to be restored, a thorough education of Dombians is required. The need to re-educate has legitimised the deployment of exceptional, extra-legal measures. A core form of "education" is the standardised use of physical violence during interrogation and arrest by the PRM on the bodies of persons who have not yet been formally convicted. These forms of extra-legal action enact the notion of Dombians as already potential criminals, who, even without the commitment of crime, can be physically punished. Furthermore, these actions form part of "educating" and "creating respect for the police".

Another form of "educative" measure is to be found in the way community police persons have been employed by the PRM since mid-2004. According to official policy, such persons should only inform the PRM about community conflicts and crime. However, the PRM in Dombe has mandated community members, primarily young men, to patrol, arrest and even beat (sjambokear) alleged criminals and suspects. A central element in these activities are nightly patrols to enforce the so-called lei fora $d a$, which can be likened to a curfew imposed between midnight and $5 \mathrm{~h}: 00 \mathrm{am}$. Although the lei is not a formal law, it is implemented as such with potentially severe consequences for trespassers. After being put into a police cell, a PRM officer interrogates such people. If they are suspected of having committed crimes in the past and/or intending to do so in the future, they are sjamboked by a community police person and put in jail "for a few days, so they can learn not to do wrong and to respect the police", as the Dombe chief of police noted. This outsourcing of "educative" measures, that is, physical violence, to persons from within the local population lies at the heart of the "politics of policing" and reveals its inherently violent side. It is political in the sense that it is predicated on some community members acting upon and combating the enemies within the community. Hence, although community policing aims to reduce crime and target criminals, it also produces the differentiation between good and bad community members. This differentiation is most spectacularly performed in public rituals at crime-combating meetings. As we shall see, there is a correlation between good and Frelimo on the one side, and bad and Renamo on the other.

\section{Crime-combating meetings - enacting unity}

At irregular intervals during 2004, a number of crime-combating meetings were staged in Dombe. During these meetings, prisoners would be dis- 
played in public. The meetings fulfilled a number of functions. According to the PRM district commander, the most pivotal aims were to "make visible" and to encourage unity or partnerships between police and people:

We have to teach people, yes, about crime, because many people, principally our rural population, don't know how to distinguish what is considered crime according to the law. But the most important part of the meetings is for people at the margin to know who we are, to know that the police is doing a job and exist for the people. That is why we also show the prisoners so that the people can see that crime will be punished. Because some out there think that we are sitting on our behind and that the police don't do anything. And also, they should know who the local state official is, the Government people and so on. That is why I present them [Frelimo and state officials] one by one and ask if the people know him and if not I explain, just as you saw me doing Helene (Police Commander, Sussundenga, 31 August 04).

"Making visible" is primarily aimed at making the faces of prisoners known. Equally important was the rendering visible of state and police hierarchies and the desirable relationship between state and community. The venue was organised around the official guests and in accordance with the state hierarchy, including the newly recognised community authority and his subordinates. They were all placed in front of the crowd - or the community, as it were. The community, for its part, was sub-divided along gender and generational lines. Furthermore, the different acts and speeches at the meetings played into making visible and "real" the ideal Unidade (unity) between "community", "community authority" and Police/State/Frelimo.

State officials and police evoked Unidade (unity) throughout the meeting. The police commander's speech centred on collaboration with the police - i.e., vigilance do povo. This was continually enacted in instances of joint singing, clapping, joking, hooting and shouting of slogans, which the state representatives orchestrated at intervals, to the extent that the meetings became celebratory events. While flowers were handed over to the police commander, those present sang Cubatana-Cubatana (unity-unity) accompanied by clapping and dancing. The always smiling and cheerful commander followed suit and saw to it that the song was repeated several times during the event. At times, he would himself lead the singing. $\mathrm{Cu}$ batana-Cubatana speaks of "unity as the winner" and that "unity forever" should exist with especially "the police", but also with "the party" (Frelimo), "the chief", "the people of the government" and "the school director". Jokes from the commander and subsequent laughter from the crowd accompanied the song, rendering the atmosphere light in contrast to the 
otherwise serious deliberations about crime. The enactment of Unidade occurred in parallel with identifying and criticising the practices the state police deemed inappropriate:

The essential agenda that I came with is that of unidade (Cubatana) ... like the song that you sang here now ... This is what we want - the population uniting with the police for us to end with the crime. How are we going to end crime? It is you that have to come and speak out. You may not say it to us [the police], but you have to say it to the chief. The information will arrive to us [the police] in order for us [police and people] to work together. Because a person that robs, a person that kills is not a good person. He is dangerous. And if you don't denounce it, for him to be captured and for him to come and be educated, then tomorrow he will come and kill you. And you leave him doing that because he is your friend or you live in the same area as him? It is you who know him [the criminal] ... We the police are here to protect you, but for our work to go well we have to unite. Our unity is you and you have to tell us secretly what happens ... you are the first police here and the thief is from your family, so you know him.

The order given to be vigilant among family members, friends and neighbours raises the question of unity with and against whom? During the speeches, the commander outlined what types of behaviour were punishable and used concrete examples of past failures to collaborate with the police. At a meeting in Chinda chieftaincy, the commander drew on the case of the son of Simbine, a resident of Chinda. The commander blamed the residents of Chinda for enabling the culprit's repeated escapes: "When you heard the police coming [to arrest the son of Simbine] you climbed a tree and began to shout 'the police is coming, Simbine. Run away!' This you are not allowed to do. When our police comes you have to catch him and help us, because if you don't he will come back and also kill you." In a contradictory move, the commander aimed to position unity and the common interest of police and citizens above the protection of those the police deemed unfit for the ideal community.

A second message conveyed through the meeting was to convince the crowd of police benevolence and to legitimise the monopoly on defining inappropriate behaviour and the prerogative to punish such behaviour. His choice of words reflected his seeming awareness of the negative ideas and experiences of everyday police practices that exist in Dombe: "The police are here to protect you and your goods ... When we arrest someone it is not to kill, but to educate him, so that he knows that what he did was bad and that he has to stop doing it. I never heard that anyone from here died in 
prison. Did you?” The crowd affirmed his words, but whispers at the back of the crowd indicated a different story.

The whispering related to the use of "educate". The term is widely understood and, by quite a number of people, cherished as sjambokear (beatings). While the commander did not explicitly state what "education" means, its local significance was rather clear. The effort to provide a less violent image of the police was thus broken down by between-the-lines messages that preserved the image of the police as capable of corporal punishment. There was clearly a purpose to the commander's non-articulation of "educating" as corporal punishment. During the meetings, "educating" underpinned the message of "who" has the sovereign authority to define "who" the appropriate community-citizen is. The protection of good citizens was hence made inseparable from preserving an image of the police as capable of "educating" and physically excluding the less-than-citizens. Nowhere was this key message of the police-state monopoly of sovereign practices more clear than in the display of prisoners that followed the commander's speech.

At the meetings in Dombe, typically 7 to 12 prisoners were brought in from the district prison. An additional number of 1 to 3 prisoners were taken from the local police station: these, as opposed to the others, had not been formally tried. The prisoners were chosen according to two criteria. On the one hand, they represented different types of criminal activity - murder, rape, drug abuse/sale, theft and insults to the government. This served the educative aspect of the meetings in respect to the law, aiming to give the crowd concrete examples of what forms of activity lead to penalties. On the other hand, the prisoners were former residents of either a close or the same "community" in which the meetings were held. The district commander gave three reasons for this: first, the public display of a prisoner in his own area might have the effect of his not returning after his release, which played on the idea of permanent rather than temporary exclusion; and second, it makes people more afraid of committing crime in the future as they can see that punishment is meted out in their area. Finally, as the commander noted, "[by] seeing the criminals, the people know it is good for them to help us [the police] to fight the misbehaviour of their neighbours and families".

During the meetings, the objective of "making visible" a line of criminals for educative purposes regarding the law became inseparable from acts of "making familiar". When each prisoner individually entered the space between the police commander and the crowd, the first thing he was asked 
to do before disclosing his criminal background was to give his family name and his place of residence:

Commander: [to prisoner] Speak your name and say why you are in prison. Tell it all loudly!

Prisoner: My name is Vasco Manuel

Commander: Where do you come from?

Prisoner: Tussene.

Public x: Hiiiii, it is here, close by!

Commander: What did you do to end up in prison?

Prisoner: I killed someone.

Public x: Hiiiii, Aaaah, yes it is him that killed that senhora. Yes it is him.

Prisoner: I was going out to drink and when I arrived where there were drinks sold I sat down and she came and began to push me. When she pushed me the first time I left it like that, and when she pushed me the second time I left her. When she pulled my shirt I also pushed her twice and then I went home. After some days had passed she said that she was sick and that it was my fault because I pushed her.

Commander: Who killed?

Public x: It was him (people from the crowd point fingers at the prisoner).

As the above extract indicates, the crowd was quite familiar with the prisoners. The commander accentuated familiarity and provided detailed accounts of family and residence. He repeatedly told the offender, "Look what can happen to you if you don't behave". By choosing familiar persons, the prisoners embodied the visible object of law-breakers and the "significant other" of the good citizen. Furthermore, they constituted those who used to be part of the community/family/neighbourhood, but who no longer belonged to it. By directly drawing on familiar relations, the commander implicitly invoked the potential of community exclusion. The joint jokes, laughter, singing and slogans further enacted divisions between the unity of "us" (police/state/Frelimo and people) and "them" (the criminals). The prisoners were deliberately ridiculed by the commander and through the subsequent laughter and hooting of the crowd. The latter were permitted and encouraged to ask questions of the prisoners: "Why did you kill her?" "What did you think about?" "Who is your father?" or "Look at him, he must be crazy. He must have smoked marijuana to speak like that!" What made people laugh was the way in which the commander addressed the prisoners. He used a tone and words in local dialect that normally apply to 
domestic animals or badly behaved children, initially shouting "Come up here criminal! Speak up loud so people can hear!" and sending away the prisoners with the words Budai Mbava! ("Get lost thief"). Budai (get lost) is used in the Ndau-dialect when chasing away domestic goats, dogs and chickens.

Discursively likened to domestic animals and stripped of any form of privacy and legal protection, the prisoners became the momentary embodiment of what Agamben (2000a) describes as "bare life". As Agamben puts it, this is the form of life "that cannot be included in the whole of which it is a part as well as what cannot belong to the whole in which it is always already included" (Agamben 2000a:31). The distinctions drawn between the prisoners and the good community citizens did not, however, become purely a question of law, the legal versus the illegal, criminals versus noncriminals. While articulating the law, the categories of crime/criminals were consistently and implicitly and explicitly politicised along party political lines.

\section{Politicisation of crime - criminalisation of political opposition}

At the crime-combating meetings, the convergence of political and criminal identities and categories came to light in diverse implicit and explicit ways. As a point of departure, the convergence of political and criminal identities had a spatial dimension: the meeting sites were chosen by the chief of police against their classification as what he termed zones "with a lot of confusion" and "where people do not know what is crime and not". Significantly, he would refer to these areas as "war zones" that had been kept in isolation from the state and hence embodied a particular security threat. It is therefore not a coincidence that the meetings were overwhelming held in remote zones in or around the mountains where Renamo was known to be particularly strong. The meetings in themselves marked out Renamo strongholds as in need of extra educational effort.

Such "education" was inherently a matter of producing political identification. This became apparent in the continuous association of law, state and Frelimo in speeches, in representations and in the organisation of the events. The presence of the Frelimo secretary (and the absence of any Renamo representative), sitting between the commander and the state administrative head, was the visible enactment of the ruling party's merger 
with the forces of the state, the police and the law. ${ }^{6}$ This link was directly articulated in the speech of the Frelimo secretary at the end of the meetings. Here the crowd was shown pictures of and told to vote for the Frelimo presidential candidate, A.E. Guebueza: "If we want to preserve the law then we should choose Guebueza and the maize and the drum [the party symbols of Frelimo]."

The repeated shouting of the Viva (long live) and Abaixa (down with) slogans underscored and consistently replayed the link between Frelimo and the law. Repeated at intervals, the slogans formed chains of equivalence (Laclau and Mouffe 1985) that separated the bad (Abaixa) from the good (Viva). The "good" was linked to alliances with the ruling party: i.e., Viva! - Frelimo, República de Moçambique, Unity, community of X, development, vigilance and security on the one hand. On the other, the "bad" (invoked through Abaixa) was linked to Mbava (thief in local dialect), Banditos/Criminosos, faqueamento (knife stabbing), Surumáticos (people who smoke marijuana), Matadores (murders), and "those who insult the state administrator". These slogans are reproductions of Frelimo war rhetoric, which depicted Renamo, now the opposition party, as the embodiment of confusion, incivility and destruction, and Frelimo as identical with civility, law and development (Alexander 1997). Through the war optic, the category of crime becomes, following Parnell, "fungible with other categories that are products of conflicts in which differences have been essentialized" (Parnell 2003:21). Such essentialised differences - Renamo (confusion and destruction) vs. Frelimo-State (law and development) - conversely underscore a criminalisation of a particular set of social relations, which points to how "... crime can be used to distribute power in a range of inter-group social processes with or without the invocation of law" (ibid:20). While the display of all prisoners was underlined by the political messages of the meetings, there were also several cases where the association between law/ Frelimo and crime/Renamo was made fully explicit.

At a meeting in mid-August 2004, a prisoner who had killed a neighbour self-consciously entered the stage shouting "Viva Frelimo!" The commander ridiculed him, shouting, "This one must be maluco [crazy] ... he sounds like he has smoked a lot of marijuana, because a person that does not smoke could never do this. Abaixa criminoso! Abaixa Indisciplina!" The crowd (many of whom did in fact vote for Renamo during the last elec-

6. This link is not a phenomenon confined to political campaigning in the rural areas, but is replicated at larger public meetings and in the speeches of Frelimo national politicians and in media debates. 
tions), at first regarded the courage of the prisoner with amazement, but then burst into uneasy laughter at the words of the commander. The prisoner was from this point on constantly ridiculed as he attempted to explain his reasons for committing the crime. The commander was exceptionally focused on disclosing all his personal data, in the end referring to him as an "example of the bad that has still not been eliminated from the war", and that "it is good that he has now been removed from the community". Arguably, ridiculing this prisoner related to his attempt to fit into or be included in the Unidade. He was consequently punished for breaking the semantic divisions between good and bad, which were produced along party political lines. A criminal could simply not be a Frelimo supporter.

At the meetings in Dombe, it was not uncommon to bring forward a prisoner who had committed insults against the government and neither was it uncommon for these prisoners to be the ones treated particularly inhumanely by the commander. In one particular case in Chinda chieftaincy, the legal protection of the prisoner, an alleged supporter of Renamo, seemed to have been compromised entirely. Unlike other prisoners, he had not been brought from the district prison but had been taken from the Dombe short-term prison, where he had spent a night. He was accused of having insulted the district administrator. At the time of the meeting he had not faced formal charges, nor was he allowed to defend himself. The commander gave his name, family and residential background (which everyone already knew) and explained the version of the story given to him by the Dombe police. When the prisoner was allowed to speak at the end of the meeting, the commander prefaced his version by insisting, "He is crazy. A crazy man can speak yes, but it is all lies." The commander explained his incarceration in party political terms:

Last week we were working in Dombe [the administrator and the commander]. The Administrator on that day explained how one must vote, just like the Frelimo Secretary explains today. He [the prisoner] was not there, but his wife was. We made an example at the meeting - saying that last month the Executive Council was arresting bicycles [at a meeting of Renamo in July 2004 where all bicycles of the participants had been taken by the administration on the official grounds that taxes for them had not been paid]. Hereafter the Renamo Deputy came to Dombe and when he came he saw that the bicycles had been taken. He said bad things about the Dombe administration and took all the bicycles and then went away. Now the Administrator said at the meeting [last week] that this is bad. When the meeting ended the wife of him [the prisoner] went home and told him the example and then he began to insult the Administrator. Can you insult an Administrator? [The crowd responded: 
No!]. No, this is not permitted. If you want to defend your party, then you should go to the police. That is why he [the prisoner] went to prison. And this is not the first time he is in prison. He has just come out of there, because he was the one who organized the Renamo stealing of bicycles from the administration in the first place.

The treatment of this prisoner as always already criminal was legitimised in essential politicised categories. This links issues of exclusion and inclusion to party political affiliations. The prisoner's body became the public display of "bare life", as the significant other of the ideal community citizen based upon transgressing the law, but as life suspended from the realm of the law as such. To underline the message conveyed, the way the prisoner walked and moved suggested he had been beaten severely before the meeting, something he later confirmed in interviews. After the presentation of this prisoner, the script of the meeting revolved around celebrating unity between police and community, as the crowd and state representatives once more sang Cubatana-Cubatana.

\section{Conclusion}

In speaking with chiefs, police officers and state officials, Dombe is said to be a much safer place to live than during and in the initial years after the war. According to the chief of police, crime levels have gone down (from six homicides per month to one every second month), and although there are still incidents of vigilantism not sanctioned by the state, more and more people are collaborating with the police. Yet as the chapter has shown, policing strategies are inseparable from acts and discourses of reordering, separation and exclusion. This has taken place in juridical-institutional terms, as well as in the form of "technologies of citizenship" (Cruikshank 1999) that provide for the (re)inclusion of rural populations. However, at the same time as the technologies potentially include new citizens, they also provide the means to exclude those who do not fit in as a specific kind of community citizen appropriate to the Frelimo state. As reflected in the field of policing, the double-edged process of recognition/inclusion and reordering/exclusion has been structured by a complex reclaiming of state sovereignty. In line with the post-war liberal democratic doctrine, this has, on the one hand, involved the creation of partnerships with rural residents, and, on the other, it has been driven by attempts to reinstate the law and the state's monopoly on the use of force and define licit/illicit forms of conduct. 
From a purely legal perspective, such combination can be seen as a way to delineate a separation between law-abiding citizens and criminals/ law-breakers as well as between hierarchies of authority. This is in no way peculiar to processes of state-making and modern citizenship production (Agamben 2000a, Isin and Turner 2002). What does seem to be a particular characteristic of the Dombe case is the way in which party political affiliations inform the categories of citizen/non-citizen and non-criminals/ criminals. At the level of concrete police practice, this is manifested in the extra-legal measures for combating crime and in the severe punishment and/or non-trial of Renamo supporters. The political and the legal converge, and while operating in the name of re-enforcing the law in former war zones, the law is suspended at crucial points in police action. While the politicised employment of the categories crime/criminal means that criminal activity is always potentially presented by the police as caused by war politics, it also has the effect of taking police work beyond a matter of purely enforcing the law: law enforcement becomes conflated with gaining political allegiance. As reflected in the strategy of people's vigilance, the aim of combating crime has been merged with gaining the allegiance of the rural population and with the boundary-making performance of producing specific citizen-communities. The collaboration with the police is presented as abiding by the law, but also as signs of relative hostility and allegiance to the Frelimo government. At the crime-combating meetings, such politicised boundary-making was taken to the public stage.

In the name of enforcing the law and the unity of people and police, the prisoners were staged as the visible embodiment of the "constitutive other" that used to, but could no longer belong to the community. This was given a political content in the various acts, prisoner cases and speeches that presented criminal and amoral behaviour as equivalent to political affiliation with the opposition party, Renamo. The convergence of crime/criminals and political identities has the peculiar effect of suspending the law in the name of reinstating law and order. This "politics of policing" is equally manifest in the various informal police measures such as random imprisonment and use of force against persons who have not yet been found guilty of crime. This approach falls back on and is to a large extent legitimised by the discursive production of Dombe as a Renamo created Zona de Confução - as a particularly risk-laden place where exceptional measures are necessary to enhance the effectiveness of combating crime-cum-subversion and for reinstating the law. 


\title{
Militarising Politics and Development The Case of Post-Independence Namibia
}

\author{
Guy Lamb
}

\section{Introduction}

In current southern African affairs, there has been a noticeable link between security and development with respect to nation-building initiatives and development programmes. The link has often been forged by means of militarisation, which is a multidimensional process comprised of a dynamic set of relationships between the armed forces, government and society. In essence, militarisation has entailed increased importance being attached to military ideologies, values and beliefs about development and nationbuilding, and how development and nation-building programmes should be designed and implemented. In addition, it has included the excessive use of violence with respect to the management of conflicts and crises that occur as a result of these programmes. Militarisation has also been characterised by increases in military and paramilitary spending and in the size of the armed forces, and to a certain extent an increase in the armed forces' political role and influence in state structures. In Southern Africa countries, pervasive militarisation has mainly become manifest as result of two factors. First, in the contexts of violent insurrection or the perception of dire threat, ruling parties and liberation movements (who later became ruling parties) have adopted militaristic strategies. Second, militaristic approaches and programmes have been pursued due to the beliefs of senior government officials, often for historical reasons, that they are the most efficient and effective way of achieving nation-building. In many instances, militarisation is stimulated by authoritarian tendencies in the relevant political entities.

During much of the 1970s and 1980s, significant aspects of political life were militarised in South Africa and Namibia (which was occupied by South Africa at the time). Influenced by the dynamics of the Cold War, key South African decision-makers perceived South Africa to be the target of a "total communist onslaught" waged on several different levels and directed from Moscow. For South African government officials, the implications of 
this were that almost every issue, domestic and foreign, was potentially a security issue, and thus justified the involvement of the security forces in almost every aspect of South African and Namibian society. Hence the South African state's response to the "total onslaught" needed to be comprehensive, coordinated and total. Consequently, an elaborate network of security committees called the National Security Management System (NSMS) was established as a shadow or clandestine administration using development provisions to further its interests. This essentially was part of the apartheid state- and nation-building processes, but ultimately led to the demise of the apartheid system due to the cost implications.

Shortly after Malawi gained independence in 1964, the Malawi Congress Party (MCP), which had become the ruling party, was afflicted by a severe crisis due to opposition to and criticism of its leader's (Dr. Hastings Banda) authoritarian approach to governance. Cabinet ministers resigned and sporadic insurrections took place, which were suppressed by the security forces. President Banda subsequently initiated a militarised strategy of nation-building and used the MCP as the main vehicle in this regard. One of the hallmarks of this approach was the creation of a youth militia known as the Malawi Young Pioneers (MYP) to be "an army for development" that would target "the new war on poverty, ignorance and disease" (Government of Malawi 1972). MYP training bases were established in 1965 with the support of the Israeli government and offered recruits an educational programme that had a strong emphasis on political indoctrination. Military-style training and drills were also adopted. Approximately 2,000 youths (mainly males) were recruited annually. However, the majority of the recruits were school dropouts whose employment opportunities were extremely limited (Charman 1999). Within a short time, the MYP became an official paramilitary force loyal only to the ruling party. It was responsible for the intimidation and harassment of suspected critics and opponents of the MCP, as well as numerous human rights abuses.

Recent instances of the militarisation of development and nation-building in southern Africa have not been as severe as the South African NSMS approach, but many of their implications may have significant negative long-term consequences for democratic consolidation and socioeconomic development. This trend has been apparent in three distinct areas.

First, militaristic and security-oriented approaches have been employed with respect to the design and implementation of a significant number of development and nation-building programmes. For example, in 1997, Botswana's military became involved in the "Bana Ba Rona" project ("Our 
Children" project) by providing skills training to street children in areas such as carpentry, mechanics and agriculture. The aim of the project was "to arouse their interest in these professions and to instil a sense of discipline in the children" (Ditirwa 2004:23). In Zimbabwe, a government youth development programme was initiated in 2001 for unemployed young people. Government announced that recruits would be trained in agriculture, carpentry and bricklaying. However, the training was highly militaristic, and after a short period it became clear that the objective of this programme was to establish a youth militia loyal to the ruling party. This youth militia has been implicated in the intimidation of supporters of opposition political parties and in human rights abuses (Catholic Commission for Justice and Peace 2004:310-11).

Second, the mandates of security forces have been expanded to include a specific development and nation-building agenda. For example, Mozambique's Defence Act states that the military is required "to maintain the independence and territorial integrity of the state, and to contribute to the promotion of peace and national unity". Consequently, it has been suggested that the Mozambican military assist with the construction and reconstruction of Mozambique's physical infrastructure and assist with disaster relief, which will "contribute to combating both a spirit and an image of uselessness" (Borges Coelho and Macaringue 2004:50-8). In a number of southern African countries, such as Zambia, South Africa and Namibia, defence legislation makes provision for the armed forces to respond to internal disorder, crime and terrorism. ${ }^{1}$

Third, there has been the direct involvement of the security forces in development-related and nation-building projects. For example, between 1996 and 1997, following an epidemic of Contagious Bovine Pleura Pneumonia, a lung disease in cattle, the Botswana Defence Force (BDF) was deployed to control the movement of cattle and separate infected animals from healthy ones (Ditirwa 2004:23). In South Africa, the South African National Defence Force (SANDF) has regularly provided security assistance and logistical support during national elections. As Swaziland has one of the highest recorded HIV infection rates in southern Africa, government has pursued a series of strategies to combat this pandemic, such as a dress code for women. In 2002, the military was ordered to ensure that this dress code was enforced (Army Times, 15 July 2002).

I. See the following pieces of legislation: South African Defence Act (2002); the Namibian Defence Amendment Act (2002) and the Zambian Defence Act (1964), as amended. 
This chapter considers the link between security, development and nation-state building in Namibia by focusing on how specific development agendas and programmes have been militarised, and seeks to explain why this state of affairs exists. This chapter consists of three sections. The first section provides an overview of South Africa's militarisation of Namibia. The second section considers the militaristic and authoritarian tendencies within Namibia's ruling party, the South West African People's Organisation (Swapo). The final section considers the link between development and security in the complex process of nation-building in post-independence Namibia.

\section{South Africa's militarisation of Namibia}

Contemporary militarisation developments in $\mathrm{Namibia}^{2}$ appear to be connected to the era of South African occupation of this territory and efforts to consolidate South African control over Namibia and its people, as well as its responses to armed resistance between 1960 and 1989. This period saw the South African police and military pitted against Swapo, the vanguard of the Namibian liberation movement. In 1975, Angola became independent and a Marxist government was installed that was hostile to South Africa and its occupation of Namibia. South Africa subsequently launched a series of military operations into Angola which lasted from 1975 until 1988.

Between 1972 and 1989, virtually the entire northern segment of Namibia was placed under a state of emergency, which included the imposition of a "dusk to dawn" curfew. By the mid-1980s, over 100,000 troops under South African command were deployed in Namibia; approximately 80 per cent of the population were living under martial law; close to 50 per cent of the population were being directly governed by the South African Defence Force (SADF); and all infrastructural developments in the north, including the construction of roads, were determined on the basis of military necessity (Seegers 1996:222). Military bases often became the centre of economic activity in many military-occupied communities. Consequently, much of the economy of north became highly dependent on the presence of the SADF and associated military institutions. By 1988, in excess of 400,000 people had become reliant on the military for employment, income and security (du Pisani 1988:9). According to Tapscott (1995:159), many local traders "expanded their businesses into multi-million rand ventures and emerged from the war as full-blooded capitalists".

2. Namibia was known as South West Africa whilst under South African control. 
The SADF, in collaboration with Namibian surrogate forces implemented a comprehensive counter-insurgency programme against Swapo in the north. The aim of this programme was to significantly reduce the support (such as food, shelter, transport and protection) that Namibian residents were providing to Swapo insurgents. In this regard, the SADF introduced socioeconomic programmes and deployed teachers, medical personnel and agricultural specialists in northern Namibia in an attempt to "win the hearts and minds" of Namibians and generate some legitimacy for the SADF presence in the area, but also to gather intelligence (Evans and Philips 1988:118, Grundy 1988:61). In the Kavango region, schools were built, boreholes were sunk and roads were built by soldiers. According to Col. Dion Ferreira, a senior SADF military officer, the objective of this approach was to "prove to the rural Kavangos that we had more to offer them than SWAPO”. The SADF also sought to discredit Swapo through propaganda and smear campaigns using print, radio and television media (Herbstein and Evenson 1989:112).

However, the efforts to "win" the support of Namibians in the north were largely undermined by violent counter-insurgency programmes. Communities in the Ovambo and Kavango regions were forcibly removed from their land to create a buffer zone in the Angola border regions. This had the effect of disrupting agriculture in these areas and seriously impoverishing the affected communities (Weaver 1989:90-102). As the war intensified, the security forces became more reliant on terror tactics to control Namibians in the north (Seegers 1996:227). Indigenous "cultural" groups were created by the South African security forces, such as Etango (in Ovamboland) and Ezuva (in Kavango), "to motivate the Owambo people to resist SWAPO and any form of communist infiltration". However, in essence they acted like vigilante groups (Herbstein and Evenson 1989:113-15). Democratic community-based organisations were discouraged from being established. Consequently, traditional authority structures and churches, which were hierarchical in nature, became the other dominant political force in the north (Tapscott 1995:160).

Money from the South African security forces was used to support artificially created political parties, such as the Democratic Turhalle Alliance (DTA), which was an attempt to create a South Africa-friendly alternative to Swapo (Saul and Leys 1995:199). The SADF was also effective in developing networks of informers in the north (Seegers 1996:186), and SADF spies were able to infiltrate Swapo and its allies. Hence, mistrust and paranoia pervaded these organisations. 
The Namibian state under South African occupation became highly militarised from the late-1970s, as the state machinery became geared to support the South African war effort and the SADF's occupation of the north. This development was also affected by the introduction of the South African NSMS in Namibia (Selfe 1989:153). White Namibian males over the age of 18 were conscripted into the military and cadet programmes were introduced at white schools. The objectives of the latter were to "ensure that white youth are able to adjust to the rigour of military life immediately on beginning their national service [and] create an ethos whereby white youth accept the military's goals without challenge" (Evans 1989:284). Black Namibian males were encouraged to volunteer for military service with the SADF surrogate forces being created. Private sector companies (especially in the mining sector) either actively supported the South African war effort or remained quietly complicit, as they were generating extensive wealth in Namibia. For example, from the 1940s, an alliance of South African-owned companies, supported and protected by the South African government, established the fish processing industry in Walvis Bay (Tapscott 1995:156).

Consequently, in 1990 when Namibia became independent, Swapo (which had been elected as the ruling party) was faced with the challenge of transforming a militarised state and society in Namibia. There were major obstacles in this regard. For example, Article 141(i) of the Namibian constitution guaranteed the job security of civil servants who had worked for the South African occupation administration (du Pisani 1994:201). Hence, this transformation was achieved with mixed results. Military conscription was abolished, despite Swapo's desire to maintain it for nation-building reasons. In its election manifesto, Swapo wanted an armed force that would be based on national conscription in terms of which all Namibians of between age 17 and 45 would undergo military service for at least two years. The conscription issue was derived from Swapo's romanticised belief that all Namibians (both male and female) should make a contribution to the building of the nation. However, the political realities directly following independence, as well as funding constraints, prevented Swapo from realising this vision.

Many government departments were demilitarised, but the police and the prison services still appear to subscribe to military values and a militaristic ethos. A clear indication of this was the creation of the Special Field Force (SFF), a paramilitary force that had some of the hallmarks of Koevoet (Crowbar), the notorious police counter-insurgency organisation that oper- 
ated in northern Namibia in the latter part of South Africa's occupation. The legacy of SADF informers and spies still haunts Namibia to date, as accusations of spying for the SADF were regularly employed by Swapo and powerful individuals to discredit critical voices and undermine political rivals after $1990 .^{3}$

Swapo's inheritance of the machinery and institutional memory of a militarised state from South Africa (which it has struggled to transform) is one of the central factors that has contributed to the militarisation of postindependence development and nation-building projects. However, there are other factors that have contributed to this state of affairs, namely the militaristic traditions that emerged during the liberation struggle, and the current authoritarian tendencies that pervade the party. These two factors are considered below.

\section{The militaristic tradition within SWAPO}

\section{The nature of Swapo's armed struggle}

Between 1960 and 1989, Swapo pursued a three-pronged strategy of international diplomacy, domestic resistance and protest and insurgent military action against South Africa. In response, South Africa militarised its governance of Namibia (particularly in the northern regions), created a surrogate military force, the South West African Territorial Force (SWATF), implemented a comprehensive counter-insurgency strategy and launched a diplomatic counter-offensive against Swapo. By 1988, with neither party able to achieve a significant military advantage and the Cold War drawing to a close, the conflict over Namibia's independence was brought to end through a ceasefire and negotiated settlement.

From 1960 to 1974, Swapo's primary strategy in response to the South African occupation of Namibia was to petition and lobby international organisations, such as the UN. This strategy was relatively successful in contributing to South Africa's international isolation, but it did not directly contribute to Swapo's goal of national liberation and independence for Namibia. Swapo was not banned by the South African authorities within Namibia. However, the repressive actions of the security forces prevented any significant coherent and sustained resistance (other than strike action

3. For example, following the launching of the Congress of Democrats (CoD), its leader, Ben Ulenger (former Swapo member and former Namibian High Commissioner to the United Kingdom) was accused by Swapo media of being a South African spy during the liberation struggle. 
and election boycotts) to South African rule from developing inside Namibia during the entire period of liberation struggle. In Tanzania, Swapo created the South West African Liberation Army (SWALA) to be the vehicle of armed struggle, which was declared in 1966. As the liberation struggle became increasingly protracted, greater emphasis was placed on military strategies and action.

In August 1966, the first armed confrontation between Swapo and the South African security forces took place following the creation by Swapo guerrillas of a training and recruitment camp at Omgulumbashe (which was between the village of Okayoko and the Finnish mission settlement at Okwaludhi). Two guerrillas were killed and nine were captured, together with the 40 recruits. Following this incident, there were further guerrilla attacks in central Ovamboland against pro-South African chiefs and some white farmers near Grootfontein. An escalation of these actions, however, was prevented when the South African Police (SAP) sealed off Swapo infiltration routes through Angola and Kavango and Swapo had insufficient access to arms. In 1973, Swapo's armed wing was reorganised and renamed the People's Liberation Army of Namibia (PLAN).

At its inception, Swapo's armed wing was based on the classical Maoist guerrilla model, which meant that the armed wing would be unconventional in character, with its military objective being attrition rather than conquest. However, as Swapo became increasing reliant on Soviet patronage, the armed wing's character and outlook changed, becoming more conventional in nature and with the idea of military victory over the SADF being seriously considered.

In 1975, Angola gained its independence from Portugal, which resulted in Swapo being granted permission to use Angola as a base for its military actions. By 1978, PLAN began operating in units of 80-100 guerrillas (Brown 1995:24-9). At this time, the SADF estimated that there were a total of 462 contacts between security personnel and PLAN in the Namibian operational area. This was to increase to 1,175 contacts in 1980 (Seegers 1996:230). The SADF also reported that, at any given time, approximately 300 insurgents were in Namibia, with some 2,000 grouped in Angola for deployment into Ovamboland, and another 1,400 in Zambia ready to target the Caprivi region (Steenkamp 1989:70-1).

By 1980, PLAN's operational structure started to change, mainly due to the regular incorporation of PLAN combatants' into units of the Angolan armed forces and the almost total reliance on Soviet financial and material support. A force of mobile guerrilla units became an army of semi- 
regular troops who made use of use of trenches, bunkers and outposts. PLAN began to adopt more conventional military structures and tactics. It started to develop mechanised brigades, which were used to protect both military and refugee bases in Angola and transport troops and supplies. Consequently, Swapo's leadership became increasing convinced that military action could ultimately bring about Namibia's liberation from South African rule. From 1982, PLAN's military advantage began to recede due to an increased SADF presence in the operational area and an increase in strikes on PLAN bases by the South African Air Force (SAAF) (Jaster 1990:12, Seegers 1996:230). However, despite these setbacks, the desirability of military action in the eyes of the Swapo leadership did not appear to diminish. This was mainly the result of authoritarian tendencies that had emerged within the liberation movement, with leadership becoming intolerant of most forms of criticism and alternative viewpoints.

\section{Crises and leadership challenges}

In the latter part of the 1960s, a group of seven Swapo cadres who had received military training in China returned to Swapo's military headquarters in Tanzania. This group criticised the Swapo leadership's understanding of military strategy and tactics and perceived the state of military inactivity and lack of weapons to be signs of mismanagement and corruption. In essence, this was direct challenge to the Swapo leadership, who feared that these "China-men" could foment internal dissent or even a coup d'état. Consequently, the Swapo leadership arranged for the "China-men" to be arrested and imprisoned by the Tanzanian authorities (Saul and Leys 1995:44).

In the mid-1970s, a serious crisis beset Swapo, brought about by tensions between the Swapo Youth League and many of the PLAN rank-andfile on one side, and the Swapo executive on the other, over issues of governance and military strategy. Towards the end of 1975, the Youth League began to demand more effective democratic governance from the executive, and insisted that a Swapo congress be held (Katjavivi 1988:106). However, these demands were ignored, and consequently in January 1976 the Youth League declared that the Swapo executive was unconstitutional and invited them to resign (Leys and Saul 1994:130-3).

At the same time, PLAN cadres, including senior military officers, became increasingly dissatisfied with the Swapo executive and expressed a lack of confidence in the political leadership's ability to direct the liberation 
struggle, as there was relative inactivity on the military front. In addition, any overly critical individual was arrested (Cliffe 1994:22, Leys and Saul 1994:133). The grievances of PLAN were not effectively addressed, and as a result a group of several hundred cadres known as the "anti-corruption fighters" began to campaign against perceived financial mismanagement in Swapo. They called for an organisational overhaul of PLAN and the holding of a party congress. In early 1976, the anti-corruption fighters seized control of the central base and a few other satellite camps in Zambia. The Zambian government, at the request of the Swapo leadership and fearing that this unrest could spill-over, sent in several battalions of the Zambian army. The PLAN dissidents were forced to surrender and were then arrested (Leys and Saul 1994:137-8). At the same time, Sam Nujoma, Swapo's paramount leader, and other senior leaders convinced the Zambian authorities to arrest the Youth League dissidents and their sympathisers. With the crisis brought to an end, Nujoma announced in a press statement that "the agents of the South African Region and imperialists have been routed out of our movement and the Central Committee carried out a systematic purge of all traitors" (Windhoek Advertiser, 3 August 1976).

From 1981 onwards, Swapo began to suffer major military setbacks which led to low morale among many of the PLAN cadres. The Swapo leadership blamed this state of affairs on South African spies within Swapo. This provided the rationale for the establishment of a Swapo military security organisation in 1981, which had extensive powers and was answerable only to the Swapo president. This security organisation consisted of 250 personnel, the majority of whom had received security training in the Soviet Union and East Germany. Its sole aim was to identify potential spies, arrest and interrogate them and detain those suspected of espionage. It could even recall Swapo cadres who were studying abroad to Lubango, Angola for questioning. This agency rapidly became an institution of organised terror that embarked on a seemingly irrational witch-hunt.

Those accused of being spies were imprisoned in covered pits, where they had to endure harsh conditions, including poor food and sanitation as well as inadequate medical care. An unknown number died as a result. With many Swapo members being arrested on a regular and random basis, and in the absence of accurate information, intense paranoia began to take root within the movement. By the late-1980s, the situation had become critical. Almost 1,000 Swapo members had been arrested and taken to Lubango. Nujoma's wife was interrogated in 1988, and his brother-in-law, 
Aaron Muchimba, a central committee member, was arrested the following year (Saul and Leys 1995:56-7).

In 1988, a diplomatic agreement was reached that sought to end the Angolan civil war, while simultaneously paving the way for South Africa's withdrawal from Namibia and securing Namibia's independence. Swapo was only a secondary party to this agreement, which had been signed by the governments of South Africa, Angola and Cuba (the main protagonists in the Angolan civil war), as well as the United States. However, the peace agreement was almost scuppered on 1 April 1989, the eve of its implementation, when Swapo launched its largest armed incursion into South Africanoccupied territory. ${ }^{4}$ The militaristic faction within Swapo had grown very powerful, especially under the patronage of the Angolan government and its military. According to a senior Swapo member, Theo-Ben Gurirab, there were many elements within Swapo that disagreed with the peace process and Swapo developed a "split personality" (Weiland and Braham 1994:79). For the militaristic faction, remembering PLAN's heyday of the late 1970s, a major military victory against the SADF would give significant weight to the argument that Namibians had been liberated by Swapo, and not the whims of superpowers. ${ }^{5}$

In an effort to defuse the crisis, senior officials from Angola, Cuba and South Africa held an emergency meeting at the Mount Etjo Safari Lodge near Windhoek on 8 and 9 April. The meeting led to the formulation of the Mount Etjo Declaration, which called for the safe passage of Swapo fighters to designated UN-mandated assembly points. From there they would be given a UN escort to bases above the 16th parallel in Angola, as stipulated in the ceasefire agreement. All Swapo insurgents would be compelled to leave Namibia by 15 April, after which the settlement process would resume. The Swapo leadership accepted the terms of the declaration, and ordered its forces to stop fighting and report to the designated assembly points within 72 hours.

4. Approximately 1,800 PLAN insurgents entered northern Namibia from Angola, which resulted in armed skirmishes between PLAN and Koevoet. The UN special representative for Namibia, Martti Ahtisaari, who was responsible for overseeing the peace process and South Africa's withdrawal from Namibia, had insufficient peacekeeping personnel or capabilities to respond. Consequently, he agreed to a limited redeployment of the SADF to support Koevoet (Weiland and Braham 1994:81).

5. In his autobiography, Nujoma erroneously states that "our PLAN combatants were effective and permanently fighting in all the regions inside Namibia at all times" (Nujoma 2001:271, 389). 
Thus, on the eve of democratic elections and independence, Swapo, which was set to become the dominant political player in Namibia, was an organisation that was largely authoritarian in nature. This authoritarianism had developed paranoid characteristics and had a penchant for militarism. In the absence of countervailing forces either inside or outside Swapo, this type of authoritarianism has persisted in post-independence Namibia.

\section{A culture of intolerance in post-independence Namibia}

Namibia achieved independence from South Africa in 1990, with the result that all South African military and administration personnel were withdrawn. Following the process of drafting a constitution, democratic elections were held in which Swapo received the majority of votes. Over the past 15 years, there have been concerted efforts by government, opposition parties and civil society groups to consolidate the fledgling democratic structures, processes and culture that were established at independence. However, despite these developments, Swapo, which currently has 76 per cent of the popular vote, has consistently displayed intolerance towards critics and criticism of the manner in which it governs.

Despite the constitution-making process in Namibia in 1989 that gave birth to a Namibian democracy in the sense of formal structures and processes, Swapo remained hierarchical and autocratic at independence. The reason for this was threefold. First, the exile leadership retained the reins of power in the organisation following Swapo's conversion from a liberation movement to a political party. In addition, many senior Swapo members, particularly President Sam Nujoma, had achieved a high degree of moral prestige in Namibia, with many party members seeing them as their liberators. Second, the "spy drama" of the 1980s had resulted in the purge of many intellectuals and democratically minded people and groups from within Swapo. Also, Swapo structures within Namibia had faced severe harassment by the South African security forces during the 1970s and 1980s. They had also been starved of funds, which meant that there were very few democratically oriented leaders inside Namibia who could balance out the autocratic exile leadership (Saul and Leys 1995:198). As a result, there had been ineffective pressure from Swapo's rank-and-file to bring about reforms in terms of greater transparency, accountability and representativeness within the organisation after 1989. Third, Swapo had been declared the "sole and authentic representative of the Namibian people" by the UN during the liberation struggle. This, coupled with Swapo's decisive victory 
(57 per cent of the popular vote) in the first national election, meant that it did not have any major electoral rivals to force it to look inward and bring about drastic changes in order to make it more attractive.

Over the next ten years, Swapo became increasingly authoritarian, cantankerous and intolerant of all forms of criticism both inside and outside the party, while at the same time consolidating its overwhelming dominance in the party political sphere. Consequently, the divide between the party and state became blurred, and Swapo's authoritarian culture began to pervade state structures and processes. In addition, those institutions that were established to hold the state accountable were undermined. This created conditions that provided powerful Swapo figures, especially President Nujoma, with the necessary leverage to compel the state to pursue their personal preferences in terms of policy design and implementation. These personal preferences were often militaristic in nature.

In 1994, Namibia's second national elections were held and Swapo won 74 per cent of the popular vote, a 17 per cent increase over the 1989 elections. Early in Swapo's second term, a number of severe public criticisms were levelled at the ruling party that stood in stark contrast to the glowing reviews it had received in the early 1990s: it was accused of failing to deliver much needed socioeconomic reforms and of tolerating the arrogation of power by the newly emergent political elite. Critics argued that Namibia was starting to exhibit patterns that typically characterise autocratic neo-colonial states elsewhere in Africa, and, in the face of ineffective political opposition, was drifting towards becoming a de facto one-party state (Saul and Leys 1995:203, Tapscott 1997:3, Melber 2003c:18, Melber 2003a:134).

According to Melber (2003a:142), this overwhelming electoral support "encouraged the misperception that the state is the property of government". The Swapo leadership started to perceive themselves as being untouchable, and in 1998 the Namibian constitution was amended (after being endorsed by both houses of parliament) to allow Sam Nujoma to stand for a third term as president. The third term issue had previously been muscled through a special Swapo congress. This was almost immediately followed by Nujoma's unilateral decision to deploy Namibian Defence Force (NDF) troops in the DRC. Following the 1999 elections, Swapo increased it popular support base to over 76 per cent of the electorate.

The Swapo-led government took a decision to "forgive and forget" past human rights abuses and injustices in the interests of forging a unified nation. However, the implications of this were that those who had occupied 
important positions within Swapo during the liberation struggle period (and then acquired high political office), and were allegedly responsible for the misuse of power and for committing human rights abuses, were not held to account for their actions, even symbolically. In fact, there has been a conspiracy of denial by the Swapo leadership over the occurrence of human rights abuses in Swapo camps in exile. This state of affairs contributed to the consolidation of an emergent tradition of impunity within the Swapo circles of power. In the words of Lombard (1999), "SWAPO was let off the hook, and allowed to continue its authoritarian and uncompromising culture".

Swapo's antagonistic intolerance of criticism has become commonplace and is widely acknowledged by commentators on Namibian politics. In fact, many of these commentators have been defamed by the poison pens of Swapo propagandists and/or have been publicly harangued and even threatened by senior government and Swapo officials. Critics of government and/or Swapo policies and actions tend to be defined as unpatriotic, racist, tribalist or imperialist. When the judiciary has made rulings in cases that are not favourable to government, the judiciary's independence has been challenged (Melber 2003c:19). Criticism within Swapo structures has become taboo, and dissenters from the official line are dealt with severely. As a result, "the circle of political office-bearers tends to be restricted to those comrades who gained a reputation within and respected the display of personality structures in a command-and-obey system, not for their democratic convictions as independent-minded, autonomous individuals" (Melber 2003c:20).

\section{The link between development and security in post-independence Namibian nation-building projects \\ Development planning and implementation}

At independence, the Swapo-led government was faced with the enormous task of designing and implementing plans, structures and processes that would build a unified nation by addressing the injustices and imbalances that had been brought about over a century of colonialism, as well as place Namibia on a constructive development path that would contribute to sustainable and equitable socioeconomic development and growth. Namibia had also been burdened with massive financial debt, which had been incurred by the South African administration and also arose from an incoherent economy and poor social service provision (du Pisani 1994:200). The 
foundation stone of this development approach was true-blue Capitalism, and the racial and class imbalances of the economy were to be addressed through conservative policies (Saul and Leys 1995:196-7). The private sector was seen to be the central actor in promoting economic growth and creating an enticing environment for foreign investment. This represented a dramatic departure from the socialist orientation of Swapo during the liberation struggle (Dobell 1995b:171).

The Namibian government sought to centralise planning through the establishment of the National Planning Commission (NPC), which was tasked with formulating the first national development plan. This was done to achieve greater efficiency of resource mobilisation and allocation (1995:42). According to the foreword in the National Development Plan (1995:vii-viii), which was written by Namibian President Sam Nujoma, the ultimate rationale of the plan was to:

... cement the foundation for building a truly democratic, transparent and vibrant economy in which all Namibians will be both participants and beneficiaries ... [and] the underdevelopment and dual nature of the economy must be overhauled completely and not just reformed.

The process of planning appeared to have been based on sound and rational principles of consultation, transparency and consensus. However, the implementation of the plan proved to be ineffective and the desired growth rates were not achieved. In fact, in the Second National Development Plan (2001:41), the NPC admitted this. Apart from the structural obstacles that stood in the path of implementing the development plan, there was a lack of necessary administrative expertise within the NPC (du Pisani 1994:216). In addition, the NPC was negatively affected by debilitating internal politics, an ineffective management approach and institutional rivalries with the finance ministry (Melber 2000a:146-7). According to the medium term review of the national development plan, the implementation of the plan was stymied by "inadequate adherence to some of the fundamental principles of planning and plan implementation; poor co-ordination and co-operation among institutions responsible for planning and plan implementation; inadequate implementation of Cabinet decisions; and inadequate financial resources" (quoted in Melber 2000a:148).

Given the pressing socioeconomic needs of the majority of Namibians and the ineffective implementation of development plans, the Namibian government began to adopt a more "quick-fix", hierarchical approach in 
this regard: development projects have become militarised with the armed forces being employed as vanguard players in nation-building initiatives.

\section{The developmentalisation of security preoccupations and nation-and state-building}

The NDF was established by the Defence Amendment Act (Act 20 of 1990) amending the South African Defence Act ( 44 of 1957), in order to "defend the territory and national interests of Namibia". During the period of political transition, it was decided that the integration of PLAN and SWATF forces into the NDF would take place on the basis of parity. This agreement was realised at the top echelons of the military structure, with two of the four heads of directorates at the ministry of defence coming from the PLAN camp and two from the former SWATF forces. The commanding officer of the 1st Infantry Battalion was a former PLAN commander, and the second in command was a former SWATF captain (Nathan 1990:9). Du Pisani (2004:82) eloquently summarises the significance of the manner in which the NDF was created:

Symbolically, [the NDF's] founding legitimised the politics of national reconciliation and nation-building. It was within the NDF that former adversaries were able to interact peacefully as Namibians, citizens of the new state. In addition to its important symbolic role, the NDF also provided the state with coercive capacity, which in turn helped the newly-elected government to consolidate power.

The selection of personnel for the NDF was based on both theoretical and practical examination methods. This proved to be a major barrier to entry for many illiterate former PLAN insurgents. It seemed as though only those who had been given the opportunity to study and train abroad achieved attractive appointments in the NDF or elsewhere in government. This led to a growing sense of resentment among many ex-combatants (Preston 1997:457).

After 1990, the parity agreement was set aside. The ministry of defence adopted an unofficial policy of limiting the numbers of former SWATF members in the NDF to 10 per cent. By 1993, the only NDF commander with a SWATF background was the director of the military school (Preston 1997:459-60). By the end of 1994, approximately 80 per cent of the 6,500-strong NDF were former PLAN cadres. The remaining NDF members were either new recruits or former SWATF, whose expertise and professionalism was valued (Colletta et al. 1996:149). 
Neither the international community nor the new Namibian government envisaged that any assistance would be necessary for ex-combatants who had not been included in the new NDF to become civilians. It was naively assumed that civilian and military returnees, and demobilised SWATF personnel, would be reintegrated into civilian life on their own accord. ${ }^{6}$ Consequently, many former combatants from both the PLAN and SWATF camps began to express their grievances through a number of demonstrations. The government, realising the potential security hazard that a significant group of unemployed and dissatisfied individuals with military training represented, responded by devising a cash payment scheme, designing vocational training programmes in the form of development brigades and including ex-combatants in the general refugee resettlement programme (Colletta et al. 1996:129).

The Namibian Development Brigade drew its inspiration from the highly successful Botswana Youth Brigades and the skills training centres that were created for ex-combatants in Zimbabwe in the early 1980s. The aim of the Namibian Development Brigade was to provide training for, among others, unskilled former combatants, in agricultural production and construction. In 1993, the Development Brigade was converted into a parastatal, the Development Brigade Corporation, which branched out into the realm of small business development but has had limited success, and has been embroiled in scandals involving financial mismanagement and corruption.

However, these efforts had only limited success in addressing the grievances, and by the late-1990s many of the former rank-and-file combatants who had not been incorporated into the NDF remained unemployed. Between 1997 and 1998, there were at least two significant protests by former combatants. Dissatisfied former PLAN combatants staged a sit-in in the parliamentary gardens, while former Koevoet members protested the lack of equity in the distribution of war veterans' benefits and threatened to destabilise the country if their demands were not met.

As a reaction to the ex-combatant crisis, the Special Field Force (SFF) was established in 1996. The SFF is a paramilitary entity, which is located within the department of home affairs, and is structurally part of the $\mathrm{Na}$ mibian Police (Nampol). It is currently comprised of six divisions and is staffed by approximately 7,000 personnel. Institutionally it was born out of the special operations division within the department of police and pris-

6. Only disabled veterans and San soldiers who fought on the South African side received specialised assistance. 
ons, which had a staff of 509. However, since its inception it has grown substantially in size, driven by instances of instability in the northern and northwestern border areas and security concerns within State House. One of the main motivating factors behind its establishment was the absorption of several thousand unemployed former PLAN members who had not been able to benefit from the programmes of the Development Brigade and were proving to be a political liability to Swapo.

Both the NDF and the SFF have been actively engaged in the area of development and nation-building. For example, the NDF, which currently comprises approximately 14,000 personnel, has engaged in de-mining, controlling locusts in the Caprivi region, fire-fighting and apprehending trawlers fishing illegally in Namibia's territorial waters. The SFF has also provided assistance to civil authorities following disasters. However, both the NDF and the SFF are required by law to prevent and suppress "internal disorder and terrorism", and their actions (and associated costs) in this regard have the potential to undermine socioeconomic initiatives in Namibia. The section below illustrates how the developmentalisation of security in post-independence Namibia has been used in a militaristic fashion to respond to discontent and perceived public enemies.

In October 1998, the NDF and the SFF uncovered a small military training camp of the Caprivi Liberation Movement (CLM) in the Mudumu national park. The CLM had aspirations for the Caprivi Strip to secede from the rest of Namibia. This discovery was followed by a largescale deployment of the Namibian security forces in the area, during which numerous Caprivi residents were harassed, detained and interrogated. In early August 1999, members of the CLM attacked the Wanella border post, local NDF bases, a police station, a shopping centre and offices of the Namibian Broadcasting Corporation in the Caprivi town of Katima Mulilo. Street battles between the rebels and security force members ensued, but by that afternoon Namibian security forces had repulsed the rebels. A state of emergency was declared and remained in place for most of August, and over 100 people were arrested and detained. During this time, the Namibian security forces undertook intensive "mopping up" operations to flush out and capture CLM insurgents. Throughout this episode, members of the security forces were implicated in human rights abuses, including intimidation, assault, torture and murder of civilians. ${ }^{7}$

7. During an open meeting with opposition parties, then Prime Minister Hage Geingob, Attorney General Vekuii Rukoro and Minister of Defence Erkki Nghimtina 
The Caprivi uprisings were directly related to the marginalisation of the Caprivi region, which was one of the poorest in Namibia, a combination of its geographical location and the political affiliations of its residents. For example, in 1999 the United Nations Development Programme estimated that the average life expectancy of a resident of Caprivi was 39.8 (compared to the national average of 52.4) and that average individual income was $\mathrm{N} \$ 1,598$ (compared to the national average of $\mathrm{N} \$ 3,608$ ). The Caprivi region had, up until the intervention of the security forces, been a stronghold of the DTA.

During the Caprivi operations, the security forces, in their attempts to capture secessionist rebels, directly contributed to the flight of approximately 2,500 Caprivi residents, many of them members of the marginalised Kxoe (San) community, into Botswana (many have since been repatriated). The majority of these refugees were deprived of their livelihoods. Development and natural resource management projects that had been initiated among this community were disrupted and/or terminated and tourism (which is one of the major income-generating activities in the area) was negatively affected (Daniels 2003:51).

In October 1999, the Namibian government, in an effort to counter unemployment among the youth, launched the National Youth Service Scheme under the ministry of youth and sport. It consisted of a 15-month training programme that would assist recruits to secure employment or setup their own businesses. Its headquarters was established at Berg Aukas on the premises of a failed employment scheme for ex-combatants devised by the Development Brigade Corporation. It was planned that recruits would be able to take classes in subjects such as agriculture, aquaculture, animal husbandry, civic education, first aid, fire-fighting, career guidance, HIV/ AIDS awareness, computer skills and human rights. It was envisaged that recruits would also undertake one year of voluntary community service and would be eligible to receive study bursaries on completing the programme. According to President Nujoma, the patron of the scheme: "[The National Youth Service Scheme] will provide a long-term and effective means of nation-building while developing the abilities of young people through service, learning and training" (The Namibian, 12 October 1999).

The recruits are required to wear NDF uniforms and undergo military-style training, including military drills, either at bases in Katutura or Walvis Bay. At the launch of the scheme, Steve Hoveka, the deputy director

admitted that the NDF had committed certain human rights abuses during the Caprivi operation (The Namibian, 19 August 1999). 
for training and employment, was quoted as saying, "It's self-discipline and self-esteem that we want to instil in our youth, because that [discipline] is the main problem" (The Namibian, 8 October 1999).

However, by early 2001 a crisis had beset the scheme. In particular, many of the skills training and employment opportunities that had been promised at the outset of the programme had not materialised. In April 2001, 52 recruits travelled to Windhoek from Mariental to present their grievances to government. Meetings were held with officials from the ministry of higher education, training and employment creation, which had taken responsibility for the political management of the Youth Service Scheme (The Namibian, 9 April 2001).

In mid-2002, 300 of the 400 recruits at the Grootfontein training centre staged a protest and marched 400 kilometres to State House to hand President Nujoma a petition claiming that they were not being provided with adequate skills training and were spending most of their time bushclearing. They were treated with disdain, accused of ill-discipline and threatened with dismissal by Nujoma, who ordered them to walk back to Grootfontein. Twenty-four of the recruits were arrested for malicious damage to property (and were subsequently expelled from the scheme), and were accused by Nujoma of being "saboteurs" and "enemies of the country". In a speech to the recruits, he threatened that "we are not going to allow chaos in this country. We have the capacity to destroy you all. Don't make a mistake" (The Namibian, 9 September 2002; 10 September 2002; 16 September 2002). ${ }^{8}$

In mid-2004, President Nujoma transferred the youth service to the ministry of defence, with the office of the president being responsible for its budget, so that the Youth Service Scheme could be "effectively and efficiently administered" (The Namibian, 6 September 2004). In early-2005, a bill to regulate the youth service was tabled in the National Assembly, which legislated for the militarisation of this body, as well as its executive control. This resulted in the Congress of Democrats, an opposition political party, expressing concern that the youth service was becoming "akin to a youth militia" and that it could be used for "party political purposes" (The Namibian, 10 March 2005).

The militarisation of development projects, as well as the use of armed forces and the militarisation of youth for nation-building purposes is not unique to Namibia. These methods have been used in varying degree in

8. Twelve of the 24 arrested were charged, but these charges were eventually dropped. 
many African countries, including Ghana, Malawi, South Africa and Zimbabwe. In those instances, where these approaches have been successfully implemented, more coherent nations that are that are more effectively controlled by central government have often been the result. However, as in the case of Namibia, such approaches have yielded violent results, marginalised communities and have damaged the more vulnerable members of society.

\section{Conclusion}

Post-independence Namibia represents an unequivocal case where a firm linkage between security and development exists. This is evident in terms of the militarisation of development and nation-building projects, not only in the manner in which they have been conceived and designed, but also in the way in which they have been implemented. Most notably this has been the case with the state's response to unemployment and secessionist tendencies. This type of militarisation has often been apparently motivated by the ruling party's desire to achieve greater efficiency and effectiveness in government services and the exercise of state power. However, it has generally been intolerant and violent, and at times crude in its delivery. Critically, the security forces, including the military, have not played an overt political role in this regard. Rather they have been exemplary in terms of their loyalty by fulfilling the instructions from their civilian masters without question.

This militarisation of development and nation-building has arisen due to the combination of Namibia's colonial history, the dynamics of Swapo's liberation struggle and the party political environment of post-independence Namibia. South Africa's militarisation of the Namibian state and society between the early-1970s and the late-1980s left an indelible mark on Namibia, particularly the northern areas, as development projects, communities and state structures were militarised in an attempt to consolidate South African control and undermine Swapo's legitimacy. The unique dynamics that shaped the growth and survival of Swapo during the liberation struggle saw the emergence and solidification of an authoritarian culture, which was intolerant and militaristic in outlook. Parallel to this consolidation of the authoritarian culture, paranoid tendencies began to emerge within Swapo (which still appear to exist today), and the leadership became hypersensitive to criticism, which it often interpreted as a threat to the survival of the organisation. Any challenge to, or criticism of the Swapo leadership has been dealt with severely. The main features of this 
authoritarian culture continued to thrive following Swapo's transformation from a liberation organisation into a political party, largely due to the lack of effective countervailing democratic forces within Swapo. Contributing to this state of affairs has been the lack of significant opposition political parties, with the result that Swapo dominates the party-political sphere in Namibia. One of the major implications of these developments for individual Namibians is that access to government-controlled resources and career advancement within government, one of the major employers in Namibia, are largely dependent on an individual's loyalty to the ruling party. 


\title{
Struggling for the City \\ Evictions in Inner-City Johannesburg
}

\author{
Jacob Rasmussen
}

\section{Introduction}

The ten-storey Manhattan Court residential building, in the inner city of Johannesburg, is threatened with eviction. With the assistance of the leftist social movement, Inner City Forum (ICF), the house committee has arranged an information meeting in the basement of the building. The summer rains have flooded the stairway and water is running down the walls in the basement where approximately 150 residents, representatives of the ICF and two delegates from the municipality have convened. The basement echoes with excitement: rumours have it that the executive mayor of Johannesburg, Amos Masondo, will attend the meeting. The residents, supported by the ICF, hope to confront him with their disappointments and fears. Most of all they hope for a resolution of their problems - the threat of eviction. To the outspoken disappointment of the residents and ICF, the mayor never shows up.

Although the meeting addresses specific concerns of particular residents, the broader theme of the discussion is the future of the inner city of Johannesburg. The three actors present (the residents, the ICF and the local government) represent differing, often opposing views and take different positions in relation to the city and where it is heading. The residents, for their part, wish to stay in and make a living close to the resources of the inner city and fear that they will be evicted. The ICF claims to serve the poor and marginalised people of the city and advocates the radical democracy it thinks has been betrayed by local government. The local government delegates, all claiming to represent the ANC's political transformation, have assumed responsibility for what they consider to be central and indispensable regeneration projects in the inner city. As part of their mandate to pursue this agenda, they are also politically responsible for what they see as unfortunate but sometimes necessary evictions. The political struggles among these groups about access to the city and its resources are the primary concern of this chapter. I argue that in order to understand these 
struggles, attention must be paid to the interconnected imaginaries and political practices of the three actors.

Manhattan Court has been short-listed for investigation and if the local government inspectors decide to hand in a court application, the next step is eviction. The meeting in the basement is an attempt to halt the process that might eventually lead to eviction of the residents. The residents fear that an eviction will not only push them out of their flats, but also out of the inner city. On an everyday level, their struggle is therefore about the right to stay in the city. The ICF, on the other hand, sees the threat of eviction as evidence of the municipality's violation of the constitutional rights of its citizens. Finally, the local government is attempting to renew and refurbish the dilapidated residential areas of the inner city. This takes place through urban regeneration projects that link development and crime prevention in intricate new ways. This struggle becomes not only a struggle about who has the right to define the city, it becomes a struggle for survival. For the residents threatened by eviction it is survival in the city; for ICF it is the survival of the recently gained democratic rights and, as such, democracy itself; and for local government it is the survival of the city.

During the meeting in the basement of Manhattan Court it became evident that this struggle about the city and who has the right to stay in it involves different perceptions of what constitutes democracy and development. The struggle about the city becomes a struggle over whose notion of democracy and development turns out to be dominant. In this process, questions concerning citizenship are raised in which the notion of "who the people is" plays a pivotal role. To explore the relationship between the different perceptions and ideas about democracy, development and people, Thomas Blom Hansen's (2001) distinction between sublime and profane dimensions of politics is useful. He argues that the state, which is his primary concern, is constitutively split between a profane dimension and a sublime dimension. The profane dimension is politics and governance in its everyday form. It is the "rough-and-tumble of negotiation, compromise, and naked self-interest displayed in local politics" (Hansen 2001:225-6). Contrary to this, the sublime dimension is what governance and politics should be. It refers to the illusions of a higher rationality and justice associated with the state as institution (Hansen 2001:226). These two dimensions exist parallel to each other. One exists as everyday governance where buildings crumble and people are evicted. The other is the ideal of fairness, justice and equal opportunity. Seen through this lens, democracy, development and citizenship are equally marked by ambiguity: all of them have a 
profane and a sublime dimension, which are evoked in different ways and by varying people.

In its sublime representation, the ANC is the party that successfully fought for democracy and development for all South Africans. The sublime ANC protects the rights of the poor and the marginalised. However, in everyday politics and governance, the ANC carries out evictions locally. Hence, there is also a profane reality to the party. Amos Masondo, the mayor of Johannesburg, incarnated part of the ambiguity. The residents waited for him to hear their grievances in the hope that he, representing the sublime ANC, would listen and stop the evictions. When they were left with civil servants from the municipality, it was, in their view, the profane side that they were encountering. ICF, on the other hand, did not trust the ANC much. In their version, the ANC in the local government had long ago betrayed ICF's hopes of a true people's democracy.

A similar split exists in regard to the "people". As suggested in the introduction to this volume, the people as a category is split between a fragmented multiplicity, and a unified and sublime body - respectively denoted as the people (in italics) and the People (with a capital P) (Agamben 2000b:30-1). Whereas the People is inclusive and captures the political existence, the people is the multiplicity of oppressed and excluded bodies. If we apply Agamben's distinction between People and people to the regeneration projects and the struggles surrounding them, we note that the council's urban regeneration project operates with a People - law-abiding, tax paying and decent on the one hand. On the other hand, the urban poor are construed as the people of Johannesburg - illegal, criminal and non-paying. The first category has the right to stay in the city, whereas the second group has but limited claims to its space and opportunities. However, both ICF and the residents of Manhattan Court operate with alternative renditions of People and people, where the People are those who fought and suffered during the apartheid regime. Although all three actors evoke different notions of People and people, all employ anti-apartheid narratives as political technologies. As Jensen (2001) argues, narratives of the apartheid past are recycled in order to come to terms with and negotiate a complicated present. It is the struggles between People and people played out through constant invocations of a reconstructed past that I trace in this chapter.

Of the three actors who left the meeting dissatisfied and with bad headaches caused by the nitre from the soaking cement walls in the basement, I begin with local government followed by the ICF and the residents. I first explore how, and the extent to which, local government links urban re- 
newal and crime prevention. Second, I trace two forms of resistance to the development projects, the ICF and the residents threatened by evictions, and how the struggles impact on the production of urban space. Before getting this far, I find it necessary to give a brief introduction to the recent development of inner-city Johannesburg.

\section{Inner-city transition}

\section{Some recent developments}

Struggles to define urban space, determine who can access its resources and how it should develop are by no means new. Since the first serious challenges to the apartheid regime in the mid-1970s, inner-city Johannesburg has been at the centre of the struggles. Through the 1980s and early 1990 s the inner-city neighbourhoods gradually changed from being exclusively white to becoming predominately African (Morris 1999:57, Emdon 2003:222). Parallel to this development, many financial institutions and businesses, which made the inner city attractive in terms of jobs, money and security, moved away to the northern suburbs (Bremner 2000:186-7). As resourceful residents moved out, poor black residents moved in and they now inhabit most residential buildings. The buildings have not been maintained for decades and are in a state of dilapidation. When the new government came to power, they took a serious look at the inner city. Arguing along lines of development and urban regeneration, they claimed that the run-down buildings firstly posed a hazard to the people living there, and secondly, that the decaying inner city constituted a security problem for the city as a whole. For them, the danger is embodied in the urban poor, whose presence perpetuates criminality and decay. In the case of Johannesburg, the inner city is perceived as a threat to not only security but also to the development of a functioning democracy (Bremner 2000:191). For the wellbeing of the residents as well as for the survival of the city, local government argued that it was compelled to act.

In recent years, several projects ${ }^{1}$ have aimed to save the inner city from crime and ongoing decay (Bremner 2000:191). However, the dangerous

I. The government and the city of Johannesburg initiated the "Igoli 2002" project, which has been followed up by the long-term plans "Igoli 2010" and "Igoli 2030", all focusing on economic growth. The Gauteng provincial government launched the "Blue IQ" growth strategy supporting 10 prestigious mega-projects in and around Johannesburg. This strategy focuses on tourism and transport and hopes to attract foreign investment (see Tomlinson et al. 2003:18). 
and violent urban environment poses an obstacle and a threat to the realisation of the projects. In an attempt to deal with the problems, the executive mayor of Johannesburg, Amos Masondo, identified inner-city regeneration, prevention of crime and enforcement of bylaws as the top three priorities for the inner city (Thale 2002). The Johannesburg Metropolitan Council released the "Igoli 2002: Transformation and Implementation Plan" in 1999. One of the central themes of the plan was the redistribution of utilities in the city. Full privatisation was discussed, but the final result was the privatisation of a few minor assets and the corporatisation of water, electricity and waste management (Morris 2001:102-5). This initiated a shift in the role of the state and its local institutions in relation to utilities: the state would no longer be directly involved in or responsible for delivery but would instead adopt a more regulatory role (Morris 2001).

Since the racial segregation of the inner city collapsed, the face of the city gradually changed: from the mid-1980s the city was primarily occupied by black residents. Alongside the decay and lack of maintenance of buildings, the city suffered financially from unpaid service bills (Oelofse 2003:93). The debts formed part of the argument for the outsourcing and corporatisation of utilities, and the expectations were for higher efficiency and better delivery. The corporatisation of city management is allegedly about greater efficiency, however, as Morris (2001) argues, there were also political reasons for the choice of outsourcing. Most politicians would, for example, find it against their political interests to shut down the electricity in a poor area, whereas a private company would not be obliged to have the same considerations (Morris 2001:99).

Parallel to the outsourcing, local government also launched three different programmes: a bad buildings programme, a better buildings programme and an unsafe buildings programme. The programmes aimed at dealing with the transfer of buildings to wealthier and investment-willing owners, maintenance and demolition (Bremner 2000:190, Thale 2002). All three programmes affect the residents of the buildings in question: they will have new owners with the possibility of facing increased rents because of investment costs, or they will be evicted if the building is set to be demolished. Residents can also be evicted if they are in arrears on rents or services. 


\section{Politics of the city}

\section{Linking crime and urban renewal}

The Igoli projects, the various building programmes and the corporatisation of utilities have resulted in a process of evictions all over the city. In 2002, the city council established a task force to launch the programmes and to execute the evictions where they were deemed necessary. The task force is constituted of different law enforcement agencies and the corporatised utility companies related to the municipality, especially water, electricity and sanitation (Thale 2002). Since the establishment of the task force, several buildings have been cleared and a number of buildings have been shortlisted for investigation. Following the investigations, the task force hand in court applications for further evictions to be authorised (Thale 2002). As is implied in the introduction to this volume, political transitions, violence and crime are often linked. In this way, seeing underdevelopment as destabilising, dangerous and as potentially generating violence and crime justifies exclusion of the urban poor, because they pose a threat to development projects and hence to the future of democracy (Duffield 2001a:7).

The task force's multi-agency composition is indicative of a renewed commitment to partnerships across different state and government agencies. The multi-agency approach has become an increasingly important element and strategy in the post-apartheid government's endeavours to resolve the intertwining problems of crime and development. These links imply linkages between urban renewal and crime prevention, in so far as police and water and electricity companies now work together in a special unit. One consequence has been that many criminal matters are resolved through the application of municipal bylaws. In two cases, residents were evicted from buildings for contravening the health, fire and town planning bylaws (Majola 2002). In both cases, the buildings were targeted through the city bylaws, but the real target was the criminal drug dealers and prostitutes allegedly living in the buildings (Majola 2002).

The creation of the interdepartmental task force signalled the merging of urban renewal and crime prevention in very real ways. The task force was the brainchild of Inner City Regional Director Yakoob Makda. He explains the rationale behind the task force: "All kinds of crime, including the continuous violation of city by-laws, constitute obstacles towards making a world-class African city of Johannesburg" (Majola 2002). In the quote, he contrasts the regeneration projects and the aim of creating a world-class city with crime. Furthermore, he defines crime broadly to include violation 
of bylaws. By defining crime in such terms, any person contravening the bylaws will constitute an obstacle to the regeneration of the inner city.

Within the first days of its existence, the task force targeted buildings in the inner city neighbourhoods of Hillbrow and Joubert Park. One of the first buildings to be chosen was Armadale Place on Bree Street in the central part of the city. It used to be an office building for the corporate sector. During the general decline of the inner city, it was taken over by slumlords who converted it into illegal residential space for the urban poor. In this way, Armadale Place illustrates quite well the general trend of urban decay that the city has set out to rectify. At the time of the evictions, the building housed approximately 2,000 residents and the debts for utilities had passed half a million Rand (Russouw 2002). As with other evictions, the Armadale eviction turned violent, not least because it was carried out by what have been dubbed the Red Ants.

The Red Ants have become a familiar sight in the Johannesburg inner city, as they carry out many of the evictions. Evictions have been outsourced to a private security company, Wozani Security. To carry out its dirty work, Wozani Security employs the Red Ants. The name "Red Ants" refers to the red overalls the men wear and the great numbers they come in. As they walk in line up and down the narrow stairways and carry out furniture on to the street, they resemble a line of crawling ants together pulling a load. The Red Ants are employed on a day-to-day basis to get the residents and their belongings out of the building in question. They are often homeless people from the inner-city streets or from the squatter camps on the outskirts of Johannesburg. They are paid between R25 and R50 per day. Given that they are recruited from among the poorest and most marginalised people in the city, it is no surprise that they have a reputation for stealing from the people they evict.

Officially, Wozani must send out a warning notifying the residents to vacate the targeted buildings. However, residents will often not receive the warning or will ignore it and stay on, which leads to clashes between the Red Ants and residents desperate to safeguard their homes and belongings. In the case of Stanhope Mansions, the building across the street from Manhattan Court, residents claim not to have received any warning ahead of their evictions. A large group of Red Ants and Wozani security people came on the afternoon on 26 August 2003 and asked the residents to assemble their belongings and leave their flats. When the residents locked their doors, the Red Ants used crowbars to break in and carry out the furniture. Some residents blocked the doors but were dragged away. A 
fight broke out between a woman and the Red Ants, whom she accused of stealing from her. In a show of solidarity, women from Manhattan Court blocked the entrance to Stanhope Mansions to obstruct the Red Ants' access to the building. Other residents began to carry the furniture back into the building. The police were called in and they managed to clear the way for the eviction to take its course.

The account of the eviction of Stanhope Mansions echoes other residents' tales of evictions in Johannesburg: "Then they came; then they broke the door". Residents harbour few doubts that local government is to blame for their misfortunes. This has led to questions being raised about the political legitimacy of the council, as Wozani Security has been associated with the city council. After a series of evictions involving bad publicity, a media spokesperson from the municipality made a public statement to distance the council from the practices of the Red Ants: "The council utilises the service of Wozani security ... Wozani is a private security provider - not a state agency" (The Star 2003). In a depoliticising move, the council exonerated itself of blame and made the issue of eviction into one in which technical matters of urban regeneration became a question of bylaws, law and order and appropriate city use. Neither the residents nor the ICF bought the argument. They insisted, in different ways and for different reasons, that evictions were political and that the council must and will be held accountable.

\section{Inner-City Forum}

\section{Slogans and mass actions}

Social movements and academics from the left have critiqued local government's urban renewal projects, which they see as representing increased privatisation and social segregation. A central point of the critique is the council's notion that the inner city is allegedly lost to and infected with crime (Bremner 2000:191-2, Tomlinson et al. 2003, ICF 2004a). These critics fear that the projects will only deepen some of the social, economic, spatial and racial gaps, and push the existing problems aside (Tomlinson et al. 2003). Johannesburg lawyer Erica Emdon (2003) echoes these critiques in her analysis of the reconfigurations of citizenship and social rights after 1994. Referring to the recent developments in inner-city Johannesburg, she states: 
They [the urban poor] want to stay in the city center. In the end they may be forced out, not by apartheid laws but by the new democratically elected local council that sees itself as promoting a clean, tidy, well-run city able to compete globally with other big cities. The council is unlikely to be very tolerant toward people who cannot contribute and who constitute obstacles to its vision of the city. (Emdon 2003:229)

In recent years, the Anti Privatisation Forum (APF) has carried this analysis on to the streets by protesting against privatisation in different sectors of South African society. APF shares the anxiety about the future presented in the academic accounts of prospects for Johannesburg. APF was founded in 2000 as a direct response to the Igoli 2002 plan. The political language of APF has a long history, dating back to the struggle against apartheid, and the founders of APF are experienced political and academic actors. Trevor Ngwane, one of the chairpersons and leading activists, is a former ANC member who is dissatisfied with the ANC's alleged failure to realise a radical democracy. Ngwane was excluded from the ANC at an internal disciplinary hearing for not following the party's political line. The forum's ideas about radical democracy and social justice have earned APF support from left-wing academics, who through their analysis of the post-apartheid city focus on the increased segregation between poverty and wealth. Furthermore, a sizeable section of township residents and other urban dwellers have joined forces with the APF in specific campaigns in the hopes that the forum might change the current political course in favour of a greater focus on socioeconomic issues. Although there are questions about the actual strength of the movement, APF has emerged as an influential player in the inner-city political scene. The APF made particular headlines during the World Social Summit for Sustainable Development in Johannesburg in 2002, where the forum and its affiliates managed to field about 30,000 demonstrators along the lines of other global anti-globalisation protests in Seattle and Genoa. ${ }^{2}$ Furthermore, the forum has been particularly active in relation to the privatisation of water and electricity in Soweto (see Lars Buur's contribution to this volume).

APF is an umbrella organisation for a number of smaller and more specialised social movements. One of the affiliates, the ICF, aims to stop evictions in the inner city. As evictions are not a phenomenon restricted to

2. Commentators have argued that to a large extent the APF draws inspiration from the global movements. It is beyond the scope of this chapter to discuss this in more detail. 
Johannesburg, there are similar movements in both Cape Town and Durban. However, Johannesburg is the economic and industrial centre of South Africa and developments there therefore take on different proportions and seem to happen faster. Consequently, the exchange of experiences among the anti-eviction movements in these three major cities seems to be limited to a one-way flow from ICF in Johannesburg.

In line with the APF, the ICF advocates radical democracy and shares the fear that the corporatisation of utilities distances the poor citizens from the state. Over time, the status of South Africans will change from citizens to customers. An APF spokesperson phrased his critique of increased corporatisation in the following terms: "Basic rights cannot be commodified" (Mail \& Guardian 2003). To help realise radical democracy and social justice, ICF engages in outreach work in communities threatened by eviction. ICF is a volunteer organisation, but two members are in charge of the administrative work and the planning of activities. One has a degree from a faculty of social science and the other a background in a law school. The ICF volunteers constitute a small core of activists who try to mobilise and motivate inner city people to support each other in the face on threatened evictions. ICF encourages people to act as human shields in front of buildings in the hope of obstructing Wozani and the Red Ants from carrying out the evictions. "Mass actions have the largest impact", a female ICF activist confesses to me. According to the ICF activist Charlene, the primary tasks for ICF, apart from mobilising people, are to locate threatened buildings, advise residents about their rights and options and draw public attention to the case. ICF activists are more experienced in navigating the bureaucracy in the city departments than most inner-city residents, and are therefore better at accessing information about threatened buildings.

ICF realised that an imminent eviction might threaten the residents of Manhattan Court when they obtained a document from the department of housing listing a number of inner-city buildings that were under investigation. Charlene distributed ICF flyers and offered advice and support to the residents. She assisted the house committee in planning the meeting in the basement and accompanied and represented a delegation of residents to the company managing Manhattan Court. The residents expressed doubts as to the ownership of the building and claimed that their rentals were administered incorrectly. The department of housing subsequently explained that the maintenance account had been drained and the debts for utilities had reached large proportions. As a way of pressuring the managing company and the local government, Charlene suggested non-payment of rent 
and utility bills as a way for the residents to gain some leverage regarding the threat of eviction. ${ }^{3}$

When Charlene is not around at Manhattan Court, ICF is present through their flyers and posters displaying their campaigns and slogans. In the months leading up to the elections and the "ten years of democracy" celebrations in April 2004, APF launched a "no vote" campaign. As part of the campaign, ICF presented its overall aims as political demands; "No Vote until: evictions stop. No Vote until: water and electricity cut-off stop". For APF and its associates, not voting became a way of flagging their dissatisfaction with the ANC and the lack of serious party political alternatives. However, it also represented a way of demonstrating that the ANC had betrayed the legacy of the anti-apartheid struggle: it was a way of fulfilling that legacy and promoting the promised radical democracy.

As mentioned above, the narratives of the struggle against apartheid are recycled in countless ways to give meaning to one's actions or to discredit those of others. Narratives of and references to the anti-apartheid struggle and its inherent association with oppression have the quality of reducing an issue to a dichotomy between "good and evil" (see Buur 2001b). This is evident in the ICF flyers. Referring to the past, they suggest that local government is immoral and evil. Under the headline, "Reconstructing Apartheid", one flyer reads:

Where Apartheid regulation kept the metropolitan centre of Jo'burg for whites and the township reserves for black labour, the government is today engineering a city and society by targeting the poor. The move to evict tenants from inner city buildings is brute force used by the city bosses to bleed the centre and push the "dirty, unsanitary, unviable and criminal" poor black [back] to their labour reserves. (ICF 2004a)

Presented this way, the profane dimensions of local governance seem to reflect a view of a split people - one that, in effect, equates the poor urban residents of Johannesburg with Agamben's notion of the oppressed and excluded bodies of the people (Agamben 2000b:30). From an ICF standpoint, the idea of the sublime state seems to be far off and still only an idea. ICF attempts to expose the rhetorical mechanisms employed by local

3. Non-payment campaigns are by no means an ICF invention. Inner-city residents have engaged in such campaigns against high and increasing rentals since the 1980s, when no agency was defending the rights of the African residents (Morris 1999). At the time, non-payment was successfully aimed at the landlords and not, as at present, at the municipality and its associated departments. 
government in its portrayal of the inner city as lost and infected with crime. Using irony, ICF deliberately employs the adjectives "dirty", "unsanitary", "unviable" and "criminal". These terms are, they suggest, what local government really thinks. By using these terms instead of the benevolent terms of renewal, development and regeneration employed by local government, the ICF attempts to convince the residents of the real intentions of council. The tactic of revealing the process of implicit, subtextual inscription of immorality on the bodies of the poor is evident in other ICF flyers: "Criminalising the poor" and "Inner city residents have already been found guilty even before they are accused" (ICF 2004a, 2004b). By portraying the "city bosses" as immoral, the ICF aims to undermine their credibility and the political basis for the regeneration projects.

\section{Manhattan Court}

\section{Living with the threat of eviction}

Living in the city is imperative for the residents because the city provides the possibility of work and prospects for a better life. The threat of eviction is therefore not only a question of shelter or a question of rights or violation of rights, it is a question of economic and social survival (Madsen 2004b). Laura's one-and-a-half room flat provides her with the possibility of running a shebeen ${ }^{4}$ and renting mattresses to two young Zimbabweans. Longiswe is selling plants at a nearby market and his flat and balcony are packed with plants and serve as storage room when the market is closed. The old lady, Sanele, runs a provisional kindergarten for some of the kids in the building. Other flats are sub-let to illegal immigrants, some housing up to 12 people. In other words, the flats are a means to make money. The location in the inner city is crucial for the residents for earning money, because it provides job possibilities both in the formal and the huge informal sector. Participation in the informal economy is complex and includes sub-letting flats, running shebeens, street-hawking, etc. Part of the local government's regeneration projects for the inner city is the elimination of the informal economy and the provision of formal markets in the inner city. This is where local government and residents are most directly at odds, as govern-

4. A shebeen is an illegal bar selling beer, sodas, booze and cigarettes. Shebeens are typically run by women. In Manhattan Court, at least five of the 108 flats housed a shebeen. 
ment attempts to distinguish between housing and places of production or livelihood directly conflict with the need to secure livelihoods.

However, the fear of being pushed out of the city and away from job possibilities is not the only consideration. In narratives and conversations, accusations of violated democratic rights, government betrayal and of politicians with secret agendas resurface frequently. Laura states adamantly: "The state has given us the subsidy for the flat, so they can't take it back". However, her narrative is riddled with anxieties and fears of betrayal. Unfortunately for the residents, their anxieties have substance, as the housing authorities claim that residents harbour false perceptions regarding the subsidies for the flats. The director of social housing clarifies: "The subsidies can be claimed back if the residents do not live up to the terms of the agreement". Most residents are guilty of not fulfilling their contractual obligations in relation to the subsidies. Running a shebeen and sub-letting flats are illegal, as is trading with the subsidies, and the repeated rent boycotts not only conflict with the contract but also increase the debts for utilities.

The residents' perceptions were based in a prior ownership arrangement from 1995. Manhattan Court was one of seven buildings in central Johannesburg selected for a pilot cooperative housing project. The residents were granted government subsidies for the flats in 1995 and were obliged to run the building collectively. Managers and administrators were appointed and saving plans for the maintenance of the buildings were agreed upon. Because of disagreements between residents and managers, Manhattan Court broke away from the collective project in 1999. Three years later, in 2002, the Johannesburg high court liquidated the building due to the high debts. Because of the subsidies, the residents perceived themselves as the rightful owners of the building and claimed not to understand how liquidation and sale were possible without their permission. The liquidation sparked-off a large-scale rent boycott. The residents legitimised the rent boycott in terms of anxiety, insecurity and fraud - they felt cheated and feared that their rentals would not be used for maintenance and utilities but would instead disappear into the pockets of unknown landlords and managers appointed after the liquidation. The residents continue to argue that the liquidation took place on illegal terms. Portraying themselves as marginalised and victimised, the residents argue that the existing threat of eviction is based on illegal actions against them. As such, they perceive the threat of eviction as a violation of their democratic rights. The awareness of these rights is recited in numerous conversations ("We know we have rights!"), as if they are attempting to convince themselves of the existence of the rights. The call to 
democratic rights seems to be the straw the residents clutch at. Taking up the ICF proposal, the residents use a rent- and service-payment boycott to pressure local government and landlords.

The residents of Manhattan Court are preoccupied with rights rather than obligations. The sense of rights draws its strength from narratives of the past, where narratives are recycled and the past thus gives new meaning, and a contextualising legacy to present actions. Like numerous other South Africans, the residents of Manhattan Court have an acute sense of entitlement due to the sacrifices they made during the anti-apartheid struggle: they have already paid the state and the democracy in advance. Their argument is that they have suffered oppression and fought against apartheid and therefore they should share in the realisation of democracy. The struggle has become an inexhaustible resource for every South African citizen. To argue for one's own rights as a victim of apartheid has become the primary political language in South Africa (Buur 2003b).

Democracy becomes tangible for every South African on election day. In the two weeks preceding the elections in April 2004, appraisals of democracy and the democratic right to vote are echoed everywhere in Manhattan Court. The celebration of "ten years of democracy" is a celebration of the country's achievements in the first ten years since the victory over the oppressive apartheid regime. The struggle for democracy is praised in rich terms. At the same time, the ICF-supported "no-vote" campaign is at its peek - people have to decide whether to spoil their ballot or to vote. The dilemma of the residents is neatly captured when they praise their democratic right to vote in one breath, only to complain about the ANC in the next. Rumours of a stay on evictions until after the election only further complicate the residents' decisions: is the ANC only "fishing for votes", as some residents put it, or has the ANC really stopped the evictions? Whether true or not, the rumour only accentuates what the residents already know: the state and the ANC party are deeply involved in the eviction process. Further confusion is created by an ICF flyer claiming to quote the mayor, Amos Masondo. The flyer revives an old rumour about the mayor and his alleged plans for the inner city. According to the flyer, Amos Masondo has stated that, "people who earn less than R3000 a month cannot afford to stay in the inner city" (ICF flyer 2004a). Some residents fear a hidden political agenda that aims to push them and the other urban poor out of the city.

On election day, the majority of the residents decide not only to vote but also to vote for the ANC, in spite of their uncertainty. The ANC gains 
two-thirds of all votes nationwide and consolidates its already strong position in Johannesburg. Desperation does not suffice to explain the residents' decision to vote for the ANC. Rather, we must explore the residents' imagination of democracy. While the ANC has a sublime dimension that is associated with the struggle against apartheid and the installation of democracy, the party is simultaneously involved in highly profane activities. It is this sublime dimension of the ANC the residents identify with in their narratives of the past. The residents' call, "We know we have rights", is an invocation of the link between the people and the ANC. However, the statement also testifies to the anxieties residents harbour about the ANC in its everyday form. Residents constantly argue and debate among themselves as to which ANC they are dealing with. As it is, they chose, once again, to vest their hopes in the sublime. If the residents of Manhattan Court had decided not to vote, they would have rejected participation in the democratic processes and, thus, would have rejected the system and the party that is supposed to protect the rights they cling to.

\section{Conclusion}

\section{Ambiguities of citizenship and state}

In this chapter I have traced the different goals for and perceptions of inner-city Johannesburg from the respective standpoints of the local government, the ICF social movement and the residents of Manhattan Court. To realise the prospects for developing the inner city, the local government links urban renewal and crime prevention, which, among other things, has resulted in the creation of the interdepartmental task force. The urban poor are caught in the middle of the process and fear they will be excluded from the city. In the introduction to this volume, the editors discuss sovereignty and the power to make political exceptions, and argue that the effect of an exception is the exclusion of "some body from the political community and the protection provided by its laws and rights". By focusing on bylaws, the local government in Johannesburg allows the task force to remove offenders against the bylaws from the inner city. Linking urban renewal and crime thus allows the local government to make a distinction between bylaws and social rights, and thereby paves the way for making a political exception of some citizens' social rights.

In order to understand the local government's decision to make an exception that will exclude a group of people - the urban poor - from the inner city, I find it useful to keep Giorgio Agamben's distinction of the 
concept of "the people" in mind. The local government claims, on the one hand, that the regeneration projects are in the interests of all citizens of Johannesburg.5 On the other, it perceives the urban poor as a threat to the achievement of the world-class city. Local government refers to the citizens as a strong and unified entity, that is as the equivalent of Agamben's idea of People (with a capital P) as one integrated body (Agamben 2000b). Opposed to the citizens are the urban poor who, in Agamben's terms, become the fragmented and excluded bodies - the people (in italics) (Agamben 2000b). According to Agamben's abstraction, the People and the people exist in parallel, but both are striving to eliminate the other in order to realise themselves (Agamben 2000b). By linking urban renewal and crime prevention, the urban poor are construed as a non-paying and criminal group of individuals. Construing the urban poor as criminals justifies an exception being made of their social rights and enables the exclusion of the urban poor from the inner city. Furthermore, it posits the citizens as a unified body. Following the discourse of the local government - in which underdevelopment is perceived as dangerous and destabilising (Duffield 2001a) - development and security merge in what seems to be both the solution and the only valid alternative if the inner city is to be saved.

The right to participate in the democratic processes, the creation of an all-inclusive constitution and equal rights for all was the primary achievement of South Africa's transition from apartheid to democracy. The residents of Manhattan Court are concerned about their social rights. Democracy has been praised as the central building block for the future South Africa, and the celebration of "ten years of democracy" only invigorates the residents' sense of democratic rights as being imperative. The residents find it difficult to understand how their social rights can be set aside, and therefore they describe possible eviction as immoral. For the residents, there is a discrepancy between the ideal political democracy portrayed in the celebrations for "ten years of democracy" and the exclusive politics practised by local government. The hopes the residents attached to the mayor as described at the outset of this chapter, and the fact that most of them end up by voting despite considering otherwise reveal that they continue to place their hopes in the sublime dimension of the South African state. However, these hopes are often compromised by local government's politics of exclusion as reflected in the regeneration projects. In other words, the profane

5. In an interview regarding the task force and the regeneration projects, Inner City Regional Director Yakoob Makda states, "The communities are fully behind us and Jo’burg will become cleaner and safer again” (Majola 2002). 
dimension threatens to extinguish the sublime dimension for a group of already marginalised citizens.

The ICF, for its part, would have approved of a collective decision by residents not to vote. For the ICF, there exists only a profane dimension of the state and the sublime dimension is still a dream to be realised. Though the ICF is in apparent support of the residents, it also has other and more far-reaching goals than halting evictions. By evoking images of past oppression, the ICF hopes to convince South Africans that the failure and unkept promises of the government lie squarely with the ANC and make people realise the advantages of a radical democracy. The regeneration projects of inner-city Johannesburg only employ crime prevention and refurbishment of dilapidated buildings as an excuse for excluding the urban poor. Privatisation and corporatisation of previously state-owned assets, as well as the urban regeneration projects are weapons in this war on the poor.

The struggle for the inner city is a question of survival of different ideologies, visions and people. The three key actors are positioned at various levels within South African society, and the struggle for the city therefore plays out as clashes of profane practices and politics versus sublime imaginaries and ideologies. These clashes are part and parcel of the continuous reconfiguration of urban space in Johannesburg, in which security and development are merging. Imaginaries of the past have become a central weapon, in so far as each of the three actors tries to inscribe immorality on the other - by criminalising the poor or by comparing government policies to apartheid oppression. 


\section{IDENTITY, VIOLENCE}

AND RIGHTS 



\title{
Through the Lens of Crime \\ Land Claims and Contestations of Citizenship on the Frontier of the South African State
}

\author{
Steffen Jensen
}

\section{Introduction}

In Nkomazi, a large rural area, located at the extreme northeastern corner of Mpumalanga province in South Africa, two main kinds of violent conflict were played out while I conducted fieldwork there in late 2002. First, several bouts of vigilantism - or popular justice - erupted in sites around the area. In each of these cases, groups of people apprehended and beat up alleged criminals. Modus operandi included beatings with a sjambok (a long rubber whip), burning of houses and evictions. It was not always the same group of people perpetrating the violence. Sometimes the violence was managed through traditional authorities, with local chiefs in a controlling position. At other times, the violence seemed to be perpetrated primarily by groups of young men. ${ }^{1}$ The second kind of violent conflict in the Nkomazi area emerged around the issue of land ownership, land use and access to development. In one case, reported by the local media (Shongwe 2000) and analysed academically (Rangan and Gilmartin 2002), elderly women who claimed to have had their land taken away from them by the local traditional authority walked naked through the streets of Buffelspruit, a village in Nkomazi, in protest against what they saw as a land grab. However, for the traditional authorities, it was not an issue of land grabbing, it was part of a state-endorsed project to develop commercial farming. As traditional authorities often enjoy privileged access to the state, the women were subsequently taken to prison on charges of public indecency. We shall return to these development projects later. Suffice it to say that the struggles over them are indicative of how development and violent conflict are intimately connected, as groups vie for control of and access to resources, which are being reconfigured in times of radical social and economic transformation.

Taking these observations about violent conflict in Nkomazi as a point of departure, this chapter explores how and to what extent the two seem-

I. See also Ritchken (1995). 
ingly different forms of conflict are related. I will offer two different interpretations. First, in Nkomazi land is being increasingly capitalised and class distinctions reconfigured, creating social inequalities among hitherto relatively equal residents. In this climate, discourses of crime provide a language for differentiating between legitimate members of a moral community and those who have no such claims. As land in Nkomazi is communal, all members of the community are in principle entitled to it - a right forfeited by sigebonga, the embodiment of that which ruins the community. In relation to the overall theme of this volume, accusations of crime, or issues of insecurity, function as a way to legitimise reconfigurations of inequality. Rather than being a question of who is getting rich and who is further impoverished, power struggles concern the definition of and actions against criminals.

However, we might provide an alternative reading of the link between vigilante practices and the reconfiguration of class. Seeing that some of the violent practices are carried out by indigent young men - sometimes against those who possess, sometimes against people like themselves - we might suggest that the language of crime provides an alternative to constituting oneself as a moral person through traditionalised age and gender hierarchies. ${ }^{2}$ This entails young men attacking those who prevent the achievement of moral status, that is, marriage, home and work, through illicit and immoral means such as witchcraft - often the prerogative of the old and the powerful. ${ }^{3}$ In other words, discourses of crime explain to some people why they have not made it, while for others, they legitimise the fact that they have.

In these remarks, there are a number of theoretical propositions about the "moral community" and about "crime" that need to be clarified. First, in the popular rendition, and indeed in much academic literature, both community and crime are taken for granted. Crime is the illicit and illegal pursuit of resources or violent acts against other people: we know implicitly what constitutes a crime. In similar fashion, communities are

2. This argument correlates with ideas proposed by Geschiere (1998) and Comaroff and Comaroff (1999) respectively in their analyses of witchcraft.

3. As Niehaus (2001) argues, it is often the relatively rich and resourceful who accuse poor people of witchcraft, citing jealousy of their success as the motive. This alternative reading of the evidence does not, to my mind, exclude or invalidate the first interpretation. The two forms of witchcraft accusation exist in parallel in places like Nkomazi. This only illustrates the pervasiveness of witchcraft accusations. Witchcraft constitutes, as argued elsewhere (Jensen and Buur 2004), a semantic universe through which misfortune can be explained by rich and poor. 
made up of people sharing one or several traits, which are also recognisable. However, as the introduction to this volume stresses, neither community nor crime can be assumed to exist as necessarily substantive, trans-historical categories. On the one hand, they are sociological facts that can be described, but on the other they are also cultural products of discourse. They come into existence as people, groups and institutions talk and act them into existence. ${ }^{4}$ Second, they exist in an interdependent relationship with one another. Whereas community is the benevolent locus of people's lives and futures, crime destroys these very aspirations. As crime destroys, it becomes the constitutive outside of the community: it constitutes the outer boundaries of the community. In this way, and in a seemingly paradoxical manner, while it is outside, its definition and naming constitutes the inside. To produce a moral community is hence partly about eradicating crime from its midst. Practices to eradicate crime - what I elsewhere term "everyday policing" (Buur and Jensen 2004) - are then midwives of community. Hence, discourses of crime are intimately linked to the exercise of authority. Carol Greenhouse writes that "categories of crime do not derive from some universal scale of evil or public consensus as to interests, but from the way systems of authority make themselves known and maintain themselves ... The interests of authority and its needs for self-legitimization determine crime, then, not the nature of the acts in question" (Greenhouse 2003:276). Greenhouse suggests an intimate link between crime and authority, or between crime and those who carry enough weight to define what constitutes the moral community. As we shall see, that is an unsettled question in Nkomazi - and depending on which individuals or groups manage to stabilise what constitutes crime, the moral community may shift dramatically. In this way, crime and community are not only inherently unstable concepts, but one of the battlegrounds on which local power struggles are fought.

The argument will proceed along two parallel trails. First, I explore how and to what extent we might talk of a reconfiguration of class, and how it intertwines with other identity markers such as nationality, ethnicity, gender and generation through notions of culture. Second, I explore different forms of everyday policing in Nkomazi. In conclusion, the link between reconfigurations of class and everyday forms of policing is revisited.

4. In relation to the constructed nature of crime, see, for example, the volume edited by Philip Parnell and Stephanie Kane, entitled Crime's Power (Parnell and Kane 2003). In relation to community, see Jensen (2004) and van Beek (1999). 


\section{At the frontier}

Nkomazi could easily be conceived in terms of marginalisation. It used to form part of the former homeland KaNgwane. KaNgwane was, in apartheid rationality, the homeland of the Swazi in South Africa. Without going into detail about the homelands' position in the broader South African political economy, ${ }^{5}$ suffice it to say that the homelands became the dumping ground for surplus labour and the place where labour was reproduced away from the production sites in the industrial, mining and commercial farming sectors. KaNgwane was no exception, although there was less migration to the mines from there than from nearby Gazankulu, "home" of the Shangaans, or from Bushbuckridge in the homeland area of Lebowa, from where the North Sotho were said to come. ${ }^{6}$ Nkomazi is the poorest section of former KaNgwane, far to the east and away from South Africa's economic centres. In spite of a renewed focus on empowering the former homelands in the post-apartheid moment, the distance to economic centres has not been reduced. Rather, it has been perpetuated, as the South African economy sheds low-skill jobs at a fast pace (Terreblanche 2003). The rising unemployment has dire consequences in a region where unemployment, according to a conservative estimate, already stood at 50 per cent in the late 1990s (Thornton and Feinstein 1998).

The isolation of Nkomazi is not only economic. Squeezed as it is between Mozambique to the west, Swaziland to the south and the Kruger National Park to the north, the area is like an appendix to Mpumalanga province. In the public imagination, and even in academia, the former homelands are still in a marginal position in South Africa. With a few notable exceptions (e.g., Ritchken 1995, Delius 1997, Niehaus 2001), South Africanist academia seems to have approached the subject of the homelands as an aberration destined to disappear with the fall of apartheid, and therefore not worth exploring in or of themselves. But rather than focusing on marginality, it seems more appropriate to invoke the concept of

5. For elaboration, see, for instance, Sparks (1990), Ross (1999), Mager (1995), Delius (1997), Niehaus (2001).

6. This differentiation between the various ethnic groups seems to be the result of the apartheid regime's management of ethnicity, where some groups were seen as particularly fit for certain forms of labour. This was probably most evident on the mines, as Moodie (1995) has argued, since recruitment to the mines was ethnically differentiated. Few Swazi went to the mines, being instead one of the preferred choices for agro-industrial labour. 
the frontier, understood as the intersection of multiple historical, political and economic fault lines.

In Nkomazi, at least five different frontiers can be identified. The first is international: both Mozambique and Swaziland border the area, with significant consequences for livelihood and identity. This frontier is especially important, as Mozambicans are often associated with crime (Crush and MacDonald 2002). Second, Nkomazi is the meeting point between several ethnic groups, particularly Shangaan and Swazi. Relations between Swazi and Shangaan are not always amicable, not least due to the easy association of Shangaans with Mozambicans. Swazis often view Shangaans through stereotypical notions of the foreigner - that is, they take the few jobs there are, they are lazy and they steal. The third frontier is the racial one between white commercial farmers and residents of the former homelands, or labour reserves. Although black and white are still separated, this frontier is under intense negotiation on two fronts: on the one hand the land claims and restitution process, which promises to restore thousands of Africans to the land whence they were forcibly removed (James 2001), and on the other, municipal reforms that have united formerly white and black residential areas under one municipal structure. Fourth, there is a governance frontier between traditional authorities and democratic rule, between chiefs and local government. This frontier is also being intensely contested. These power struggles are nowhere more clearly evident than in relation to the controversial Communal Land Bill. November 2002 saw the release of its eighth draft, which was immediately contested by traditional leaders, including the Zulu king, who invoked the war in KwaZulu-Natal in the early 1990s to illustrate what would happen if the act were passed. In 2003 it was finally passed as a compromise between individual and collective land rights. Land was handed over to a representative committee on which tribal authorities would occupy an important role. The final frontier is that of class, which will be explored in more detail below. These frontiers should not be conceptualised as clear-cut dividing lines but rather as zones of intense negotiation, competition and ambivalence. Furthermore, they never figure alone but intertwine with the other frontiers, as well as with gender (Sideris 2004) and generational structures (Oomen 2004).

\section{The reconfiguration of class}

Although Nkomazi never was a place of equality, the 1990s have offered new opportunities to some Africans while further impoverishing others. 
Most new opportunities were created by the development initiatives that flowed from the democratic revolution and the political will to advance the interests of Africans. Some problems stem from a general economic downturn, while others seem to relate to government interventions (Marais 1998, Terreblanche 2003). ${ }^{7}$ One of the prime drivers behind the production of African elites has been the public sector, especially what has come to be known as "developmental local government". As much as it was a vehicle for Afrikaner betterment during apartheid (Posel 1999), the public sector now appears, not least in Mpumalanga, to promote black economic empowerment. Class is also reconfigured through agriculture, access to land and rural development projects to create a class of black commercial farmers. As the slow and often problematic process of land restitution and reform (James 2001) gets under way, some Africans have accessed land and resources that enable them to improve their lives. These land claims, while on the one hand involving negotiation of the frontier between white commercial farming areas and the former homeland, KaNgwane, are simultaneously creating a class of black commercial farmers - the relatively rich - and a class of the much poorer.

Modest attempts to boost commercial agriculture in KaNgwane took place in the 1980s, but it was not until the ANC took over that these attempts gained substance - especially after 1999. Ben Cousins, land activist and academic, asserts that promotion of emergent farmers should be seen in relation to an unresolved debate within the ANC: should rural reform be aimed at production or at equity, rights and historical redress (Cousins 2000)? Cousins has a number of reservations about the attempts to promote production over historical redress. First, a relatively large amount of government funds would be dispensed to a small number of the rural poor (Cousins estimates this to be less than 2 per cent), who are already relatively well off. Second, allocating land for commercial farming would mean alternative land use would suffer, such as collection of firewood and other activities carried out mainly by the poorest, (Shackleton et al. 2000). Third, ownership of land is currently unresolved. Hence, Cousins argues, it is problematic for communal land to be "handed over" to traditional authorities. Whatever the outcome of the debate, traditional authorities currently possess the right to allocate, at a price, communal land for residential as well as commercial use. These processes, integral to rural development

7. Marais (1998) and Terreblanche (2003) both assert that the neo-liberal policies have failed to generate more jobs and that the increased poverty might, in part, be attributed to these policies. 
reform in the homelands, create particular structures in which the reconfiguration of class is articulated. In Nkomazi, this is intimately related to sugar.

\section{Culture and class on the rural frontier}

As one drives west over the cattle-grid marking the entrance into Nkomazi on the road to Tonga, one is struck by the difference between verdant, white-owned farmland and the brown-grey colour of the former homeland, where desolate peri-urban habitation stretches seemingly without end. However, further inside the area one begins to note vast tracts of land green with sugar cane. These fields form part of the so-called sugar projects. They have emerged in a partnership between TSB (Transvaal Suiker Beperk), the Land Bank and Nkomazi residents. Sugar projects have been initiated by local community members who formed a cooperative. The Land Bank and TSB supply farming implements, machinery to transform veld into agricultural land, 24-hour irrigation systems, cane and other necessities for farming sugar cane. TSB is contractually obliged to buy all the cane from emergent farmers, who must subsequently service their long-term loans and the short-term production loans from the bank and from TSB. The projects incorporate ideas about social partnerships in which state, market and civil society enter into committed cooperation. The (white) corporate sector assumes a social responsibility. The racial face of South African agriculture changes and becomes slightly darker. The projects have meant an inflow of resources into Nkomazi that is rare and much needed for groups of people who would otherwise not stand a chance of becoming farmers. The barren land of Nkomazi is transformed and there is still much land left. The development projects have, in other words, delivered what they promised. So how can one utter a word of concern?

On a macro-level, it seems the Land Bank favours sugar projects above all others. Hence, Nkomazi is turning to monoculture in spite of the risks this involves in a global market, ${ }^{8}$ but the projects have other implications for local livelihood strategies. The proponents of the projects and of commercial farming argue that the land was empty and under-utilised, but livelihood strategies on the rural frontier are complex and rely on practices other than farming. Of particular importance are practices of natural resource management, which commercial farming potentially endangers

8. Ironically, as I was leaving one of the project sites, the radio announced that CocaCola would not buy as much South African sugar as before. 
(Shackleton et al. 2000). Examples are, for instance, the collection of firewood, to which people in the area no longer have access. Second, there are all the invisible proceeds from the "empty" land: ingredients for medicine (muti), wood for carving, etc. Of all these, particularly the amarula tree has multiple uses (muti, firewood, construction, processing of fruits for commercial sale and celebrations, to name some of them). When transforming the land into a site for monoculture, many of these resources, used in particular by the poorest - often women - will disappear or diminish considerably.

Other issues impact the level of participation in the projects and proceeds from them. Maria, a 33-year old newcomer to a particular village, confirmed the presence of projects and initially evaluated them positively. She explained that this would mean irrigation 24 hours a day: "Before the mielie meal [corn] died because it lacked water but now, with the projects, the water comes". I asked whether she was a part of the project. This time she said no. "My ancestors are not from here. I will have to go to Naas [a village some twenty kilometres away], dig them up and bury them here again". She continued after a while, "So maybe it is good for people, but it is not good for Maria!" This excerpt of our conversation provides insights into several principles of exclusion that lie at the intersection of rights and belonging. Anna had no ancestral claims to the land and hence she did not expect to be included in the sugar projects. The principle of exclusion also applies to ethnicity, where only those with the cultural rights to stay in the area, that is, Swazi-speakers, are entitled to participate in the projects. Cultural rights of belonging have, in other words, immense importance for the allocation of land and inclusion in the projects.

Although some sugar cane farmers bought land with their new-found wealth from public sector employment, most participants in the projects were older men. There were specific historical reasons for this. When the apartheid regime forcibly removed people from the areas that became white commercial farmland, tribal chiefs and structures went first and picked the best land along the riverbanks for themselves and their relatives. In one particular village, most arable land had been allocated by 1970 when new waves of migrants came to the village after the removal of yet more people. These newcomers hardly ever received any land unless they were able to pay considerable sums for it. Mozambican refugees and migrants, who came in the late 1980s and early 1990s, constituted the third wave of migrants. They almost exclusively received housing plots. Hence, in Maria's village, as with others, there exists a social hierarchy in which those who came first 
form a rural aristocracy (literally so, because they are often related to the chiefly, royal family) of old men (as women seldom have land). As part of rural development in general and the upcoming sugar projects in particular, the early 1990s saw the construction of dams around Nkomazi. In this particular village, the dam was built in such a way that some people lost access to land. They were compensated, but their new tracts of land lay away from the river and away from the emerging irrigation opportunities. The now irrigated land in the village was of poor quality and the tracts were too small for commercial sugar cane farming. Hence, the chief and the tribal authorities made bigger plots out of the existing ones. In this process of land distribution, the land went primarily to the royal family, his headmen and members of the tribal council.

The way in which land was allocated and the resources in relation to the sugar projects were distributed was articulated through the cultural sphere. As Gerald Sider (1986) argues in his study of class and culture in Newfoundland, culture is intimately related to processes of class and capitalist formation, where culture emerges as the social organisation that "fits" a particular capitalist moment. Sider writes: "It is precisely these traditional social forms that are bent into the service of production for ... capital (if not directly created by this service)" (Sider 1986:37). Hence, what Hobsbawn and Ranger termed the "re-invention of tradition" took place at a time of reconfigured capitalist formation (Sider 1986). As an example of the argument, a particular culture involving migration patterns, a specific gender and age structure and modes of livelihood emerged in what became the homelands around the time of the mining boom in Southern Africa. As the formal sector began to shed jobs in the 1980s and onwards, cultural patterns were being reconfigured. In Barbara Oomen's words, "tradition is on the move" again (Oomen 2000).

This makes culture an unstable concept, fluctuating with the reconfiguration of capital. But culture is not merely the by-product of capitalist formation. It is, Sider argues, the register through which class contradictions are articulated. If we relate this to Nkomazi, it becomes clear that the invocation of ancestral claims, notions of ethnic differentiation and national belonging are part of a particular moment of class reconfiguration and a "defence" for particular interests and class claims. Those not deemed part of "our culture" or "our tradition" are relegated to an inferior status. Tradition, that is, culture, becomes a lived practice of distinguishing between those with entitlements and those without - or as Sider argues regarding the relationship between class and culture, "Culture enters the dynamic of 
class because ... it is where class becomes dynamic; where the lines between antagonism and alliance come together and apart" (Sider 1986). Hence, the class antagonisms between young and older elite men are dynamic because of the position that the young occupy within culture, which means that they cannot simply be excluded outright. This also explains why the position of young men is so ambiguous: while they experience increasing marginalisation and economic exclusion, they might still claim access to recognition and access to resources, including state development projects. This ambiguity is largely what animates the gendered and generational contestations.

Culture is always embedded in particular institutions and Nkomazi is no exception: traditional authority occupies a critical position in settling what "culture" is about. As noted above, evidence suggests that it is imperative to be on a good footing with the chiefs. As the analysis by Rangan and Gilmartin (2002) also indicates, chiefs act as gate keepers by virtue of their right to allocate land. Although highly contested, the ANC's invocation of the chiefs as "custodians of culture" posits them in a central position. This is not only in regard to cultural practices as artefacts - which is what the ANC would like to limit their role to - but also, as Sider points out, in determining what social relations are congruent with tradition and the culture of the people, and hence, which resources different groups can command. As development in the form of commercial farming projects was pivotal in the allocation of resources, development entered the cultural sphere and was directed by it, in spite of ANC's dedicated attempts to target the "poorest of the poor".

The cultural edifices of the rural frontier helped direct resources in such a way as to stabilise rural elites, especially in the form of a gerontocracy, that is, the rule of the old over the young. The inequalities that existed were also perpetuated in the post-apartheid moment. Aided by tradition and culture, those who already had access to resources benefited once more in the developmental mode of the post-apartheid moment. In parallel with the gerontocracy's cashing in on commercial farming projects, the young men especially suffered, as the downscaling of the mines and the economic restructuring resulted in decreasing employment possibilities for young men migrating to the cities. Hence, while some benefited from the political and economic changes brought about in the 1990s, others suffered a loss of livelihood. As we shall see, these events perpetuated inter-generational conflicts, even if the sugar projects turned out to be less remunerative than expected. Initially these projects promised great change and carried tales 
of infinite riches for those who could participate. However, during the late 1990 s, the sugar projects, especially in the village mentioned above, failed to generate the income they were supposed to. Many reasons exist for the failure that I will not detail here. ' In spite of the falling income levels, the sugar projects did produce a relatively well-off farming class. Furthermore, although revenues have dropped in recent years, the reconfiguration of the economy that was affected through the projects was also symbolic, in that the sugar farmers are perceived to be richer by those not participating.

The reconfiguration of class is articulated in and through notions of culture, as the gerontocracy defends its privileged access to rural resources by pointing to tradition. Through notions of culture and tradition, a range of identities are brought together and expressed in, through and in opposition to each other. These include particular gender and generational structures and notions of ethnicity and national belonging that are embodied in the rural elites - those who have assumed the right to speak and act on behalf of the people and who manage to sanction particular modes of being worthy of the moral community. With this right also comes the right to decide on who is entitled to what form of livelihood, and consequently to exclude those without such entitlements. It is here that I argue that the discourses of crime play a pivotal role in determining or constituting moral personhood in a context of intense renegotiations. Or to rephrase the central argument of the chapter: discourses of crime, and practices to end it, play a pivotal role in enabling the establishment of a particular class society in Nkomazi in which young men and women must suffer the authority of old men. It is to these discourses and practices that I now turn.

9. As many as 30 per cent of the farmers no longer make money from sugar production. This indicates the vulnerabilities of black emergent farmers, as the land they farm is poor and they have few resources to withstand the cyclical crises of agriculture. For instance, in one project poor soil makes it imperative to irrigate on a continual basis, but due to poor rain, irrigation had to be limited to less than two hours a day. As a consequence, the cane no longer grew. Many farmers also lacked financial and agricultural skills to run commercial projects. A final reason was that many of those who benefited from the sugar projects had little inclination or ambition to farm. They saw the projects as ways of accessing credit with which they bought cars and built houses. The farming operation was left to underpaid Mozambicans who did only the absolute minimum. Consequently, many farmers were in constant arrears with the bank and TSB. 


\section{Cleaning up crime}

As the son of the local chief showed me around in the tribal offices, we reached a small room. On the floor lay a blood-soaked mattress and there were traces of blood on the walls. At one end, chains ran through an iron ring. "This is where we hold those caught by the Khukula", my guide informed me. The Khukula means "the cleaning" and it is a loosely organised entity that targets the sigebonga or the criminals of the area. The Khukula began operating in 2001 in response to a steady stream of stolen cars being exported over the border to Swaziland. It was conceived by a number of local businessmen, that is, owners of shops and small businesses in one particular village. All these businessmen were closely linked to the tribal authorities and belonged to the local elite of older, landed and moneyed men. They began patrolling the streets of the village at night and responded to calls from the local population. After an initial bout of activity, the patrols became more intermittent and mostly came into effect in time of need. With the passage of time, the initial focus on border control changed to encompass other categories of crime. In 2002, after an ebb in activities, the Khukula resurfaced with renewed vigour in relation to the murder of two boys. The number and intensity of activities increased. More meetings were held and more people beaten up. The Khukula even went to the regional capital, Nelspruit, to lure a group of criminals back to Nkomazi. As these remarks indicate, the Khukula is both an operation and a group of people working to combat crime. In this sense, the Khukula also provides financial resources for those participating. A local headman explained: "The Khukula are those people who are catching the criminals. That is their responsibility. That is the only respectable work you can do. But it is also a dangerous job. They can die and get hurt".

Most inhabitants, not including young men, were quite positive about the Khukula. The headman, otherwise at odds with the chief, observed, "The Khukula is good. If you must wait for the police they will always be late". This was echoed by the local station commander. She is the head of a small station with 35 police officers covering huge tracts of land. She therefore depends on the cooperation of local residents, especially the tribal authorities. In the area where we find the Khukula, she is particularly satisfied: "That is also why the sub-forum works well [there]. They are really working hard. They do case handling. They investigate cases, apprehend the suspects and then hand them over to the police. So as a result we have had only one case in the last month [there]". The Khukula does not always hand the suspect over to the police - at least not directly. The police com- 
mander admits that sometimes violence might be involved in obtaining confessions: "Sometimes you have to turn the blind eye for the sake of crime. If you for instance have someone coming in accused of raping a three-year-old, and he has been beaten up, then you do turn the blind eye. You know that it is like victim support". Note that she uses rape, where there can be no compassion for the perpetrator, as an example to make a general point.

The state's invitation to enter into a partnership in the form of the community policing forum yet again gave renewed vitality to the Khukula, which had been suffering from yet another low in participation and activities. However, the police's interest and offer of partnership carried its own dangers, as the police would sometimes have to react to the violence employed in the practice of policing. The ambiguity of the police is considerable. The prime way of handling the ambiguity appears to be through whether the police "see" the violence, that is, whether victims lay charges or not. The station commander asserts, "We get very few complaints about violence". By not "seeing" the violence, the police will not have to deal with the excesses. However, in one case two members of the Khukula were arrested, as a charge had been laid by a girl's family. The girl had been beaten up severely during a public meeting and the family had taken the case to the police, who were obliged to investigate. Sometimes the violence of the Khukula became too excessive even for its supporters. One headman asserted: "Sometimes the way they beat people is wrong. People can die. They use the sjambok and beat them badly. I only use a stick that can break, so you cannot kill anybody".

The manhandling of the girl bears testimony to the way in which crime is understood among the members of the Khukula. The girl was beaten up for disrespectful behaviour towards her parents. The parents had complained to the Khukula that the girl had had multiple sexual relations. When the parents reprimanded her, she had told them to mind their own business, as she was free to do as she pleased. She had been reproached in a public meeting and punished by having her exposed buttocks beaten. This case is atypical of the Khukula only in one respect, that is, the case involves a girl. In the majority of cases, the objects of everyday forms of policing are young men. It is typical in the sense that it targets perceived aberrant sexual mores and lack of respect for authority among the youth. As Oomen points out in relation to the infamous vigilante group Mapogo a Mathamaga (Oomen 2004), young men are being harassed and targeted by anti-crime organisations such as the Khukula for multiple moral transgressions regard- 
ing sexual mores, walking the streets after nightfall and for disrespectful behaviour, along with clearer criminal offences such as theft. In interviews, members of the Khukula did not distinguish clearly between transgressions of legal norms (like theft) and transgressions of moral norms. Both forms of transgression were policed in much the same way and both forms were seen as destructive of the community. Suzette Heald makes much the same point about the similarities between witchcraft and theft accusations among the Bugisu in Uganda when she asserts that their "trials" follow the same accusational patterns, and the punishment (even sometimes the death) of transgressors of either category is viewed as a service to the community (Heald 1999:74). The conflation of legal and moral transgressions suggests that the differentiation between the two, which is undertaken by the state apparatus, is less than fruitful. Rather, these transgressions belong to the realm of culture preserved and protected by the gerontocracy, as its members decide on the culturally appropriate way to act.

As Sider (1986) points out, culture cannot be separated from livelihood strategies and struggles over resources. Incidents involving Mozambican migrants and refugees and members of the gerontocracy illustrate this point vividly. Mozambicans escaped their war-torn home in great numbers at the end of the 1980s and the beginning of the 1990s. In the chieftaincy that constitutes the empirical basis for this chapter, they were allocated land to build houses, but none for farming. Their arrival was already shrouded in contestation over land rights, and when they began cultivating "vacant" land, these conflicts escalated. The autochthonous inhabitants of the village claimed that the Mozambicans stole the land they used for grazing their cattle. The land was subsequently burnt twice in 1995 and 1998. In 2002, the conflicts resurfaced. The Mozambicans, now long in the area, had replanted the fields, which were subsequently burnt. After the incident, the leader of the Mozambicans went to the chief to complain. He pleaded with the latter to restore the land to the Mozambican farmers. In the process, he argued that those who had lost their fields had no option but to turn to crime to feed their families. To this the chief replied that these people were Mozambicans and hence already criminals. Dispossessing them of their land would therefore change little in regard to their criminal disposition.

The chief's argument linked criminality and ethnicity (Shangaan versus Swazi), nationality (Mozambican and South African) and class (cattle owners/commercial farmers and subsistence farmers). Due to the alleged criminality of Mozambicans, he condoned the dispossessions effected by 
members of the rural elite with prior cultural claims. The latter were not, per definition, criminals, whereas there was no need to question the criminality of Mozambicans. Due to their inherent criminality, their claims were illegitimate, and they could be excluded and exorcised from the body polity. The culturalistic argument served not only to shore up structures of authority, land was also won.

Mozambicans are described and acted upon as "ethnic" others, who are constructed as criminals with no rights to protection. Young men face somewhat different problems. While young men occupy a place within the gendered and generational hierarchies of autochthonous society, they are viewed with considerable suspicion across the board: it is on them that most crime control focuses. As one resident close to the Khukula who engages in everyday policing asserts, "Those who steal are not the old people. It is the young - those in school or just after school. They are very difficult. I cannot begin to say how difficult they are". The crimes policed are, as we have seen, cultural in that they encompass legal as well as moral transgressions. Furthermore, everyday policing initiatives often emerge out of business environments, and the Khukula, for example, have a history of protecting property and privileged access to resources, for instance access to natural resources, grazing and land for farming. Even minor offences like the theft of cane for individual consumption have been known to trigger Khukula action. Most often, the gerontocracy succeed in asserting authority in the community. Young men submit to their decisions and the violence imposed both in everyday encounters and during special sessions, during which their behaviour becomes the focal point of public performances to assert the community. In reference to a particular incident where young men were punished publicly, an elderly man stated, "We did it because we got emotionally relieved. We can't just continue to talk. But it helped that the boys were beaten in front of the whole community. The parents are relieved because something is done for the victims as well". In this regard, ritualised enactments of generational hierarchies function as a means of reaffirming a particular social order.

\section{The "criminals" strike back}

Young men have few avenues for contesting the power of the gerontocracy in everyday life. They must submit to the humiliations of inspections and irregular beatings, often performed in public; they must accept being branded as potentially criminal. However, once in a while young men suc- 
ceed in rising to the occasion and assert a moral comportment independent of, and sometimes even in opposition to the gerontocracy. As in the case of the gerontocracy, young men often claim morality through discourses of crime. However, in opposition to the gerontocracy, their legitimisations are political rather than cultural, as they evoke the category of the "comrade" or "youth" to define their actions. These categories entered into the realm of the political during the struggle against apartheid. By asserting and occupying this position, young men can claim legitimacy from the struggle which is denied them in everyday life, as the struggle was a time when young men as "youth" and "comrades" acted in defence of the community and in the promotion of justice and equality and freedom from exploitation.

During the months of October and November 2002 and into 2003, a series of mass meetings, demonstrations and the targeting of particular families were staged in a town in Nkomazi. These activities developed over several weeks, with highly complex and contradictory narratives. The immediate reason for the activities was that a group of young male criminals, the so-called Tollgate gang, had targeted the area, and were stopping traffic passing through the town to steal money, cell phones and other valuables. According to testimony, the gang had been in operation on and off for several years. This particular Saturday, the leader shot and wounded three people. This enraged the residents and they caught three members of the gang. They searched them and found mut $i$ ingredients, used to avoid detection, ${ }^{10}$ in their pocket. They beat one of the young men within an inch of his life, asking him who was in charge and from where he had got the gun. He went to hospital and was told to leave town for good. He gave names and the march continued to the houses of the persons concerned. "It was like a chain", one woman said, "they went from place to place and the people gave up other people". A week later, another mass meeting was held and the chairman of the community policing forum $(\mathrm{CPF})$ shouted to the crowd, "Can you see the difference? It is really helping!" At the meeting, the problem of some taking revenge for the beating of the Tollgate gang was raised. According to one testimony, those responsible were dragged to the centre of the crowd and beaten up. Then the crowd agreed to contribute R15 (\$2) each if bail was required.

Io. The muti is sprinkled outside the house that is entered and this should hide the intrusion. In a later incident in Nkomazi, a man lost his life since he was alleged to produce the said muti. 
In the meeting, a number of community leaders were present - the ANC, the CPF, ward councillors, teachers and police officers in civilian clothes. But most active were a group of "youth" or "comrades". A woman asserted, "The youth went around with a megaphone, calling everybody to the meeting. 'Nobody must be shy!' The marches and the meetings continued for weeks, and some residents increasingly feared them. More and more people were pointed out by other people. At least one house was burnt down, people were evicted and others were beaten up. One woman stated:

You see, I am afraid that they will point at me. Everybody is afraid. I am thinking that I must leave [this place]. I am tired. [It] is much too busy now. Nobody wants to die alone, so they point to others as well. One of my neighbours said, "You are lucky because you don't have boys in the house. We are in trouble because we have boys".

She talks about those who try to protect the boys: "The community leaders say 'the relatives are hiding the criminals'. The leaders say 'you must stop hiding the criminals'. The leaders say, 'you know who they are' - but in the meantime, you don't know anything about the criminals".

For this particular woman, although she supported the anti-crime dimension of the young men's activity, these incidents were all too similar to events that had taken place in Nkomazi (and elsewhere in rural South Africa, see Ritchken 1996, Delius 1997, Niehaus 2001) when many youngsters protested against the apartheid regime and witchcraft in 1986. "When they call", she continues, "You must put aside what you do and go. If you cook or put your child to sleep, you go, because if you don't, they will point to you next time". But the events seemed to trouble not only this woman. The chairman of the police forum had mostly spoken in favour of the incidents at the meeting, but had also tried to calm down the youth. They had replied with defiance: if he didn't support them, they wouldn't listen to him. In interviews, he asserted that he was desperately trying to control events. As a "community leader" he had to walk a fine line between asserting control of responsible elders and the dangers of his being swept aside by the claims of the "comrades" or the "youth".

In many of these incidents where the "youth" strikes back there are accusations of witchcraft involved, which render the paradoxes that the older community leaders face more serious, as witchcraft is often the prerogative of the old (Jensen and Buur 2004). In the incident recounted above, the charges of witchcraft were less explicit, but the "youth" were looking for a controlling agent behind the "Tollgate" gang with access to and control of 
occult means of enrichment. The incidents occurred in what the apartheid regime called a "declared town", that is, a town not under the control of a chief. However, in other instances the "comrades" directly challenge the gerontocratic rule, as they assert that the rural elite commits violent crimes in the pursuit of resources. In one such case, which I explore in detail elsewhere (Jensen forthcoming), a sugar cane farmer was accused of killing neighbour and kin in order to turn them into zombies that would work his fields for free. The sugar cane farmer was intimately connected to the rural elites - chiefs, tribal councillors and landed men. While the incident lasted, the gerontocracy abstained from involving itself in support of one of its members, and for a brief period another moral community emerged, based on the fight against inequality, exploitation and injustice. In this brief period (less than two weeks) the "comrades" or the "youth", otherwise at the receiving end of everyday policing, asserted control vis-à-vis the gerontocracy. Rather than being the defenders of a culturalistic rendition of the "right way", the gerontocracy became those that incarnated the criminals, destroying the community.

This analysis feeds into the argument proposed by Jean and John Comaroff (1999) and Peter Geschiere (1998). In their analyses, witchcraft accusations function as modes of explaining why some are getting richer while they, the accusers, are not. Through sordid nocturnal deeds, witches take the lifeblood of the poor in order to enrich themselves or those in whose service they are. In this way, the actions of the "comrades" are ways of contesting the rule of gerontocracy, while the Khukula represents the preservation and perpetuation of rural elite privilege. Hence policing, as a way of protecting and performing the moral community, relates intimately to reconfiguring class structures in the former homelands. Both sides of the new and deepening class divides produce and police the boundaries of the moral community and its constitutive outside - the witches, the robbers, the thieves and the murderers - in order to come to terms with, understand and preserve privileged access to resources and livelihoods.

\section{Conclusion: Inequality and insecurity on the rural frontier}

In this chapter, I have explored the relationship between reconfigurations of class and discourses of crime, expressed through the multiple forms of everyday policing on South Africa's rural frontier. I suggest that crime has become the constitutive outside of moral communities: crime is what prevents the community from assuming its full potential. However, neither 
crime nor community exist in untransmutable, trans-historical form. They are as much produced through discourse as they are substantive entities. Those groups who are able to define crime and criminals have come a long way towards assuming the authority to define community. Practices to uncover and punish criminals are community-producing performances, as well as attempts at eradicating crime. They are the performances of those who legitimately can lay claim to membership of the community and of those who are entitled to enjoy the livelihood benefits of post-apartheid development. In this way, insecurity (or attempts to do away with it) paves the way for reconfigurations of structures of inequality.

In Nkomazi, one group has most successfully claimed the right to define the moral community, that is, the gerontocracy. Through discourses of crime they protect their privileges and legitimate the increasing inequality on the frontier. Mozambicans have, by definition, forfeited their rights to protection and even livelihood, as they have a known criminal disposition. Young men steal and behave disrespectfully and, as such, should be punished. Most often, the punishment was carried out by the Khukula, the anti-crime movement closely linked to the tribal community and, ironically, to the state through its participation in state initiated anti-crime partnerships. Although the Khukula is not a permanent presence on the streets of the villages, the cultural, gendered and generational logic that brings it to life once in a while is.

While Mozambican refugees and migrants have few public avenues for contesting the framing of them as criminal apart from tactics of dodging and evading (de Certeau 1984), young men of South African origin do. Although they must submit to the practices of everyday policing while facing increased socioeconomic marginalisation, once in a while they manage to assert a different moral community parallel and even in opposition to the gerontocracy. By evoking the category of "youth" and "comrade", they can be the protectors of a moral community of the dispossessed and the exploited. These categories invoke notions of the political struggle against apartheid, which stood in opposition to the rule of the gerontocracy. Crimes against this community constitute a different order of crime: witchcraft and bodily exploitation. In this way, everyday forms of policing as the performances of different and competing notions of right and wrong provide one of the important languages - the language of the moral community - through which the reconfiguration of class, intertwined with culture, plays itself out on the frontier of the New South Africa. 


\title{
Criminality, Security and Development Post-Colonial Reversals in Zimbabwe's Margins $^{1}$
}

\author{
Amanda Hammar
}

\section{Introduction}

In May 2005, the Zimbabwe government initiated a brutal urban "clean up" campaign called Operation Murambatsvina (translated as Operation Restore Order), weaving security and development discourses into its justification. This was a militarised, nation-wide operation aimed at "driving out the filth" and "restoring order" in all urban areas, which, not by chance, were the strongholds of the broad-based political opposition that the present regime had been attempting to crush since 2000. Accusations were made repeatedly by President Mugabe and other state officials in various arenas against the "filth" and "criminals" occupying the now outlawed urban informal sector. ${ }^{2}$ Street vendors, tuck-shop owners and small-business operators, including many with licences, were variously accused of operating illegally, stealing foreign currency from the state, creating health hazards or generating crime and violence. Similarly, own-built homes in high-density townships, some of which had been occupied for decades, were suddenly de-legalised in a conspicuous reversal of the de facto acceptance by the state since independence - and even encouragement after the introduction of structural adjustment policies in 1990 - of self-assisting activities especially, in trade and housing. In August 2005, a UN report claimed that up to 700,000 urban residents were deprived of either their homes or livelihoods, or both, and up to 2.4 million people overall were said to be affected by the operation. ${ }^{3}$ This initiative induced unprecedented

I. I would like to thank Steffen Jensen for provocative discussions and comments related to earlier drafts of this chapter. The empirical material concerning the agrarian margins draws on doctoral fieldwork undertaken in Zimbabwe in 1998-99.

2. See for example "Siyaso demolished", The Herald, 31 May 2005; "State to relocate informal traders", The Herald, 2 June 2005; "Mugabe defends urban demolitions", BBC News (on-line), 18 September 2005.

3. See "Harare's hawkers go undercover", Sunday Independent (SA), 31 July 2005; "Vending blitz hurting Zimbabwean hawkers", Associated Press, 20 September 2005; "Zimbabwe arrests vendors", New York Times, 8 October 2005. 
scales of poverty, homelessness and extreme vulnerability, particularly in terms of food security and health.

Six months later, the situation remained dire, and yet the Mugabe government consistently refused to accept the humanitarian assistance being offered by the United Nations, denying there was any humanitarian crisis to address. ${ }^{4}$ Indeed, the president claimed that the entire clean-up operation had been well designed and was linked to a "vast reconstruction programme [of] properly planned accommodation, factory shells and vending stalls". Zimbabwe, he said, "would not lower its urban living standards to allow for mud huts and bush latrines, and did not need 'development in reverse". 5 Evidence on the ground strongly refuted such claims (Solidarity Peace Trust 2005). However, even when a concession was eventually made about receiving some external support, it was on terms that donors found politically and financially questionable, with concerns that only those favoured by the ruling party would benefit. ${ }^{6}$

Yet despite the specific partisan politics underscoring Operation Murambtasvina and its aftermath, one of the key arguments in this chapter is that state cleansing ${ }^{7}$ and containment campaigns are a familiar aspect of historically continuous processes of state formation. These have been conducted in diverse settings and on differing scales, with the application of varying degrees of state or state-sanctioned violence, and have often featured forced displacement. Clearly, state violence - both in its overt expression as physical force and in terms of structural violence - is not an aberration but rather an ever-present possibility and fairly common practice in contemporary African states.

The focus in this chapter is on Zimbabwe's post-colonial period wherein selected spaces and citizens, particularly in the margins, have been simulta-

4. See "In Zimbabwe, homeless belie leader's claim", New York Times, 13 November 2005; "Zimbabwe rejects UN assistance to provide shelter to victims", People's Daily (China), 3 November 2005.

5. See "Mugabe defends urban demolitions", BBC News (on-line), 18 September 2005.

6. See "Zimbabwe agrees to UN aid for demolition victims", Mail \& Guardian (SA), 16 November 2005; "Donors wary of funding housing programme", IRIN (UN), 17 November 2005.

7. Cleansing in this sense is in direct contrast to the ritual cleansings evoked as forms of healing to resolve the legacies of both the liberation war and post-independence conflict and violence. Regarding the latter, see Alexander et al. 2000, Eppel 2005. 
neously criminalised and securitised through particular state campaigns, ${ }^{8}$ producing a form of highly uneven, perverse, or for some even "denied" development (Bracking 2005). Examples of such campaigns since independence in 1980 include among others: the arbitrary rounding up of and assaults on "single" urban women in 1983 who, if unable to prove on demand that they were attached to a husband, father or employer, were accused of being prostitutes, arrested and sent off to rural re-education camps; the ethno-politicidal Gukurahundi campaign in Matabeleland and Midlands provinces in the mid-1980s, ostensibly aimed at "weeding out" so-called dissidents, yet in practice aimed at destroying the-then opposition party, ZAPU, and terrorising its actual or assumed constituencies (CCJP \& LRF 1997, Pohjolainen-Yap 2001); and frequent cases of forced evictions of "squatters" and other unwanted settlers within both communal and commercial farming areas, ${ }^{9}$ the most dramatic example being the sustained post-2000 eviction of thousands of white commercial farmers and hundreds of thousands of black farm workers as part of the so-called radical land reform programme (Hammar et al. 2003, Sachikonye 2003).

A common characteristic of these campaigns has been the practice of identifying a dangerous other and then cleansing (by fire, demolition or displacement) or containing (by imprisonment, intimidation, torture or even death) the said danger. Usually, these acts have been justified publicly through invoking the law or in terms of particular administrative, developmental or moral-political projects. This combination of discourses has attempted to portray an image of the responsible and/or caring state that nonetheless is able to assert its full sovereignty and exclude from development or security those it deems unworthy or defines as enemies of the state (Hammar 2003, Worby 2003).

Yet while violent state practices have both increased and become increasingly visible in Zimbabwe's worsening crisis since $2000,{ }^{10}$ more needs to be known in general about how criminalised and securitised subjects themselves experience and respond to acts of state violence and exclusion. Countering the over-privileging of state perspectives in much of the literature on the security-development nexus, this chapter argues for closer

8. By "securitised" here, I mean that they have become both the objects and subjects of security policies and practices.

9. For trends in state evictions since 1980, see for example Moyo 1995, Moore 1999, Nyambara 2001, Matondi 2001, Alexander 2003.

Io. See, for example, Hammar et al. 2003, Human Rights Watch 2003, Raftopoulos and Savage 2005, Solidarity Peace Trust 2005. 
(ethnographic) attention to the ways in which those violated and excluded by the state attempt to interrupt these practices so as to redefine the terms of their entitlement to livelihoods, security and belonging, and to re-legitimise their own citizenship. The chapter explores this through the lens of a local-state eviction of migrant farmers in the agrarian margins of northwest Zimbabwe in the late 1990s.

It begins by outlining the political-economic context in which migrant farmers moved into the remote area in question from which they were subsequently brutally evicted, and discussing the ways in which discourses of violence, security and development played into trans-local contestations over land, legitimacy, authority and belonging. The core of the chapter, however, examines the ways in which the evictees responded to their criminalisation and displacement. This is traced primarily through the practices and narratives of Tendai Mabika, one of the central figures in the process of resistance and redefinition and a key leader in the evictee community who, in the eyes of the local state, became the embodiment of the dangerous outsider - one of the "less desirable forms of life" - needing to be removed. While deconstructing such labels, through Mabika we simultaneously gain insight into the complexity and messiness of local resistance and redefinition and learn that there is nothing automatically "pure" about those victimised by the state.

\section{Reshaping production and power in the agrarian margins}

In late 1997, the Gokwe North Rural District Council (GNRDC) violently evicted up to 140 migrant farmer households from a place called Vumba, in a remote corner of the district in northwest Zimbabwe. Despite the migrants' strongly asserting that they had followed the correct land allocation procedures when they first arrived in the area in the late 1980s and early 1990s, the council subsequently accused them of being illegal, of being squatters. The council had been trying for some years to remove them from where they were settled in communal lands bordering a state national park on one side and a safari area on the other. Decades earlier, in the late 1950s, the area had been used for dumping Tonga communities forcibly displaced by the colonial government from the Zambezi valley when construction began on Kariba dam, and had since then remained a neglected part of the country. Yet this started to change during the 1990s as the economic value of wildlife became more evident and the productive potential of such 
marginal spaces began to be redefined (Moyo 2000). This contributed to the popularisation of a home-grown approach to community-managed natural resources that both drew on and expanded global environmental discourses. ${ }^{11}$ Consequently, in places like Vumba new opportunities arose for substantial revenue generation from various kinds of safari-related activities both for private safari operators and rural district councils, as well as for local communities (Murphree 1990).

The 1990s was a decade in which public sector funds had steadily diminished and pressures had been mounting on Rural District Councils (RDCs) - newly constituted in 1993 through decentralisation reforms - to generate their own revenues. Income sources for RDCs were limited, especially in the poorest districts (usually those in the least productive agroecological zones), where there was no substantial commercial farming that could generate unit taxes from privately owned land. This was the case in Gokwe North. Even the very productive small-scale cotton farming in some parts of the district, because it was being undertaken on untaxable communal land, brought no revenues directly to the council. In such circumstances, turning dry and seemingly ecologically fragile lands in the margins into joint-venture community-managed wildlife areas - in a sense "rewildernising" the agrarian margins (Hammar 2001a) - promised income (for example, from hunting licences) not only to communities but also to councils, by way of lucrative management fees.

This was also a time in which RDCs had begun to assert their recently devolved political and developmental authority, facilitated by the promulgation of the 1988 Rural District Councils Act. It was at this juncture that the Gokwe North RDC found itself confronting what it viewed as a recalcitrant group of migrant farmers in Vumba. The council had been hoping to establish a safari lodge precisely where the Vumba farmers were settled, and, through decidedly opaque practices, had redefined the area as a wildlife "buffer zone". This required the manufacture of what Sundar (2001) calls "new legal geographies", in which "legal categories are used to construct and differentiate material spaces which, in turn, acquire a legal potency that has a direct bearing on those using and traversing such spaces". It was primarily on the basis of the buffer zone that the council applied to the courts to issue summons for the eviction of the migrant farmers, now labelled squatters.

II. CAMPFIRE (Communal Area Management Programme for Indigenous Resources) in fact became internationally renowned. 
Earlier attempts by the council to persuade the newcomers to leave the area had failed. These farmers, who against great odds had begun to grow cotton and other crops fairly successfully in this far-flung corner of the district, persistently refused to go on the grounds of their being "correctly" settled there. They were easily able to name which traditional leaders they had approached on arrival in Vumba, in which order, to request the allocation of plots. Many of the Tonga leaders confirmed this. Despite the fact that legislative reforms after independence had given rural local government councils land allocation authority - albeit always retaining some level of ambivalence in relation to traditional leaders - in practice chiefs, headmen and kraalheads were still considered by most rural residents as having the legitimate authority to decide on who should have land, where and how much.

Subsequent to the local allocation of plots, many, though not all of the newcomers had then visited the council to obtain a "letter of removal", a form of documentary evidence that acknowledged and on some level "legalised" their move from one district to another. These letters constitute part of what Das (2004:234) has called "the documentary practices of the state", which together with "the utterances that embody it ... acquire a life in the practices of the community". The absence or loss of such letters (many during the eviction itself) - or denial by the council of having issued them at all - would later contribute to the criminalisation of selected households, and fuel accusations of their illegality. Yet even where such letters of removal could be proven to exist, in the moment of eviction they lost their illusory power of protection, revealing not only "the blurred lines between law and its violation", but more generally the "illegibility of the state, the unreadability of its rules and regulations" (Das 2004:234).

From the council's point of view, the forced removal was fully justified by the "fact" that the migrant settlers in Vumba were illegal squatters, lawless, uncontrollable. In addition, they were portrayed by the council (and a handful of their Tonga allies in Vumba), as "foreign" and outsiders, clearly distinct from the "authentic" Tonga firstcomers, insiders. Furthermore, their public resistance and insistence on their rights to land and belonging subverted both the council's and the local Tonga chief's assertions of authority, and challenged the state's sovereignty and project of political hegemony in the margins. Added to this, the ruling ZANU (PF) party had a record of crushing any form of emerging leadership independent of its own control (Alexander and McGregor 2003), and the rebelliousness and organising capacity of some of the migrant households in resisting removal 
had begun to seem far too spirited and independent. As such, in addition to the economic and administrative pressures on the council, a convergence of various political histories and discourses of danger and criminality came to bear on its justifications for removing the migrants from Vumba. As the chief executive officer of the council commented one year after the eviction:

We were saying these people illegally settled in the area, because if you had not been given permission by the council to settle in a given area you were actually classified as a squatter. So from our point of view those people were squatters. At the same time, what actually happens is that, you know, these people become lawless, like they wouldn't even allow any civil servants, any workers from government I would say, to go there for their normal duties. And they had no respect for the chief ... Because of this lack of respect, they were trying to actually establish themselves as a certain, sort-of separate entity, you know, with their own sort of leaders ... They thought that they could actually represent themselves in whatever they were doing. Their own authority, they stamped their own authority. ${ }^{12}$

Criminalising the settlers on multiple levels had a dual effect in undermining their legitimacy and inclusion within the realms of sovereignty. First, it undermined them in "civic" terms, as worthy citizens of a common nation with rights to development and equal protection under the law. Second, it undermined them in "customary" terms, as "ethnic" subjects entitled to rights, resources and protection within the more localised traditional framework governing the communal lands. Increasingly, then, they became the unworthy, the excludable.

But what ultimately legitimised the use of violence by the council was the consistent interpretation and portrayal of Vumba, and certain of its inhabitants, as already violent and dangerous. ${ }^{13}$ In the council's minutes over several years prior to the 1997 eviction, there were recurring references to the migrant settlers as hostile, uncooperative and belligerent. Some were in fact arrested in 1995 for threatening and assaulting council officials, following an attempted eviction exercise at that time. The point here is not to refute the existence of violence in Vumba itself, but rather to assert that

I2. Interview with Alan Chinho, Nembudziya, 10 October 1998.

13. See Das and Kleinman (2000:4) for a discussion of the devastating effects elsewhere (Yugoslavia) of the essentialising attribution of a form of dangerous subjectivity to the inhabitants of a particular territory, consistently defined as a "violence-prone area", marked by an inherent "culture of violence". 
the council consistently magnified a certain image of violence in order to justify its own violent intrusions, ostensibly as a means of restoring stability and order. This constitutes part of the state's ongoing and complementary projects of legitimating itself and policing the periphery.

\section{Local logics of entitlement and exclusion}

In the course of the evictions during September and October 1997, many of the evictees' homes and food granaries were either burnt or demolished and much property - including furniture, clothing, kitchen utensils, farm implements and small livestock - was damaged or lost. The majority were forcibly removed from the area, although some managed to find temporary shelter with neighbours and friends nearby. There were some alleged beatings and rough treatment during the eviction and there was mention of teargas being used. Lorries were hired by the council to ferry people and their remaining possessions to the nearest business centre some 40 kilometres away at Chitekete, where they were dumped "on the tar" and left to fend for themselves outdoors without adequate shelter or provisions, just at the onset of the rainy season. They spent almost five months under extremely poor conditions, during which time many claimed to have fallen ill from lack of clean drinking water and proper sanitation. Evictees' narratives of their experiences were marked by a mixture of humiliation, betrayal, anger and loss. The loss was expressed in relation to physical homes and material belongings - usually listed in great detail - and also to overall security and certainty. Not least, there was the loss of faith in a government for whom blood was shed during the liberation struggle, a struggle fought in large part over the right to land.

Throughout this period, a small and active committee of evictees led by Tendai Mabika (not his real name) worked closely first with Legal Aid at the University of Zimbabwe, and then with Zimrights, a local human rights organisation, to appeal against the eviction through the courts. What they finally achieved was not a formal rejection of the legitimacy or legality of the eviction itself, which was unlikely given that such evictions were normalised by state policies and practices. Instead, based somewhat ironically on a technicality - namely, the incorrect delivery of summons by the council to the evictees - the presiding magistrate issued a "rescission of judgement" on 25 February 1998, and ordered all the evictees to return to Vumba, albeit under temporary and uncertain terms. 
When they returned to Vumba in February 1998, houses and granaries had to be rebuilt, neglected fields cleared and new crops planted where possible before the advent of the next rains in October 1998. In the course of their eviction, much of their livestock had been lost, and having been evicted at the start of the rains in 1997, the evictees had been unable to cultivate their crops during the 1997-98 growing season. This meant losing not only that year's harvest, but without receipts for the sale of cotton to the cotton companies for that season, they were also unable to receive credit for essential inputs for the next season's crop. The denial of access to the means to generate livelihoods from their fields for such an extended period had inevitably undermined household food security. Issues of hunger and a continued sense of insecurity were constant preoccupations. There were also allegations made by several evictees that the council had denied them access to food grain under the national grain loan scheme after their return to Vumba. ${ }^{14}$ Thus despite the "victory" of their return to Vumba, overlapping material, emotional, legal and other needs among the returnee community required urgent attention. As Jackson (2004:37) writes, "what destroys us is not loss in itself, but the lack of what we need to go on".

It was at this point that Tendai Mabika re-emerged as a critical figure in the evolving struggles over entitlement to land, authority and belonging in Vumba. Mabika was both a charismatic and, by local standards, relatively well-educated man who travelled comfortably between worlds - rural and urban, political and religious, pragmatic and intellectual - imbuing him with great skills of articulation and translation. With "own knowledge" political experience, and the airs and ambitions of a modernising pioneer, he was easily portrayed by his critics as the embodiment of arrogance and, as the owner of a gun, as potentially dangerous. Being politically active and outspoken against both the council and various local Tonga leaders made him a ready target for these and other accusations, some undoubtedly justified.

Repeatedly, Mabika was the target of the council's frustration and fury at being denied access to the land it wanted to use for the safari lodge, and at having its authority publicly challenged. Symbolised as the dangerous outsider, by association this label encompassed all his supporters whom the council could then legitimately, even heroically, remove from Vumba with the promise of restoring "peace and stability". An awareness of this

I4. In present-day Zimbabwe, the politicisation of food aid and denial of essential food to impoverished opposition supporters has been widely documented. See, for example, Human Rights Watch 2003. 
made some evictees ambivalent about supporting him openly. His complex character - combining immense energy, commitment and tactical ability in defending the rights of his fellow evictees with a shrewd manoeuvring of relationships and resources to strengthen his own authority - did little to protect him from attack. That he was viewed as autocratic and even threatening by some of the evictees themselves, only served to deepen the council's case against him.

But returning now to the aftermath of the eviction, together with his committee Mabika had continued to try and find ways and means for the evictees to remain in Vumba legally, as well as to get compensation for destroyed property, travelling when he could to provincial towns and to Harare to seek support from politicians or NGOs willing to provide legal assistance. Those evictees he represented in Vumba were required to pay "subscriptions" (elsewhere called "buffer zone fees") to help with the costs of such journeys. In fact, an out-of-court agreement between the council and the evictees (represented by Zimrights) in October 1998 had concluded that the evictees would be allowed to remain in Vumba until after the harvest in August 1999, when they would have to move to alternative land to be shown to them by the council by January 1999. However, in the short term there was the more pressing problem of how to regenerate livelihoods and food security.

Having lost access to the credit facility previously provided by the cotton companies, by early January 1999 Mabika was searching desperately for alternative sources of credit support for essential farm inputs. Using his contacts and skills of persuasion to great effect, he was able to secure donor funds for a local development project that would supply basic inputs for cotton farming such as fertiliser, herbicides and pesticides to the evicted households. ${ }^{15}$ Importantly, and deliberately, the project did not include any investment in fixed infrastructure or long-term services, and hence in no way seemed to contradict or undermine the existing out-of-court agreement that the evictees would later relocate.

Yet for both pragmatic and political reasons, the project was not channelled through the council, inevitably provoking a backlash from the council, given the obsession with control over resources by most state authorities. This exemplifies Ferme's (2004:82) notion of the state as "an apparatus of capture that operates through specific places". On the pragmatic side,

15. The details and complexities of this process (including my own enrolment in it by Mabika), and the highly uneven and unpredictable effects of the project are discussed in Hammar (2001b). 
timing was of the essence. It was critical to apply inputs to the crops before the end of the rains in April, but preferably before the end of February. Going through government bureaucracy would have created delays that may well have made the inputs irrelevant. At the same time, politically it was not feasible to go through the council, given the deep animosity between the council and the evictees and the latters' fear that their initiative would be sabotaged or diverted by the council for its own (exclusionary) purposes. Instead, the project was channelled through a registered non-governmental organisation (NGO) that was already established in the area with the council's knowledge and approval. In addition, it was understood that the chief and other local leadership would be directly involved in the project, which in addition to the farm inputs included a component of supplementary child feeding for all children in the area.

Despite the formalities of working through the NGO, and promises to establish a more widely representative project committee in Vumba, Mabika and his evictee committee took charge of the project. They diligently undertook all the arduous work of loading and transporting thousands of heavy bags of fertiliser and other goods from Chitekete business centre to Vumba, using cattle-drawn scotch carts and one tractor to traverse almost non-existent roads and semi-flooded rivers. However, things began to get very messy once the goods arrived in Vumba. Complex processes of discipline and punishment, accumulation and denial, inclusion and exclusion, came into play. In the end, the project not only alienated the council further but precipitated and deepened divisions in Vumba and within the evictee community itself.

Despite the fact that the project designers had set up all the appropriate technical mechanisms and local committees to ensure transparent, fair and accountable distribution of the various inputs - in the manner of "the good development project" - most of these procedures were either ignored, distorted or co-opted by Mabika and his committee. The basis of the distribution had been a carefully compiled - and, until the project was initiated, previously unattainable - list of names of evicted households, together with their plot sizes and acreage under cotton cultivation in Vumba, verified by individual signatures. The list of apparently all 140 evicted households had been prepared by Mabika and his committee. However, it appeared to be seriously flawed if not partly fraudulent. Allegations were made that some of the names on it were of people no longer living in Vumba, or in some cases no longer even alive. Other names, it was reported, were either of spouses or dependent children of individuals already named on the list. 
There were some evictees resident in Vumba whose names had been placed on the list without their knowledge, and others whose names had been left out altogether. Besides this, once the actual distribution began, the wellplanned calculation of who was entitled to what according to indicated plot size and cultivation requirements, was entirely dismissed. There were evictees, it was claimed, who received far more than they were entitled to according to the distribution criteria, and others who received less than stated in the distribution schedule, or indeed nothing at all. In addition, there were migrant settlers from non-evicted households who allegedly received inputs, some of these apparently substantial.

Following these widespread accusations, the NGO responsible for the project was compelled to initiate a local evaluation of what had happened, which confirmed many of the allegations. What was perhaps most striking about the comments made by different members of the evictee community was their deep sense of betrayal by Mabika, described by one evictee as "a rough man [that] distorted the gift for all the evicted households". On the one hand, those excluded from the distribution of inputs were scathing about the leadership that had "shown us oppression", that had "distorted distribution and they did not handle us with care". For many, however, it had been a surprise that things had turned out this way. It was evident that most of the evictees had not anticipated that Mabika would exclude them, in particular penalising those who had not paid "subscriptions". Many seemed to have viewed him as a "genuine leader" concerned for their wellbeing, making their sense of betrayal that much deeper. Yet it seemed there was a violent dimension to his leadership style, to his mode of politics, if you will, that the debacle of the project exposed somewhat dramatically, revealing an image of him more closely aligned with that portrayed by the council.

According to several accounts, on the supposed day of distribution of the farm inputs at Mabika's own homestead (rather than at the school as stated in the project document), he had met people there with a gun in hand. This was allegedly used to intimidate those who had not supported him, those not of his "faction". ${ }^{16}$ As one man recounted, Mabika had said that, "all those who didn't pay buffer zone donations were not going to

I6. There were a number of different groupings among the evictees, some of whom allied themselves with Mabika, while others felt at different points more secure in being loyal to the local Tonga leadership, and in some cases were indeed offered a degree of protection. 
receive anything". ${ }^{17}$ This violated the stated principles and procedures of the project, which clearly defined the farm inputs as being for all evictee households. Yet, as another man commented:

[W] hen we heard it was for all people evicted we went to Mabika's house and saw him with the rifle. He never talked to anyone. He gave that task to his committee. His deputy said, "anyone who did not pay the buffer zone fee will receive nothing. Only those names I call". Then they started to call out names and my name was not called, even though my name was on the list. With my neighbour, we left for home. The way Mabika behaves, he uses intimidation. We once attended another meeting at the school. The councillor wasn't there. Mabika then said, "I myself alone can speak with my gun". ${ }^{18}$

Besides the distortions of distribution produced by and through the list that Mabika and his committee had compiled, the list in itself was also significant for the wider struggles over land, authority and belonging in Vumba. No matter how partial or inaccurate, it represented a concrete assertion by Mabika of the continued presence of the evictees in Vumba and their intention to stay. The list constituted not only a set of names, but a set of names of farmers attached to particular plots of land they intended to go on cultivating. In this sense, it was an overt and powerfully subversive act of "naming and claiming". At the same time, it was a symbolic tool through which Mabika could envisage expanding his authority beyond just the sphere of the evictees. By bringing the list into being, he could assert control over previously hidden information about the evictees. By offering it as a gift of "truth" both to the donors supporting the project, and to me as a researcher, it became his currency for generating material resources, but also for extending the scope and legitimacy of his authority in Vumba.

\section{Narrations of loss and retrieval ${ }^{19}$}

At the time of our first meeting in Harare in September 1998 in the offices of a local NGO working in Vumba, Mabika was 70. His life story paral-

17. Interview with DS, Vumba, 26 April 1999.

I8. Interview with GM, Vumba, 26 April 1999. This last comment has a disturbing resonance with Mugabe's rhetoric concerning the use of the gun. See for example Meredith 2002.

19. All the quotes and material for this section draw on transcripts of numerous interviews conducted with Mabika in both Vumba and Harare between October 1998 and July 1999. 
leled that of many of the other newcomers in Vumba - and in the agrarian margins more generally - in that it was a tale of multiple migrations, both voluntary and forced, stretching from his childhood in Mberengwa district in the 1930s until his move to Vumba in 1991. This latter he had hoped would be his last. Mabika's dreams of studying beyond three years of secondary school education had been dashed by the realities of poverty, but his schooling had allowed him to do temporary teaching in the rural areas during the 1950s. In the 1960s, he had mainly worked for construction companies in Harare and smaller towns, but jobs became scarce in the 1970s, forcing him to return to Mberengwa, where he survived mainly by piecework, building huts and houses for others. The area had been too dry and depleted to allow for cash crop production. During this same period, he was exposed to the nationalist liberation struggle and his political consciousness grew:

These political leaders came preaching the gospel of freedom. We heard it and really knew we were oppressed. We joined the party, ZAPU. Our job was to preach the gospel of freedom to others in our community. When independence came, we thought we were free. We were happy. We thought we were free from colonialism. We didn't know things were to change later.

After independence and through much of the 1980s, he managed to work again as a rural teacher. But like many others without formal teaching qualifications, he was eventually dismissed from his post in favour of those who were trained. After this he returned home "to plough", having by then found land in a resettlement area in Kadoma district. But the land there was poor too and the prospects for the future dismal, prompting him to move again.

And so in 1991, I had to move again to this area [Vumba]. Some people from this area were telling us there was good land and then I had to seek for a place. Then I had to cross-examine to see if it was suitable for cultivation, and I saw that it was. I had to seek the kraalheads and ask for land, and they allocated me some. We went through those procedures. The land allocated to me is the land I'm on today.

Like many of his fellow migrants, here Mabika establishes the basis for his legitimacy in Vumba, reiterated many times over in different interviews. It is an assertion that combines his authenticity as a farmer, a man of the soil, together with his authenticity as a citizen of a specific place - albeit an ethnic citizen in Mamdani's (1996a) terms - observing and protected by 
its (customary) laws. At other moments, both in relation to his organising for legal defence against further eviction and demanding compensation from the council for destroyed property, he asserts his civic citizenship in relation to statutory laws, national politics and international standards of justice and human rights.

These latter discourses became more explicit in his narratives about the eviction itself, and the way in which the newcomers' land was redefined as a buffer zone and they were themselves labelled squatters by the council:

People were shown land only to be shown it belongs to the animals. Then they had to call us squatters. How can a man be a squatter if he followed the right procedures to get land? If they wanted a project that would benefit us all, they could've explained it to us. The problem is that they came telling a lie that we were squatters.

The eviction itself was described by him during one interview at his own home in Vumba through a physical demonstration of those parts of his homestead burnt or destroyed by the council, and "measured" through a specification of items lost in the process.

That was my fowl run. Fifty broilers, fifty others, twenty-five layers, there where those pots are. This was maize stock. I had fifteen tonnes or more of maize. There, my wife had to put some bundles of thatching grass. Here was the granary where I stocked about fifteen tonnes of grain. There were tyres in the roof that was burnt down. I had about twenty-four pigeons. My herbicides, pesticides, tyres and tubes for my scotch carts, all destroyed.

This act of naming of "objects on which violence leaves its mark" (Mehta and Chatterji 2001:210) seemed to be a way to apprehend in the present that which might otherwise remain invisible but which must be witnessed and remembered. At the same time it reinforced, through such quantification, Mabika's ongoing battle with the council over what he referred to as "reparations". At a later point, when the council was supposed to show the original evictees alternative land on which to be resettled, Mabika insisted that "we should be paid for our burnt property before we can be resettled. We shall discuss about land allocation after paying". Time and again he expressed his faith in the law and the courts, and yet he was not blind to its partiality. At one point, pondering on what he viewed as the council's veiled acknowledgement of its culpability in the eviction and its responsibility for compensating the evictees for their losses, he asked, "If the coun- 
cil has admitted that they did wrong, why hasn't the law accused them for doing wrong?"

Mabika's sense of injustice and betrayal was geared not only towards the council but was also directed at the Tonga leadership with whom there had been growing animosity, especially since the eviction and his subsequent return. However, he described the tensions as having started some years earlier, when the kraalhead of his village had attempted to take back some of his land:

The first sign of harassment was by my kraalhead himself. The land he allocated himself, he said "you have jumped the demarcation line". He came with other neighbours to my land. They wanted to cut a piece of 3 acres. He wanted to give it to his son.

Mabika refused to budge. At this point, he was still on good terms both with the then chief, and even with the district administrator, who had written a letter in support of his claim, ensuring he could hold on to his land.

However, his own sense of betrayal was increasingly portrayed in ethnic terms. Ethnicity in itself was not a key source or site of conflict when the migrants first began arriving in Vumba in the late 1980s and early 1990s. Yet as time passed and the council began pushing to control the "buffer zone" in order to establish a safari lodge, the category of newcomer - linked, however incorrectly, to being "Shona" 20 - began to be reframed first as squatter, then dangerous outsider, then unwanted evictee, then belligerent returnee. With encouragement from the council, some of the Tonga leadership and households began to view and portray Mabika's group as "blocking development" in the area.

Mabika was keenly attuned to this growing politics of difference. In a large public meeting in Vumba in October 1998, he appealed to his fellow evictees: "Can you see there is no-one in the Tonga land who likes us, only Siachalema", naming an older Tonga resident also evicted by the council. On another occasion, he claimed that Tonga village development committees and the local councillor were saying openly that, "no authority should be given to a Shona person. Segregation is there, just like that." Elsewhere, continuing with this theme, he noted with some bitterness: "Tongas thought 'our prosperity and fame is lost to the Shona'. In my committee there were Tongas and Shonas. But they didn't like a Shona man to lead in the area". At the same time, Mabika acknowledged the openness of the

20. Although Shona-speaking migrants were predominant, the range of ethnicities of migrant farmers in Vumba was much more varied than this. 
younger incumbent chief, whom he viewed as treating all his subjects "as one". However, this was largely superseded by Mabika's defensive blaming of the local leadership for ethnic tensions in the area. This conveniently masked some of the patronising ways in which both he and some of his fellow migrants constructed themselves as modern and progressive relative to "the Tonga". This was a sentiment not lost on some of the Tonga leadership, who were openly scathing of Mabika and the newcomers, accusing them of being arrogant, disrespectful and at times even dangerous. In this context, the trope of Shona-ness (incorporating any or all outsiders, whether Shona or not) became for some a singular marker of unwelcome otherness, of unworthiness.

With regard to the question of party-political leadership in the area, Mabika had been very active after his arrival in establishing ruling party structures in Vumba, which had been largely absent until then. Yet as with many of Mabika's "good intentions", they had had contradictory effects:

I knew there was such a great tension between Shonas and Tongas since the things we wanted to do in 1992/3. We wanted our own party committee, trying to unite everyone through politics. Those who were councillors or kraalheads thought I was after their rule. They thought I wanted to grab the chieftainship.

Inevitably, tensions arose. Reports were made to the council. Mabika was accused of trying to start his own political party in Vumba called Zvidozvavanhu (people's wishes). He defused the situation by assuring the soldiers and police sent to his home that he was involved in building up ZANU (PF). In fact, Mabika did successfully build up the ruling party in the Vumba area. Working together with others, party branch committees were indeed formed and a district committee elected, of which Mabika became chairman. However, at a later date, as the council grew wary of his growing political influence and his central role in organising resistance to its efforts to evict settlers, it requested the party's provincial committee to nullify Mabika's chairmanship, which it did. This was repeated later on when Mabika stood for council elections. The council was closely aligned with, if not "under" the ruling party. Thus, despite being successfully nominated as party candidate and reportedly voted in as councillor for his area in 1997, again Mabika's successful election was allegedly nullified jointly by the party and the council.

Mabika professed not to bear a grudge about being politically sidelined, emphasising instead that what he opposed was corruption and dishonesty: 
I don't care if they don't include me. I'm not a man that can revenge in any way. We should cooperate, that's what I always tell them. Some are alright [in Vumba]. But the leaders - Village Development Committee (VIDCO) chairmen, kraalheads - they oppose. If the council itself had dissolved, starting with new leaders, we would have better thinking. There are corrupt leaders today in the council. They influence our leaders here.

Such accusations need to be set against the extensive list of allegations and even evidence about Mabika in his own dubious dealings with the Vumba project and the list. And yet over and over, in different contexts, he emphasised the need for truth and honesty, at times using Christian idioms to strengthen his truth claims. He often represented himself as "one who tells the truth", as his own version of his role in the tainted Vumba project attests:

I'm a father of children. I can't be so disastrous. I must be very aware. I am responsible; better than other men, not a thief. What did I steal? I'm trying to help the community, to discuss and shake hands together as fellow Zimbabweans. They can tell any lie about me. But the truth will ever conquer, I tell you this. I'm not crooked. I walk straight.

Mabika's paradoxes were numerous. Even while accusations of intimidation and exclusion were made against him in relation to the Vumba project, he continually portrayed himself as a man committed to peace and unity as compared with others' attempts to "divide". He even accused the NGO that had helped facilitate the project of "dividing people" on ethnic grounds through a much earlier youth empowerment project geared initially only towards the Tonga community. Making productive use of the organisation's claims to be "uprooting poverty", he portrayed himself as being there "to uproot divisions". In late 1998, one of the staff members of the NGO mentioned that "Shona" villagers from Vumba had approached the organisation through its local coordinating committee, "pleading" to be included in their activities. This, she astutely observed, was "about recognition of their permanence in the area".

Like many of his fellow evictees, Mabika had spent a lifetime of migrations in search of a secure future, restarting his life over and over again. His resilience, inventiveness and optimism were admirable, but given his age, the toll that these endless searches for security for himself and his family had taken on him were beginning to show. What Vumba represented then was more than a battleground of opposing wills involving himself and his committee against the council, or against the Tonga leadership. Clearly he 
was a man driven by his own notion of "justice", and his skills and force of character fitted him to be a leader. But he was equally a man battered by multiple disappointments, displacements and marginalities, and in need of security and a reliable income. It seemed to be an understatement when, one late afternoon sitting beside his home, he said quite simply, "The land is what we really want. It's very productive. Getting out of the area is a great loss." Like many others, Mabika was desperate to find a place of belonging that was essential not only for himself but as a legacy for his large family. But this was not to be.

\section{Epilogue}

In December 1999, two years after the original Vumba eviction, The Standard newspaper carried a report with the headline "Gokwe boots out villagers to make way for wildlife project". The Zimrights executive director, Munyaradzi Bidi, was reported as saying that "around 114 villagers had been affected by the evictions and the destruction of property that occurred on 17 November this year". ${ }^{21}$ Bidi described the eviction, carried out by the Gokwe North Rural District Council, as a "blatant disregard for human dignity and a disgrace". In addition, he noted that it was unlawful with respect to the out-of-court settlement reached in October 1998, as well as a stay of execution granted by the courts in mid-November 1999 to stop the council from evicting the settlers again. Besides the council's own conduct, it appeared that a series of procedural irregularities, miscommunications and incompetence within the court system were identified as contributing to the "illegal action". The governor for Midlands and the district administrator were both alleged to be "very much aware of what was going on".

It would be hard to refute the evidence that Tendai Mabika was vindictively targeted in the whole exercise. The report quoted Bidi as follows:

In one particular case, a villager, [Tendai Mabika] ${ }^{22}$ had his entire homestead razed to the ground, including his granary which had been reduced to ashes. [Mabika], who vocally opposed the council, suffered the most losses with nearly everything he owned being destroyed or taken away. His $24(90 \mathrm{~kg})$ bags of maize were taken away by the council, and out of 26 cattle in his kraal, only

2I. This figure was 114 villagers, as opposed to households. Compared with the overall population affected by the previous eviction, this constituted - at a very rough estimate - perhaps only 13 per cent of the evictees.

22. His real name was given. 
one remained. Worse still, four of [Mabika's] children, aged between four and 13 , were inexplicably taken away by the raiding party without their parents, and dumped at an abandoned minesite in Buchwa Mine. ${ }^{23}$

In the correspondence I received from Mabika in the years that followed, he continued against all the odds to try to return to Vumba and to fight for "reparations" for all he had lost on account of the council. In neither sense was he ultimately successful. He was eventually forced out again, but this time by a different politics that had begun to consume the countryside after 2000. As Mugabe's "radical" land reform was under way in commercial farming areas, displacing thousands of white farmers and hundreds of thousands of black farm workers, in the communal lands the focus was on "weeding out" all opposition to the ruling party. Always on the frontier of conflict, Mabika had by this time joined the opposition Movement for Democratic Change and hoped to stand as a local MDC candidate in council, if not parliamentary elections. In this sense he attempted to shift the terms of his local claims to an alternative national discourse of justice and rights. But once again he was on the wrong side of history. Gokwe North was a ZANU (PF) stronghold. Eventually, threats against his life by loyalist war veterans and youth militia accomplished what the council had tried for almost a decade to achieve, to get rid of him. He moved finally to Binga district, tired and dispirited, but still trying to rebuild in some way. His last letter spoke of his wanting to start a small chicken project. He died there in April 2004 of malaria.

\section{In conclusion}

Criminality, security and development are recurring themes running through everyday encounters between states and citizens, especially in authoritarian post-colonial states such as Zimbabwe. Increasingly, they have come to constitute the normal workings of sovereignty, whereby the unclean, the unwanted or the unruly are transformed into the unworthy and subjected to both subtle and more overt technologies of violence, displacement and exclusion. Linking the urban and the rural margins and past practices with the political present, the chapter has highlighted the resonances that constitute both a spatial and temporal continuum in post-colonial state making. Through the lens of a local-state eviction in the agrarian

23. See Itayi Viriri, "Gokwe boots out villagers to make way for wildlife project", The Standard, 12-18 December 1999. 
margins in the late 1990s, it has been possible to trace how discourses of criminality, security and development are woven into one another to legitimise or mask the violent displacement of those who have become non-citizens, while boldly asserting the sovereignty of both ruler and state. Through such discursive practices and their material manifestations, not only does the Zimbabwe state define who is worthy of development and who shall be excluded as unworthy, it goes further by attributing qualities of violence, disruption and danger - even contamination - directly to excludable others. This facilitates a double-sided self-representation of the state as both "vulnerable" to the uncontrollable popular passions of the unworthy (Das 2004:247), and as the impenetrable sovereign warrior ready to defend the authentic nation, in both cases investing itself with the right to act against the unworthy with counter-violence (Balibar 1991).

Yet what this chapter has been equally interested in examining are the ways in which those criminalised by sovereign power - those deemed unworthy of either security or development in the name of security and development - refuse, or in some cases mirror, the terms of sovereignty. Drawing on the narratives of one emblematic figure in the agrarian margins, the chapter has argued for a closer reading of the experiences and practices of (non-idealised) subjects of exclusion in order to disrupt an overly statecentric perspective on the workings of the security-development nexus. Addressing multiple levels and localities, such a perspective insists upon a less absolute, monolithic view of the state and sovereign power. In addition, it provides intellectual and political space for recognising acts of resistance and reinvention by sovereign citizens, especially in the margins - both rural and urban - where struggles over rights and resources continue to be marked by the perverse merging of discourses and practices of security and development. 


\title{
Post-Apartheid South Africa - Gender, Rights and the Politics of Recognition New Avenues for Old Forms of Violence? ${ }^{1}$
}

\author{
Tina Sideris
}

\section{Introduction}

In the context of South Africa's transition to political democracy, which has increasingly been framed in terms of human rights, the continuity of everyday violence between men and women seems to be a paradox. As part of human rights, gender rights aim to secure women against violence and domination and to ensure that they are equal beneficiaries of development. To this extent, the gender rights project incorporates the notions of personal security, and social, economic and political participation contained in discourses on human security and human development. Yet a massive expenditure of resources in new legal regimes and institutions to uphold gender rights and equality has not had the effect of diminishing gender-related violence. In spite of the constitutional endorsement of gender equality, legislation that protects the physical and emotional integrity of individuals in the domestic arena, civil society organisations advocating for gender justice, training of public servants in the implementation of the legislation and evidence that growing numbers of women are accessing the public domain, violence in intimate relations continues.

As has been suggested in the introduction to this volume, it cannot be assumed that the process of democratisation and the rights project inevitably results in decreases in violence. Post-apartheid laws and policies have been put in place that are designed to prohibit violence, yet violence in intimate relations persists. The evidence presented in this chapter suggests that the continuity of violence cannot simply be understood as a residue of the old order, which will give out with the progress of transformation. Violence in intimate relations draws on the past but is reproduced under

I. Thanks to colleagues at WISER for their intellectual insights. The support of the Mellon Foundation is gratefully acknowledged. Without the collaboration of Masisukumeni Women's Crisis Centre, the fieldwork on which this paper is based would not have been possible. 
new conditions and emerges in different forms. Hence the question arises: how do we conceptualise this apparent paradox?

With reference to the legacy of race and class oppression and the destabilising effects of social and political change on many men's lives, violence perpetrated by men against women has been linked to a "crisis in masculinity". Popular versions of the "crisis in masculinity" theory suggest that male insecurity follows the social gains made by women. Noting confusion among men about their roles and uncertainties about their performance, such versions of the "crisis in masculinity" posit men as beleaguered and link this to violent behaviours. In popular discourse, this notion is easily appropriated for conservative use in calls for consolidating conventional gender hierarchies and for the recovery of masculine pride. In this discourse, the tendency is to focus attention on masculinity as a fixed identity and thereby essentialise gender, rather than taking into account the ways in which "masculinities" are constituted in practice as part of a wider order of gender relations (Connell 1995:84). Thus, the structural inequalities that configure relations between men and women, and indeed relations among men and women are obfuscated.

In South Africa, the process of democratisation has not dismantled the structures that secure men's power in the state, the economy and the realm of private relations. Nor has the widely held view that men should be in dominant positions - over women, children and other men - been displaced (Segal 1990, Sideris 2004). Nevertheless, there is no doubt that the experience of apartheid and the challenges of transition in South Africa have put men under pressure. Research evidence reveals that social, economic and political changes exert varying degrees of strain on different sectors of men and have sharpened the tensions that characterise gender relations (see, for example, Morrell 2001, Posel 2003, Sideris 2004, Walker 2003). The human rights discourse and new legal regimes signal that women are equal legal persons. The growing presence of women in spheres of public life, previously the preserve of men, and the increasing numbers of women who are accessing the benefits of development programmes and the state's welfare grants facilitate relative independence from men. Together, these interrogate the order of gender relations and pose significant challenges to the "legitimacy" of men's privileged status over women (Segal 1990).

Responses to these challenges are diverse. Mediated by race and class, men's practices and the meanings given to gender identity are being contested, defended and redefined in institutions, in interpersonal relationships and by individual men and women (Sideris 2004). Importantly, re- 
search shows that the requirements of new behavioural standards resulting from social and political challenges have opened a space for reflection among some men and even criticism of past models of manhood (Hunter 2003, Posel 2003, Walker 2003, Sideris 2004). However, it is indisputable that many men express deep insecurities about the gender rights project. In particular, men who feel disillusioned by their marginal socioeconomic status experience the rights that secure women against violence and those that ensure women's access to social development as unfairly privileging women. Many of those men who feel insecure construe challenges to the gender order as a struggle between tradition or culture and rights, and invoke culture to legitimise gender as an organising principle of status in social and interpersonal relations (Sideris 2004).

As a counterpoint to dominant notions of the "crisis in masculinity" that focus on gender roles and status, this chapter draws on the concept of recognition to reflect on men's insecurities and on violence in gender relations. Drawing on intersubjective conceptions of recognition, the chapter explores men's sense of threat at the interface between social structures and the psychological dynamics of gender. The value of applying an intersubjective theory of recognition to gender-related violence lies in the theory's assumption of the relational foundations of gender. This is in contrast to the dominant discourse of human rights that assumes discrete individuals and conceals the relations of power that configure gender. The lens of recognition provides important insights into the deeper relational dynamics that contribute to the sense of insecurity and crisis that wider social changes have evoked in so many men.

Furthermore, focusing on the relational dimensions of men's anxieties and of their violent behaviours raises questions about the possibilities and constraints that discourses of universal individual rights hold for ensuring security in relations between men and women. The evidence presented in the chapter points to the limitations of the focus on rights as legal processes. The law is inclined to construe social categories and identities as fixed and discrete, thereby essentialising what is variable and contested. As has been argued by many, the law cannot "eradicate" the complexity of social facts and legal principles are constantly "readjusted" (see, for example, Cowan et al. 2001:6). Nevertheless, the fixation on legal remedies that the human rights discourse encourages pays little attention to the social and psychological forces that sustain relations of domination and subordination and is unable to account for the contradictory outcomes of rights claims. 
This chapter argues that macro-political changes, in particular women's access to the entitlements of citizenship whereby they are recognised as equal legal persons in the public sphere, has exposed a crisis of recognition in the "private" realm of intimate relations. From an intersubjective perspective, the problem of recognition lies in coming to terms with our dependence on an other who is beyond our control (Benjamin 1990, 1998). We desire the other to recognise our self-assertion. Yet this remains meaningless unless the other's will for independent recognition is simultaneously met. Hence, reciprocal recognition requires that we come to terms with the tension between dependence and independence in human relationships. This amounts to constraining the tendency towards omnipotence, that is, curbing the desire for absolute control over the other (Benjamin 1998).

The dictates of socially constructed gender difference illustrate the problem well. Conventional gender ideology construes masculine ideals in terms of the absolute assertion of independence. In other words, socially constructed gender difference whereby masculinity requires the refusal of the dependency and vulnerability associated with the feminine, impedes the capacity to tolerate the contradiction between dependence and independence and the anxiety it provokes. Instead, polarised gender categories facilitate the tendency to avoid anxiety by loading the other with what we cannot bear in ourselves. Consequently, for men the feminine other becomes the container of disowned feelings of dependency.

Accordingly, where shifts in the gender order make it more difficult for men to construct women as dependent, instead of depositing disavowed dependence into women, men may conjure them as the threatening other who must be controlled. This constitutes a breakdown of recognition. If we add to this that where norms permit violence, the threat to male dominance constitutes a risk for violence (Connell 1995, Segal 1999), then it could be that the contradictions contained in South Africa's transformation have opened new avenues for old problems. Thus, the chapter does not make direct links between men's expressions of insecurity and male violence. Instead, it supports the argument that the question of recognition is central to violent relationships, more particularly everyday violence between men and women. Violence represents the inability to recognise the other as an independent entity who cannot be controlled and forced to be or do what we want without becoming a threat (Benjamin 1998).

The first section of the chapter briefly outlines theoretical accounts of recognition that signal the relevance of the psychological for our understanding of recognition. With this theoretical perspective in mind, the 
chapter turns to a more detailed examination of the responses men living in a specific social context make to changes in the gender order. Focusing on a particular case, the chapter highlights the importance of interrogating the relational matrix (Englund 2004) out of which claims for recognition emerge and the social conditions under which the breakdown of recognition may be enacted in violence. Apart from revealing how gender ideologies and cultural representations of masculinity and femininity mediate the dynamics of recognition, the social context examined throws up the question of socioeconomic injustice and its relation to the problem of recognition in gender relations.

It remains difficult when writing about gender relations to reflect the diversity and specificity of men and women and to counter writing about masculine and feminine as fixed categories (Frosh 1994). Nevertheless, in many people's everyday lives differences between masculine and feminine are sharply drawn. For the people who live in the remote rural area that this chapter focuses on, gender categories are represented as fixed. Hence, domination in domestic life continues to define successful masculinity. These sharp distinctions between what is masculine and feminine combine with the realities of poverty and unemployment, which undermine male domination to exacerbate the problem of recognition. ${ }^{2}$

\section{Recognition, negation and the psychic dynamics of domination and subordination}

Axel Honneth $(1995,2004)$ is among the better-known political philosophers to draw on a Hegelian framework to outline an inter-subjective approach to recognition. Noting three domains of recognition, he posits forms of recognition particular to each domain: recognition of the unique needs and desires of the other in primary relationships; recognition of universal equal rights in the legal sphere; and recognition of the contribution that the unique abilities of the other make to a concrete community.

For the purposes of this chapter, Honneth's (1995) typology of recognition is useful on two counts. His three-part division allows for examining tensions between domains and modes of recognition. Thus, under current conditions in South Africa the question arises how recognition in one social domain of social relating exposes the failures of recognition in others. Sec-

2. Likely, an examination of other contexts in which race and class positioned men differently would reveal subtle differences in how the tensions and failures of recognition play out. 
ond, in a social context where practices in intimate relations have become a key site of contestation, Honneth's (1995) suggestion that recognition in primary relations is a precondition for all future forms of self-respect and participation in public life (1995) is provocative, inviting us to consider the significance of psychological and relational dynamics for wider social and political relations.

Despite these merits, Honneth does not effectively theorise the domination that is contained in the dynamic of recognition. Psychoanalytic feminist Benjamin (1998), whose work addresses the question "how is it possible to recognise an other?" seeks, as does Honneth (1995), mutual recognition as an ideal. However, Benjamin (1998) concedes, indeed emphasises, the universal human tendency towards omnipotence and hence assimilation of the other. To this extent, Benjamin (1995) posits there is no ideal context that can eliminate the anxiety evoked by the encounter with the other. She argues that when such encounters are experienced as challenges to omnipotent control the tendency to reduce the other to same, or to convert her to a threat, is exaggerated. Thus the encounter with otherness inevitably involves a tendency to negation. According to Benjamin (1995) symbolic processing of this negation is critical to recognition of the other as an independent entity.

Minsky (2004), in her analysis of the impact of changes in gender relations on men, takes up the psychoanalytic theory that gender categories require men to defensively disown their feelings of dependence and vulnerability and cast these on to women. Women's access to the world of men in work, education and knowledge and their growing sense of identity as active agents, characteristics usually associated with the masculine, erode the defence of projecting vulnerability on to women, "because it so obviously flies in the face of all evidence to the contrary" (Minsky 2004:2). Growing unemployment among men, women competing in the job market and women's access to welfare undermine men's roles as protectors and providers. This, combined with women's sense of agency, Minsky argues, constitutes the risk that "for the first time" men's vulnerability will be exposed (2004:3).

\section{Transformation in South Africa - Tensions between domains of recognition}

The men whose testimony this chapter draws on live in a rural corner of South Africa, Nkomazi, a slither of land and congested villages stradd- 
ling the Mozambican and Swaziland borders in the south-east corner of Mpumalanga province. Part of a former homeland under the previous regime, the area still bears the scars wrought by apartheid's separate development policies - extreme poverty, high levels of unemployment, poor infrastructure, no industrial base and a limited commercial sector. More recently, the visible gap in wealth between an emerging elite and the rest of the population, and an alarming rate of AIDS-related deaths have intensified the harsh conditions of life for the majority of people living there.

Under apartheid, the dogma of the homeland project had as a central theme ethnic division under the scheme of preserving "tradition" and "culture". Of course, this form of rule relied on caricatures of tradition and particularly static notions of culture. Yet one of the continuing effects of this system is that the notion of "culture" retains a powerful place in specifying identity and gender conflicts. Although post-apartheid local government structures are being established to take over some of the functions of the tribal authorities, the South African constitution protects traditional institutions, and in many rural areas they continue to wield power. In the face of challenges to male domination, representatives of these institutions are at the forefront of appealing to tradition to reassert male authority, especially in the "private" sphere of family relations.

There is no typical family form in Nkomazi. Domestic arrangements vary widely. There are female-headed households in which women bear the major responsibility for the care and subsistence needs of children and elderly adults. There are households where aged grandparents assume responsibility for their children's children. In addition, there are cases in which children orphaned by AIDS-related deaths are becoming responsible for each other. Despite such wide variations in family structures, a set of dominant beliefs regarding family roles, duties and obligations has wide currency. Particularly strong are those relating to age and gender hierarchies and the influence of extended family networks and external traditional authorities. Calling on elder members of the extended family and representatives of traditional authorities to resolve family conflicts continues and usually this practice operates to reinforce hierarchies. A brief description of a case presented to a local women's centre, Masisukumeni Women's Crisis Centre, illustrates this process.

A young married woman, having heard about rights to protection from abuse under the Domestic Violence Act, sought help from the centre to apply for a court interdict to protect her from frequent and regular physical abuse by her husband. Her application was successful and the sheriff of 
the court delivered a protection order to the husband instructing him to cease beating her, failing which he faced arrest. The man, incensed by her actions, called a meeting of the family elders, which included elder females. Upon deliberation, the elders decided that the woman had acted against "tradition" on two counts. In the first place, they felt there was some justification in her husband's violence, which they considered discipline rather than abuse. Second, it was felt that she should have brought her complaint to the elders rather than taking it to an outside agency. On these grounds, they imposed a fine on her.

Given the centrality of the family to the definition of successful manhood, it is not surprising that challenges to the order of gender relations in the domestic sphere are responded to with such alarm. It is widely held that having a wife and child over whom one has authority confers the status of manhood. In others words, boyhood aspirations to manhood incorporate the fantasy of becoming the head of a family. This heterosexual imperative animates the following two excerpts from interviews with men in Nkomazi.

To be considered a man you must have a woman. If you are not married, you can't go to the places where men are discussing problems. Without a wife and a child, you are still a boy.

The man should have the final say. We are two in the house but I am the boss of the house. Because I have married this wife she must obey the rules and regulations of my home. I don't want her to lend my things to others. I don't want my wife to have friends outside and discuss things. I don't want her to leave the premises.

Clearly, while political change challenges the "legitimacy" of men's privileged status over women, the ideology that constructs masculinity in terms of power has not been displaced (Segal 1990). And in places like Nkomazi, "culture" or "tradition" are invoked to justify this authority. Arguably, challenges to the legitimacy of male domination, which confront men with women as independent others, reveal the fragile foundations on which their own sense of difference, their sense of themselves as men, is based. Consequently, for those men who continue to hold domination as an ideal but whose capacity to exercise absolute control is constrained, there is a risk that their fragility is being exposed (Segal 1990, Minsky 2004)

However, it is not the "first time" (Minsky 2004:3) that men living in areas such as Nkomazi have experienced challenges to the order of gender relations in the household. Apartheid undermined African masculinity (see 
Campbell 1992, Simpson and Kraak 1999, Morrell 2001). Where male labour migrancy was dominant, women left to manage the household exercised significant power in the domestic area. Moreover, racial and class oppression saw to it that many men were unable to adequately fulfil their role as providers. In the past, however, when women's exercise of power and self-sufficiency was perceived as a threat, traditional authority structures, the custodians of patriarchy, supported by the apartheid state rallied to keep women in their place and reinforced the construction of women as the weak and dependent other.

What is significant in the current context of political transformation is that there is a formal limit to such attempts to reassert male dominance. The equal status of men and women enshrined in the constitution obliges the state to enforce legal equality. In practice, the implementation of this obligation often miscarries. Complex plays of power between men and women influence the success of struggles to reassert male control. However, the constitutional order and new legal regimes present men at the very least with symbolic limits.

To this extent, men cannot completely escape the obligation to recognise women as autonomous legal persons. Even in remote rural areas, more women are pursuing legally defined rights, such as those to financial maintenance and protection from violence. Generally, they pursue these as individuals, and defensively rather than in a collective bid to reconfigure wider structures of power. Nevertheless, such individual forms of resistance test the boundaries of male authority and present many men with women with whom they must enter relations of negotiation rather than subjugation. Furthermore, the increasing regulation of domestic relations through the courts alters the terms of negotiating power. For example, laws such as those that order men to pay maintenance transform the personal obligation of the individual patriarch to provide for his family into a legal duty, undermining his status (Brod 1990:132). Simultaneously, women's access to welfare benefits, in particular childcare grants, undercuts dependence on men,

The following statements express the sense of unease that these challenges provoke.

Gone are the days of a man being in power. We are inheriting western style. As African we are lost. As men we are feeling it. As African we don't know where we are. 
We are moving to equity very fast. Even in the work sphere there is equity. Men feel threatened by this. We don't know what the role of men is any more. This is a challenge. If you look at a man's status culturally, it was above, also in the church and in religion. One has to prove oneself. Some men resort to force to protect their status.

Clearly, current conditions expose men's fragility. As has been suggested above, the fact of women's presence in the public sphere and the growing numbers of women who survive independently defy the fantasy that women are the vulnerable ones. Thus, we might argue that the "crisis" is constituted not simply by the exposure of male fragility. Indeed it is reasonable to argue that for men the "crisis" lies in having to take ownership of their vulnerability, since social conditions render its disavowal more difficult. The key question that arises then is, how do men deal with the vulnerability that is cast back to them?

\section{Changes and continuities in the conditions for the possibility of violence}

There is ample evidence to show that the ideal of male domination in intimate relationships is strongly associated with the violation of women. A long tradition of feminist scholarship has identified a high correlation between violence against women and rigidly defined gender categories, which contain definitions of masculinity associated with absolute dominance. However, within this body of knowledge there is a strong argument that the conditions constituting the highest risk for violence are those in which men's dominance is frustrated. For example, Segal (1990) and Connell (1995), both of whom interrogate social situations to identify factors that promote or constrain violence, note men's differential access to power and the elusive nature of the success and agency associated with masculinity as high risk factors. In this view, violence may be enacted as a compensation for the emptiness of the promise of masculine ideals.

Thus, men's anxieties about failure are best understood in relation to the social assumption that men should dominate (Segal 1990, 1999). Emphasising the relational dimensions of this dynamic, Benjamin suggests that the desire for omnipotence or absolute control is recharged in the moment we confront reliance on an other who is outside our control (Benjamin 1998:95). While this body of work provides a general theoretical perspective on the risks of male violence, it simultaneously stresses that violent be- 
haviour is most likely where locally specific moral codes and norms permit violence.

In Nkomazi, violence and the threat of violence against women in intimate relations, though regulated, are sanctioned both to define male authority and to defend against its destabilisation. Below, an induna, a local headman, describes the mechanisms used to deal with conflicts that arise when women transgress their expected submission to men as heads of families.

The community does not just accept that violence. What is acceptable is that a woman must submit. Nowadays there are laws. Before there were indunas and they put him at the ibandla [traditional court]. If he is wrong they penalise him. You cannot beat your wife for anything. After you have undergone certain stages of disciplining and they don't work, then you can beat her

Thus, everyday beatings, verbal abuse and sexual abuse in families are not new phenomena. Many men interviewed gave accounts of their own experiences of domestic violence as children. For example:

My father used to beat my mother. I remember one day I saw my mother with sores. My father used to beat her with a sjambok [a whip]. I still see those sores now. I thought my mother would die with those wounds. As a boy I was afraid, thinking it was not right the way he beat her. I was also afraid when he beat me thinking that I have done a bad thing.

Instead of eradicating these forms of violence, conditions of social and political transformation have revealed the contradiction between men's culturally invested fantasies of absolute independence and control (Benjamin 1986) and their actual relations with women. In areas like Nkomazi, the construction of women as submissive and dependent continues to hold a key place in defining the success of manhood. This ideal constitutes a constant reminder of men's dependence on women. However, by promoting women's relative autonomy, the gender rights project exposes men's dependence on women who are beyond their control.

Men's testimony quoted below communicates the particular kind of threat that these developments provoke. The assumption that as women assert their independence they will render men impotent echoes with the anxiety evoked by the paradox of recognition.

Women think they should do things their way, irrespective of what their husband says and in the end they get divorced. That is what is happening. In our African way the man has the last word at home. This affects them, they (wom- 
en) make the man think that they are no more the heads and they are inferior. I take gender rights as a threat to the family. It is a threat to me for instance when it is said the wife has the right to do whatever she thinks is good.

Mmm, you see these equal rights, I think sometimes they are a burden for men. Especially when you find that a woman is working and the man is not working. Or maybe they are both working but the woman is earning more than the man. Obviously she turns to undermine her husband you see. You have to do one, two, three, when she tells you to. Every time she will tell you what to do. If you go against her or refuse then she tells you her rights. So this thing of rights I don't like it.

I don't say the law is wrong. The people who are using the law are the people who are wrong. Now you can hear there is women's rights. Women want all their rights. This shocks men. I have seen many men leaving their homes because of women's rights.

If, as Benjamin (1998) argues, mutual recognition requires symbolic processing of the inevitable negation contained in the other's assertions of independence, then this testimony speaks to significant obstacles. It is evident that these men do not envision taking ownership of the vulnerability that is cast back to them. In Benjamin's (1998) terms, we can argue that there is a breakdown of recognition. "(I)t is when the other is not able to change or recognize the effect, but only deflects, attacks, or withdraws (the other is 'destroyed') that we can speak of a breakdown of recognition" (Benjamin 1998:96).

In summary then, beliefs that men's superiority over women is "natural", verified by culture, the Bible and even God, still have currency. The contradiction between this ideology and actual experiences of women's capacity requires that men vigorously disavow what is associated with the feminine. The alternative, that is, to accept women as independent persons, confronts them with taking ownership of fragility and dependence for which there are few role models. Instead, these contradictions "recharge" fears of loss of omnipotence (Benjamin 1998:95). This provokes intense anxieties and with little social support men are liable in defensive manoeuvres to convert the other into threat. They reduce the women with whom they are intimately involved into threatening others, whom they blame for the socially generated frustration of masculine ideals. This breakdown in recognition combines with the permission given to male violence by prevailing customs and moral codes to provide a route via which men may discharge vulnerability in violence against women. 
Hence, everyday violence between men and women gives continuity to the past, but is reproduced by a new set of social forces in similar ways to the misogyny described by Blagojevic, who writes about transition in Serbia.

(M) isogyny is both new and old; it is based on relatively permanent cultural patterns, but it is also renewed in a different context, reproduced differently, influenced by new social forces (Blagojevic 2004:4).

\section{Misrecognition and maldistribution - "Crosscutting axes of subordination"?}

It is not surprising that, alongside gender rights, many men name poor economic prospects as a critical threat to their sense of themselves as men. By frustrating the requirement to provide, economic marginalisation makes realising the role of head of a family and the authority contained in this position more remote for a growing number of men.

I also see that she is worried about my not being able to maintain the family. She looks at me. Even if I speak with her, there is no respect. I do not feel like a proper man.

It's painful. All the children are attending school. It is difficult to support them. In the community you are not respected. You don't communicate well with others, even your own children. Because you don't have enough money your wife does not respect you.

Neither is it unexpected that poverty increases risks for interpersonal violence. South African research documents increased risks of violence for the poor (see Bennet 2000, Rasool et al. 2002). Socioeconomic vulnerabilities afflicting men and women do intersect with particular patterns of value to aggravate conflicts, which often end in violent attacks on women. Furthermore, poverty limits the possibilities for escape and the options for change (Bennet 2000, Sideris and Nsimbini 2001).

In his explanation of what led him to beat his wife, one of the men interviewed described how the frustrations generated by scarcity meet with gendered assumptions about respect and submission.

I asked her to give me food. She said, where do you think I must get food. You can see there is no food. There was a little that I bought. She took it and gave it to the children. She didn't answer me in a good way - she shouted at me. It's the way she spoke and behaved. Then I beat her. 
More sinister, however, is the backlash that may arise when men fuse the threats they experience in relation to gender rights and economic marginalisation. For example:

I am only a listener in the house. But one day if I can get a job all the rights will stop. In my home the rights will finish. Now my wife earns R250.00 [about $\$ 40]$ per month. If I go and work and earn R2000.00 [about \$300] then I will be the father [patriarch] of the house. Then I can have equality. Now with her R250.00 she just talks. I know the father should have the final word. But husbands not working have no say. You eat what you get. If you want to ask a question you must put your money down. The wife even puts you down in front of your children.

Simplistically, we might argue that economic injustice is an impediment to the development of mutual recognition. However, there is abundant evidence to show that struggles for redistribution do not necessarily displace those cultural ideals that systematically devalue the feminine. Neither can we assume that economic justice empties gender categories of the polarised content whereby masculine and feminine come to be associated with independence and dependence, domination and submission.

However, from the evidence presented it is clear that axes of subordination do crosscut (Fraser 1995) in complicated ways and with negative effects. The men on whom this chapter draws are simultaneously silencers and silenced. They are the other of racial projections and the subjects of denigrating constructions of women. Concurrently, they are exploiters and exploited, subjected to economic marginalisation and the consumers of the unpaid labour of women.

If we consider the implications of the potential backlash suggested above for continuities of violence between men and women, then it is important to understand contributing factors. Fraser's work $(1995,2000)$, in which she examines the intersection of different forms of social injustice, provides important insights. In her critical response to theories and politics of recognition (Fraser 1995), she laments the displacement of struggles for redistribution by claims for recognition of identity, and cautions against the increasing mobilisation around such claims towards separatism, intolerance and authoritarianism (Fraser 1995, 2000). While she accepts the validity of injuries of misrecognition, she insists on a politics and a critical theory that addresses maldistribution, asserting that these injustices have distinct causal roots and require unique remedies. 
Of particular relevance to the arguments put forward in this chapter is Fraser's (1995) point that, because affirmative remedies do not transform the underlying structures which generate injustice, simultaneous claims for recognition and redistribution may not only be at cross purposes but can result in backlash responses. She notes affirmative remedies to gender injustice in the economy involve surface reallocation. In practice, Fraser (1995) argues, these reallocations result in differentiating women as a needy group who in time come to be seen as recipients of undue special treatment and privilege. This has the potential effect of galvanising gender-based conflicts over resources, thereby fuelling misrecognition. Where this combines with affirmative strategies of recognition that, by calling attention to women's difference, underscore rather than deconstruct polarised gender categories, the result may be to intensify the resentment generated by affirmative redistribution.

It is not difficult to see how these factors play out in South Africa, where the gender rights project has encompassed affirmative action. This has had the complicating effect of differentiating women as a group and marking them as privileged recipients of benefits (Fraser 1995), providing a rationale for the perception among many men that women have gained disproportionately from political transformation. Simultaneously, the discourse of rights that assumes autonomous individuals and conceals the relational matrix (Englund 2004:12) out of which claims for women's recognition emerge, tends to reinforce gender antagonisms. Consequently, as Fraser (1995) contends, this discourse adds fuel to the flames of resentment.

The theories of Benjamin $(1990,1998)$ and Fraser $(1995,2000)$ address distinct structures, the psychic and the social, and arrive at seemingly contrary views on the problem of difference. Nevertheless, the case study examined in this paper suggests a potentially useful intersection of their theories that reinforces the significance of psychological and relational dynamics for wider social and political relations. For Fraser (1995), the ideal contained by transformative remedies for injustice lies in destabilising group differentiation by deconstructing identities and undermining distinctions grounded on disadvantage via politico-economic restructuring. Benjamin (1990; 1998), on the other hand, seeks respect and recognition of difference.

It has been argued that the dangerous effects of what Fraser (1995) terms affirmative remedies lie less in acknowledging difference than in the fixing of polarities (Lister 2003). Looking more concretely at the example of economic injustice, we might suggest that affirmative remedies identify 
women as a special case. Perceptions that development initiatives aimed at women as a discrete group are designed to increase their economic independence evoke in men precisely those feelings that culture demands they should disavow - vulnerability and dependence (Benjamin, 1990; 1998). Simultaneously, affirmative remedies that allow for relative economic selfsufficiency among women operate to render less effective the defence of projecting these disavowed feelings (Minsky, 2004). We return to the argument that South Africa's political transformation, or more accurately, drawing on Fraser (1995), the particular form that transformation has taken, contributes to the breakdown of recognition and the conjuring of women as the threatening other. Hence, positive and emancipatory policies can hold the possibility of renewed violence.

\section{Conclusion}

In South Africa, old patterns of violence between men and women are being reproduced at an alarming rate in the moment of a political transformation that advances human rights with the aim of promoting freedom from violence and facilitating human development. The attempt in this chapter to contribute some insight into this paradox has generated two principal arguments. First, the chapter provides an alternative view of the sense of crisis and insecurity that so many men are communicating. Second, by focusing on how the relational foundations of gender complicate legal assertions of equality, it has suggested the limitations of the human rights discourse as a solution to problems of security and development.

The examination of men's responses to challenges to the order of gender relations through an intersubjective theory of recognition provides a deeper understanding of the anomalies of the gender rights project as it has unfolded in South Africa. Honneth's (1995) theory of different domains of recognition provides an important tool with which to understand how the recognition of women as equal legal persons in the public sphere has evoked a crisis of recognition in the "private" sphere. On the evidence presented, it is reasonable to argue that in the context of transformation in South Africa we witness a significant tension between these domains of recognition.

The constitutional endorsement of gender equality and the will growing numbers of women are showing to assert their rights in the "private" domain presents individual men with the test of recognising the women they are involved with as persons in their own right, with unique needs and independent wills. This is in direct contrast to traditional notions of het- 
erosexual relationships, which, organised by gender hierarchies, grant men the authority to decision-making without the obligation to consider the needs and wills of their subordinates. Using Honneth's (1995) terms, we might argue that including women in the ascription of universal rights has unsettled the assumption that rights in the domain of domestic relations are conferred by gender status, thus provoking this tension.

Of course, it is not surprising that so many men in South Africa have been taken aback by recent constitutional and legal changes. South Africa has moved from a situation in which patriarchal ideology was allied to racial oppression and found expression in apartheid through Christian nationalism and customary law. Despite this, the salience of racial oppression and the project of national liberation obfuscated gender in the structures of coercion that characterised apartheid. Gender equality did not figure prominently in liberation fantasies. Nor did most South Africans imagine that gender rights, as part of the human rights discourse, would reach so far into the domains of life assumed to be under the charge of custom or considered to be "private". Neither is it unexpected that many men feel threatened by the challenges to the assumed legitimacy of their positions of power and communicate a sense of "crisis" about their manhood. But, this chapter has argued, the picture is more complex because, in their testimony, the men on whom the chapter focuses locate the threat in the women with whom they are intimately involved.

This raises the question that is implicit in the chapter, "wherein lies the crisis?" The work of psychoanalytic feminist Benjamin (1990, 1998), for whom the tension between dependence and independence is foundational to recognition in gender relations, shows a keen perception of the links between deep psychological dynamics of gender and socially constructed gender categories. The anxieties about dependency that masculine ideals fuel, and the constraints that social change place on the defensive tendency to cast vulnerability on to women, give us a more critical interpretation of the men's tendency to conjure the women to whom they are closest as the threat. Thus, the chapter suggests, "crisis" is evoked when men confront, in their most intimate relations, their dependence on women who are positioned beyond their control by socio-political transformation.

The application of Fraser's (1995) insights to testimony that shows men merge the threat they feel in relation to gender equality and economic marginalisation further bears out the value of a relational perspective for comprehending the contradictory outcomes of the rights and development projects in South Africa. The analysis of where, and with what consequenc- 
es, inequities in economic distribution and the injuries of misrecognition crosscut Fraser's (1995) work highlights the wider structural relations that underpin gender. Particularly relevant in the South African context is Fraser's (1995) theory that interventions that are affirmative, rather than those which transform the structural relations that underpin inequity, have the paradoxical effect of fuelling difference, divisions and antagonisms. And based on the evidence in this chapter, it is reasonable to argue that under particular conditions affirmative remedies may contribute to reproducing violent conflicts between men and women (Fraser 1995).

On the other hand, it goes without question that legislative reforms constitute a significant advance for South African women, opening up new possibilities to protect their integrity and to participate in public life. Neither should we underestimate the utility the rights discourse has had in the South African context in emphasising state obligations towards human security and for improving the potential of individual women in relation to these obligations. Without negating these possibilities, the evidence on which the arguments in this chapter draw raises critical questions for those who commonly posit human rights as the bridge between human security and development. 


\section{List of Authors}

Dr. LARS BUUR is senior researcher at the Danish Institute for International Studies and research associate at the University of the Witwatersand's Institute for Social and Economic Research, Johannesburg. He has long-term field research experience from South Africa and Mozambique on truth and reconciliation, community policing, vigilantism and sovereignty. His current research focuses on public participation and representation in the politics of decentralisation and governance, and the relationship between the informal economy and politics. He has co-edited the following volumes: Everyday Policing in South Africa (African Studies 2004); State Recognition of Local Authorities and Public Participation (Kapicua 2006 forthcoming); A New Dawn for Traditional Authorities? (Palgrave forthcoming). He has published articles in Anthropology and Humanism, Journal of the Danish Ethnographic Society and, more recently, in the Journal of South African Studies and Development and Change, as well as numerous peer-reviewed book articles on human rights, truth and reconciliation, vigilantism, traditional authority and sovereignty.

Dr. STEFFEN JENSEN is senior researcher at the Rehabilitation and Research Centre for Torture Survivors and teaches at the International Development Studies Centre at Roskilde University. He has worked on issues of state formation, local politics, vigilantism, policing and youth cultures in rural and urban South Africa. As part of the research project "The Political Economy of Victimhood", his current research focuses on how local NGOs and the beneficiary population negotiate and appropriate global victim categories in Guatemala and South Africa. He has co-edited the volume, Everyday Policing in South Africa (African Studies 2004) and is presently working on a volume entitled Reforming State Violence on prison, court and police reform in transitional societies. He is the author of several articles in journals and edited volumes. He is finalising a book on gangs, politics and dignity in Cape Town. 
Dr. FINN STEPPUTAT is senior researcher at the Danish Institute for International Studies. Trained in economic geography and cultural sociology, he has published extensively on issues of forced migration, conflict, state formation and sovereignty. He has long-term field experience in Guatemala, Peru, Mexico and Colombia, but has more recently taken an interest in comparisons across Africa, Asia and Latin America. He co-edited the volumes States of Imagination. Ethnographic Explorations of the Post-colonial State (Duke University Press 2001), Sovereign Bodies. Citizens, Migrants and States in the Postcolonial World (Princeton University Press 2005), and Fragile States and Insecure People (Palgrave forthcoming).

HELENE MARIA KYED is a PhD candidate at Roskilde University and the Danish Institute for International Studies, with an MA honours in social anthropology from Aarhus University, Denmark. Her master's thesis dealt with decentralisation and local politics in Zimbabwe. At the moment, she is completing her $\mathrm{PhD}$ thesis on "State Formalisation of Traditional Authority: State Formation, Decentralisation and Changing Forms of Authority in Mozambique", based on 14 months of fieldwork in Manica Province. She co-edited the volume, State Recognition of Local Authorities and Public Participation (Kapicua 2006 forthcoming). She has published articles in Development and Change and the Journal of Southern African Studies.

Dr. HENNING MELBER is executive director of the Dag Hammarskjöld Foundation in Uppsala. He studied political science at the Free University of (West-)Berlin, graduating in 1977, received his $\mathrm{PhD}$ from the University of Bremen in 1980 and obtained a venia legendi (habilitation/associate professor status) in development studies in 1993. He was senior lecturer in international politics at the University of Kassel (1982-92), director of the Namibian Economic Policy Research Unit (NEPRU) in Windhoek (1992-2000), and research director at The Nordic Africa Institute in Uppsala (2000-06). He has published widely on racism, solidarity and liberation movements, in particular in southern Africa and Namibia. His latest publications include (as editor and contributor): Re-examining Liberation in Namibia. Political Culture since Independence (Nordic Africa Institute 2003); Limits to Liberation in Southern Africa: The Unfinished Business of Democratic Consolidation (HSRC Press 2003); Legacies of Power. Leadership Change and Former Presidents in African Politics (HSRC Press and The Nordic 
Africa Institute 2006); Transitions in Namibia: Which Changes for Whom? (Nordic Africa Institute 2007 forthcoming). He is a co-editor of the Africa Yearbook (Brill) published annually since 2005.

AMANDA HAMMAR is a programme coordinator at The Nordic Africa Institute in Uppsala, Sweden, where she coordinates the "Currencies of Transformation in Africa in Times of Uncertainty" research programme. She has over 15 years of policy and practical experience in various aspects of rural development, natural resource management, local government reform and decentralisation in southern Africa. Her previous research focused on the cultural politics of land in Zimbabwe, agrarian politics more broadly in southern Africa, state formation in the margins and the complex dynamics and effects of the Zimbabwe crisis. Based on her doctoral ethnographic research on land, authority and belonging in Zimbabwe's agrarian margins, she has published articles in several peer-reviewed journals and edited and co-edited books, including Zimbabwe's Unfinished Business: Rethinking Land, State and Nation in the Context of Crisis (Weaver Press 2003).

JACOB RASMUSSEN recently received his MA in social anthropology from the University of Copenhagen. His thesis is entitled "Living with Fear: Violence and the Practice of Avoidance in inner city Johannesburg". It was based on seven months of fieldwork in Johannesburg's inner city. For three years, he has been on the editorial board of the Danish popular scientific journal Jordens Folk. Current research interests include urban development in southern Africa.

Dr. TINA SIDERIS is a clinical psychologist practising in South Africa. Over the past 12 years she has combined theoretical work, field research, clinical practice and activism in work on gender-related violence. Her work has covered the psycho-social sequelae of sexual violence perpetrated during war; sexual violence in the aftermath of conflict; gender, identity and power; masculinity in the context of political transformation; gender and social reconstruction; psychosocial research and the significance of the psychological for our understanding of social phenomena. She has written numerous articles that have been published in the popular media, edited collections and in peer-reviewed journals, including AGENDA, African Studies, Psychoanalytic Psychotherapy in South Africa, Psychoanalysis and Culture and Society. 
GUY LAMB is the head of the Arms Management Programme at the Institute for Security Studies in Pretoria/Tshwane, South Africa. He has been undertaking research on peace and security issues in Africa for the past ten years. His current research interests include causes and consequences of armed violence, as well as arms control and disarmament in Africa. He is co-editor of: Demilitarisation and Peace-Building in Southern Africa Volume III: The Role of the Military in State Formation and Nation-building (Ashgate 2004); Hide and Seek: Taking Account of Small Arms in Southern Africa (Centre for Conflict Resolution/Gun Free South Africa/Institute for Security Studies 2004); and National Human Rights Institutions in Africa: Defenders of Human Rights, Managers of Conflict, Builders of Peace? (Centre for Conflict Resolution 2006).

LALLI METSOLA is a $\mathrm{PhD}$ candidate at the Institute of Development Studies, University of Helsinki, with an MA in cultural anthropology from the same university. His $\mathrm{PhD}$ research examines ex-combatant "reintegration" in Namibia as a way of studying issues of state formation, citizenship and subjectivity, on the basis of fieldwork in Windhoek and the Ohangwena and Oshana regions. He his most recent article was published in Third World Quarterly.

THOMAS MANDRUP is a PhD candidate at the Institute for Political Science, University of Copenhagen, with field research experience in South Africa, Zimbabwe, DR Congo and Sudan on post-conflict nation-state formation, peace support operations, defence sector reform and conflict management. His current research focuses on the role of the South African National Defence Force in South Africa's foreign policy. His most recent article was published in the South African armed forces journal, Scientia Militaria, on the concept of sovereignty in Africa. 


\section{List of References}

Adler, G. and J. Steinberg, 2000, "Introduction: From Comrades to Citizens", in Glen Adler and Jonny Steinberg (eds), From Comrades to Citizens: The South African Civics Movement and the Transition to Democracy. London: Macmillan., pp. $1-25$.

Agamben, G., 1998, Homo Sacer: Sovereign Power and Bare Life. Stanford: Stanford University Press (translated by Daniel Heller-Roazen).

—, 2000a, Means Without End: Notes on Politics. Vol. 20. Minneapolis and London: University of Minnesota Press.

—, 2000b, "What is a People?", in Giorgio Agamben, Means without End. Notes on Politics. Minneapolis and London: University of Minnesota Press, pp. 28-34.

Alexander, J., 1997, “The Local State in Post-war Mozambique: Political Practices and Ideas About Authority”, Africa, vol. 6, no. 1, pp. 1-26.

—, 2003, “'Squatters', Veterans and the State in Zimbabwe”, in Hammar, A., B. Raftopoulos and S. Jensen (eds), Zimbabwe's Unfinished Business: Rethinking Land, State and Nation in the Context of Crisis. Harare: Weaver Press, pp. 83-117.

—, and J. McGregor, 2003, "Democracy, Development and Political Conflict: Rural Institutions in Matabeleland North After Independence", in Ranger, T. (ed.), The Historical Dimensions of Democracy and Human Rights in Zimbabwe. Volume Two: Nationalism, Democracy and Human Rights. Harare: University of Zimbabwe Press, pp. 113-33.

-, J. McGregor and T. Ranger, 2000. Violence and Memory: One Hundred Years in the 'Dark Forests' of Matabeleland. Oxford, Portsmouth, Cape Town, Harare: James Currey/Heinemann/David Philip/Weaver Press.

Andersen, L., 2005, International Engagement in Failed States: Choices and TradeOffs. DIIS Working Paper no. 2005/20. Copenhagen: Danish Institute for International Studies, pp. 1-43.

Anderson, B., 1991, Imagined Communities. London and New York: Verso.

Arendt, H., 1982, Lectures on Kant's Political Philosophy. Chicago: University of Chicago Press.

Baker, B., 2002a, "Living with non-State Policing in South Africa: The Issues and Dilemmas", Journal of Modern African Studies, vol. 40, no. 1, pp. 29-53.

—, 2002b, Policing and the Rule of Law in Mozambique. Wolverhampton: Centre for International Development and Training, University of Wolverhampton.

Balibar, E., 1991, “The Nation Form: History and Ideology”, in Balibar, E. and I. Wallerstein, Race, Nation and Class. Ambiguous Identities. London and New York: Verso, pp. 86-106.

Banda, C., 2003, Eskom writes off R1.4bn for Joburg townships. IOL.co.za. 1 May 2003. Bayley, D., 1995, "A Foreign Policy for Democratic Policing", Policing and Society, vol. 5, no. 2, pp. 79-93. 
Becker, B. (ed.), 2005, Speaking Out. Namibians Share their Perspectives on Independence. Windhoek: Out of Africa.

Benjamin, J., 1986, “A Desire of One's Own: Psychoanalytic Feminism and Intersubjective Space", in de Lauretis, T. (ed.), Feminist Studies/Critical Studies. Indiana: Indiana University Press. http://www.dspp.com/benjamin.htm, accessed 23 March 2004.

—, 1990, Bonds of Love. Psychoanalysis, Feminism and the Problem of Domination. New York: Pantheon.

—, 1995, "Recognition and Destruction: An Outline of Intersubjectivity", in Benjamin, J., Like Subjects, Love Objects: Essays on Recognition and Sexual Difference. New Haven: Yale University Press. http://psychematters.com/art2. htm, accessed 23 February 2004

—, 1998, Shadow of the Other. Intersubjectivity and Gender in Psychoanalysis. London: Routledge.

Bennet, J., 2000, Summary Report: Preliminary Review of Current South African Research Being Undertaken (or Completed) on Gender-Based Violence, Peace-Building and Development Initiatives in South Africa, for Oxfam, Canada.

Blagojevic, M., 2004, "Misogyny: Invisible Causes, Painful Consequences”. http://216.239.41.104/search?q=cache;b36XhJ87G4cJ:www.awin.org.yu/, accessed 21 April 2004.

Borges Coelho, J.P. and P. Macaringue, 2004 “The Role of Mozambique's Armed Forces in a Changing Security Context", in Batchelor, P., K. Kingma and G. Lamb (eds), Demilitarisation and Peace-building in Southern Africa Vol. III. Aldershot: Ashgate, pp. 34-61.

Boshoff, H., 2005, Summary Overview of the Security Sector Reform Processes in the $D R C$. Pretoria: Institute for Security Studies.

Bourdieu, P., 1991, Language and Symbolic Power, Cambridge: Polity Press.

—, 1999, "Rethinking the State: Genesis and Structure of the Bureaucratic Field", in Steinmetz, G. (ed.), State/Culture: State-Formation after the Cultural Turn. Ithaca, NY and London: Cornell University Press.

—, and L.J.D. Wacquant, 1992, An Invitation to Reflexive Sociology. Cambridge and Oxford: Polity Press.

Boyarin, J., 1994, “Introduction”, in Boyarin; J. (ed.), Remapping Memory. The Politics of Time Space. Minneapolis and London: University of Minnesota Press.

Bracking, S., 2005, "Development Denied: Autocratic Militarism in Post-election Zimbabwe”, Review of African Political Economy, vol. 32, nos. 104 \&105, pp. 341-57.

Bratton, W., 1998, "Crime is down in New York City: Blame the Police", in Dennis, N. (ed.), Zero Tolerance: Policing a Free Society. London: IEA Health and Welfare Unit.

Bremner, L., 2000, "Reinventing the Johannesburg Inner City", Cities, vol. 17, no. 3, pp. 185-93.

Breytenbach, W., D. Chilemba, T.A. Brown, and C. Plantive, 1999, Conflicts in the Congo: From Kivu to Kabila. Pretoria: Institute for Security Studies. 
Brod, H., 1990, "Pornography and the Alienation of Male Sexuality", in Hearn, J. and David Morgan (eds), Men, Masculinities and Social Theory. London: Unwin Hyman.

Brogden, M., 2004, "Commentary: Community Policing: A Panacea from the West", African Affairs, vol. 103, no. 413, pp. 635-49.

-, and C. Shearing, 1993, Policing for a New South Africa. London: Routledge.

Brown, S., 1995, "Diplomacy by Other Means - SWAPO's Liberation War", in Leys, C. and J.S. Saul (eds), Namibia's Liberation Struggle: The Two-Edged Sword. London: James Currey, pp. 19-39.

Bukurura, S., 1996, "Combating Crime among the Sukuma and Nyamwezi of WestCentral Tanzania”, Crime, Law and Social Change, vol. 24, no. 3, pp. 257-66

Bundy, C., 2000, "Survival and Resistance: Township Organizations and Non-violent Direct Action in the Twentieth Century", in Adler, G. and J. Steinberg (eds), From Comrades to Citizens: The South African Civics Movement and the Transition to Democracy. London: Macmillan, pp. 26-51.

Buur, L., 2000, "Institutionalising Truth: Victims, Perpetrators and Professionals in the Everyday Work of the South African Truth and Reconciliation Commission". PhD dissertation, Department of Ethnography and Social Anthropology, Aarhus University, Denmark.

—, 2001a, "Making Findings for the Future: Representational Order and Redemption in the Work of the TRC", South African Journal of Philosophy, vol. 20, no. 1, pp. 42-65.

—, 2001b, "The South African Truth and Reconciliation Commission - a Technique of Nation-state Formation", in Hansen, T. Bolm and F. Stepputat (eds), States of Imagination. Durham NC and London: Duke University Press, pp. 149-81.

—, 2003a, "Crime and Punishment on the Margins of the Post-Apartheid State", Anthropology and Humanism, vol. 28, no. 1, pp. 23-42.

—, 2003b, “'In the Name of the Victims': The Politics of Compensation in the Work of the South African Truth and Reconciliation Commission”, in Gready, P. (ed.), Political Transition: Politics and Cultures. London and Sterling VA: Pluto Press, pp. 148-64.

—, 2005a, "The Sovereign Outsourced: Local Justice and Violence in Port Elizabeth", in Hansen, T. Blom and F. Stepputat (eds), Sovereign Bodies: Citizens, Migrants, and States in the Postcolonial World. Princeton: Princeton University Press, pp. 192-17.

—, 2005b, "Sovereignty and Democratic Exclusion in the New South Africa", Review of African Political Economy, vol. 32, no. 104/5, pp. 253-68.

— and H. Kyed, 2005, State Recognition of Traditional Authority in Mozambique: The Nexus of Community Representation and State Assistance, Discussion Paper, no. 28. Uppsala: Nordic Africa Institute, pp. 5-30.

— and H. Kyed, 2006 forthcoming, "Contested Sources of Authority: Re-claiming State Sovereignty by Formalising Traditional Authority in Mozambique", Development and Change.

— and S. Jensen, 2004, "Introduction: Vigilantism and the Policing of Everyday Life in South Africa”, African Studies, vol. 63, no. 2, pp. 139-52. 
Buzan, B., O. Wæver and J. de Wilde, 1998, Security. A New Framework for Analysis. Boulder: Lynne Rienner.

- and Ole Wrever, 2003, Regions and Powers - The Structure of International Security. Cambridge: Cambridge University Press, Cambridge Studies in International Relations.

CADI, 2002, "Police Bomb Peaceful Protestors at World Summit". Center for Alternative Development Initiatives, News and Features, 28 August 2002. http://www.cadi.ph/Features/Features_9_WSSD.htm.

Campbell, C., 1992, "Learning to Kill? Masculinity, the Family and the Current Natal Violence", Journal of Southern African Studies, vol. 18, no. 3, pp. 614-28.

Carter, C., 1992, "Community and Conflict: The Alexandra Rebellion of 1986", Journal of Southern African Studies, vol. 18, no. 1, pp. 115-42.

Catholic Commission for Justice and Peace, 2004, "Zimbabwe", in Gould, C. and G. Lamb (eds), Hide and Seek: Taking Account of Small Arms in Southern Africa. Pretoria: Gun Free South Africa/Centre for Conflict Resolution/Institute for Security Studies.

Catholic Commission for Justice and Peace and Legal Resources Foundation (CCJP \& LRF), 1997, Breaking the Silence - Building True Peace. Harare: CCJP/LRF.

Cawthra, G., 1993, Policing South Africa: The SAP and the Transition from Apartheid. Cape Town: David Philips.

—, 1999, From 'Total Strategy' to 'Human Security': The Making of South Africa's Defence policy 1990-98, COPRI Working Paper No. 8. Copenhagen: COPRI.

Certeau, M. de, 1984, The Practice of Everyday Lives. Berkeley: University of California Press.

Chachiua, M., 2000, "Internal Security in Mozambique. Concerns versus Policies", African Security Review, vol. 9, no. 1, http://www.iss.co.za/pubs/ASR/9No1/ $\% 20$ SecurityMozambique.html

Chandavarkar, R., 1998, Imperial Power and Popular Politics: Class, Resistance and the State in India, c. 1850-1950. Cambridge: Cambridge University Press.

Charman, A., 1999, "Civil-Military Relations in Malawi: Historical Context and Contemporary Dilemmas”. Unpublished paper. Cape Town: Centre for Conflict Resolution.

Chatterjee, P., 2001, "On Civil and Political Society in Post-colonial Democracies", in Kaviraj, S. and S. Khilnani (eds), Civil Society: History and Possibilities. Cambridge: Cambridge University Press.

—, 2004, The Politics of the Governed: Reflections on Popular Politics in Most of the World. New York: Columbia University Press.

Chipkin, I., 2003, “'Functional' and 'Dysfunctional' Communities: the Making of National Citizens", Journal of Southern African Studies, vol. 29, no. 1, pp. 63-82.

—, 2004, "Nationalism as Such: Violence during South Africa's Political Transition", Public Culture, vol. 16, no. 2, pp. 315-35.

Clark, J.F. (ed.), 2002, The African Stakes of the Congo War. New York and Houndsmills: Palgrave Macmillan. 
Cliffe, L. et al., 1994, The Transition to Independence in Namibia. Boulder and London: Lynne Rienner.

Coelho, J.P., 1993, "Protected Villages and Communal Villages in the Mozambican Province of Tete (1968-82)”, PhD thesis, University of Bradford, Bradford, UK.

Colletta, N.J., Kostner, M. and I. Wiederhofer, 1996, The Transition From War to Peace in Sub-Saharan Africa, Washington DC: World Bank.

—, with the assistance of Emilio Mondo, Taimi Sitari and Todesse A. Woldu, 1996, Case Studies in War-to-Peace Transition: The Demobilization and Reintegration of Ex-Combatants in Ethiopia, Namibia, and Uganda. Washington DC: World Bank.

Collier, P. and A. Hoeffler, 2001, Greed and Grievance in Civil War. Washington: World Bank.

Comaroff, J. and J. Comaroff, 1991, Of Revelation and Revolution, Volume One: Christianity, Colonialism and Consciousness in South Africa. Chicago and London: University of Chicago Press.

—, 1997, Of Revelation and Revolution, Volume Two: The Dialectics of Modernity on a South African Frontier. Chicago and London: University of Chicago Press.

Conflicts in the Congo: From Kivu to Kabila. Pretoria: Institute for Security Studies.

—, 1999, "Occult Economies and the Violence of Abstraction: Notes From the South African Post-colony”, American Ethnologist, vol. 26, no. 4, pp. 279-301.

Connell, R. 1995, Masculinities. Cambridge: Polity.

Corbridge, S., G. Williams, M. Srivastava, and R. Véron, 2005, Seeing the State: Governance and Governmentality in Rural India. Cambridge: Cambridge University Press.

Cousins, B., 2000, "Does Land and Agrarian Reform have a Future, and if so, Who will Benefit?", in Cousins, B. (ed.), At the Crossroads: Land and Agrarian Reform in South Africa into the 21st Century. Cape Town: Plaas.

Cowan, J, M-B. Dembour and R. Wilson (eds), 2001, Culture and Rights: Anthropological Perspectives. Cambridge: Cambridge University Press.

Cruikshank, Barbara, 1999, The Will to Empower: Democratic Citizens and Other Subjects. Ithaca and London: Cornell University Press.

Crush, J., 1992, "Inflexible Migrancy: New Forms of Migrant Labour on the South African Gold Mines", Labour, Capital and Society, vol. 25, no. 1, pp. 46-71.

—, 1997a, "Contract Migration to South Africa: Past, Present and Future". Paper presented to the Task Team, Green Paper on International Migration, Johannesburg South Africa.

—, 1997b, “Temporary Work and Migration Policy in South Africa”. Paper presented to The Task Team, Green Paper on International Migration, Johannesburg South Africa.

— and D.A. McDonald, 2001, "Introduction to Special Issue: Evaluating South African Immigration Policy after Apartheid”, Africa Today, vol. 48, no. 3, pp. $1-13$. 
- and D.A. McDonald, 2002, Transnationalism and New African Immigration to South Africa, Cape Town: Southern African Migration Project (SAMP)/Canadian Association of African Studies (CAAS).

Daniels, Clement, 2003, “The Struggle for Indigenous People's Rights”, in Melber H. (ed.) Re-examining Liberation Namibia: Political Culture Since Independence. Uppsala: Nordic Africa Institute, pp. 47-68.

Das, V., 2004, "The Signature of the State. The Paradox of Illegibility", in Das, V. and D. Poole (eds), 2004, Anthropology in the Margins of the State. Sante Fe and Oxford: School of American Research Press, James Currey, pp. 225-52.

— and A. Kleinman, 2000, "Introduction", in Das, V., A. Kleinman, M. Ramphele and P. Reynolds (eds), Violence and Subjectivity. Berkeley, Los Angeles and London: University of California Press, pp. 1-17.

— and D. Poole (eds), 2004, Anthropology in the Margins of the State. Santa Fe and Oxford: School of American Research Press and James Currey.

Davies, R. and J. Head, 1995, "The Future of Mine Migrancy in the Context of Broader Trends in Migration”, Journal of Southern African Studies, vol. 21, no. 3, pp. 439-50.

De Certeau, M., 1984, The Practice of Everyday Life, Berkeley: University of California Press.

de Sousa Santos, B. and J-C. Trindade (eds), 2003, Conflito e Transformaçao Social: Uma Paisagem das Justiças em Moçambique. vol. 1. Porto: Edições Afrontamento.

Dean, M., 1999, Governmentality: Power and Rule in Modern Society. London and New Delhi: Thousand Oaks and SAGE.

Delius, P., 1997, A Lion amongst the Cattle: Reconstruction and Resistance in Northern Transvaal. London: James Currey.

Dennis, N., 1998, Zero Tolerance: Policing a Free Society. London: IEA Health and Welfare Unit.

Department of Defence, 2004, SANDF Military Strategy Paper. Pretoria: DOD.

—, 2005a, Briefing of the Portfolio Committee on Defence. South African Parliament, Cape Town, 28 February.

_, 2005b, Briefing of the Portfolio Committee on Defence South African Parliament, Cape Town, 25 February.

Department of Foreign Affairs, 1999, South African White Paper on Participation in International Peace Missions. DFA, Pretoria.

—, 2003, Presentation by the RSA DFA to the Foreign Affairs Portfolio Committee. South African Parliament, Cape Town, 16 April.

Ditirwa, B.S., 2004, "The Role of the Military in State Formation and NationBuilding in Botswana”, in Batchelor, P., K. Kingma and G. Lamb (eds), Demilitarisation and Peace-building in Southern Africa Vol. III. Aldershot: Ashgate, pp. 18-33.

Dixon, B., 2000, The Globalisation of Democratic Policing: Sector Policing and Zero Tolerance in the New South Africa. Occasional Paper Series, Institute of Criminology, University of Cape Town, pp. 1-66. 
—, 1995a, "Namibia's Transition under the Microscope: Six Lenses", Journal of Southern African Studies, vol. 21, no. 3, pp. 529-35.

-, 1995b, "SWAPO in Office", in Leys, C. and J.S. Saul (eds), Namibia's Liberation Struggle: The Two-Edged Sword. London and Athens: James Currey and Ohio University Press, pp. 171-95.

—, 1998, Swapo's Struggle for Namibia 1960-1991: War by Other Means. Basel: Schlettwein.

Draft Green Paper on International Migration, 1997, Presented to the Minister of Home Affairs The Honourable M. Buthelezi. 13 May 1997. General Notice 849 of 1997. Government Gazette No.18033, 30 May 1997.

du Pisani, A., 1988, Beyond the Barracks: Reflections of the Role of the SADF in the Region, Johannesburg: South African Institute of International Affairs.

—, 1994, "Namibia: Impressions of Independence", in Rich, P.B. (ed.), The Dynamics of Change in Southern Africa. New York: St. Martin's Press, pp. 199-217.

—, 2004, "The Role of the Military in the Formation and Consolidation of the Namibian State," in Batchelor, P., K. Kingma and G. Lamb (eds), Demilitarisation and Peace-building in Southern Africa Vol. III. Aldershot: Ashgate, pp. 65-87.

Duffield, Mark, 2001a, Global Governance and the New Wars: the Merging of Development and Security. London and New York: Zed Books.

—, 2001b, "Governing the Borderlands: Decoding the Power of Aid", Disasters, vol. 25, no. 4: pp. 308-20.

—, 2004a, Human Security: Reinstating the State. Lancaster: Lancaster University Dept. of Politics and International Relations.

—, 2004b, Carry on Killing: Global Governance, Humanitarianism and Terror. DIIS Working Paper 2004/23. Copenhagen: Danish Institute for International Studies.

Duncan, J., 2003, FXI Reviews State of Free Expression in South Africa”. Paper presented on World Press Freedom Day, University of the Witwatersrand, 3 May 2003.

Earle, A., J. Goldin and P. Kgomotso, 2006 forthcoming, Domestic Water Provision in the Democratic South Africa - Changes and Challenges. Unpublished Research Report.

Ellis, S., 1998, "The Historical Significance of South Africa's Third Force”, Journal of Southern African Studies, vol. 24, no. 2, pp. 261-99.

Emdon, E., 2003, "The Limits of the Law: Social Rights and Urban Development", in Tomlinson, R., R.A. Beauregard, L. Bremner, and X. Mangcu (eds), Emerging Johannesburg. Perspectives on the Post-apartheid City. London: Routledge, pp. 215-30.

Englund, H., 2004, "Introduction: Recognizing Identities, Imagining Alternatives", in Englund, H. and F.B. Nyamjoh (eds), Rights and the Politics of Recognition in Africa. London and New York: Zed Books. 
Eppel, S., 2005, “Gukurahundi: The Need for Truth and Reparation”, in Raftopoulos, B. and T. Savage (eds), Injustice and Political Reconciliation. Cape Town: Institute for Justice and Reconciliation, pp. 43-62.

Erasmus, G., 2000, “The Constitution: Its Impact on Namibian Statehood and Politics", in Keulder, C. (ed.), State, Society and Democracy: A Reader in Namibian Politics. Windhoek: Gamsberg Macmillan.

Escobar, A., 1995, Encountering Development: The Making and Unmaking of the Third World. Princeton: Princeton University Press.

Evans, G., 1989, "Classrooms of War: The Militarisation of White South African Schooling", in Cock, J. and L. Nathan (eds), War and Society: The Militarisation of South Africa. Cape Town: David Philip, pp. 283-97.

Evans, I., 1997, Bureaucracy and Race: Native Administration in South Africa. Berkeley: University of California Press.

Evans, M. and M. Philips, 1988, "Intensifying Civil War: The Role of the South African Defence Force", in Frankel, P., N. Pines and M. Swilling (eds), State, Resistance and Change in South Africa. Johannesburg: Southern Books, pp. 118-45.

Eveleth, A., 2003, “Criminalising Dissent: Experiences of the Landless People's Movement and the National Land Committee during the WSSD", in Kimani, S. (ed.), The Right to Dissent: Freedom of Expression, Assembly and Demonstrations in South Africa. Johannesburg: Freedom of Expression Institute, pp.84-91.

Fajnzylber, P., D. Lederman, and N. Loayza1, 1998, Determinants of Crime Rates in Latin America and the World: An Empirical Assessment. Washington DC: World Bank.

Feldman, A., 2004, "Securocratic wars of public safety: globalized policing as scopic regime", Interventions, vol. 6, issue 3, pp. 330-350.

Ferguson, J. and A. Gupta, 2002, "Spatializing States: Toward an Ethnography of Neoliberal Governmentality”, American Ethnologist, vol. 29, no. 4, pp. 9811002.

Ferme, M.C., 2004, "Deterritorialized Citizenship and the Resonances of the Sierra Leonian State", in Das, V. and D. Poole (eds), 2004, Anthropology in the Margins of the State. Sante Fe and Oxford: School of American Research Press, James Currey, pp. 81-115.

Final Report, 1998, South African Truth and Reconciliation Commission. The Final Report Vol. 1-5. Cape Town: Juta Press.

First, R., 1983, Black Gold: The Mozambican Miner, Proletarian and Peasant. Sussex: Harvester Press.

Fleisher, M., 2000, "Sungusungu: State-sponsored Village Vigilante Groups among the Kuria of Tanzania," Africa, vol. 70, pp. 209-28.

Foucault, M., 1978, The History of Sexuality. Vol. 1. An Introduction. New York: Pelican.

—, 1979, Discipline and Punish: The Birth of the Prison. New York: Vintage. 
—, 1982, "The Subject and Power", in Dreyfus, H. and P. Rabinow (eds), Michel Foucault: Beyond Structuralism and Hermeneutic. Chicago: University of Chicago Press.

—, 1991, "Governmentality", in Burchell, G., C. Gordon and P. Miller (eds), The Foucault Effect: Studies in Governmentality. London, Toronto, Sydney, Tokyo and Singapore: Harvester Wheatsheaf.

Fraser, N., 1995, "From Redistribution to Recognition? Dilemmas of Justice in a 'PostSocialist' Age”, New Left Review, no. 212, pp. 67-93. www.ceu.hu/nation/ theses/pallai0203.pdf accessed 23 February 2004.

—, 2000, "Rethinking Recognition", New Left Review, no. 3, pp. 107-20.

Frosh, S., 1994, Sexual Difference: Masculinity and Psychoanalysis. London: Routledge.

Fuller, C.J. and V. Bénéi (eds), 2001, The Everyday State and Society in Modern India. London: Hurst.

FXI/RED, 2005, "Establishing a Historical Record of Violations of the Regulation of Gatherings Act and the Right to Freedom of Assembly amongst Social Movements in Johannesburg". Draft Report, Freedom of Expression Institute and Research \& Education in Development. Unpublished draft 2005, pp. $1-22$.

Garland, D., 2001, The Culture of Control: Crime and Social Order in Contemporary Society. Oxford and New York: Oxford University Press.

Geschiere, P., 1998, "Globalization and the Power of Indeterminate Meaning: Witchcraft and Spirit Cults in Africa and East Asia", Development and Change, vol. 29 , no. 4, pp. 811-37.

- and F. Nyamnjoh, 2000, "Capitalism and Autochthony: The Seesaw of Mobility and Belonging", Public Culture, vol. 12, no. 2, pp. 423-52.

Gleichmann, C., 1994, "Returned Exiles in Namibia: The Dynamics of Reintegration and Political Change", unpublished MA thesis, University of Hamburg.

—, M. Odenwald, K. Steenken and A. Wilkinson, 2004, Disarmament, Demobilisation and Reintegration: A Practical Field and Classroom Guide. Frankfurt a. M.: GTZ, NODEFIC, PPC and SNDC.

Gordon, R.J., 1998, "Vagrancy, Law and 'Shadow Knowledge": Internal Pacification 1915-1939”, in Hayes, R., J. Silvester, M. Wallace and W. Hartmann (eds), Namibia under South African Rule: Mobility and Containment 1915-46. Oxford, Windhoek and Athens, OH: James Currey, Out of Africa and Ohio University Press.

Gore, C. and D. Pratten, 2003, "The Politics of Plunder: The Rhetorics of Order and Disorder in Southern Nigeria", African Affairs, vol. 102, pp. 211-40.

Government of Malawi, 1972, Malawi Young Pioneers: Spearhead for Progress. Lilongwe: Ministry of Information and Broadcasting.

Government of Namibia, 1995, First National Development Plan (NDP1) Volume I and II. Windhoek: National Planning Commission.

—, 2002, Defence Amendment Act (No. 1 of 2002). Windhoek: Government Printer.

Government of South Africa, 2002, South African Defence Act (No. 42 of 2002).

Pretoria: Government Printer. 
Government of Zambia, 1964, Defence Act (No. 45 of 1964). Lusaka: Government Printer.

Green, J., 2002, Disconnections Outstrip Electrification Drive. IOL.co.za. 21 August 2002.

Greenhouse, C., 2003, "Solidarity and Objectivity", in Parnell, P. and S. Kane (eds), Crime's Power: Anthropologists and the Ethnography of Crime. New York: Palgrave Macmillan.

Groth, S., 1995, Namibia - The Wall of Silence: The Dark Days of the Liberation Struggle. Wuppertal: Peter Hammer.

Gupta, A., 1998, Postcolonial Development: Agriculture in the Making of Modern India. Durham, NC: Duke University Press.

Hacking, I., 1991, "How Should We Do the History of Statistics?”, in Burchell, G., C. Gordon and P. Miller (eds), The Foucault Effect: Studies in Governmentality. Chicago: University of Chicago Press.

Hammar, A., 2001a, “The Day of Burning': Eviction and Reinvention in the Margins of Northwest Zimbabwe", Journal of Agrarian Change, vol. 1, no. 4, pp. $550-74$.

_, 2001b, "Lists and Legitimations: Retrieving Lost Livelihoods in Northwest Zimbabwe" (published in Danish translation as "Lister som legitimering"). Den Ny Verden, vol. 34, no. 2, pp. 32-47.

—, 2003, "The Making and Unma(s)king of Local Government in Zimbabwe", in Hammar, A., B. Raftopoulos and S. Jensen (eds), Zimbabwe's Unfinished Business: Rethinking Land, State and Nation in the Context of Crisis. Harare: Weaver Press, pp. 119-54.

—, B. Raftopoulos and S. Jensen (eds), 2003, Zimbabwe's Unfinished Business: Rethinking Land, State and Nation in the Context of Crisis, Harare: Weaver Press.

Hansen, T. Blom, 2001, "Governance and State Mythologies in Mumbai”, in Hansen, T. Blom and F. Stepputat (eds), States of Imagination. Ethnographic Explorations of the Postcolonial State. London: Duke University Press, pp. 221-54.

—, 2005, "Sovereigns beyond the State: On Legality and Authority in Urban India", in Hansen, T. Blom and F. Stepputat (eds), Sovereign Bodies. Citizens, Migrants and States in the Postcolonial World. Princeton and Oxford: Princeton University Press, pp. 169-91.

- and F. Stepputat (eds), 2001, States of Imagination: Ethnographic Explorations of the Postcolonial State. Durham, NC and London: Duke University Press.

— and F. Stepputat, 2005, "Introduction", in Hansen, T. Blom and F. Stepputat (eds), Sovereign Bodies: Citizens, Migrants, and States in the Postcolonial World . Princeton: Princeton University Press, pp. 1-36.

— and F. Stepputat (eds), 2005, Sovereign Bodies: Citizens, Migrants and States in the Postcolonial World. Princeton and Oxford: Princeton University Press.

Hardt, M. and A. Negri, 2000, Empire. Cambridge: Harvard University Press.

Haysom, N., 1989, Vigilantes: A Contemporary Form of Repression. Seminar series no. 4. Johannesburg: Centre for the Study of Violence and Reconciliation. 
Heald, S., 1986, "Mafias in Africa: The Rise of Drinking Parties and Vigilante Groups in Bugisu District, Uganda", Africa, vol. 56, pp. 446-66.

—, 1999, Manhood and Morality: Sex, Violence and Ritual in Gisu Society. London and New York: Routledge.

Heinecken, L., 1999, "Regional Involvement: Attitudes of SANDF Officers towards Future Military Missions”, Strategic Review for Southern Africa, vol. 21, no. 1, pp. 44-65.

Herbst, J., 2000, States and Power in Africa: Comparative Lessons in Authority and Control. Princeton: Princeton University Press.

Herbstein, D. and J. Evenson, 1989, The Devils are Amongst us: The War for Namibia. London: Zed.

Hindess, B., 2001, The Liberal Government of Unfreedom, Alternatives, vol. 26, no. 2, pp. 93-111.

Hishongwa, N., 1983, Women of Namibia: The Changing Role of Namibian Women from Traditional Precolonial Times to the Present, By och Bygd (no information on place of publication, presumably in Sweden).

Holsti, K.J., 1996, The State, War, and the State of War. Cambridge: Cambridge University Press.

Honneth, A., 1995, "Patterns of Intersubjective Recognition: Love Rights, and Solidarity". Chapter 5. The Struggle for Recognition. The Moral Grammar of Social Conflicts. 1995. Cambridge: Polity Press. http://www.cebrap.org.br/pdf/ Tex, accessed 23 March 2004.

—, 2004, "Mutual Recognition as a Key for a Universal Ethics". http://www.unesco. or.kr/kor/science_s/project/universal_ethics/asianvalues/honne accessed 12 March 2004.

Human Rights Watch, 1997, "Prohibited Persons": Abuse of Undocumented Migrants, Asylum Seekers, and Refugees in South Africa. New York, Washington, London and Brussels: Human Rights Watch.

—, 2003, "Zimbabwe. Not Eligible: The Politicization of Food in Zimbabwe", Human Rights Watch, vol. 17(A), no. 15, pp. 1-52.

Hunter, M., 2003, "Masculinities and Multiple Sexual Partners in Kwa-Zulu Natal: The Making and Unmaking of Isoka". Paper presented at the Sex and Secrecy Conference. Fourth Conference of the International Association for the Study of Sexuality, Culture and Society. University of the Witwatersrand, Johannesburg, South Africa, 25-28 June.

ICF (Inner City Forum) Information Sheet. History and Political Agenda, 2004a, Flyer. "Jhb. Inner City - Anti Eviction Campaign".

—, 2004b, Flyer. "No Vote! Why Vote When?"

Isin, E.F. and B.S. Turner, 2002, Handbook on Citizenship Studies. London: Sage.

Jackson, M., 2004, In Sierra Leone. Durham and London: Duke University Press.

Jackson, R., 1993, Quasi-States: Sovereignty, International Relations, amdthe Third World. Cambridge: Cambridge University Press. 
James, D., 2001, "Land for the Landless: Conflicting Images of Rural and Urban in South Africa's Land Reform Programme", Journal of Contemporary African Studies, vol. 19, no. 1, pp. 93-109.

James, W.G., 1987, The State of Apartheid: An Introduction, in James, W.G. (ed.), The State of Apartheid. Boulder: Lynne Rienner, pp. 1-4.

Janoski, T. and B. Grant, 2002, "Political Citizenship: Foundations of Rights", in Isin, E.F. and B.S. Turner (eds), Handbook of Citizenship Studies. London: Sage.

Jaster, R.S., 1990, "The 1988 Peace Accords and the Future of South Western Africa", Adelphi Papers, Vol. 253. London: Brassey's.

Jensen, S., 2001, “The Battlefield and the Prize: ANC's Bid to Reform the South African State", in Hansen, T. Blom and F. Stepputat (eds), States of Imagination: Ethnographic Explorations of the Postcolonial State. Durham, NC and London: Duke University Press, pp. 97-122.

—, 2004, "Claiming Community: Local Politics on the Cape Flats, South Africa", Critique of Anthropology, vol. 24, no. 2, pp. 179-207.

—, 2005a, "The South African Transition: From Development to Security?" Development and Change, vol. 36, no. 3, pp. 551-70.

—, 2005b, "Above the Law: Practices of Sovereignty in Surrey Estate, Cape Town", in Hansen, T. Blom and F. Stepputat (eds), Sovereign Bodies: Citizens, Migrants, and States in the Postcolonial World. Princeton: Princeton University Press.

—, forthcoming, "Security and Violence on the Frontier of the State: Vigilant Citizens in Nkomazi, South Africa”, in Bethlehem, L., R. Gunio and P. Ahluwalia (eds), Violence and Non-violence: African Perspectives, London: Routledge.

— and L. Buur, 2004, "Everyday Policing and the Occult: Notions of Witchcraft, Crime and 'the People", African Studies, vol. 63, no. 2, pp. 193-212.

Jochelson, K., 1990, "Reform, Repression and Resistance in South Africa: A Case Study of Alexandra Township, 1979-89”, Journal of Southern African Studies, vol. 16, no. 1, pp. 1-32.

Jordan, Z.P., 2004, Statement by ANC Member of Parliament. South African Parliament, Cape Town, 10 February.

Kappeler, V. and G. Potter, 2000, The Mythology of Crime and Criminal Justice. Prospects Heights: Waveland Press.

Katjavivi, P.H., 1986, “The Rise of Nationalism in Namibia and Its International Dimensions", unpublished DPhil thesis, St. Antony's College, University of Oxford.

—, 1988, A History of Resistance in Namibia. London: James Currey.

Kimani, S., 2003, "Introduction", in Kimani. S. (ed.), The Right to Dissent: Freedom of Expression, Assembly and Demonstrations in South Africa. Johannesburg: Freedom of Expression Institute, pp. 11-24.

Kinnes, I., 2000, From Urban Street Gangs to Criminal Empires: The Changing Face of Gangs in the Western Cape. Monograph vol. 48. Pretoria: ISS.

Klaaren, J. and J. Ramji, 2001, "Inside Illegality: Migration Policing in South Africa after Apartheid", Africa Today, vol. 48, no. 3, pp. 35-47. 
Kössler, R., 2003, "Public Memory, Reconciliation and the Aftermath of War: A Preliminary Framework with Special Reference to Namibia”, in Melber, H. (ed.), Re-examining Liberation in Namibia: Political Culture Since Independence. Uppsala: The Nordic Africa Institute.

Kyed, Helene Maria and Lars Buur, forthcoming 2006, "New Sites of Citizenship: Recognition of Traditional Authority and Group-based Citizenship in Mozambique". Journal of Southern African Studies.

Kyed, H.M., 2005, "Formalisation of Traditional Leaders in Post-war Mozambique: The Ambiguous Space between State and Non-state Domains". Paper presented at international conference, "Beside the State; New Forms of Political Power in Post-1990s Africa”, Milan, 15-17 December 2005.

Kynoch, G., 2000, “Marashea on the Mines: Economic, Social and Criminal Networks on the South African Gold Fields, 1947-99”, Journal of Southern African Studies, vol. 26, no. 1, pp. 79-103.

Laclau, E. and C. Mouffe, 1985, Hegemony and Socialist Strategy: Towards a Radical Democratic Politic. London: Verso.

Laclau, E., 1994, The Making of Political Identities. London: Verso.

Lalá, A., 2003, "Security Sector Reform as a Governance Issue: The Case of Mozambique”, Journal of Security Sector Management, vol. 1, no. 2, pp. 1-31.

LeBeau, D., 2005, An Investigation into the Lives of Namibian Ex-fighters Fifteen Years after Independence. Windhoek: P.E.A.C.E. Centre.

Lekota, M.G.P., 2004, Statement by the Defence Minister in Parliament. South African Parliament, Cape Town, 8 June.

Leon, T., 2000, Democratic Alliance Leader Statement during the Parliamentary Debate. South African Parliament, Cape Town, 8 February.

Leys, C. and S. Brown (eds), 2005, Histories of Namibia. Living through the Liberation Struggle. London: Merlin Press.

Leys, C. and J.S. Saul, 1994, "Liberation without Democracy? The Swapo Crisis of 1976", Journal of Southern African Studies, vol. 20, no. 1, pp. 123-47.

- (eds), 1995, Namibia's Liberation Struggle: The Two-Edged Sword. London and Athens, OH: James Currey and Ohio University Press.

Lister, G., 1992, "Political Perspective”, The Namibian, 27 November.

Lister, R., 2003, "Justice, Equality and Dependency: A Critical Social Policy Perspective”. Symposium on Nancy Fraser's work, Warwick Centre for the Study Women and Gender, 22 March.

Lombard, C., 1999, "The Role of Religion in the Reconstruction of Namibian Society: The Churches, the New Kairos and the Visions of Despair and Hope", Journal of Religion and Theology in Namibia, no. 1, pp. 38-87.

Lubkemann, S.C., 2002, "The Transformation of Transnationality among Mozambican Migrants in South Africa”, in Crush, J. and D. McDonald (eds), Transnationalism and New African Immigration to South Africa. Cape Town: Southern African Migration Project (SAMP)/Canadian Association of African Studies (CAAS). 
Lund, C., 2001, "Precarious Democratisation and Local Dynamics in Niger: Cases of Local Politics in Zinder", Development and Change, vol. 32, no. 5, pp. 845-69.

Madsen, M. Lynge, 2004a, A Walk through Thick Bushes: An Ethnographic Account of Undocumented Migrants in Johannesburg. Copenhagen: Institute of Anthropology, University of Copenhagen.

—, 2004b, "Living for Home: Policing Immorality among Undocumented Migrants in Johannesburg", African Studies, vol. 63, no. 2, pp. 173-92.

Mager, A., 1995, Gender and the Making of a South African Bantustan: A Social History of the Ciskei, 1945-59. London: Greenwood.

Mail \& Guardian, 2003, “Social Movements: 'Ultra-left' or 'Global Citizens'?” by Dikatso Mametse, 4 February.

_, 2002, 'We'll take Sandton', 15 August 2002. Mail and Guardian Online: http:// www.mg.co.za/articledirect.aspx?area=mg_flat\&articleid=143994.

Mail \& Guardian Online, 2004, "Africa Breeds Terror, says Blair”. 7 October 2004. http://www.mg.co.za/articlepage.aspx?articleid=138933\&area=/breaking_news/ breaking_news_africa/

Majola, B., 2002, “'Strike Team’ Targets Inner City Ills”, 25 November. http://www. joburg.org.za (official webpage of the City of Johannesburg).

Mamdani, M., 1996a, Citizen and Subject: Contemporary Africa and the Legacy of Late Colonialism. Princeton, NJ: Princeton University Press.

_, 1996b, "Reconciliation without Justice", Southern Review of Books, vol. 10, no. 6: $22-5$.

Manby, B., 2001, Unequal Protection: The State Response to Violent Crime on South African Farms. New York: Human Rights Watch.

—, 2002, "A Failure of Rural Protection”, Transformation, vol. 49: 86-104.

Mandrup Jørgensen, T., 2001, “Carry a Big Stick, but Use it Gently”, unpublished MA thesis, Roskilde University, Roskilde, Denmark.

—, forthcoming, "Salvation or Despair of Africa? - A Study of the Post-apartheid South African Government's Use of the Military Tool in its Foreign Policy Conduct”, Danish Institute for International Studies, Copenhagen.

Manor, J., 1999, The Political Economy of Democratic Decentralisation: Directions in Development. Washington DC: World Bank.

Marais, H., 1998, South Africa - Limits to Change: The Political Economy of Transformation. Cape Town: UCT Press.

Maré, G., 2000, "Versions of Resistance History in South Africa: The ANC Strand in Inkatha in the 1970s and 1980s", Review of African Political Economy, vol. 83, no. 83 , pp. 63-84.

— and T. Waetjen, 1999, "Workers and Warriors: Inkatha's Politics of Masculinity in the 1980s", Journal of Contemporary African Studies, vol. 17, no. 2, pp. $197-216$.

Martorell, J., 2002, ANC Government Tries to Silence its Critics with Apartheid-style Repression. Http://www.marxist.com/Africa/wssd_repression.html. 
Matondi, P.B., 2001, "The Struggle for Access to Land and Water Resources in Zimbabwe. The Case of Shamva District", Doctoral thesis, Swedish University of Agricultural Sciences, Uppsala.

Matshikiza, J., 2005, “A Grave Case of Memory Loss”, Mail \& Guardian Online (accessed 29 November).

Mayekiso, M., 1996, Township Politics: Civic Struggles for a New South Africa. New York: Monthly Review Press.

Mbamba, A. Mauno, 1979, The Namibia Education and Health Centres: A Study of Swapo Schools among Namibian Refugees in Zambia and Angola, University of Stockholm, Institute of International Education.

Mbeki, Thabo, 2000, State of the Nation Address. South African Parliament, Cape Town, 4 May.

Mbembe, A., 2001, On the Postcolony. Berkeley, Los Angeles and London: University of California Press.

McCuen, J. , 1966, The Art of Counter-revolutionary War : The Strategy of Counterinsurgency. London: Faber.

McDonald, D.A., 2002, "The Theory and Practice of Cost Recovery in South Africa", in McDonald, D.A. and J. Pape (eds), Cost Recovery and the Crisis of Service Delivery in South Africa. London and New York: Zed Books, pp. 17-37.

McKinley, D.T., 2002, "State Repression Intensifies! Freedom of Expression March Attacked by Police”. A-Infos 26 August, 2002, http://www.ainfos.ca/02/aug/ ainfos00409.html.

—, 2003, "Trying to 'Kill' the Messenger and Failing: Experiences of the AntiPrivatisation Forum during the WSSD", in Simon Kimani (ed.), The Right to Dissent: Freedom of Expression, Assembly and Demonstrations in South Africa. Johannesburg: Freedom of Expression Institute, pp. 92-100.

McMullin, J., 2005, "Far from Spontaneous: Namibia's Long Struggle with ExCombatant Reintegration", in Fitz-Gerald, A.M. and H. Mason (eds), From Conflict to Community: A Combatant's Return to Citizenship. Shrivenham: Global Facilitation Network for Security Sector Reform (GFN-SSR).

Mehta, D. and R. Chatterji, 2001, "Boundaries, Names, Alterities. A Case Study of a 'Communal Riot' in Dharavi, Bombay", in Das, V., A. Kleinman, M. Lock, M. Ramphele and P. Reynolds (eds), Remaking a World. Violence, Social Suffering, and Recovery. Berkeley, Los Angeles, London: University of California Press, pp. 201-48.

Melber, H. (ed.), 2000a, "Economic and Social Transformation in the Process of Colonisation: Society and State Before and During German Rule", in Keulder, C. (ed.), State, Society and Democracy: A Reader in Namibian Politics. Windhoek: Gamsberg Macmillan.

—, 2000b, Namibia: A Decade after Independence. Windhoek: Namibian Economic Policy Research Unit.

—, 2003a, "From Controlled Change to Changed Control", in Melber, H. (ed.), Limits to Liberation in Southern Africa: The Unfinished Business of Democratic Consolidation. Cape Town: Human Sciences Research Council, pp. 134-55. 
-, 2003b, "From Controlled Change to Changed Control: The Case of Namibia", Journal of Contemporary African Studies, vol. 21, no. 2, pp. 267-84.

_, 2003c, "Limits to Liberation: An Introduction to Namibia’s Postcolonial Political Culture", in Melber, H. (ed.), Re-examining Liberation Namibia: Political Culture Since Independence. Uppsala: Nordic Africa Institute, pp. 9-24.

—, 2003d, "Namibia, Land of the Brave': Selective Memories on War and Violence within Nation Building", in Abbink, J., de Bruijn, M. and K. van Walraven (eds), Rethinking Resistance. Revolt and Violence in African History. Leiden and Boston: Brill.

—, 2003e, "Of Big Fish and Small Fry: The Fishing Industry in Namibia", Review of African Political Economy, vol. 30, no. 95, pp. 142-8.

—, 2004, "Decolonization and Democratisation: The United Nations and Namibia's Transition to Democracy", in Newman, E. and R. Rich (eds), The UN Role in Promoting Democracy: Between Ideals and Reality. Tokyo, New York, Paris: United Nations University Press.

—, 2005a, "Land and Politics in Namibia", Review of African Political Economy, vol. 32, no. 103, pp. 136-42.

—, 2005b, "Namibia's Past in the Present: Colonial Genocide and the Liberation Struggle in Commemorative Narratives", South African History Journal (in preparation).

—, 2005c, "Namibia's Post-colonial Socio-economic (non-)Transformation: Business as Usual?", Nord Süd aktuell, vol. 19, no. 3/4, pp. 306-21.

Menkhaus, K., 2004, "Vicious Circles and the Security Development Nexus in Somalia", Conflict, Security and Development, vol. 4, no. 2, pp. 149-65.

Meredith, M, 2002, Our Votes, Our Guns: Robert Mugabe and the Tragedy of Zimbabwe. Oxford: Public Affairs.

Metsola, L., 2001, “The Liberation Narrative and the Post-return Life Stories of Namibian Former Exiles", unpublished MA thesis in cultural anthropology, University of Helsinki.

—, 2005, "Reintegration" of Namibian Ex-combatants and Former Fighters: Plans and Practices, Politics and Techniques". Paper presented to the European Conference of African Studies, organised by AEGIS at the School of Oriental and African Studies and the Institute of Commonwealth Studies, London, 29 June 29-2 July.

Ministry of Internal Affairs (MINT), 2005, Policiamento Comunitáriop e Serviços Provinciais de Bombeiros, Reunião com os Municípios, Manica, 25-27 July 2005.

Minsky, R., 2004, “Beyond Nurture: Finding the Words for Male Identity”. http:// human-nature.com/free-associations/minskynurture.html accessed 2 March 2004.

Mitchell, T., 1999, "Society, Economy, and the State Effect”, in Steinmetz, G. (ed.), State/Culture: State-Formation after the Cultural Turn. Ithaca, NY and London: Cornell University Press.

Moodie, D., 1995, Going for Gold: Men, Mines and Migration. Berkeley: University of California Press. 
Moore, D.S., 1999, “The Crucible of Cultural Politics: Reworking 'Development' in Zimbabwe's Eastern Highlands", American Ethnologist, vol. 26, no. 3, pp. 654-89.

Morrell, R. (ed.), 2001, Changing Men in Southern Africa. London: Zed Books.

Morris, A., 1999, Bleakness and Light. Inner-city Transition in Hillbrow, Johannesburg. Johannesburg: Witwatersrand University Press.

—, 2001, "Progress and Setbacks for local Government: Democratic Practice and Redistribution in Johannesburg in the 1990s”, Social Dynamics, vol. 27, no. 2, pp. 86-108.

Mouffe, C., 1999, "Introduction: Schmitt's Challenge”, in Mouffe, C. (ed.), The Challenge of Carl Schmitt. London and New York: Verso, pp. 1-6.

Moyo, S., 1995, The Land Question in Zimbabwe. Harare: SAPES Books.

—, 2000, Land Reform under Structural Adjustment in Zimbabwe. Land Use Change in the Mashonaland Provinces. Uppsala: The Nordic Africa Institute.

Murphree, M.W., 1990, "Decentralising the Proprietorship of Wildlife Resources in Zimbabwe's Communal Lands”, CASS Occasional Paper Series - NRM. Harare: University of Zimbabwe.

Namakalu, O.O., 2004, Armed Liberation Struggle. Some Accounts of PLAN's Combat Operations. Windhoek: Gamsberg Macmillan.

Namhila, E.N., 2005, Kaxumba kaNdola. Man and Myth. The Biography of a Barefoot Soldier. Basel: Basler Afrika Bibliographien.

Nathan, L., 1990, "Marching to a Different Drum: A Description and Assessment of the Formation of the Namibian Police and Defence Force", Southern African Perspectives, no. 4. Bellville: Centre for South African Studies.

Nathanael, K.P., 2002, A Journey to Exile: The Story of a Namibian Freedom Fighter. Aberystwyth: Sosiumi Press.

News24, 2004, "FXI to Challenge Gathering Act. 28 April 2004. http://www.news24. com/News24/South_Africa/News/0,,2-7-1442_1518832,00.html

Ngcobo, C., 2003, "Local Authorities and the Regulation of Assemblies and Demonstrations: The WSSD as a Case Study", in Kimani. S. (ed.), The Right to Dissent: Freedom of Expression, Assembly and Demonstrations in South Africa. Johannesburg: Freedom of Expression Institute, pp. 74-7.

Niehaus, I., 2001, Witchcraft, Power and Politics: Exploring the Occult in the South African Lowveld. Cape Town: David Philip.

Nina, D., 1995, Rethinking Popular Justice: Self-regulation and Civil Society in South Africa. Cape Town: Community Peace Foundation.

Norval, A., 1996, Deconstructing Apartheid Discourse. London: Verso.

Noticias, 13 July1995, Régulos de Dombe continuam contra presença da Polícia.

—, 29 June 1995, Régulos expulsam agentes da PRM em Dombe.

—, 4 July 1995, Problemas dos Régulos em Dombe requerem medidas urgentes.

—, 4 July1995, Régulos em Dombe expulsam enfermeiros provocando òbitos.

Nujoma, S., 2001, Where Others Wavered: The Autobiography of Sam Nujoma. London: Panaf Books. 
Nyambara, P.S., 2001, "The Closing Frontier: Agrarian Change, Immigrants and the 'Squatter Menace' in Gokwe, 1980-1990s', Journal of Agrarian Change, vol. 1, no. 4, pp. 534-49.

OECD/DAC 1997. DAC Guidelines on the Use of Incentives and Disincentives in Situations of Violent Conflict. Paris: OECD.

Oelofse, M., 2003, "Social Justice, Social Integration and the Compact City: Lessons from the Inner City Johannesburg", in Harrison, P., M. Huchzermeyer and M. Mayekiso (eds), Confronting Fragmentation. Housing and Urban Development in a Democratising Society. Cape Town: University of Cape Town Press, pp. 88-108.

Oomen, B., 2000, Tradition on the Move; Chiefs, Democracy and Change in Rural South Africa,. Nederlandse Organisatie voor Wetenschappelijk Ondersoek, Leiden.

_, 2004, "Vigilantism or Alternative Citizenship? The Rise and Fall of Mapogo a Mathamaga", African Studies, vol. 63, no. 2, pp. 153-72.

Parliament, 2005, Foreign Minister's Briefing on International Relations, Peace and Security Cluster. South African Parliament, Cape Town, 15 February.

Parnell, P. and S. Kane, 2003, Crime's Power: Anthropologists and the Ethnography of Crime. New York: Palgrave Macmillan.

Parnell, P.C., 2003, “Introduction: Crime's Power”, in Parnell, P.C. and S.C. Kane (eds), Crime's Power: Anthropologists and the Ethnography of Crime. New York and Basingstoke (UK): Palgrave Macmillan, pp. 1-32.

Peberdy, S., 1997, “The Participation of non-South Africans in Street Trading in South Africa and in Regional Cross-Border Trade: Implications for Immigration Policy and Customs Agreements". Briefing paper for the Green Paper Task Group on International Migration, Pretoria, 12 March 1997.

—, 2001, "Imagining Immigration: Inclusive Identities and Exclusive Policies in Post1994 South Africa", Africa Today, vol. 48, no. 3, pp. 14-33.

- and C. Rogerson, 2002, "Transnationalism and Non-South African Entrepreneurs in South Africa's Small, Medium and Micro-Enterprises (SMME) Economy", in Crush, J. and D. McDonald (eds), Transnationalism and New African Immigration to South Africa. Cape Town: Southern African Migration Project (SAMP)/Canadian Association of African Studies (CAAS).

Peltola, P., 1995, The Lost May Day: Namibian Workers'Struggle for Independence. Helsinki: Finnish Anthropological Society in association with the Nordic Africa Institute.

Pohjolainen-Yap, K., 2001, "Uprooting the Weeds. Power, Ethnicity and Violence in the Matabeleland Conflict 1980-87", PhD thesis, University of Amsterdam.

Porter, T.M., 2001, "Quantification in the History of the Social Sciences", in Smelser, N.J. and P.B. Baltes (eds), International Encyclopedia of the Social and Behavioral Sciences. Amsterdam, Paris, New York, Oxford, Shannon, Singapore and Tokyo: Elsevier.

Posel, D., 1999, "Whiteness and Power in Southern African Civil Service: Paradoxes of the Apartheid State", Journal of Southern African Studies, vol. 25, no. 1, pp 99-119. 
—, 2003, “The Scandal of Manhood: 'Unmaking' Secrets of Sexual Violence in Post-Apartheid South Africa and Beyond". Paper presented at the Sex and Secrecy Conference. Fourth Conference of the International Association for the Study of Sexuality, Culture and Society. University of the Witwatersrand, Johannesburg, South Africa, 25-28 June.

Preston, R., 1997, "Integrating Fighters after War: Reflections on the Namibian Experience, 1989-1993”, Journal of Southern African Studies, vol. 23, no. 3, pp. 453-72.

—, C. Solomon, C. Gleichmann, K.Tamas, D. LeBeau and W. Pendleton, 1993, The Integration of Returned Exiles, Former Combatants and Other War-affected Namibians. Windhoek: Namibian Institute for Social and Economic Research/ University of Namibia (NISER Research Report: 6).

Preuss, U.K., 1999, "Political Order and Democracy: Carl Schmitt and His Influence", in Mouffe, C. (ed.), The Challenge of Carl Schmitt. London and New York: Verso, pp. 155-79.

Procacci, G., 1991, "Social Economy and the Government of Poverty", in Burchell, G., C. Gordon and P. Miller (eds), The Foucault Effect: Studies in Governmentality. Chicago: University of Chicago Press.

Raftopoulos, B. and T. Savage (eds), 2005, Injustice and Political Reconciliation. Cape Town: Institute for Justice and Reconciliation.

Ramphele, M., 1993, A Bed Called Home. Cape Town: David Philips.

Rangan, Priya and Mary Gilmartin, 2002, "Baring it All: Gender, Traditional Authority, and the Politics of Rural Reform in South Africa", Development and Change, vol. 33, no. 4, pp 633-58.

Rasool, S., K. Vermaak, R. Pharoah, A. Louw and A. Stavrou, 2002, Violence Against Women. A National Survey. Pretoria: Institute for Security Studies.

Regulamento do Decreto 15/2000, de 25 Agosto de 2000, Boletim da República. Publicação Oficial da República de Moçambique. Ministério da Administração Estatal.

Republic of Namibia, 1996, Programme for the Socio-economic Integration of Ex-combatants. Windhoek: Office of the President, National Planning Commission, September.

—, 1997, National Resettlement Policy. Ministry of Lands, Resettlement and Rehabilitation, October.

-, 1998, Report on the Registration, Verification of, and Investigations into the Condition of Ex-PLAN Combatants. Technical Committee on Ex-Combatants, November.

—, 1999, War Veterans Subvention Act (Act 16 of 1999), in Government Gazette of the Republic of Namibia 2211, 20 October.

—, 2000, Namibia, A Decade of Peace, Democracy and Prosperity. Windhoek: Office of the Prime Minister.

-, no date [2001], Final Report of the Technical Committee on Ex Combatants to the Cabinet Committee on Defence and Security (CCDS). Technical Committee on Ex-Combatants. 
Reuters, 2005, AU wants African Force to Disarm Congo-based Rebels. Reuters News Agency, 13 January.

Ritchken, E., 1995, "Leadership and Conflict in Bushbuckridge: Struggles to Define Moral Economies in the Context of Rapidly Transforming Political Economies", PhD thesis, University of Witwatersrand, Johannesburg.

Robertson, M., 1990, Human Rights for South Africans. Oxford: Oxford University Press.

Rose, N., 1999, Powers of Freedom: Reframing Political Thought. Cambridge: University of Cambridge Press.

Ross, R., 1999, A Concise History of South Africa. Cambridge: Cambridge University Press.

Russouw, S., 2002, “Armadale Evictions: Tenants Moving On”, 21 November. http:// www.joburg.org.za (official webpage of the City of Johannesburg).

Ruteree, M. and M-E. Pommerolle, 2003, “Democratizing Security or Decentralizing Repression: The Ambiguities of Community Policing in Kenya", African Affairs, vol. 102, pp. 587-604.

Sachikonye, L., 2003, The Situation of Commercial Farm Workers after Land Reform in Zimbabwe: A Report Prepared for the Farm Community Trust of Zimbabwe, London: CIIR.

SAHRC, 2000, The Second Lindela Report: At the Crossroads for Detention and Repatriation. An Assessment of the Conditions of Detention. South African Human Rights Commission, Johannesburg.

Saul, J.S. and C. Leys, 1995, "SWAPO: The Politics of Exile", in Leys, C. and J.S. Saul (eds), Namibia's Liberation Struggle: The Two-Edged Sword. London and Athens, $\mathrm{OH}$ : James Currey and Ohio University Press, pp 40-65.

Saunders, C., 2003, "Liberation and Democracy: A Critical Reading of Sam Nujoma's 'Autobiography”, in Melber, H. (ed.), Re-examining Liberation in Namibia: Political Culture since Independence. Uppsala: The Nordic Africa Institute.

Sayedali-Shah, M., 2004, Statement by Democratic Alliance Speaker on Defence in Parliament. South African Parliament, Cape Town, 8 June.

Schafer, J., 2001, "Guerrillas and Violence in the War in Mozambique: Desocialization or Re-socialization?”, African Affairs, vol. 100, no. 399, pp. 215-37.

Schärf, W., 2001, "Police Reform and Crime Prevention in Post-Conflict Transitions: Learning from South Africa and Mozambique”, in Danida, Conflict Prevention and Peace-building in Africa. Report from the Maputo Conference, 28-29 June 2001. Copenhagen: Danish Ministry of Foreign Affairs, Danida, pp. 178-86.

Schmitt, C., 1985, Political Theology: Four Chapters on the Concept of Sovereignty. Cambridge MA: MIT Press.

Schonteich, M., 2000,'Justice Versus Retribution: Attitudes to Punishment in the Eastern Cape", Monograph 45. Pretoria: Institute for Security Studies.

Scott, J.C., 1998, Seeing Like a State: How Certain Schemes to Improve the Human Condition Have Failed. New Haven and London: Yale University Press. 
Seegers, A., 1987, “Apartheid's Military: Its Origins and Development”, in James, W.G. (ed), The State of Apartheid. Boulder: Lynne Rienner, pp. 143-72.

Seegers, A., 1996, The Military in the Making of Modern South Africa. London: Tauris.

Seekings, J., 1996, “The Decline of South Africa's Civic Organizations, 1990-96”, Critical Sociology, vol. 22, no. 3, pp. 135-57.

—, 2000a, "The Development of Strategic Thought in South Africa's Civic Movements, 1977-90", in Adler, G. and J Steinberg (eds), From Comrades to Citizens: The South African Civics Movement and the Transition to Democracy. London: Macmillan, pp. 52-85.

—, 2000b, The UDF: A History of the United Democratic Front in South Africa 198391. Cape Town: David Philip.

—, 2001, "Social Ordering and Control in the African Townships of South Africa: An Historical Overview of Extra-state Initiatives from the 1940s to the 1990s", in W. Schärf and D. Nina (eds), The Other Law: Non-State Ordering in South Africa. Landsdowne, Cape Town: Juta, pp. 71-97.

Segal, L., 1990, Slow Motion. Changing Masculinities. Changing Men. London: Virago. —, 1999, Why Feminism? Gender, Psychology, Politics. Polity Press: Cambridge.

Seleoane, M., 2003, "Contextualising Dissent: Freedom of Expression, Assembly and Demonstration in South Africa", in Kimani, S. (ed.), The Right to Dissent: Freedom of Expression, Assembly and Demonstrations in South Africa. Johannesburg: Freedom of Expression Institute, pp. 26-47.

Selfe, J., 1989, "South Africa's National Management System”, in Cock, J. and L. Nathan (eds), War and Society: The Militarisation of South Africa. Cape Town: David Philip, pp. 149-58.

Shackleton, C., S. Shackleton and B. Cousins, 2000, "The Economic Value of Land and Natural Resources to Rural Livelihoods: Case Studies from South Africa”, in Cousins, B. (ed.), At the Crossroads: Land and Agrarian Reform in South Africa into the 21st Century. Cape Town: Plaas.

Shaw, M., 1996, "Policing the Transformation: New Issues in South Africa's Crime Debate", Monograph 3. Pretoria: Institute for Security Studies.

Shongwe, N., 2000, "Women Strip Naked to Show Hungry Stomachs", Land and Rural Digest, vol.10, pp. 18-20.

Sider, G., 1986. Culture and Class in Anthropology and History: A Newfoundland Illustration. Cambridge: Cambridge University Press.

Sideris, T., 2004, "You have to Change and You Don't Know How! Contesting What it Means to be a Man in a Rural Area of South Africa", African Studies, vol. 63, no. 1, pp. 29-49.

- and R. Nsimbini, 2001, Social Constructions of Masculinity in the NkomaziDistrict of Mpumalanga Province - Links to Domestic Violence. Unpublished Research Report for Oxfam Canada, December.

Simon, D. and R. Preston, 1993, "Return to the Promised Land: The Repatriation and Resettlement of Namibian Refugees, 1989-1990", in Black, R. and V. Robinson (eds), Geography and Refugees: Patterns and Processes of Change. London: Bellhaven Press. 
Simpson, G. and G. Kraak, 1998, The Illusions of Sanctuary and the Weight of the Past: Notes on Violence and Gender in South Africa. Development Update: Interfund.

Sitas, A., 1996, “The New Tribalism: Hostels and Violence”, Journal of Southern African Studies, vol. 22, no. 2, pp. 135-48.

Solidarity Peace Trust, 2005, "Discarding the Filth. Operation Murambatsvina. Interim report on the Zimbabwean Government's 'Urban Cleansing' and forced Eviction Campaign May/June 2005”. Johannesburg: Solidarity Peace Trust.

Solomon, M.H., 1997, "South African Minerals Industry: Implications of Downscaling", Journal of Mineral Policy, Business and Environment. Raw Materials Report, vol. 12, no. 4, pp. 21-30.

Sooka, Y., 2003, "Defining the Constitutional Right to Freedom of Expression, Assembly and Demonstration", in Simon Kimani (ed.), The Right to Dissent: Freedom of Expression, Assembly and Demonstrations in South Africa. Johannesburg: Freedom of Expression Institute, pp. 50-61.

Sparks, A., 1990, Mind of South Africa. London: Heinemann.

The Star, 2003, "Red Ants are Private Workers", by Mbanga Xaba, 14 October.

Steenkamp, W., 1989, South Africa's Border War 1966-89. Gibraltar: Ashanti.

Steinmetz, G., 1999, "Introduction: Culture and the State", in Steinmetz, G. (ed.), State/Culture: State-Formation after the Cultural Turn. Ithaca, NY and London: Cornell University Press.

Stepputat, F., 1999, "Politics of Displacement in Guatemala", Journal of Historical Sociology, vol. 12, no. 1, pp. 54-80.

Stiglitz, J., 1998, Towards a New Paradigm for Development: Strategies, Policies, and Processes. Paper given at the 1998 Prebish Lecture, 19 October. Geneva: UNCTAD.

Sundar, N., 2001, "Beyond the Bounds? Violence at the Margins of New Legal Geographies", in Peluso, N.L. and M. Watts (eds), Violent Environments. Ithaca and London: Cornell University Press, pp. 328-53.

Swilling, M., 1997, "Building Democratic Local Urban Governance in Southern Africa”, in Swilling, M. (ed.), Governing Africa’s Cities. Johannesburg: Witwatersrand University Press, pp. 211-71.

Tamas, K., 1992, After Return - Repatriated Exiles in Independent Namibia. Windhoek: Namibian Institute for Social and Economic Research/University of Namibia (NISER Discussion Paper; 15).

Tapscott, C., 1995, "War, Peace and Social Classes", in Leys, C. and J.S. Saul (eds), Namibia's Liberation Struggle: The Two-Edged Sword. London and Athens, OH: James Currey and Ohio University Press.

—, 1997, "The Autocratic Temptation: Politics in Namibia Now", Southern Africa Report, vol. 12, no. 3, pp. 3-6.

—, 2001, "Class Formation and Civil Society in Namibia", in Diener, I. and O. Graefe (eds), Contemporary Namibia. The first Landmarks of a post-Apartheid Society. Windhoek and Nairobi: Gamsberg Macmillan and IFRA. 
- and B. Mulongeni, 1990, An Evaluation of the Welfare and Future Prospects of Repatriated Namibians in Northern Namibia. Windhoek: Namibian Institute for Social and Economic Research/University of Namibia (NISER Research Report; 3).

Terreblanche, S., 2003, A History of Inequality in South Africa 1652-2002. Durban: University of Natal Press.

Thale, T., 2002, “Jo'burg Moves in on Derelict Buildings”, 2 April. http://www.joburg. org.za (official webpage of the City of Johannesburg).

Thornton and Feinstein Consultants, 1998, Phase 1 Report in Retrospect of a Study to Examine the Socio-economic Impact of the Maputo Development Corridor on Mpumalanga Province. Johannesburg: unpublished consultancy report.

Tomlinson, R., R. Beauregard, L. Bremner, and X. Mangcu, 2003, "The Post-apartheid Struggle for an Integrated Johannesburg", in Tomlinson, R., R. Beauregard, L. Bremner, and X. Mangcu (eds), Emerging Johannesburg. Perspectives on the Postapartheid City. London: Routledge, pp. 3-20.

Trinquier, R., 1961, Modern Warfare. A French View of Counterinsurgency. New York: Praeger.

Trouillot, M-R., 2001, “The Anthropology of the State in the Age of Globalization”, Current Anthropology, vol. 42, no. 1, pp. 125-38.

Truth and Reconciliation Commission (TRC), 1998, Final Report of the South African Truth and Reconciliation Commission. Volume 1-5. Cape Town: Juta.

Tshehla, B., 2005, Traditional Justice in Practice: A Limpopo Case Study. ISS Monograph Series, No. 115, April 2005. Cape Town.

UNDP, 1994, Human Development Report. New York and Oxford: Oxford University Press.

UNRISD, 1995, States of Disarray: The Social Effects of Globalization. London: United Nations Research Institute for Social Development.

United Nations, 2001, Report of the Security Council Mission to the Great Lakes Region, New York 15-26 May.

—, 2003, UNSC Resolution 1484. New York, 30 May.

—, 2004, UNSC Resolution 1565. New York, 30 September.

Vally, S., 2003, "The Political Economy of State Repression in South Africa”, in

Kimani, S. (ed.), The Right to Dissent: Freedom of Expression, Assembly and

Demonstrations in South Africa. Johannesburg: Freedom of Expression Institute, pp. 62-72.

van Beek, M., 1999, "Hill Councils, Development and Democracy: Assumptions and Experiences from Ladakh", Alternatives, vol. 24, no. 4, pp. 435-460.

Viljoen, C., 2000, Statement during the Parliamentary Debate on South African Troop Contribution to the DRC. South African Parliament, Cape Town, 10 May.

Wacquant, L., 1999, "How Penal Common Sense Comes to Europeans - Notes on the Transatlantic Diffusion of the Neoliberal 'Doxa”", European Societies, vol. 1, no. 3, pp. 319-52.

Wæver, O., 1997, “Conceptualizing Security”. PhD Dissertation, University of Copenhagen, Denmark. 
—, 2004, "Securitization: Taking Stock of a Research Programme”. Paper presented to Pipes, University of Chicago, March.

Wagner, S., 2002, "Putting a Face on Transnationalism: Migration, Identity, and Membership in the Transnational City of Johannesburg”. Paper. Department of Anthropology, Harvard University.

Walker, L., 2003, "Men Behaving Differently: South African Men since 1994”. Paper presented at the Sex and Secrecy Conference. Fourth Conference of the International Association for the Study of Sexuality, Culture and Society. University of the Witwatersrand, Johannesburg, South Africa, 25-28 June.

Wallace, M., 2002, Health, Power and Politics in Windhoek, Namibia, 1915-45. Basel: Schlettwein.

Walters, W., 2000, Unemployment and Government: Genealogies of the Social. Cambridge: Cambridge University Press.

Weaver, T., 1989, “The South African Defence Force in Namibia”, in Cock, J. and L. Nathan (eds), War and Society: The Militarisation of South Africa. Cape Town: David Philip, pp. 90-102.

Weiland, H. and M.Braham (eds), 1994, The Namibian Peace Process: Implications and Lessons for the Future: A Review of an International Conference jointly organized by the Arnold Bergstraesser Institute and the International Peace Academy, 1-4 July 1992. Freiburg: Arnold Bergstraesser Institut.

West, H.G., 2005, “'Govern Yourselves': Democracy and Carnage in Northern Mozambique”. Paper presented at Anthropology Seminar, Instituto de Ciências de Universidade de Lisboa, April 2005.

White Paper on International Migration, 1999, Presented to the Minister of Home Affairs Dr. Mangosuthu Buthelezi by A.S. Mokoena, Chairperson of the Task Team on International Migration on Behalf of the Task Team. As modified and approved by Cabinet, Pretoria: 31 March 1999.

Wieviorka, M., 2003, “The New Paradigm of Violence”, in Friedman, J. (ed.), Globalization, the State, and Violence. Walnut Creek, Lanham, New York, Oxford: Rowman \& Littlefield, pp. 107-39.

Williams, R., 1988, Keywords. London: Fontana.

Williams, R., 2001, "Defence and Development: Some Thematic Issues", Development Southern Africa, vol. 18, no. 1, pp. 57-77.

Wilson, F., 2004, “Towards a Political Economy of Roads: Experiences from Peru”, Development and Change, vol. 35, no. 3, pp. 525-46.

Wilson, J.Q. and G. Kelling, 1982, "Broken Windows: The Police and Neighbourhood Safety", Atlantic Monthly, vol. 127, March 1982, pp. 29-38.

Wilson, R., 1996, "The Siswe Will Not Go Away. The Truth and Reconciliation Commission, Human Rights and Nation-Building in South Africa", African Studies, vol. 55, no. 2, pp. 1-20.

Wilson, R., 2001, The Politics of Truth and Reconciliation in South Africa: Legitimizing the Post-Apartheid State. Cambridge and New York: Cambridge University Press. 
Wisler, D. and B. Bonvin, 2004, Human Security, Development and Local Policing. www.humansecuritygateway.com

Worby, E., 2003, “The End of Modernity in Zimbabwe? Passages from Development to Sovereignty", in Hammar, A., B.Raftopoulos and S. Jensen (eds), Zimbabwe's Unfinished Business: Rethinking Land, State and Nation in the Context of Crisis. Harare: Weaver Press, pp. 49-81 (eller 82?).

World Bank, 1998, Conflict Prevention and Post-Conflict Reconstruction: Perspectives and Prospects. Washington DC: World Bank Post-Conflict Unit.

—, 2003, Breaking the Conflict Trap. Washington DC: World Bank.

Zulu, P., 1993, "Durban Hostels and Political Violence: Case Studies in Kwamashu and Umlazi", Transformation, vol. 21:1-23.

Zuma, N.D., 1999, Foreign Minister's Speech to SAIIA. SAIIA, Johannesburg, 1 November.

— 2000, African Briefing by the Foreign Minister to the Foreign Affairs Portfolio

Committee. South African Parliament, Cape Town, 15 February.

—, 2002, The South African Foreign Minister's Budget Speech. South African Parliament, Cape Town, 28 May.

—, 2005, The Foreign Minister in Parliament during the Debate on the State of the Nation Address. South African Parliament, Cape Town, 16 February. 


\section{Index}

Agamben, Georgio 83-4, 87, 128, 133 see also bare life; people/People AIDS see HIV/AIDS

ANC (African National Congress) 12, $70-4,82,117,123,129,182$, 184, 187-8, 190

Johannesburg 174, 176

Angola 40, 155, 159, 160, 161, 162

Anti Privatisation Forum see APF apartheid 68-9, 82-3, 111, 112, 153, $176,240-1$

struggle against $17,22,122-8$, 184, 187, 188, 208, 211

APF (Anti Privatisation Forum) 114, $115-17,118,130,182-4$

authoritarianism 16, 20, 231 Swapo 92, 163-5, 172-3

bare life $15,16,17,18,147,150$ biopolitics 13-18, 87-8, 101-2, 104-5 Botswana 53, 75, 153-4, 154, 168, 170

chiefs $11,27-8,135-7,138,139,193$, 197, 202 and land 200-1, 206-7, 217, 227 citizenship 21, 33, 103, 133, 150, 151, $175,175-6$

Namibia 85, 87, 104

reconfiguration 17-18, 64-5, 81-2

South Africa 16-17, 67-9, 83-4, 112

class 197-9, 201-3, 206-7, 210-11

cleansing 17, 212-15

community 20-1, 143, 194-5, 210-11

community policing $11,30-2,133,134$, 138-47

counter-insurgency $11,28-9,30-1,156$, 157-8

see also Koevoet crime 9, 23-4, 30-1, 47, 63, 194, 195, 210-11

cleaning up (Nkomazi) 204-7

and development 23-4, 179, 212-13

discourses of 203, 208, 210-11

inner city 178, 181, 185

politicisation of 147-50, 151

prevention 179-81, 188-9

South Africa 59

crime-combating meetings $11,21,134$, $142-7,148-50,151$

criminalisation $21,24,32-3,142,189$, 194

of Mozambicans 206-7, 211

of politics 24-5, 133-4, 141-2, 147-50, 151

of poverty 25, 190

of protest 116

Zimbabwe 212-15, 217-18, 231-2

culture 200, 201-3, 206, 237, 239, 240, 244, 248-9

democracy 13, 29-30, 83, 112, 113, 175-6, 187-8, 189-90

Democratic Republic of Congo see DRC democratisation 13, 16, 22-4, 132-4, 234

development 9-10, 11-12, 16, 129, 175-6, 231-2 crime and 23-4, 179, 212-13 exclusion from 137-8, 214, 218, 232

militarisation of 153-4, 156, 166-73

securitisation of $9,25,86-7$

and security $24,37,133,152$, 190

and violence $23-4,110-11,127$, 179, 193 
Dombe (Mozambique) 11, 21, 133, $133-8,142-51$

DRC (Democratic Republic of Congo) $11,12,37-8,48-56,164$

electricity, disconnections 110-11 everyday policing 195, 204-6, 207, 211

evictions 212, 214

Gokwe (Zimbabwe) 215, 216-19, 220, 225, 226, 230-1, 231-2

Johannesburg 16-17, 174-7, $178,179-81,182-4,185-8$

ex-combatants $18,50-2,85-7,91$, 92-106, 167-9

Frelimo 11, 21, 28, 132 as state $134-42,143,147-8$, 151

gender rights project $23,233,235$, 243-4, 247-8, 248-9

gerontocracy 200-1, 202, 203, 204, 206, 207, 211

Gokwe (Zimbabwe) 215-31

HIV/AIDS 41, 46-7, 63, 98, 154, 239

human rights $24,29,67,68,74-5$, 233,250

abuses 68-9, 153, 164-5, 169-70

discourse 234, 235, 248

ICF (Inner City Forum) 16-17, 174-5, 176, 181-5, 186-7, 190

IFP (Inkatha Freedom Party) 70-4, 82,83

Johannesburg (South Africa) evictions 16-17, 174-7, 178, 179-81, 182-4 urban renewal 16-17, 174, 178-81, 188-9, 189-90
Khukula 204-6, 207, 210, 211

Koevoet 9, 85, 157-8, 162, 168

land claims 193-5, 198-9, 206-7, 222, 224

Lindela Repatriation Camp (South Africa) 18, 80-1, 83, 84

Mabika, Tendai 219-30, 230-1

Malawi 75, 153, 172

Manhattan Court (Johannesburg) $174-5,176,181,183-4$, 185-8, 189

masculinity 234-7, 240, 240-1, 242, 246, 248, 249

men 23, 234-6, 237, 238-46, 248-50

migrants 3-4, 18, 47, 69, 90-1, 229 to South Africa 58, 63-7, 69, 70-81, 82, 206-7

militarisation $20,152-7,166-73$

monism 32, 111, 113, 125, 127-8, 130,131

MONUC 37-8, 51-2, 53-6, 60-1

Mozambique 11, 27-8, 66, 132-8, 154, 197

migrants from $66-7,69,74-8$, 206-7

see also Dombe; Frelimo; PRM; Renamo; unity/Unidade

Namibia 88-92, 154, 164-73

militarisation 20, 152-3, 155$8,166-73$

see also ex-combatants; Swapo

nation-building 20, 98, 130, 151, $152-5,165-73$

national security 45-8, 58-62, 84

Nkomazi (South Africa) 21, 193-4, 196-210, 238-42

Nujoma, Sam 89, 90, 161, 161-2, 162, $163,164,166,170,171$

Operation Gcin’amanzi 112, 113-20 
Operation Murambatsvina 17, 212-13

outsiders 32-3, 65, 214, 215, 217, 220-1, 227-8

Peace Support Operations see PSOs the people/People 16-17, 176, 188-9

People's Liberation Army of Namibia see PLAN

'people's vigilance' 133, 141, 142-7, 151 Phiri (Soweto) 112, 113-17, 120

PLAN (People's Liberation Army of Namibia) 85, 159-61, 162, 167 see also ex-combatants

police 24, 25, 95-6, 96 see also policing; PRM

Polícia da República de Moçambique see PRM

policing 30-2, 150, 210

community policing $11,30-2$, 133, 134, 138-47

everyday 195, 204-6, 207, 211

politics of 133-4, 141-2, 151

politicisation of crime 147-50, 151

politics

criminalisation of 24-5, 133-4, 147-50, 151

of policing 133-4, 141-2, 151

profane and sublime dimensions 175-6, 184-5, 188, 189-90

poverty $9,45,47,133,237,245$

criminalisation 25,190

privatisation of utilities $11,112,113-17$, 120, 183

PRM (Polícia da República de

Moçambique) 132-4, 136-7,

138, 139-40, 141

protest 109-10, 116, 131

PSOs (Peace Support Operations) 37-43, $51,53-8,59,60$

recognition $14,22,235,236-7,237-8$, 244, 246-7, 248-9

redistribution 46, 246-8, 249-50

Reef, violence on 70-4, 83 regeneration $16-17,174,178-81,185$, 188-9, 189-90

Renamo 21, 32, 132, 134-8, 141-2, $147-50,151$

SADF (South African Defence Force) 29, $38,40,56,155-8,159-60,162$

SANDF (South African National Defence Force) 11, 37-43, 53-4, 154 problems 12, 38, 41, 45, 54-8, 62

SECC (Soweto Electricity Crisis Committee) 110, 115-17, 118, 130

securitisation $12-13,32-3,43-8,128$ of development 9, 25, 86-7

security $9,10,12,16,39,43-4,86-8$, $101,231-2$

apartheid and 112, 113, 153

and development 24, 37, 133, 152,190

and foreign policy $47-8$

human security 10, 23, 46

and sovereignty $128-9$

security-development nexus 10-12, 22-3, 26-30, 111, 165-73

South Africa 22-3, 63, 81-4, 109-11, 131

as African peace broker 48-52, 53 citizenship 17-18, 64-5, 81-2 democratisation $64,109,187-8$, 233, 234

foreign policy $38,41,59-62$

HIV/AIDS 41, 46-7, 63, 239 migrants $58,63,69,74-81,82-3$ militarisation 152-3, 155-8, $171-2$

national security $39-40,43-5$, 45-8, 58-62, 84, 153, 154 role in PSOs 41-2, 53, 59, 60 violence on the Reef 70-4 
see also apartheid; gender rights project; Johannesburg; MONUC; Nkomazi; Operation Gcin'amanzi; SANDF; Soweto South African Defence Force see SADF South African National Defence Force see SANDF

sovereignty $10,11,23,84,128-9,130$, $131,140-1,231$ and biopolitics 13-14, 14-18 Soweto 110, 112, 113-17, 120, 123, 182 Soweto Electricity Crisis Committee see SECC

state $13,83-4,86,232$

formation $17,85,86-7,90-2$, $104-5,151$

violence by 17, 33, 213, 232

see also nation-building

sugar projects 199-201, 202-3

Swapo 85-6, 88-90, 91-2, 96-7

armed struggle $155,156,158-$ 60, 172

authoritarianism 20, 92, 163-5, 172-3

government 89-90, 93, 102, 104, 157

militaristic tradition 158-65

see also ex-combatants

'Third Force' 70, 118-20, 127, 129

Tollgate gang 208-10

townships $112,122-8$

tradition 135-6, 239, 240, 248-9

Truth and Reconciliation Commission 67-9

UDF (United Democratic Front) 123-4, $125,126-7$

unity/Unidade 20-1, 133, 134, 142-7, 149,151

urban renewal 16-17, 174, 179-81, 188-9, 189-90 utilities $11,112,113-17,120,178,179$, 183

vigilança do povo 133, 141, 142-7, 151

vigilantism 127, 156, 193, 208-10

violence 9, 14-15, 23-4, 127, 130, 152, 179

domestic 23, 233-4, 235, 236, 239-40, 242-5, 248

'education' by $142,144-5,147$, 150

image of 218-19

Nkomazi 156, 193-5, 204, 208-10

reaction to protests $110-11$

on the Reef 70-4, 82

state violence 17, 33, 213, 232

township struggle 123-5, 126

Vumba (Zimbabwe) 215, 216-24, 230 $1,231-2$

water meters 112, 113-17, 120

WHAM (Winning Hearts and Minds) 28,126

women

equality $234,235,236,241$, 248-9

relative independence 234,238 , 241

violence towards 23, 233-4, 235, 236, 239-40, 242-5, 248

young men 194, 205-6, 207-10, 211

Zimbabwe 11, 48, 76, 77, 134, 172 authoritarianism 212-13, 214, 231

Operation Murambatsvina 17, 212-13 see also Gokwe

'zones of confusion' 132, 134, 138-42, 147,151 